\title{
Genetic mapping of QTL controlling salt tolerance and glucosinolates in Brassica napus and Brassica oleracea
}

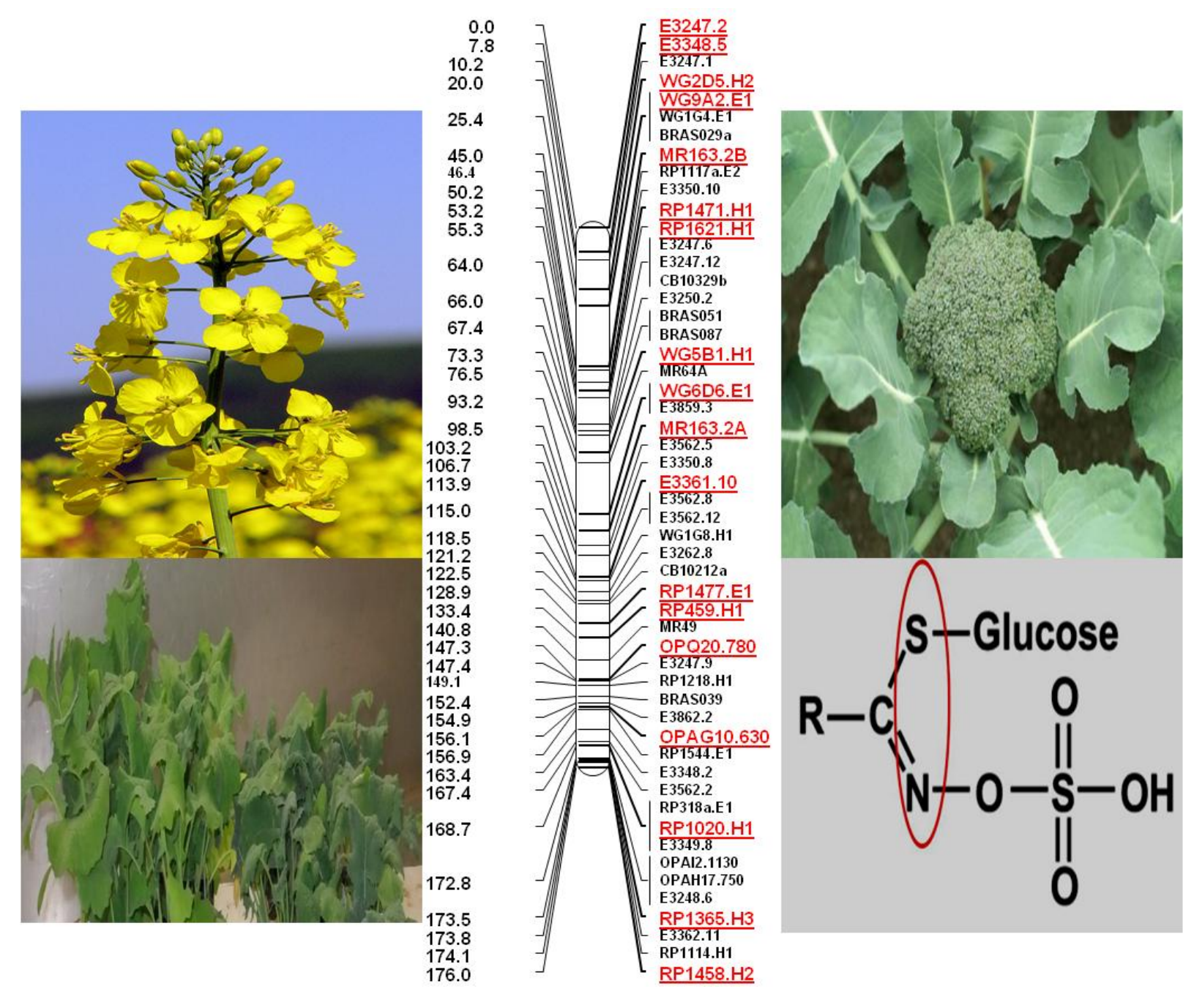

Yasser Shaaban Sayed Moursi

Georg-August-Universität Göttingen 


\section{Genetic mapping of QTL controlling salt tolerance and glucosinolates in Brassica napus and Brassica oleracea}

Doctoral Dissertation

Submitted for the Ph. D. degree at the Faculty of Agricultural Sciences, Georg-August-University Göttingen, Germany

presented by

Yasser Shaaban Sayed Moursi

born in Fayoum, Egypt

Göttingen, November 2014 
1. Name of referee: Prof. Dr. Heiko Becker

2. Name of co-referee: Prof. Dr. Klaus Dittert

Date of dissertation: 10.11.2014 


\section{Dedication}

To my family for their moral support

To my wife and my children for their patience 


\section{Table of contents}

Chapter I: Literature Review

1.1 The family Brassicaceae

Genomic relationships between the diploid and polyploid Brassica species

Brassica napus

Brassica oleracea

1.2 Salinity

Types of salinity

Phases of salt stress and mechanisms of response

Effect of salinity on seed germination and plant growth

Effect of salinity on photosynthesis

Effect of salinity on seed oil quantity and quality

Strategies to solve the salinity problem

1.3 Salt tolerance in Brassica

Improving salt tolerance in Brassica

1.4 QTL and Salinity

The QTL controlling salt tolerance during different growth stages

1.5 Glucosinolates

Importance of glucosinolates

Glucosinolates in Brassica species

Glucosinolates and quantitative trait loci

What Glucosinolates can do under abiotic stresses?

Salinity effect on GSL

\section{Chapter II: Experiments to develop a screening method and to select a suitable DH} population

2.1 Objectives

2.2 Experiment 1: Testing 13 genotype under different $\mathrm{NaCl}$ concentrations 16

$\begin{array}{ll}\text { 2.2.1 Materials and methods } & 16\end{array}$

2.2.2 Results 16

2.2.3 Conclusion 16

2.3 Experiment 2: Testing six genotype under $200 \mathrm{mM} \mathrm{NaCl}$ concentrations 20

2.3.1 Materials and methods $\quad 20$

2.3.2 Sodium and potassium content analysis $\quad 20$

$\begin{array}{ll}2.3 .3 \text { Results } & 20\end{array}$

$\begin{array}{ll}\text { 2.3.4 Conclusion } & 21\end{array}$

2.4 Experiment 3: Testing the performance of Mansholts $\times$ Samourai and Sollux $\times \quad 26$

Gaoyou under $200 \mathrm{mM} \mathrm{NaCl}$

$\begin{array}{ll}2.4 .1 \text { Materials and methods } & 26\end{array}$

$\begin{array}{ll}2.4 .2 \text { Results } & 26\end{array}$

2.4.3 Conclusion $\quad 26$

2.5 General conclusion $\quad 26$

Chapter III: Mapping QTL for salt tolerance at seed germination in Brassica napus and Brassica oleracea doubled-haploid populations

3.1 introduction

QTL and genes related to salt tolerance at seed germination 29

$\begin{array}{ll}3.2 \text { Objectives } & 29\end{array}$

$\begin{array}{ll}3.3 \text { Materials and Methods } & 30\end{array}$

$\begin{array}{ll}\text { 3.3.1 Plant materials } & 30\end{array}$

3.3.2 Germination experiment 30

$\begin{array}{ll}\text { 3.3.3 statistics } & 31\end{array}$ 
$\begin{array}{lr}\text { 4.7 Discussion II } & 101\end{array}$

3.3.4 Linkage maps $\quad 31$

3.3.5 QTL analysis protocol 32

3.4 Results $\quad 35$

$\begin{array}{ll}\text { 3.4.1 Traits variations } & 35\end{array}$

3.4.2 Framework maps 41

3.4.3 QTL analysis and localization $\quad 49$

3.5 Discussion 56

3.5.1 Traits variations $\quad 56$

3.5.2 QTL analysis and localization 56

Chapter IV: Mapping QTL for salt tolerance at the young plant stage and leaf glucosinolates in a Brassica napus DH population

4.1 Introduction $\quad 59$

4.2 Objectives $\quad 59$

Chapter IV-Part I: Mapping QTL for salt tolerance at the young plant stage in B. napus

$\begin{array}{ll}\text { 4.3 Materials and Methods } & 60\end{array}$

$\begin{array}{ll}\text { 4.3.1 Plant materials } & 60\end{array}$

$\begin{array}{ll}\text { 4.3.2 Greenhouse experiment } & 60\end{array}$

$\begin{array}{ll}\text { 4.3.3 Germination and establishment } & 60\end{array}$

$\begin{array}{ll}\text { 4.3.4 Salt stress } & 60\end{array}$

$\begin{array}{ll}\text { 4.3.5 Harvest and biomass } & 61\end{array}$

$\begin{array}{ll}\text { 4.3.6 Relative water content } & 61\end{array}$

$\begin{array}{ll}\text { 4.3.7 Chlorophyll content } & 61\end{array}$

4.3.8 Sodium $\mathrm{Na}^{+}$and Potassium $\mathrm{K}^{+}$analysis $\quad 61$

$\begin{array}{ll}\text { 4.3.9 Glucosinolates analysis } & 61\end{array}$

4.3.10 Statistics $\quad 62$

4.4 Results I 63

4.4.1 Traits variations 63

$\begin{array}{ll}\text { 4.4.2 Correlations } & 64\end{array}$

$\begin{array}{ll}\text { 4.4.3 QTL analysis and localization } & 73\end{array}$

$\begin{array}{ll}4.5 \text { Discussion I } & 78\end{array}$

$\begin{array}{ll}\text { 4.5.1 Traits variations } & 78\end{array}$

$\begin{array}{ll}\text { 4.5.2 QTL analysis and localization } & 79\end{array}$

Chapter IV- Part II: Mapping QTL for leaf glucosinolates variation under control and salt stress conditions in $B$. napus

4.6 Results II 83

4.6.1 Parents' GSL profile and content under control 83

Mansholts GSL content under control $\quad 83$

Samourai GSL content under control $\quad 83$

4.6.2 Parents' GSL profile and content under salt $\quad 88$

Mansholts GSL content under salt stress $\quad 88$

Samourai GSL content under salt stress $\quad 89$

4.6.3 Glucosinolates' profile and content of the DH population under control 89

conditions

$\begin{array}{ll}\text { Aliphatic GSL under control } & 90\end{array}$

Indolic GSL under control $\quad 90$

$\begin{array}{ll}\text { Aromatic GSL under control } & 90\end{array}$

4.6.4 Glucosinolates' profile and content of the DH population under salt stress 90

$\begin{array}{ll}\text { Aliphatic GSL under salt stress } & 90\end{array}$

$\begin{array}{ll}\text { Indolic GSL under salt stress } & 91\end{array}$

Aromatic GSL under salt stress $\quad 91$

$\begin{array}{ll}\text { 4.6.5 Correlations } & 91\end{array}$

4.6.6 QTL analysis and localization 96

QTL associated with the aliphatic GSL under control and salt 96

QTL associated with the indolic GSL under control and salt $\quad 97$

QTL associated with the aromatic GSL under control and salt 97

QTL associated with the total GSL content under control and salt 97 
Chapter V: Mapping QTL for salt tolerance at the young plant stage and leaf glucosinolates in a Brassica oleracea $\mathrm{DH}$ population

5.1 introduction

5.2 objectives

Chapter V- Part I: Mapping QTL for salt tolerance at the young plant stage in $B$. oleracea

5.3 Materials and methods

5.3.1 Plant material

$\begin{array}{ll}\text { 5.3.2 Greenhouse experiment } & 106\end{array}$

$\begin{array}{ll}5.4 \text { Results I } & 107\end{array}$

$\begin{array}{lr}\text { 5.4.1 Traits variations } & 107\end{array}$

$\begin{array}{ll}\text { 5.4.2 Correlations } & 108\end{array}$

5.4.3 QTL analysis and localization $\quad 115$

$\begin{array}{lr}5.5 \text { Discussion I } & 120\end{array}$

$\begin{array}{ll}\text { 5.5.1 Traits variations } & 120\end{array}$

5.5.2 QTL analysis and localization $\quad 121$

Chapter V- Part II: Mapping QTL for leaf glucosinolates variation under control and salt stress in B. oleracea

5.6 Results II

5.6.1 Parents' GSL profile and content under control 123

$\begin{array}{ll}\text { TO1000DH3 GSL content under control conditions } & 123\end{array}$

Early Big GSL content under control conditions 124

$\begin{array}{ll}\text { 5.6.2 Parents' GSL profile and content under salt stress } & 124\end{array}$

$\begin{array}{ll}\text { TO1000DH3 GSL content under control conditions } & 124\end{array}$

$\begin{array}{ll}\text { Early Big GSL content under salt stress conditions } & \\ \text { Glucosinolates' profile and content of the DH population under control } & 125\end{array}$

5.6.3 Glucosinolates' profile and content of the DH population under control
conditions

$\begin{array}{ll}\text { Aliphatic GSL under control } & 125\end{array}$

$\begin{array}{ll}\text { Indolic GSL under control } & 125\end{array}$

Aromatic GSL under control $\quad 126$

5.6.4 Glucosinolates' profile and content of the DH population under salt stress $\quad 126$

$\begin{array}{ll}\text { Aliphatic GSL under salt stress } & 126\end{array}$

$\begin{array}{ll}\text { Indolic GSL under salt stress } & 126\end{array}$

Aromatic GSL under salt stress 126

$\begin{array}{ll}\text { 5.6.5 Correlations } & 132\end{array}$

$\begin{array}{ll}\text { 5.6.6 QTL analysis and localization } & 134\end{array}$

QTL associated with the aliphatic GSL under control and salt 134

QTL associated with the indolic GSL under control and salt 134

QTL associated with the aromatic GSL under control and salt 135

QTL associated with the total GSL content under control and salt 135

5.7 Discussion II 139

5.7.1 Variation of GSL under control and salt stress conditions 139

$\begin{array}{ll}\text { 5.7.2 QTL analysis and localization } & 140\end{array}$

Chapter VI: General discussion

6.1 Effect of salinity on seed germination $\quad 143$

$\begin{array}{ll}6.2 \text { Effect of salinity on plant growth } & 143\end{array}$

6.3 Glucosinolates variation under control and salt stress conditions 145

6.4 QTL for seed germination versus QTL for plant growth at the young stage 146

Summary 149

$\begin{array}{ll}\text { Zusammenfassung } & 152\end{array}$

$\begin{array}{ll}\text { References } & 155\end{array}$

$\begin{array}{lr}\text { Appendices } & 167\end{array}$

Acknowledgement 


\section{List of tables}

\section{Chapter II: Experiments to develop a screening method and to select a suitable DH population}

Table II-1: The mean values of fresh weight (g), dry weight $(\mathrm{g})$, SPAD values, sodium content $\left(\mathrm{Na}^{+} \mathrm{mg} / \mathrm{g} \mathrm{DM}\right)$ and potassium content $\mathrm{K}^{+} \mathrm{mg} / \mathrm{g} \mathrm{DM}$ of the different parts in Mansholts and Samourai under control and salt stress (200 mM NaCl)

Table II-2: The mean values of fresh weight (g), dry weight (g), SPAD values, sodium content $\left(\mathrm{Na}^{+} \mathrm{mg} / \mathrm{g} \mathrm{DM}\right)$ and potassium content $\mathrm{K}^{+} \mathrm{mg} / \mathrm{g}$ DM of the different parts in Sollux and Gaoyou under control and salt stress $(200 \mathrm{mM} \mathrm{NaCl})$

Table II-3: The mean values of fresh weight (g), dry weight (g), SPAD values, sodium content $\left(\mathrm{Na}^{+} \mathrm{mg} / \mathrm{g} \mathrm{DM}\right)$ and potassium content $\mathrm{K}^{+} \mathrm{mg} / \mathrm{g}$ DM of the different parts in Alesi and $\mathrm{H} 30$ under control and salt stress $(200 \mathrm{mM} \mathrm{NaCl})$

Table II-4: The mean values of fresh weight, dry weight, sodium content $\left(\mathrm{Na}^{+} \mathrm{mg} / \mathrm{g} \mathrm{DM}\right)$ and potassium content $\mathrm{K}^{+} \mathrm{mg} / \mathrm{g}$ DM of the different parts in Mansholts and Samourai under control and salt stress $(200 \mathrm{mM} \mathrm{NaCl})$

Table II-5: The mean values of fresh weight $(\mathrm{g})$, dry weight $(\mathrm{g})$, sodium content $\left(\mathrm{Na}^{+} \mathrm{mg} / \mathrm{g}\right.$ $\mathrm{DM}$ ) and potassium content $\mathrm{K}^{+} \mathrm{mg} / \mathrm{g}$ DM of the different parts in Sollux and Gaoyou under control and salt stress $(200 \mathrm{mM} \mathrm{NaCl})$

\section{Chapter III: Mapping QTL for salt tolerance at seed germination in Brassica napus and Brassica oleracea doubled-haploid populations}

Table III -1: Linkage group size, number of markers, and marker density per linkage group of the full map of Brassica napus $\mathrm{DH}$ population (Alesi $\times \mathrm{H} 30$ )

Table III -2: Linkage group size, number of markers, and marker density per linkage group of the full map of Brassica napus DH population (Mansholts $\times$ Samourai)

Table III -3: Linkage group size, number of markers, and marker density per linkage group of the full map of Brassica oleracea DH population (Bo1TBDH)

Table III -4 : Mean squares, respective $F$ tests, and heritabilities estimated from the ANOVA of Brassica napus DH population (Alesi $\times \mathrm{H} 30$ ), $138 \mathrm{DH}$ lines were tested under control conditions and at salt treatment $(200 \mathrm{mM} \mathrm{NaCl})$

Table III -5: Mean squares, respective $F$ tests, and heritabilities estimated from the ANOVA of Brassica napus DH population (Mansholts $\times$ Samourai), $138 \mathrm{DH}$ lines were tested under control conditions and at salt treatment $(200 \mathrm{mM} \mathrm{NaCl})$

Table III -6: Mean squares, respective $F$ tests, and heritabilities estimated from the ANOVA of Brassica oleracea DH population (Bo1TBDH), $145 \mathrm{DH}$ lines were tested under control conditions and at salt treatment $(200 \mathrm{mM} \mathrm{NaCl})$

Table III -7: Linkage group size, number of markers, and marker density per linkage group of the framework map of Brassica napus DH population (Alesi $\times \mathrm{H} 30$ )

Table III -8: Linkage group size, number of markers, and marker density per linkage group of the framework map of Brassica napus DH population (Mansholts $\times$ Samourai)

Table III -9: Linkage group size, number of markers, and marker density per linkage group of the framework map of Brassica oleracea DH population (Bo1TBDH).

Table III -10: QTL detected at LOD > 1.2 under control treatment (C) and Salt treatment (S) for germination percentage (G\%), germination pace (GP), and respective salt tolerance 
indices (G\%STI, GPSTI) in Brassica napus mapping population (Alesi $\times$ H30)

Table III -11: QTL detected at LOD > 1.2 under control treatment (C) and Salt treatment (S) for germination percentage (G\%), germination pace (GP), and respective salt tolerance indices (G\%STI, GPSTI) in Brassica napus mapping population (Mansholts $\times$ Samourai). (QTL significant with $P=0.05$ are marked bold)

Table III -12: QTL detected at LOD $>1.2$ under control treatment (C) and salt treatment (S) for germination percentage (G\%), germination pace (GP), and respective salt tolerance indices (G\%STI, GPSTI) in Brassica oleracea mapping population (Bo1TBDH). (QTL significant with $P=0.05$ are marked bold)

\section{Chapter IV: Mapping QTL for salt tolerance at the young plant stage and leaf glucosinolates in a Brassica napus DH population}

Table IV-1: Mean squares and $\mathrm{F}$ test of significance from the ANOVA and heritabilities of growth traits fresh weight (FW), dry weight (DW), relative water content, chlorophyll content measured by SPAD (SPAD1, SPAD2) of Brassica napus DH population Mansholts $\times$ Samourai $(n=138) \mathrm{DH}$ lines were tested under control conditions and at salt treatment (200 $\mathrm{mM} \mathrm{NaCl})$

Table IV-2: Spearman's rank correlations of growth traits of Brassica napus mapping population $(n=138)$ Mansholts $\times$ Samourai at control

Table IV-3: Spearman's rank correlations of growth traits of Brassica napus mapping population $(n=138)$ Mansholts $\times$ Samourai at salt

Table IV-4: QTL detected with LOD > 1.5 under control treatment (C) for fresh weight, dry weight, SPAD1, SPAD2, relative water content, sodium content $\mathrm{Na}^{+} \mathrm{mg} / \mathrm{g}$ DM and potassium content $\mathrm{K}^{+} \mathrm{mg} / \mathrm{g} \mathrm{DM}$ in Brassica napus mapping population (Mansholts $\times$ Samourai). (QTL significant with $P=0.05$ significance are marked bold)

Table IV-5: QTL detected with LOD > 1.5 under salt treatment (S) for fresh weight, dry weight, SPAD1, SPAD2, relative water content, sodium content $\mathrm{Na}^{+} \mathrm{mg} / \mathrm{g} \mathrm{DM}$ and potassium content $\mathrm{K}+\mathrm{mg} / \mathrm{g} \mathrm{DM}$ in Brassica napus mapping population (Mansholts $\times$ Samourai). (QTL significant with $P=0.05$ significance are marked bold)

Table IV-6: Systematic names and trivial names of the glucosinolates detected in the leaf of Brassica napus DH population (Mansholts $\times$ Samourai)

Table IV-7: Minimum maximum and mean of GSL content $\mu \mathrm{Mol} / \mathrm{g}$ DM of Brassica napus $\mathrm{DH}$ population (Mansholts $\times$ Samourai) and parents under control and salt treatment $(200$ $\mathrm{mM} \mathrm{NaCl)}$

Table IV-8: Minimum, maximum and mean values of the major categories; aliphatic, indolic and aromatic GSL $\mu \mathrm{mol} / \mathrm{g}$ DM of Brassica napus DH population (Mansholts $\times$ Samourai) and parents under control and salt treatment $(200 \mathrm{mM} \mathrm{NaCl})$

Table IV-9: Spearman's rank correlations of glucosinolates in Brassica napus Mansholts $\times$ Samourai mapping population under control condition

Table IV-10: Spearman's rank correlations of glucosinolates in Brassica napus Mansholts $\times$ Samourai mapping population under salt stress $(200 \mathrm{mM} \mathrm{NaCl})$ condition

Table IV-11: QTI detected at LOD > 1.2 under control treatment (C) for glucosinolates $\mu \mathrm{Mol} / \mathrm{g}$ DM in Brassica napus DH population (Mansholts $\times$ Samourai). (QTL significant with $P=0.05$ are marked bold) 
Table IV-12: QTI detected at LOD > 1.2 under salt treatment (S) for glucosinolates $\mu \mathrm{Mol} / \mathrm{gDM}$ in Brassica napus DH population (Mansholts $\times$ Samourai). (QTL significant with $P=0.05$ are marked bold)

\section{Chapter V: Mapping QTL for salt tolerance at the young plant stage and leaf glucosinolates in a Brassica oleracea $\mathrm{DH}$ population}

Table V-1: Mean squares, respective $\mathrm{F}$ tests, and heritabilities estimated from the ANOVA of Brassica oleracea Bo1TBDH population, $138 \mathrm{DH}$ lines were tested under control conditions and at salt treatment $(100 \mathrm{mM} \mathrm{NaCl})$

Table V- 2: Spearman's rank correlation of growth traits for Brassica oleracea Bo1TDH at control conditions

Table V- 3: Spearman's rank correlation of growth traits for Brassica oleracea Bo1TDH under salt stress $(100 \mathrm{mM})$ conditions

Table V- 4: QTL detected at LOD > 2 under control treatment (C) for fresh weight, dry weight, SPAD1, SPAD2, relative water content, Sodium content " $\mathrm{Na}^{+} \mathrm{mg} / \mathrm{g} \mathrm{DM}$ " and potassium content " $\mathrm{K}^{+} \mathrm{mg} / \mathrm{g}$ DM" in Brassica oleracea mapping population "Bo1TBDH". (QTL detected at $P=0.05$ significance are marked bold)

Table V-5: QTL detected at LOD > 2 under salt treatment (S) for fresh weight, dry weight, SPAD1, SPAD2, relative water content, Sodium content " $\mathrm{Na} \mathrm{mg} / \mathrm{g} \mathrm{DM}$ " and potassium content " $\mathrm{K} \mathrm{mg} / \mathrm{g} \mathrm{DM}$ " in Brassica oleracea mapping population "Bo1TBDH". (QTL significant with $P=0.05$ are marked bold)

Table V-6: Minimum, maximum and mean of GSL content $\mu \mathrm{Mol} / \mathrm{g}$ DM of $B$. oleracea Bo1TBDH population and parents under control and salt treatment $(100 \mathrm{mM} \mathrm{NaCl})$

Table V-7: Minimum, maximum and mean values of the major categories; aliphatic, indolic and aromatic GSL $\mu \mathrm{mol} / \mathrm{g}$ DM of $B$. oleracea Bo1TBDH population under control condition and salt treatment $(100 \mathrm{mM} \mathrm{NaCl})$

Table V-8: Spearman's rank correlations of glucosinolates in B. oleracea Bo1TBDH mapping population under control condition

Table V-9: Spearman's rank correlations of glucosinolates in B. oleracea Bo1TBDH mapping population under $(200 \mathrm{mM} \mathrm{NaCl})$ salt stress condition

Table V-10: QTL detected at LOD > 2 under control treatment $(C)$ for glucosinolate content $\mu \mathrm{Mol} / \mathrm{g}$ DM in Brassica oleracea mapping population Bo1TBDH. (QTL significant with $P=$ 0.05 are marked bold)

Table V-11: QTL detected at LOD > 2 under salt treatment (S) for glucosinolate content $\mu \mathrm{Mol} / \mathrm{g}$ DM in Brassica oleracea mapping population Bo1TBDH. (QTL significant with $P=$ 0.05 are marked bold) 


\section{List of figures}

\section{Chapter I: Literature Review}

Figure I-1: U-triangle showing the evolution of the amphidiploids Brassica species from the

diploid species (according to Morinaga 1934 and U 1935)

Figure I-2: Summary of salinity detrimental effects on plant growth

\section{Chapter II: Experiments to develop a screening method and to select a suitable DH population}

Figure II-1: Fresh weight (g) of the 13 founder under control and salt stress (200 mM NaCl)

Figure II-2: Dry weight (g) of the 13 founder under control and salt stress $(200 \mathrm{mM} \mathrm{NaCl})$

Figure II-3: Fresh weight $(\mathrm{g})$ of six genotypes under control and salt stress (200 mM NaCl)

Figure II-4: Dry weight (g) of six genotypes under control and salt stress $(200 \mathrm{mM} \mathrm{NaCl})$

Figure II-5: Fresh weight (g) of six genotypes under control and salt stress (200 mM NaCl)

Figure II-6: Dry weight (g) of six genotypes under control and salt stress $(200 \mathrm{mM} \mathrm{NaCl})$

\section{Chapter III: Mapping QTL for salt tolerance at seed germination in Brassica napus and Brassica oleracea doubled-haploid populations}

Figure III-1: Frequency distribution of germination parameters under control under salt stress conditions of Brassica napus mapping population (Alesi $\times \mathrm{H} 30$ ); a) Germination percentage (\%) under control and b) Germination percentage under salt; c) Germination pace (GP) under control and d) Germination pace under salt, e) Salt tolerance index for germination percentage and f) Salt tolerance index for germination pace

Figure III-2: Frequency distribution of germination parameters under control under salt stress conditions of Brassica napus mapping population (Mansholts $\times$ Samourai); a) Germination percentage (\%) under control and b) Germination percentage under salt; c) Germination pace (GP) under control and b) Germination pace at salt, d) Salt tolerance index for germination percentage and d) Salt tolerance index for germination pace

Figure III-3: Frequency distribution of germination parameters under control under salt stress conditions of Brassica oleracea mapping population (Bo1TBDH); a) Germination percentage (\%) under control and b) Germination percentage under salt; c) Germination pace (GP) at control and d) Germination pace at salt, e) Salt tolerance index for germination percentage and f) Salt tolerance index for germination pace

Figure III-4: Framework map of Brassica napus mapping population (Alesi $\times \mathrm{H} 30$ ). The vertical bars are the linkage groups N1-N10 = A1-A10 and N11-N19 = C1-C9 (international nomenclature).

Figure III-5: Framework map of Brassica napus mapping population (Mansholts $\times$ Samourai) based on a population of double haploid lines. The Vertical bars represent linkage groups N1-N10 = A1-A10 and N11-N19 = C1-C9 (international nomenclature).

Figure III-6: Framework map of Brassica oleracea mapping population Bo1TBDH. The vertical bars represent linkage groups N11-N19 = C1-C9 (international nomenclature). 
Figure III-7: Localization of QTL for germination parameters in Brassica napus DH population (Alesi $\times \mathrm{H} 30$ ). The names of QTL significant with $P=0.05$ are marked bold

Figure III-8: Localization of QTL for germination parameters in Brassica napus DH population (Mansholts $\times$ Samourai). The names of QTL significant with $P=0.05$ are marked bold

Figure III-9: Localization of QTL for germination parameters in Brassica oleracea Bo1TBDH population. The names of QTL significant with $P=0.05$ are marked bold

\section{Chapter IV: Mapping QTL for salt tolerance at the young plant stage and leaf glucosinolates in a Brassica napus DH population}

Figure IV-1: Frequency distribution of fresh and dry weight of Brassica napus DH population (Mansholts $\times$ Samourai); a) Fresh weight under control and b) Fresh weight under salt stress , c) Dry weight under control and d) Dry weight under salt stress

Figure IV-2: Frequency distribution of relative water content of Brassica napus DH population (Mansholts $\times$ Samourai); a) relative water content under control and b) relative water content under salt stress

Figure IV-3: Frequency distribution of chlorophyll content measured by (SPAD) of $B$. oleracea Bo1TBDH population; a) SPAD under control and b) SPAD under salt stress

Figure IV-4 : Frequency distribution of Sodium content $\mathrm{Na}^{+} \mathrm{mg} / \mathrm{g} \mathrm{DM}$ and Potassium content $\mathrm{K}^{+} \mathrm{mg} / \mathrm{g}$ DM of Brassica napus $\mathrm{DH}$ population (Mansholts $\times$ Samourai); a) sodium content under control and b) sodium content under salt stress , C) potassium content under control and d) potassium content under salt stress

Figure IV-5: Localization of QTL for growth traits in Brassica napus DH population (Mansholts $\times$ Samourai). QTL significant with $P=0.05$ are marked bold

Figure IV-6: (a) Total glucosinolate content $\mu \mathrm{mol} / \mathrm{g}$ DM of each component in parents and the DH population under control and salt, (b) Percentage of each component relative to the total GSL content in parents and the DH population under control and salt

Figure IV-7: a) Absolute values of aliphatic GSL components $\mu \mathrm{mol} / \mathrm{g}$ DM in the parents and the DH population under control and salt, b) Percentage of each ingredient of the aliphatic GSL in the aliphatic GSL content in parents and the DH population under control and salt

Figure IV-8: a) Absolute values of indolic GSL components $\mu \mathrm{mol} / \mathrm{g}$ DM in the parents and the $\mathrm{DH}$ population under control and salt, b) Percentage of each ingredient of indolic GSL in the indolic GSL content in parents and the $\mathrm{DH}$ population under control and salt

Figure IV-9: Absolute values of aromatic GSL components $\mu \mathrm{mol} / \mathrm{g}$ DM in the parents and the $\mathrm{DH}$ population under control and salt

Figure IV-10: Distribution of total GSL $\mu \mathrm{mol} / \mathrm{g}$ DM of Brassica napus DH population (Mansholts $\times$ Samourai) under control and salt stress

Figure IV-11: Localization of QTL for glucosinolates $\mu \mathrm{Mol} / \mathrm{g}$ DM in Brassica napus DH population (Mansholts $\times$ Samourai). The names of QTL which were identified at $P=0.05$ are marked bold) 


\section{Chapter V: Mapping QTL for salt tolerance at the young plant stage and leaf glucosinolates in a Brassica oleracea $\mathrm{DH}$ population}

Figure V-1: Frequency distribution of fresh weight and dry weight of Brassica oleracea Bo1TBDH population a) Fresh weight at control and b) Fresh weight at salt stress, c) Dry weight at control and d) Dry weight at salt stress

Figure V-2 : Frequency distribution of relative water content) of Brassica oleracea Bo1TBDH population a) Relative water content at control and b) Relative water content at control at salt stress

Figure V-3: Frequency distribution of chlorophyll content measured by (SPAD) of $B$. oleracea B01TBDH population; a) SPAD under control and b) SPAD under salt stress

Figure V-4 : Frequency distribution of Sodium content $\left(\mathrm{Na}^{+} \mathrm{mg} / \mathrm{g} \mathrm{DM}\right)$ and Potassium content $\left(\mathrm{K}^{+} \mathrm{mg} / \mathrm{g} \mathrm{DM}\right)$ of Brassica oleracea Bo1TBDH population a) sodium content under control and b) sodium content under salt stress , C) potassium content under control and d) potassium content under salt stress

Figure V-5: Localization of QTL for growth traits and physiological traits in Brassica oleracea Bo1TBDH population. QTL significant with $P=0.05$ are marked bold

Figure V-6: (a) Total glucosinolate content $\mu \mathrm{mol} / \mathrm{g}$ DM of each component in parents and the DH population under control and salt, (b) Percentage of each component relative to the total GSL content in parents and the DH population under control and salt

Figure V- 7: Absolute values of aliphatic GSL components $\mu \mathrm{mol} / \mathrm{g} D M$ in the parents and the $\mathrm{DH}$ population under control and salt, b) Percentage of each ingredient of the aliphatic GSL in the aliphatic GSL content in parents and the DH population under control and salt

Figure V-8: Absolute values of indolic GSL components $\mu \mathrm{mol} / \mathrm{g} D M$ in the parents and the DH population under control and salt, b) Percentage of each ingredient of indolic GSL in the total indolic GSL content in parents and the DH population under control and salt

Figure V-9: The aromatic GSL content $\mu \mathrm{mol} / \mathrm{g}$ DM in Brassica oleracea DH population under control and salt

Figure V-10: Distribution of total GSL in the parents and the DH population under control and salt

Figure V-11: Localization of QTL for glucosinolate in Brassica oleracea Bo1TBDH population. QTL significant with $P=0.05$ are marked bold

\section{Chapter VI}

Figure VI-1: The relation between QTL for germination and QTL for growth traits in

Brassica napus DH population Mansholts $\times$ Samourai.

Figure VI-2: The relation between QTL for germination and QTL for growth traits in Brassica oleracea DH population Bo1TBDH 


\section{General introduction}

The Brassicaceae family includes many important forage crops such as $B$. rapa, $B$. napus, and $B$. oleracea. This family is the source of a number of oilseed (oilseed rape) and fodder crops, in addition to ornamentals such as Cheiranthus (wallflower), Lobularia maritima (sweet alysson), and Hesperis (rocket). Brassica is one of the most important genera of the Brasicaceae, comprising up to 100 species, including cauliflower, broccoli, brussels sprouts, turnips and various mustards (Gómez-Campo and Prakash 1999). Brassica napus (rapeseed, oilseed rape, Canola) is an oilseed crop of global economic importance. Brassica napus L. is the main European oilseed crop. The oil is used for human consumption, and in the chemical and pharmaceutical industries or as fuel (Wittkop et al. 2009). Brassica napus is an important crop for the human food supply and for animal feed. It originated from interspecific hybridizations between turnip rape (Brassica rapa L.; $A A, 2 n=20$ ) and cabbage (Brassica oleracea L.; $C C, 2 n=18$ ) that occurred spontaneously (Iñiguez Luy and Federico 2011) and is considered a new crop, its production beginning about 500 years ago (Gómez-Campo and Prakash 1999).

Salinity is a soil condition in which the soil includes excess soluble ions (Munns 2005). Salinity can decrease crop productivity by $20 \%$. This reduction is attributed to the reduction in different stages from seed germination until the fruiting stage (reviewed by Ashraf et al. 2008). The deleterious effect of salinity on seed germination and plant growth is a biphasic process. The first phase is the osmotic stress which exerts a negative effect on plant growth immediately with onset of the salt stress. The second phase is ion toxicity which results from the accumulation of excess ions in the plant tissues, especially $\mathrm{Na}^{+}$and $\mathrm{Cl}^{-}$(Munns and Tester 2008). Salinity tolerance varies across the plant ontogeny. Therefore, salt tolerance at one stage like seed germination is not necessarily correlated with another stage such as vegetative growth (Mano and Takeda 1997, Foolad 1999). The investigation of salt tolerance during different growth stages is necessary to disentangle the problem of salinity. Brassica species were ranked as moderately salt tolerant, with a superiority of the polyploid species like $B$. napus over their diploid ancestors $B$. rapa and B. oleracea (Ashraf et al. 2001, Ashraf 2001).

Many approaches have been proposed to relieve the detrimental effects of salinity. One of these is the technical approach, which modifies the soil to meet plant demands through the construction of efficient irrigation systems, but this is a costly and temporal solution. Another solution is to select for salt-tolerant varieties, an approach known as the biological approach (Ashraf et al. 2001). A number of methods have been employed to implement the biological approach, such as conventional breeding, which is time-consuming and laborious. Another disadvantage is the transfer of undesirable genes (reviewed by Ashraf and Foolad 2013). Thus there was a need for fast, efficient and cheap techniques such as marker assisted selection (MAS) or gene transfer. A prerequisite for MAS or gene transfer is the identification of the genomic regions harboring the causal genes, which can be achieved by the mapping of quantitative trait loci (QTL). 
Glucosinolates (GSL) are plant Sulfur and Nitrogen containing secondary metabolites. More than 120 derivatives were recorded in glucosinolate-containing plant families as a result of secondary modifications (Halkier and Gershenzon 2006). Glucosinolates exhibit a wide spectrum of biological activities with both negative and positive nutritional attributes (Mithen 2001). Recently, the importance of the Brassica crops increased due to the discovery of their cancer-preventing compounds. Isothiocyanate sulforaphane, a derivative of 4-methylsulfinylbutyl (glucoraphanine), was found in broccoli. Sulforaphane and other isothiocyanates may stop tumor growth by cutting off the cell cycle and enhancing programmed cell death (Thornalley 2002).

So far no QTL analysis of the salt tolerance of Brassica species has been published (Nayidu et al. 2013). Our knowledge about the genetic control of leaf GSL is rather limited compared to that about seed GSL. Furthermore, few reports have been released about the effect of salinity on GSL variation and content. Xin et al. (2008) found that the total indolic and the total aromatic GSL increased in Arabidopsis under application of $150 \mathrm{mM} \mathrm{NaCl}$. The GSL content and single components varied between different organs under salt stress with developmental stages in Thellungiella salsuginea under different concentrations of $\mathrm{NaCl}$ (Pang et al. 2012). In another study in broccoli, the GSL level was high in florets compared with newly occurring leaves, possibly due to GSL transfer through phloem tissue to another organ or in situ biosynthesis in florets (López-Berenguer et al. 2009).

Therefore, the present study addresses the following topics in six chapters. The first chapter comprises a general introduction and a literature review on the salt tolerance of the Brassica species and GSL. The second chapter shows the preexperiments that we conducted to develop a suitable method to test Brassica mapping populations at the juvenile stage in the greenhouse, in order to determine the most suitable salt concentration and to select a suitable mapping population based on the performance of the parents. The third chapter shows the analysis of the genetic variation in seed germination under control and salt stress conditions in doubled-haploid $(\mathrm{DH})$ mapping populations of $B$. napus and $B$. oleracea and identifies the QTL that govern the genetic variation in seed germination under control and salt stress conditions. The fourth chapter addresses the effect of salinity on B. napus in a DH mapping population under $200 \mathrm{mM} \mathrm{NaCl}$ at the young plant stage, and identifies the QTL for traits measured under both growth conditions. Additionally, we analyze the leaf GSL variation under control and salt stress and map the QTL that control the variation in leaf GSL profile and content under both growth conditions. The fifth chapter seeks to determine the effect of salinity on $B$. oleracea in the $\mathrm{DH}$ mapping population Bo1TBDH under treatment with $100 \mathrm{mM} \mathrm{NaCl}$ at the young plant stage and to identify the QTL for traits measured under both growth conditions, i.e. control and salinity. Furthermore, this chapter investigates the variation in leaf GSL under control conditions and salt stress and maps the QTL for this variation. The sixth chapter includes a general discussion of the results. 


\section{The main objectives of the present study are}

1. To establish a suitable method to test a large number of genotypes for salinity in the greenhouse and to select a mapping population based on the performance of its parents.

2. To address the effect of salinity on seed germination in $\mathrm{DH}$ mapping populations of $B$. napus and $B$. oleracea and to identify the QTL that control the variation in the measured germination parameters.

3. To analyse the effect of salinity on plant growth at the juvenile stage and to identify the QTL that control the variation in different traits under control and salt stress.

4. To measure the variation in leaf GSL under control and salt stress and to identify the QTL that underlie the genetic variation in leaf GSL under control and salt stress. 


\section{Chapter I}

\section{Literature review}

\subsection{The family Brassicaceae}

The Brassicaceae exhibit a cosmopolitan distribution, although certain regions of the world have a greater density of genera. Some members of this family are found in most parts of the world, but they are mainly concentrated in the northern temperate region, especially in the countries surrounding the Mediterranean basin and in southwestern and central Asia (Gómez-Campo and Prakash 1999). The Brassicaceae are widely distributed all over the world and comprise approximately 338 genera and 3709 species (Warwick et al. 2011). The most important diversification centers are found in The Irano-Turanian region with ca. 150 genera and ca. 900 species with 530 endemics and in the Mediterranean region with ca. 113 genera and ca. 630 species with 290 endemics. The Saharo-Sindian region includes 65 genera and 180 species with 62 endemics and North America has ca. 99 genera and 778 species with 600 endemics. This smaller species diversity is continued in the southern hemisphere: South America with 40 genera and 340 species; Southern Africa with 15 genera and at least 100 species; and Australia and New Zealand with 19 genera and 114 species (Lysak and Koch 2011). The Brassicaceae include many important forage crops, such as B. rapa, B. napus, and $B$. oleracea. This family is the source of a number of oilseed (oilseed rape) and fodder crops, in addition to ornamentals such as Cheiranthus (wallflower), Lobularia maritima (sweet alysson), and Hesperis (rocket). The genus Brassica is one of the most important genera of the Brasicaceae, comprising up to 100 species, including cauliflower, broccoli, brussels, sprouts, turnips and various mustards (GómezCampo and Prakash 1999).

\section{Genomic relationships between the diploid and polyploid Brassica species}

The relationships between the different cultivated Brassica genomes that characterize the different species of the Brassica genus have been addressed in a cytological work (Morinaga 1934). The species $B$. napus $(2 \mathrm{n}=38$, AACC), $B$. juncea $(2 \mathrm{n}=36, \mathrm{AABB})$, and $B$. carinata $(2 \mathrm{n}=34, \mathrm{BBCC})$ are amphidiploids, comprising pairs of chromosome sets from their diploid ancestors $B$. rapa $(2 n=20$, $A A), B$. oleracea $(2 n=18, C C)$ and $B$. nigra $(2 n=16, B B)$, (Figure 1$)$. This hypothesis was verified $(U$ 1935) in a successful resynthesis of $B$. napus by crossing $B$. rapa with $B$. oleracea. The resynthesis of $B$. juncea and $B$. carinata was done later by (Frandsen 1943, 1947).

\section{Brassica napus}

Brassica napus (rapeseed, oilseed rape, Canola) is an oilseed crop of global economic importance. Brassica napus is the main European oilseed crop. The oil is used for human consumption, and in the chemical and pharmaceutical industries or as fuel (Wittkop et al. 2009). Brassica napus was originated from a spontaneous interspecific hybridization between turnip rape (Brassica rapa L.; $A A, 2 n=20$ ) and cabbage (Brassica oleracea L.; CC, $2 n=18$ ), (Iñiguez-Luy and Federico 2011). 


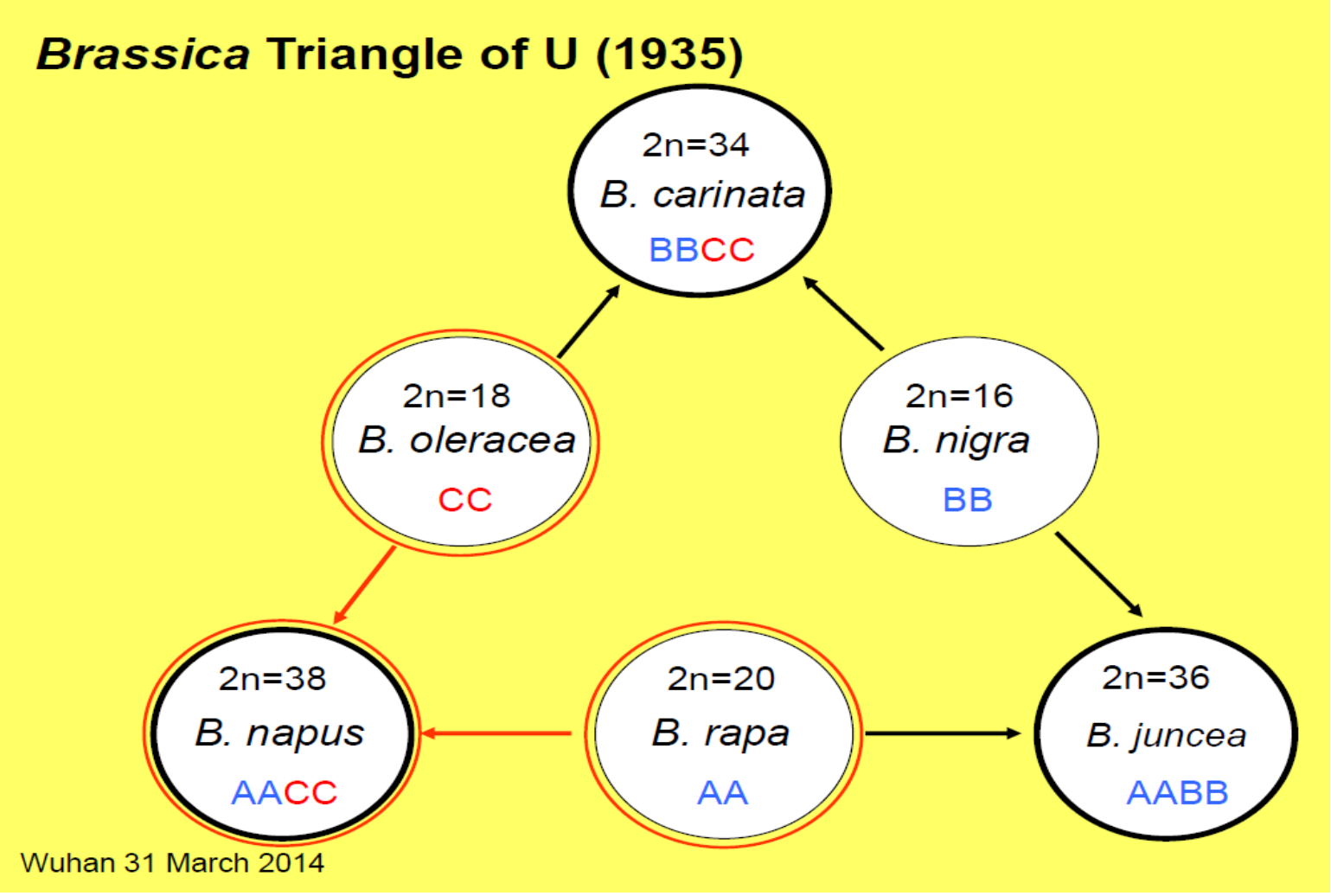

Figure I-1: Triangle of $U$ shows the evolution of the amphidiploids Brassica species from their diploid progenitors according (Morinaga 1934 and $U$ 1935)

Brassica napus is thought to be a relatively new species that was developed only 500 years ago (Gómez-Campo and Prakash 1999). Based on chloroplast DNA investigation, Allender and King (2010) reported that there were two species, $B$. rapa (brocoletto crop type) from southern Italy, and a second one grown in Portugal. One of them would have been hybridized with $B$. oleracea. It is apparent that the former was grown close to $B$. oleracea crops like kale, cabbage and broccoli, which smoothed the hybridization with $B$. oleracea and led to the evolution of $B$. napus. A clear differentiation between $B$. rapa, $B$. oleracea and $B$. napus using highly diverse chloroplast microsatellite markers was unsuccessful because $B$. napus formed its own cluster (Zamani-Nour et al. 2013). Becker et al. (1995) reported that the modern elite varieties possess low levels of diversity due to few hybridization events together with the occurrence of two bottlenecks during $B$. napus breeding. Brassica napus has achieved economic importance as an oilseed crop in the past 40 years following an intensive breeding program. This breeding program aimed at increasing yields and decreasing the high levels of erucic acid in the seed oil to make it relevant for human consumption. Moreover, reducing the high levels of aliphatic glucosinolate in the residue after oil extraction made it more relevant and safe for animal feed (Wittkop et al. 2009).

\section{Brassica oleracea}

Representing the cole crops, this species is a member of the $\mathrm{CC}$ genome cohort, which includes several interfertile species, i.e. Brassica cretica, Brassica hilarionis, Brassica incana, Brassica insularis, Brassica macrocarpa, Brassica montana, 
Brassica rupestris, and Brassica villosa (Warwick 2011). The wild forms of $B$. oleracea have been found in the coastal areas of western Europe and Brassica bourgeaui in the Canary Islands (Warwick 2011). The cultivated forms of $B$. oleracea can be subdivided into different classes based on their edible parts. In kales (var. viridis, var. costata, var. medullosa, var. sabellica) and branching bush kales (var. ramosa), the edible part is the foliage leaves. The tightly packed leaves are the edible part of cabbages (var. capitata and var. sabauda) and brussels sprouts (var. gemmifera). The above-ground, thickened stem is the edible part of kohlrabi (var. gongyloides). Cauliflower and broccoli (var. botrytis and var. italica) are cultivated for their thickened edible inflorescences (Warwick 2011). These diverse morphotypes provide an ideal material to investigate human-directed evolution (artificial selection) and the processes involved in domestication. Brassica oleracea genome structure is not only related to the vegetable crops that it represents itself, but also one of the parents of $B$. napus, oilseed rape, the second edible oil source among the oilseed crops (Warwick 2011). Song et al. (1990) reported that the cultivated forms have a monophyletic origin from the same progenitor. Probably it was a leafy kale from which the other cultivated types diverged. Moreover, this study revealed that other wild CC genomes cytodeme, such as $B$. insularis and $B$. incana, may also share the diversity of cultivated $B$. oleracea. Brassica vegetables appear to protect against cancer and heart disease, principally due to the presence of glucosinolates which are secondary metabolites that break down into isothiocyanate (sulphoraphane). These Sulphur-containing compounds act as anti-cancer agents, inducing detoxification enzymes and limiting tumors growth by nullifying carcinogenic- chemicals in cells (Talalay et al. 1995).

\subsection{Salinity}

Soil is classified as saline when the electric conductivity (ECe) exceeds 4 EC (40 $\mathrm{mM} \mathrm{NaCl}$ ), (USDA Salinity Laboratory 2005). Worldwide, more than 800 million hectares, which represent $6 \%$ of the earth, are salt-affected lands (USDA Salinity Laboratory 2005). The major factors reducing crop productivity are abiotic stresses (Boyer 1982). Yield losses due to individual abiotic stresses were estimated as $17 \%$ for drought, $20 \%$ for salinity, $40 \%$ for high temperature stress and $15 \%$ for frost (Ashraf et al. 2008). With regard to salinity, plants can be categorized into two categories, tolerant plants (halophytes) and non-tolerant plants (glycophytes). Halophytes can withstand high amounts of $\mathrm{Na}^{+}$and $\mathrm{Cl}^{-}$due to anatomical adaptations and intracellular partitioning. Dicotyledonous halophytes developed two types of anatomical adaptations: an increase in cell size due to increased vacuole volume (succulence), or the exclusion of $\mathrm{Na}^{+}$and $\mathrm{Cl}^{-}$by salt glands or bladders (Flowers et al. 1977).

\section{Types of salinity}

Natural or primary salinity is the accumulation of salts over the long term, via two processes. The first is soil erosion, which releases many soluble salts. The second is precipitation of salts carried by rains and wind. Secondary or human-induced salinity results from human activities such as land clearing, replacement of natural vegetation with crops, and/or use of poor irrigation water (Munns 2005).

\section{Phases of salt stress and mechanisms of response}

Plants have developed numerous defense strategies to overcome salt stress. These strategies include minimizing exposure, avoidance, and/or tolerance. 
Minimizing exposure is achieved by inducing early flowering and a short life cycle. Avoidance is accomplished through exclusion of salt ions, increasing water uptake and decreasing water loss by closing stomata to prevent or decrease water evaporation. Tolerance becomes the alternative when the other defenses against salt stress are impossible (Chaves et al. 2003). Plant salt tolerance involves osmotic adjustment, exclusion of excess ions and sequestering the excess ions in the vacuole. When these mechanisms are inadequate, plants develop peripheral defense mechanisms such as detoxification of reactive oxygen species (Munns and Tester 2008). The abilities of plants to withstand salt stress depend on the species, period of exposure, the concentration of the salt and the growth conditions (Ashraf and Foolad 2013). The physiological adaptations of plants to salt stress are summarized in Figure 2 (Nayidu et al. 2013).

\section{Effect of salinity on seed germination and plant growth}

Seed germination and seedling establishment are two crucial steps in the life cycle of plants. The absence of optimum plant germination causes a reduction in plant density, which may result in yield reduction (El-Hendawy et al. 2011). Salt stress delays germination and increases its time-course (Foolad and Jones 1991). High concentrations of salts surrounding roots impair seed germination and crop establishment (Fowlers 1991).

High salinity reduces plant growth and development dramatically. This reduction could be due to osmotic stress or adverse specific ion toxicity (Munns and Tester 2008). The steep build-up of sodium and chloride perturbs membrane integrity and function, and causes nutrient ion imbalances. High levels of sodium or chloride impair the uptake of essential minerals such as potassium, nitrate or phosphate (Grattan and Grieve 1999). Osmotic stress has a more severe impact than ionspecific stress. The former begins much earlier, especially under low and moderate salt concentrations. It is accompanied by a slower development of new leaves, lateral buds and fewer lateral branches. Ion-specific stress on the other hand more strongly affects sensitive plants that are not able to control salt uptake. The death of older leaves is a sign of the second phase (Munns and Tester 2008).

\section{Effect of salinity on photosynthesis}

Stomata closure is the immediate and fastest response of the entire plant to osmotic stress. The reduction of photosynthesis is accompanied by other changes in the leaf anatomy and carbohydrate metabolism. Under salt stress the leaves become smaller and thicker, resulting in high chloroplast number per leaf area (Fricke et al. 2004). The accumulation of unused carbohydrates generates feedback signals to slow down the photosynthesis (Paul and Foyer 2001). The reduction in photosynthesis might be attributed to the inhibition of cytosolic enzymes, which catalyze the carbohydrate metabolism, or to the accumulation of $\mathrm{Na}^{+}$and $\mathrm{Cl}^{-}$ions in chloroplasts (Munns and Tester 2008). 


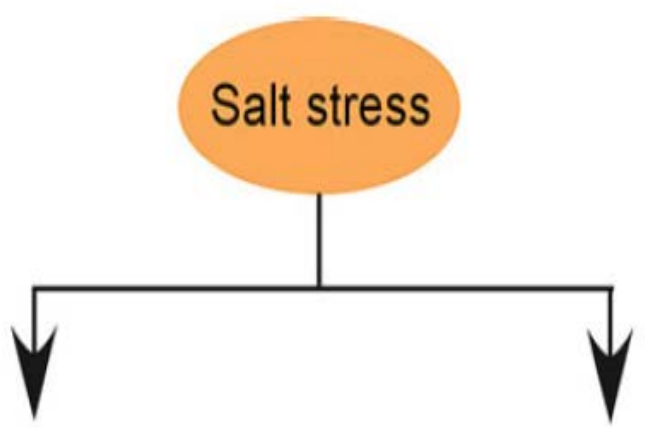

\section{Physiological drought}

*Accumulation of $A B A$

${ }^{*}$ Closure of Stomata

${ }^{\star}$ Reduction in $\mathrm{CO} 2$ assimilation

* Reduction in transpiration

* Reduction of leaf expansion

* Reduction in light interception

${ }^{*}$ Reduction in photosynthetic rate

${ }^{*}$ Reduction in biomass accumulation

* Delay in onset of flowering

* Reduction in number of flowers

\section{Oxidative stress}

${ }^{\star}$ Accumulation of reactive oxygen species

* Lipid peroxidation of membranes

* Denaturation of nucleic acids and proteins

* Inhibition of accumulation of essential macro molecules such as photosynthetic pigments, proteins, nucleic acids and lipids
Ion excess effect

* Inhibition of enzymes responsible for carbon assimilation

* Inhibition of photosynthetic electron transport

* Reduction in accumulation of photosynthetic pigments

* Reduction in carbon metabolism

* Effect on mobility of metabolites from the site of production to site of utilization

* Inhibition of metabolic processes such as synthesis of proteins, amino acids, sugars, starch and other organic compounds

\section{Nutrient imbalance}

* Reduction in uptake of $\mathrm{K}^{+}$and $\mathrm{Ca}^{2+}$

${ }^{*}$ High $\mathrm{Na}^{+} / \mathrm{K}^{+}$ratio

* Inhibition of metabolic and

physiological processes

Figure I-2: Summary of salinity detrimental effects on plant growth

Source: Nayidu et al. 2013 


\section{Effect of salinity on seed oil quantity and quality}

In oilseed crops, the quality of seed oil depends on the composition of fatty acids such as palmitic, stearic, oleic and linoleic acid. Salinity directly inhibits enzymes, such as glyoxysomal catalase, malate synthase, isocitratelyase and oleatedesaturase. These enzymes regulate fatty acid biosynthesis and modification. For instance, sunflower plants grown on saline irrigation water exhibited a progressive increase in oleic acid content and a decrease in linoleic acid level (Nayidu et al. 2013).

\section{Strategies to solve the salinity problem}

There are two major scenarios to minimize the detrimental effects of high soil or water salinity. Both of these strategies could be applied to maintain sustainable crop production in the presence of high salinity (Epstein et al. 1980). The first is a technical approach and involves large engineering schemes for reclamation, drainage and irrigation with high-quality water. Although these practices have had success in some areas, their costs were high. Moreover, their solution to the problem is often only temporary. The second approach is a biological one employing biological solutions based on the use or development of salt-tolerant plants (Ashraf et al. 2008). Another biological solution is the domestication of halophytes (Flowers 2004). The biological approach encompasses several steps; development of efficient screening tools for selection and evaluation of specific traits. These steps include estimating the salt tolerance of plants at different developmental stages, investigating the biological mechanisms that control salt tolerance, and developing efficient direct or indirect breeding methods to transfer the tolerance genes (Ashraf and Foolad 2013). Nobel and Rogers (1992) observed that the somewhat limited success in producing salt-tolerant genotypes is due to many factors, including the polygenic nature of salinity, the lack of efficient evaluating and selecting criteria, and a limited understanding of the mechanisms that regulate salt tolerance.

\subsection{Salt tolerance in Brassica}

Salinity reduces the growth, yield, and oil production of Brassica species. In Brassica species, seed germination and early seedling are the most sensitive stages (Ashraf and Harris 2004). There is a potential inter- and intraspecific variation in salt tolerance among the Brassica species. This variation can be exploited through selection and breeding to ameliorate salt tolerance. Brassica was classified as moderately salt tolerant with a superiority of amphidiploids species over the diploid species (Mailk 1990; He and Cramer 1992). Ashraf and Harris (2004) reported that the amphidiploids species are more salt tolerant compared to the diploid species, and that the salt tolerance of amphidiploids species was inherited from the diploid progenitors. This is in agreement with the findings of Stebbins (1966), who reported that the polyploid species can withstand adverse environmental stresses better than their respective diploid ancestors.

\section{Improving salt tolerance in Brassica}

Several approaches were harnessed to enhance salinity tolerance in Brassica. Conventional breeding approaches have allowed the production of many salttolerant varieties of Brassica. In India, salt-tolerant varieties of Brassica juncea were developed (Purty et al. 2008). Salt tolerance of the Brassica tribe was analysed by 


\section{Chapter I}

estimating the whole plant growth, proline accumulation, $\mathrm{K}^{+} / \mathrm{Na}^{+}$ratio and electrolyte leakage (Purty et al. 2008). Brassica juncea var. CS52 was recommended for cultivation in saline soils. More lines and varieties were developed in other species, like $B$. carinata and $B$. rapa. The names of lines and varieties, selection parameters and the authors are summarized (Appendix 5).

Jain et al. (1990) developed salt-tolerant lines of $B$. Juncea using an in vitro approach. Out of 2,650 cotyledons cultured in high salt level media, three calli survived and resurrected shoots. When these three lines were tested on saltenriched medium, two of them flowered and produced seeds. The third displayed abnormal morphological features and was sterile. Kirti et al. (1991a) produced sodium chloride-tolerant lines from somatic embryos of $B$. juncea line RLM198. In this experiment, the plants, which were regenerated from the tolerant lines, were tested for salt tolerance by measuring esterase isozyme pattern and proline accumulation. The tolerant calli accumulated higher amounts of proline than the sensitive ones. Elavumoottil et al. (2003) developed salt-tolerant calli and cell suspension from $B$. oleracea var. botrytis. The salt-tolerant ones showed high sucrose content and reduced sugars and sucrose synthase.

Fast and efficient techniques were used to speed up the development of salttolerant lines by gene transfer to modify metabolic pathways or to engineer ions exchange. For example, the expression of the bacterial codA gene in $B$. napus improved the salt tolerance. The transgenic lines showed a significant increase in seed germination and seedling under salinity compared to the wild ones (Huang et al. 2000; Prasad et al. 2000). Zhang et al. (2001) transformed $B$. napus by the AtNHX gene, coding for a vacuolar $\mathrm{Na}^{+} / \mathrm{H}^{+}$antiporter from $A$. thaliana. Whereas the growth of the wild lines was markedly reduced, the transformed lines were able to continue growing, flowering and producing seeds. Another successful example was the production of high $\mathrm{NaCl}$-tolerant cultivars of Brassica oleracea var. capitata cultivar 'Golden Acre', by transformation with a bacterial betA gene (Bhattacharya et al. 2004). The overexpression of the (PR)-10 family derived from Pea in $B$. napus improved seed germination in the presence of $\mathrm{NaCl}$ (Srivastava et. al. 2004). Park et al. (2005) stated that the expression of $B$. napus late embryogenesis (LEA) group 3 abundant protein genes boosted salinity and drought tolerance of the Chinese cabbage $B$. rapa. Brassica juncea was able to withstand high salinity levels of up to $300 \mathrm{mM} \mathrm{NaCl}$ after being transformed with the PgNHX1 gene from Pennisetum glaucum (Rajagopal et al. 2007). The overexpression of Arabidopsis Dehydrationresponsive element binding factor $2 \mathrm{C}$ (DREB2C) in $B$. napus ameliorated the salt tolerance. The overexpression of this gene increased chlorophyll content and reduced water loss in the transformed types compared to the wild types (Song et al. 2014). These reports demonstrate the considerable increase in salt tolerance achieved by single gene overexpression, despite the fact that salt tolerance is a polygenic trait.

\subsection{QTL and Salinity}

A current approach to increase the efficiency of selection and breeding for complex traits such as salt tolerance is indirect selection using genetic markers. This target requires identifying these genetic markers, which are linked to the traits of interest. The use of quantitative trait loci (QTL) is a powerful method for finding the link 
Chapter I

between the genetic markers mapped on the chromosomes and the traits of interest (Ashraf and Foolad 2013).

\section{The QTL controlling salt tolerance during different growth stages}

Several QTL controlling seed germination under salinity conditions were mapped. Fourteen QTL controlling salt tolerance at germination and during vegetative growth have been detected in tomato (Foolad and Chen 1999). In wheat, several QTL were mapped these QTL increase biomass, root length, shoot length, proline and chlorophyll content during germination and seedling survival (Ma et al. 2007). Several QTL were identified for salt tolerance at the reproductive stage of tomato (Villalta et al. 2007). These studies suggest that an understanding of the complexity of salt tolerance can be achieved through investigation of salt tolerance at different developmental stages.

\section{QTL for ion uptake}

Several QTL regulating ion uptake were identified in different crops. For example, four QTL for the ion transport were detected in wheat (Huang et al. 2006). In wheat, the QTL Kna1 was identified for $\mathrm{Na}^{+} / \mathrm{K}^{+}$selectivity (Dubcovsky et al. 1996). In rice, several QTL were QTL for $\mathrm{Na}^{+} / \mathrm{K}^{+}$homeostasis in roots and shoots (Ming-zhe et al. 2005, Sabouri and Sabouri 2008). Fourteen QTL for mineral ions uptake, including one QTL for $\mathrm{Na}^{+}$exclusion, were mapped in sunflower (Lexer et al. 2003).

\subsection{Glucosinolates}

Glucosinolates are plant Sulfur and Nitrogen containing secondary metabolites. Glucosinolates are distributed in 16 dicotyledonous plant families. The Brassicaceae family, including important Brassica crops such as oilseed rape (Brassica napus), cabbage (Brassica oleracea) and the model plant (Arabidopsis thaliana), is well-known for the presence of glucosinolates (Mithen 2001). More than 120 derivatives were recorded in glucosinolate-containing plant families as a result of secondary modifications (Mithen 2001; Halkier and Gershenzon 2006). The structure of the glucosinolate molecule is made up mainly of a $\beta$-thioglucose moiety, a sulphonated oxime core and alterable side chains. This moiety is derived from different amino acids: alanine, valine, leucine, isoleucine, phenylalanine, tyrosine and tryptophan. The biosynthesis of glucosinolates is a triphasic process. The first step is the elongation of the amino acid side chain by adding a methylene group. The second and the third steps are the formation of the core structure, and the modification of the side chain (Halkier and Gershenzon 2006, Sønderby et al. 2010). Glucosinolates are classified into three classes according to the precursor amino acid. The aliphatic glucosinolates are derived mainly from methionine. The indolic glucosinolates are derived from tryptophan. The aromatic glucosinolates are derived from phenylalanine (Halkier and Gershenzon 2006).

\section{Importance of glucosinolates}

Glucosinolates (GSL) exhibit a wide spectrum of biological activities, such as its effective role in plant-herbivore interactions. Glucosinolates degradation products repel herbivores such as birds, mammals and molluscs (Mithen 2001). The repellant ability of glucosinolates depends basically on their composition and population diversity of the herbivores (Giamoustaris and Mithen 1995). The chemical structure of the glucosinolate products plays a striking role in their biological activity (Mithen 2001). Glucosinolate are vacuole-sequestered metabolites and chemically stable (Koroleva et al. 2000). After cell injury, pathogen 
infection, or pest attack, GSL come in contact with the cytosolic hydrolases (myrosinases). This enzyme hydrolyses GSL and highly toxic products are released. These products generate the plant-herbivore interactions (Bennett and Wallsgrove 1994).

Recently, the importance of Brassica crops increased due to recognition of their cancer-preventing components, released by GSL degradation. These GSL hydrolysis products induce phase II detoxification enzymes, or hinder tumor growth by enhancing programmed cell death (Thornalley 2002). The isothiocyanate sulforaphane, a derivative of glucoraphanine (RAA), shows a potential influence against gastritis and stomach cancer (Fahey et al 2002). In animal nutrition, the presence of high levels of GSL in the seeds of cruciferous oilseed crops markedly reduces the quality of the seed meal left after oil extraction. This is mainly due to the presence of certain GSL compounds such as progoitrin. Thus feeding rapeseed meal with high levels of progoitrin causes thyroid gland disorder, kidney and liver failure (Mithen 2001).

It has been observed that myrosinase activity is high, particularly in developing tissue, which suggests that GSL influences plant growth (Husebye et al 2000). The involvement of glucosinolates-myrosinase complex in plant growth was reported in Arabidopsis. The mutant lines lacking the gene that regulates the short chain glucosinolates biosynthesis (CYP79F1) showed a strong dwarf, bushy and semisterile phenotype (Reintanz et al. 2001).

\section{Glucosinolates in Brassica species}

In the Brassicaceae family, about 30-40 different glucosinolates are produced by each species, the methionine-derived (aliphatic GSL) being predominant (Halkier and Gershenzon 2006). Brassica napus has a restricted and unique aliphatic glucosinolate profile. It contains butenyl and pentenyl glucosinolates and their hydroxylated counterparts (Mithen 2001). Conversely, the GSL composition of $B$. rapa and $B$. oleracea, the putative donors of $A$ and $C$ genomes of $B$. napus, have different profiles. Brassica oleracea may contain propenyl and/or butenyl glucosinolates, while $B$. rapa contains butenyl and often pentenyl glucosinolates. Both species may also have significant quantities of methylthioalkyl and methylsulphinylalkyl homologues. This seems to be plentiful, especially within the cultivated forms of $B$. oleracea (Magrath et al 1993). Synthetic B. napus lines, which were derived from $B$. rapa and $B$. oleracea by interspecific hybridization or by embryo rescue techniques have different GSL profiles to those of the natural forms of $B$. napus. This is due to the interaction between the $A$ genome and the $C$ genome (Magrath et al. 1993). It was reported that in Brassica species, GSL represent $1.7 \%$ to $8.0 \%$ of total plant sulfur content (reviewed by Falk et al. 2007).

Great attention has been given to reducing the glucosinolate content of the seeds of oilseed rape $B$. napus. This aim has been successfully accomplished via the introgression of alleles from the low seed GSL cultivar Bronowski into Canadian spring rape cultivars and then into European winter rape cultivars. This integration led to the development of the current 00 cultivars. Cultivars or lines with low seed GSL were selected successfully without pernicious effects on the GSL content of other tissues (Mithen 2001). The genotypes with low seed GSL do not necessarily have low glucosinolate content in vegetative tissues. Lines with high glucosinolate 
Chapter I

content may have low/high leaf glucosinolates content. There was no correlation between the glucosinolate content of leaves, stems, and seeds ( $\mathrm{Li}$ et al 1999; Cleemput and Becker 2011). Thus, GSL synthesis and accumulation seems to be under tissue-specific control, and the effect of mutation which blocks accumulation of glucosinolates in seeds is tissue-restricted ( $\mathrm{Li}$ et al 1999). Similarly, tissuesspecific profile was observed in a set of Chinese lines that were utilized to produce synthetic B. napus (Giamoustaris and Mithen 1995).

\section{Glucosinolates and quantitative trait loci}

In different plant materials, mostly four QTL on $B$. napus chromosomes N9, N12, N17, and N19 were detected independently (Uzunova et al. 1995; Quijada et al. 2006). These findings indicate that these QTL are major loci for seed GSL content (Hasan et al. 2008). Howell et al. (2003) found that the QTL on N9, N12 and N19 were homoeologous loci. In Arabidopsis, a number of QTL controlling the accumulation of aliphatic, aromatic, and indole glucosinolates in leaves and seeds were identified in Landsberg erecta (Ler) X Cape Verde Islands (Cvi-0) recombinant inbred lines. In another study on the same plant material, Kliebenstein et al. (2001b) mapped six QTL that control the total aliphatic GSL accumulation. Of these, two QTL harbored the genes GS-Elong and GS-AOP. Additionally, six QTL controlling the total indolic GSL, and three QTL controlling the aromatic GSL accumulation were mapped.

\section{The interaction between glucosinolates and abiotic stresses}

The role of glucosinolates in biotic stresses such as insect attack and pathogens has been intensively studied. In contrast, the role of GSL under abiotic stressors such as light, drought, salinity and heat is still vague. Several environmental factors affect the concentration and composition of GSL, including light, water supply, temperature and salinity (Rosa et al. 1998; Qasim et al. 2003; Velasco et al. 2007; López-Berenguer et al. 2008; Mewis et al. 2012). In B. rapa, the activity of the transcription factors involved in GSL synthesis has been altered under different growth regimes (Justen 2010). The HY5 transcription factor, which is involved in the assimilation of sulfur-containing metabolites, down regulated the transcription of aliphatic GSL-related MYB transcription factors and enhanced indolic GSL-related MYB transcription factors (Huseby et al. 2013). These results suggest a cross-talk between GSL and the sulfur-containing assimilates of biosynthesis.

\section{What can glucosinolates do under abiotic stresses?}

Plants cannot escape external stressors due to their immobile nature. Therefore, they developed different mechanisms to face these stressors. One of these is the redistribution of resources among the secondary metabolites like GSL (Falk et al. 2007). Under sub-optimal growth conditions, GSL are multifunctional. Under nutrient deficiency growth conditions, in particular, Sulfur and Nitrogen, plants tend to catabolize GSL to use the released $\mathrm{S}$ and $\mathrm{N}$ in the primary metabolic processes (Falk et al. 2007). The highest activity of myrosinase was monitored in the guard cells to release isothiocyanates (AITCS). The AITCs impair the influx of $\mathrm{K}^{+}$into the guard cells, keeping them flaccid. This action induces stomatal closure, reduces the loss of water and fungi infections (Zhao et al. 2008). Khokon et al. (2011) found that in Arabidopsis, the AITCs induced the production of ROS and nitric oxide. These products act as secondary messengers in the ABA-dependent stomatal closure. The indolic GSL, glucobrassicin (GBC), induces the biosynthesis of auxins. These 
Chapter I

auxins stimulate root growth under sub-optimal growth conditions, ensuring efficient uptake of nutrients (reviewed by Falk et al. 2007). These findings indicate that GSL may act as a secondary messenger to activate other signaling pathways.

\section{Salinity effect on GSL}

López-Berenguer et al. (2008) hypothesized that the accumulation of GSL in $B$. oleracea under salt stress plays a role in the osmotic adjustment. In Thellungiella salsuginea, the GSL concentration increased upon exposure to $200 \mathrm{mM} \mathrm{NaCl}$, but with $300 \mathrm{mM}$ there was a dramatic reduction in GSL levels (Pang et al. 2012). Likewise, Guo et al. (2013) observed a 2.1-fold increase in sulforaphane, one of the products of glucoraphanin hydrolysis under $100 \mathrm{mM} \mathrm{NaCl}$ in Brassica oleracea var. italica cv. Youxiu. Xin et al. (2008) found increases in the total indolic and aromatic GSL in Arabidopsis upon $150 \mathrm{~mm} \mathrm{NaCl}$. The GSL content and single components varied between different organs under salt stress in the developmental stages of Thellungiella salsuginea under different concentrations of $\mathrm{NaCl}$ (Pang et al. 2012).

The depletion in GSL content under stressful growth conditions might be due to many factors, such as the degradation of GSL to release the stored elements like Sulfur and Nitrogen, the redistribution of GSL within different organs to ensure certain defense levels. Another reason might also be a strategic use of sources, e.g. when plants experience stresses they tend to invest more energy in primary metabolism to ensure continuous growth. Sometimes the biosynthesis and translocation of GSL is costly. Another possibility is the hydrolysis of GSL by myrosinase after leakage of GSL from the vacuole (reviewed by Martinez-Ballesta et al. 2013). 


\section{Chapter II}

\section{Experiments to develop a screening method and to select a suitable DH population}

Consecutive experiments were conducted to develop an applicable method and to select the suitable doubled-haploid population (DH) population. The selection of the $\mathrm{DH}$ population was based on the performance of its parental lines under salt stress. To address this point the genetic variation in salt tolerance of genetically diverse genotypes was evaluated. Each couple of these genotypes represented the parental lines of a $\mathrm{DH}$ mapping population. These parental lines are available at the Department of Crop Sciences, Georg-August-Universität Göttingen.

\subsection{The objectives of this chapter are to}

(1) develop a method in which a high number of genotypes could be tested.

(2) detect the optimal concentration and parameters to distinguish between the salttolerant and salt-sensitive genotypes.

(3) select two parental lines that varied significantly in salt tolerance, from which a $\mathrm{DH}$ population was derived.

Different methods were developed by other researchers, for example, Ashraf et al. (2001) tested the performance of six species of Brassica: Brassica oleracea, $B$. rapa, $B$. nigra, $B$. napus, $B$. Juncea and $B$. carinata in pot experiment. Each pot was filled with $7.52 \mathrm{~kg}$ well-washed sand. The six genotypes were tested. The control treatment was full-strength Hoagland solution. The salt treatments were $100 \mathrm{mM}$ $\mathrm{NaCl}$ and $200 \mathrm{mM} \mathrm{NaCl}$ supplemented with full-strength Hoagland solution. El Hendawy et al. (2005b) tested the effect of different salt concentrations on eight varieties of Egyptian wheat. These varieties were tested in a greenhouse experiment under control conditions (watering with tap water), and watering with different concentrations of $\mathrm{NaCl}(50 \mathrm{mM}, 100 \mathrm{mM}$ and $150 \mathrm{mM})$. Loamy soil was filled into 7-litre pots; the soil water content for each treatment was adjusted to $25 \%$ using tap water for control or the respective salt concentration for saline conditions. During the experiment the pots were weighed daily and the soil-water content was adjusted by adding tap water as needed. Tunçtürk et al. (2011) examined the performance of $12 \mathrm{~B}$. napus cultivars. In a greenhouse experiment, the cultivars were tested in 4-litre pots filled with loamy soil collected from the field. The control treatment was tap water and the salt stress was $150 \mathrm{mM} \mathrm{NaCl}$.

In the present study, the above-described methods were not used because these methods were applied to test only a few genotypes. The application of these methods to test the $\mathrm{DH}$ populations which include hundreds of genotypes would be laborious, time- and space-consuming. Therefore; we decided to develop a new method to phenotype a high number of genotypes for salt tolerance in a greenhouse experiment. The parental lines were tested using the flooding method; this method will be described in detail below. The aims of the first experiment were to reduce the number of genotypes and to test the suitability of the flooding method to evaluate all of the lines of the $\mathrm{DH}$ population, as well as to discover the advantages and disadvantages of this method. 


\subsection{Experiment 1: Effect of salinity on the young plant growth of 13 Brassica napus parental lines.}

In this experiment the fresh weight (FW) and dry weight (DW) were the parameters to select the parents; these revealed significant differences.

\subsubsection{Materials and methods}

The experiment was conducted according to Abel et al. (2006), with minor modifications. Thirteen genotypes: Alesi, H30, Mansholts, Samourai, Sollux, Gaoyou, Sansibar, Oase, Express, R53, Digger, DH14 and L16 were tested in the greenhouse. Six seeds of each genotype were sown in $7 \times 7-\mathrm{cm}$ pots filled with a soil mix of $50 \%$ composite and $50 \%$ sand. The soil and sand were sieved through a 5$\mathrm{mM}$ mesh and dried for $24 \mathrm{~h}$ at $105^{\circ} \mathrm{C}$. The pots were randomized on tables in a complete block design, where each genotype was represented by two pots in each replication. Each pot was watered by $100 \mathrm{ml}$ tap water. After seedling emergence the soil was kept humid by overhead spraying for one week.

At day 12, plants were thinned into two plants per pot. The plants were watered every $2^{\text {nd }}$ or $3^{\text {rd }}$ day by placing them for $1 \mathrm{~h}$ into a bowl filled with tap water, ca 3-4 $\mathrm{cm}$ high. Plants were grown without saline solution till they had four leaves, around two weeks after sowing. The control plants continued to be watered with tap water until harvest. The salt-stressed plants were treated with two different salt concentrations. For acclimation, the saline concentrations were elevated gradually from the $1^{\text {st }}$ day to the $4^{\text {th }}$ day, to the final concentrations of $200 \mathrm{mM}$ and $300 \mathrm{mM}$, respectively. The saline treatment continued for two weeks by applying saline solution via dipping into the bowl as described above. At day 28 , the plants were harvested, whereby the shoot system was divided into different parts; $1^{\text {st }}+2^{\text {nd }}$ leaves, $3^{\text {rd }}$ and $4^{\text {th }}$ leaves, hypocotyl and sprouts. The FW for each part was measured immediately, and the leaf area was measured. For DW estimation samples were dried for $72 \mathrm{~h}$ at $60^{\circ} \mathrm{C}$.

\subsubsection{Results}

A significant reduction in FW and DW was observed for all parts under both the 200 $\mathrm{mM} \mathrm{NaCl}$ and $300 \mathrm{mM} \mathrm{NaCl}$ treatment compared to the controls. However, six parental lines, Mansholts, Samourai, Sollux, Gaoyou, Alesi and H30, showed higher biomasses compared to the other genotypes (Figures 1 and 2). Leaf chlorolysis, leaves dropping and plant loss were observed, especially under $300 \mathrm{mM} \mathrm{NaCl}$.

\subsubsection{Conclusion}

The flooding method was suitable for phenotyping plants under salt stress in greenhouse experiments. The six parental lines of Mansholts, Samourai, Sollux, Gaoyou, Alesi and $\mathrm{H} 30$ were included in the following experiment. We also concluded that fertilization would be necessary to avoid the above-mentioned problems of leaf chlorolysis, leaf-drop and plant loss. The $200 \mathrm{mM} \mathrm{NaCl}$ treatment was more relevant than the $300 \mathrm{mM} \mathrm{NaCl}$ condition. Leaf area results were valuable, but this parameter made it impossible to harvest the whole plants at the same time. Moreover, the measurement process took too long, thus, this parameter was not considered in the next experiments. 
The advantages of the flooding method

- No microenvironment differences because all genotypes were irrigated together, not independently.

- No logging or water deficiency because all pots were immersed in the tap water or in the saline solution. This method allows the plants to take up the optimum amount of water.

The disadvantages of the flooding method

- After watering the discharge of the rest of the water is laborious.

- The water and saline solution should be enriched with a fertilizer. 


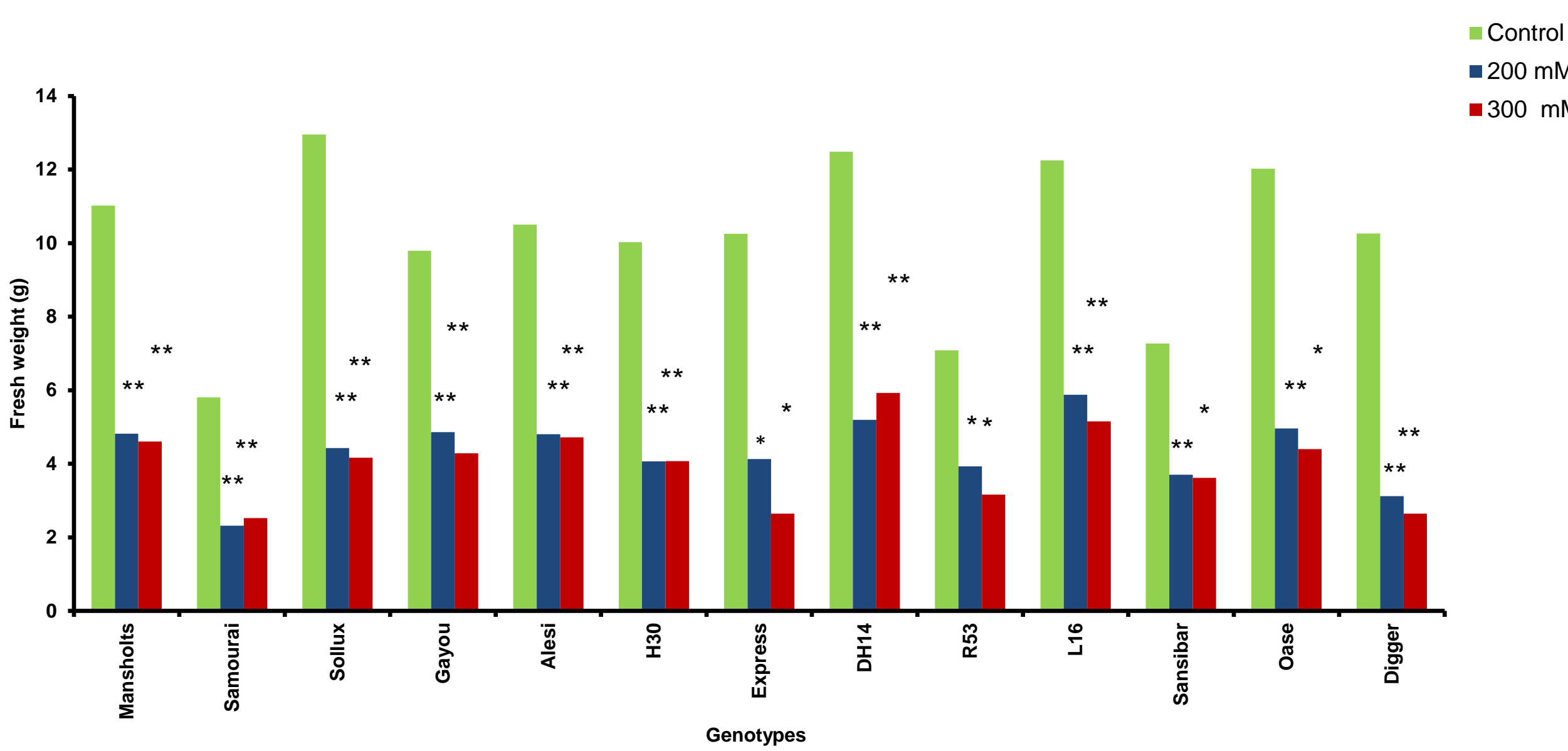

Figure II-1: Total plant fresh weight $(\mathrm{g})$ mean values and significance levels of the 13 parental lines under control and salt stress

** Significant at $P=0.01 ;$ * significant at $P=0.05,+$ significant at $P=0.1$ and ns $=$ non-significant. The significance test was done by simple ANOVA using the software Plabstat (Utz 2003). 


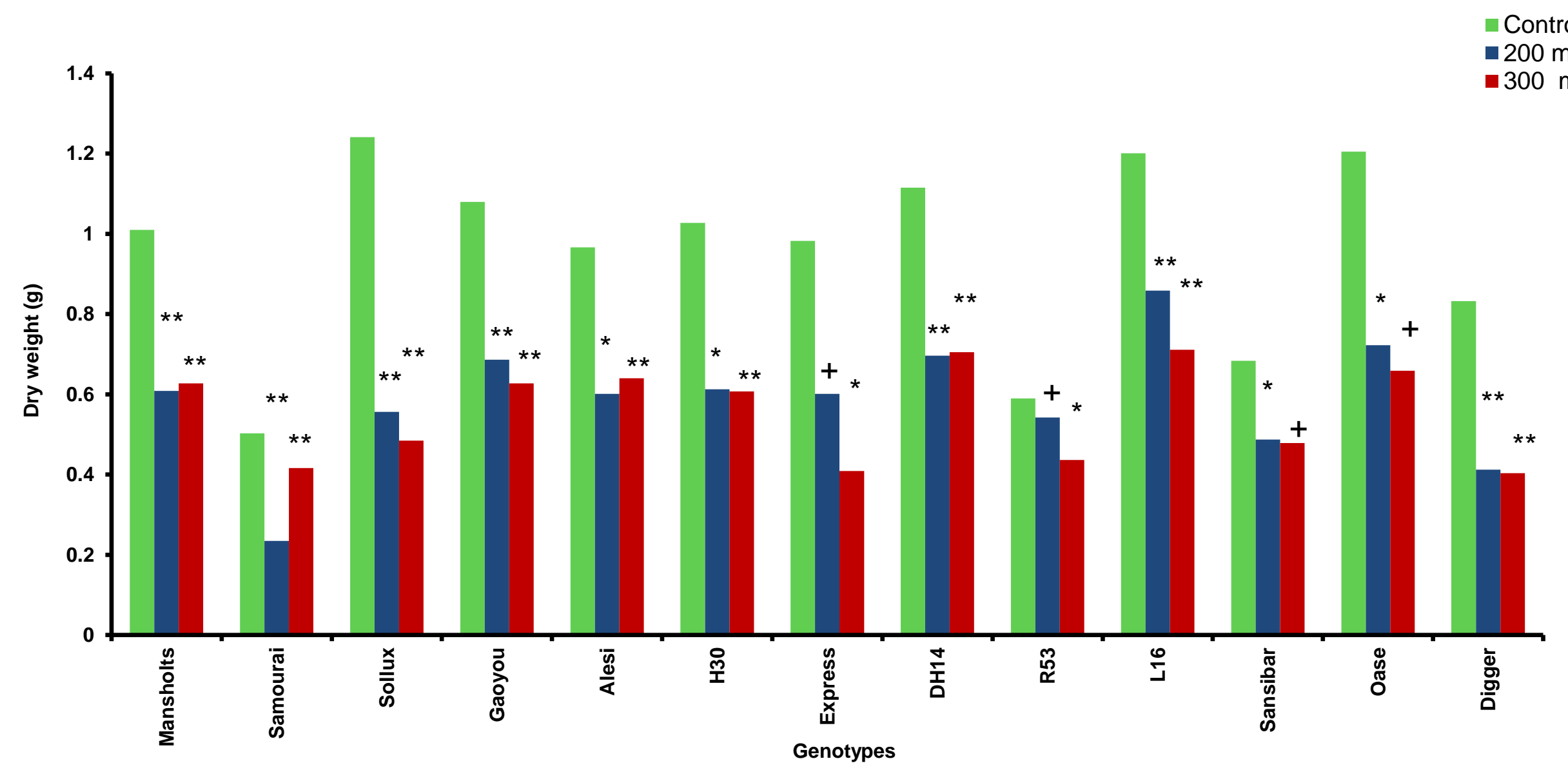

Figure II-2: Total plant dry weight $(\mathrm{g})$ and significance levels of the 13 parental lines under control and salt stress

** Significant at $P=0.01 ;$ * significant at $P=0.05,+$ significant at $P=0.1$ and ns $=$ non-significant. 
2.3 Experiment 2: Salinity effect on the selected six genotypes; Mansholts, Samourai, Sollux, Gaoyou, Alesi and H30.

\subsubsection{Materials and methods}

The six selected genotypes: Mansholts, Samourai, Sollux, Gaoyou, Alesi and H30 were tested under both control and the salt treatment of $200 \mathrm{mM} \mathrm{NaCl}$. The soil contents, pot size, pots and randomization were the same a mentioned above. Experiment one (2.2): In experiment one, some leaves became chlorotic earlier; therefore, to avoid nutrient deficiency the control treatment and saline solution were both supplied with Hakaphos blue (COMPO, Netherlands).

At day 15, the salt treatment was started with $100 \mathrm{mM} \mathrm{NaCl}$ supplemented with $0.5 \mathrm{~g} / \mathrm{l}$ Hakaphos in the saline solution. At day 17, the saline solution concentration was increased to $150 \mathrm{mM} \mathrm{NaCl}$ enriched with $1 \mathrm{~g} / \mathrm{l}$ Hakaphos. Finally, at day 19 the final concentration of $200 \mathrm{mM} \mathrm{NaCl}$ was reached. From day 19 until the end of the experiment the stressed plants were watered with the final concentration on alternative days; one day with water only and the second day with the saline solution. The control plants were always watered with tap water enriched with $1 \mathrm{~g} / \mathrm{l}$ Hakaphos.

The chlorophyll content was measured with a SPAD-meter Minolta 502 (Osaka, Japan). The measurement was made one week from the beginning of salt treatment. The measurements were scored for two different plant parts: the $1^{\text {st }}$ and the $2^{\text {nd }}$ leaves, and the $3^{\text {rd }}$ and the $4^{\text {th }}$ leaves. The plants were harvested two weeks from the beginning of the salt treatment. The shoot system was separated into $1^{\text {st }}$ and $2^{\text {nd }}$ leaves, $3^{\text {rd }}$ and $4^{\text {th }}$ leaves, stem and rest. Fresh weight was determined immediately after harvesting. For DW estimation, the plant parts were dried for $72 \mathrm{~h}$ at $60^{\circ} \mathrm{C}$.

\subsubsection{Sodium and potassium content analysis}

For sodium and potassium concentration measurement, the dried samples were pulverized, using a coffee grinder (KRUPS 75, Germany). One day before digestion the samples were dried overnight at $100{ }^{\circ} \mathrm{C}$. $300 \mathrm{mg}$ from each sample were placed in the microwave system MLS-MEGA II (Leutkirch, Germany). Four $\mathrm{ml} 65 \% \mathrm{HNO}_{3}$ and two $\mathrm{ml} \mathrm{H}_{2} \mathrm{O}_{2} 30 \%$ (Roth, Germany) were added for each sample. The samples were placed in the microwave system at $200^{\circ} \mathrm{C}$ for 55 minutes under 15 atmospheric pressure (atm) and cooled down for 20 minutes. After digestion, the samples were diluted up to $25 \mathrm{ml}$ using Seralpur water (deionized and filtered water). The samples were further diluted at $1: 10(0.5 \mathrm{ml}$ plant material extract $+4.5 \mathrm{ml}$ Seralpur water $)$. The $\mathrm{Na}^{+}$and $\mathrm{K}^{+}$concentration was measured using the flame photometer Eppendorf, Elex 6361 (Hamburg, Germany). The flame photometer was calibrated along with ten samples using two calibration standards for both elements. The low standard was 0 $\mathrm{mg} / \mathrm{I} \mathrm{Na} \mathrm{Na}^{+}$and $0 \mathrm{mg} / \mathrm{K} \mathrm{K}^{+}$and the high standard was $100 \mathrm{mg} / \mathrm{I} \mathrm{Na}{ }^{+}$and $100 \mathrm{mg} / \mathrm{I}$ $\mathrm{K}^{+}$. The $\mathrm{Na}^{+}$and $\mathrm{K}^{+}$contents were calculated as $\mathrm{mg} \mathrm{g}^{-1} \mathrm{DW}$ and the $\mathrm{Na}^{+} / \mathrm{K}^{+}$ratio was calculated.

\subsubsection{Results}

The salt treatment caused a significant reduction in the total plant FW and the total plant DW of the tested genotypes (Figures 3 and 4). The parental lines tested showed different interaction with salinity. The reductions in the entire plant FW were $60 \%$ for 
Chapter II-

Samourai and $50 \%$ for Mansholts, respectively. The DW reductions were $53 \%$ and $40 \%$ for Samourai and Mansholts, respectively (Table 1, and Figures 3 and 4). In the cases of the Sollux and Gaoyou lines, the reductions in plant FW were $60 \%$ and $51 \%$, respectively. Also the reductions in the total DW of Sollux and Gaoyou were 55\% and $37 \%$, respectively (Table 2, and Figures 3 and 4). The reductions in FW were 55\% and $60 \%$, for Alesi and $\mathrm{H} 30$, respectively. The DW reductions were $39 \%$ and $40 \%$ for Alesi and $\mathrm{H} 30$, respectively. The biomass yield was higher in case of Mansholts, Samourai, Sollux, and Gaoyou lines compared with Alesi and H3O. The variations between Alesi and $\mathrm{H} 30$ were non-significant (Table 3, and Figures 3 and 4). All parental lines showed a significant variation in the other parameters, such as the $\mathrm{Na}^{+}$ content of the $1^{\text {st }}$ and the $2^{\text {nd }}$ leaves and also the total plant $\mathrm{Na}^{+}$content.

\subsubsection{Conclusion}

The flooding system is applicable and efficient. A number of parameters, including the $\mathrm{FW}, \mathrm{DW}, \mathrm{Na}^{+}$content of the total plant and the $\mathrm{Na}^{+}$content of $1^{\text {st }}+2^{\text {nd }}$ leaves were relevant parameters to differentiate among the considered genotypes. As these parameters were suitable for phenotyping, the other parameters were not included in the next evaluation experiments. Because of the non-significant genotypic variation between Alesi and $\mathrm{H} 30$, they were not included in the further evaluation experiment.

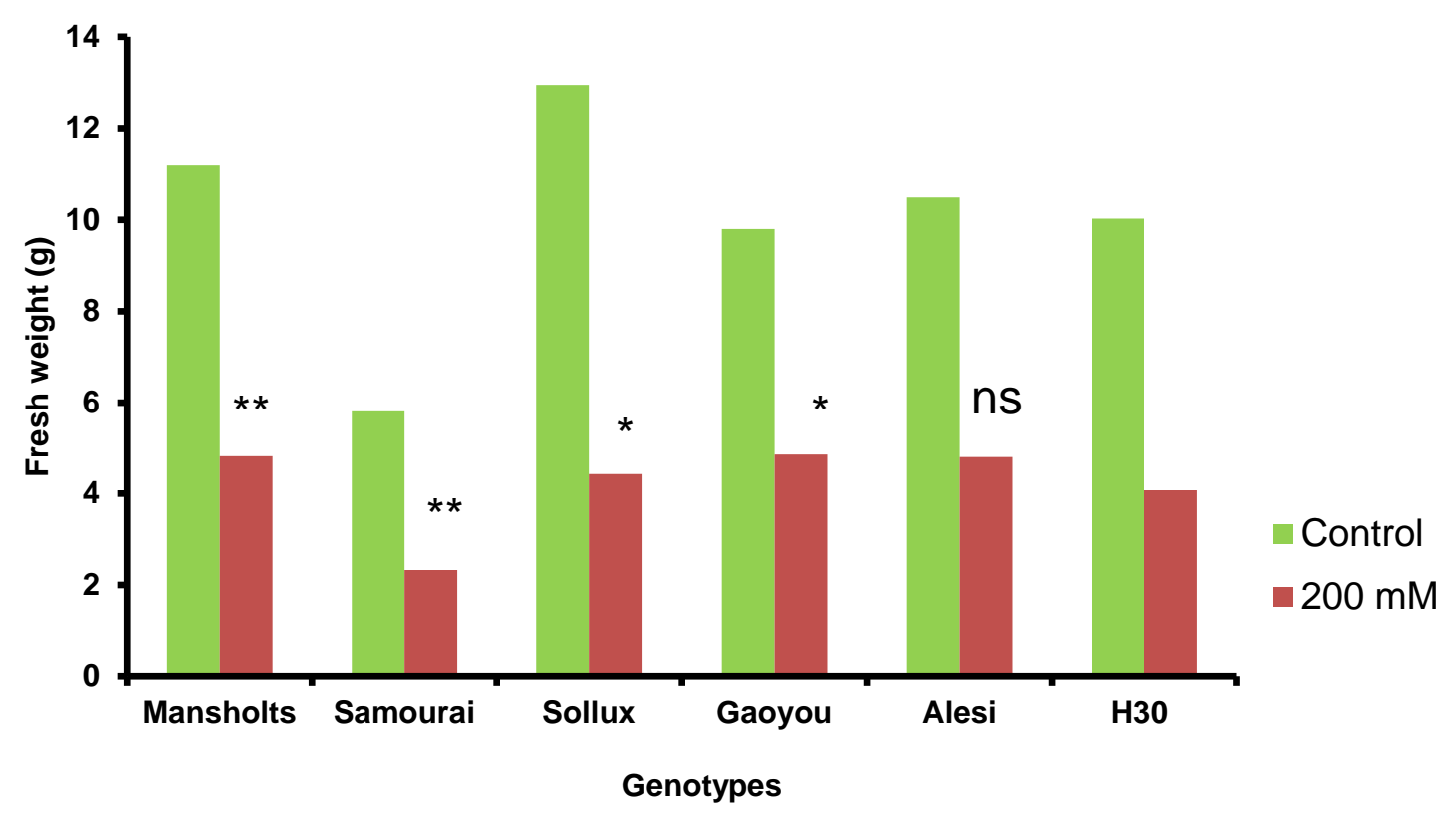

Figure II-3: Total plant fresh weight $(\mathrm{g})$ and signifcance levels of the six genotypes: Mansholts, Samourai, Sollux, Gaoyou, Alesi and H30 under control and salt stress 


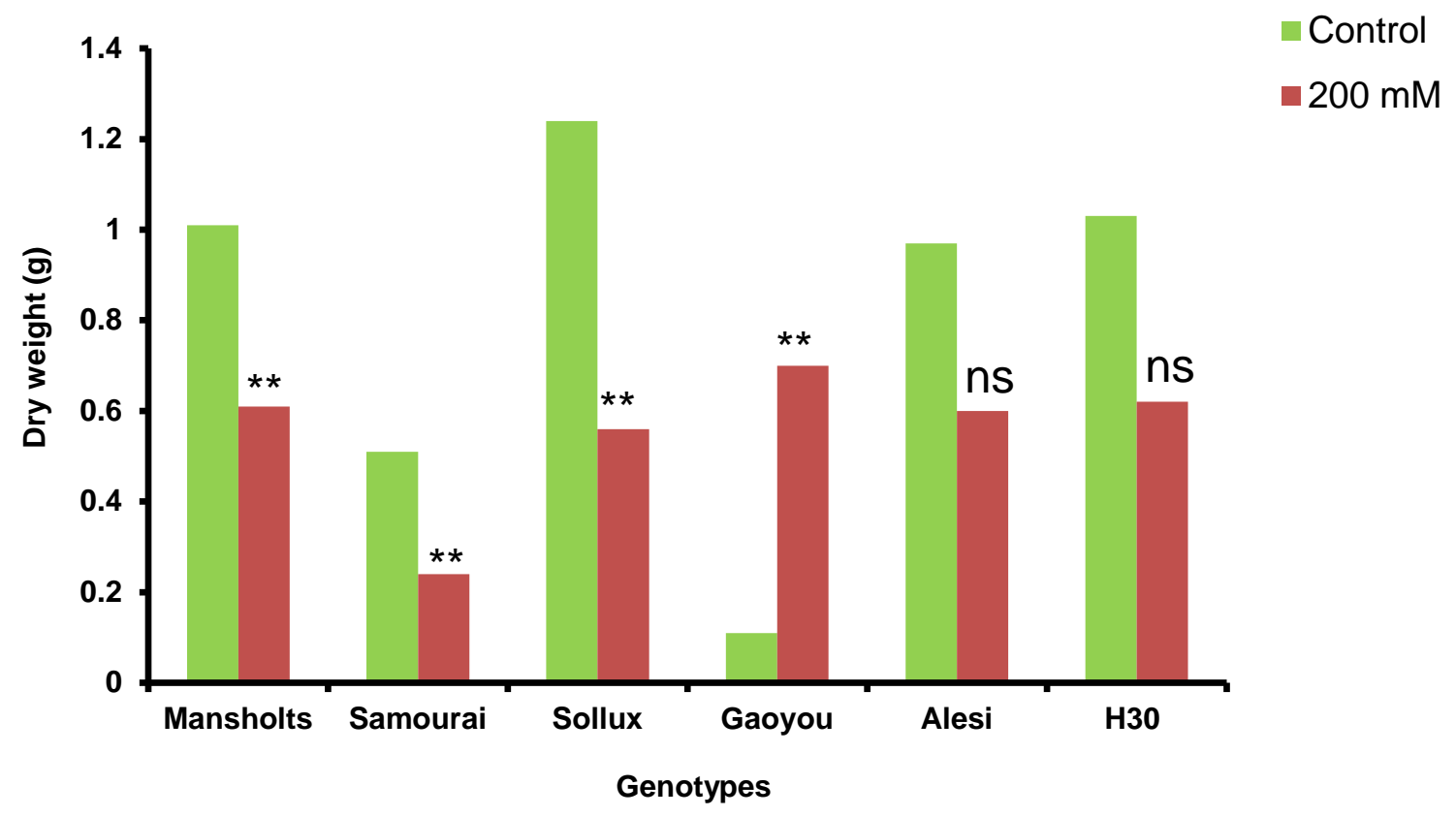

Figure II-4: Total plant dry weight (g) mean values and signifcance levels of the six genotypes: Mansholts, Samourai, Sollux, Goyou, Alesi and $\mathrm{H} 30$ under control and salt stress

** Significant at $P=0.01 ;$ * significant at $P=0.05,+$ significant at $P=0.1$ and ns $=$ nonsignificant. 
Chapter II-

Table II-1: Experiment 2: The mean values of fresh weight (g), dry weight (g), SPAD values, sodium content $\mathrm{Na}^{+} \mathrm{mg} / \mathrm{g} \mathrm{DM}$ and potassium content $\mathrm{K}^{+} \mathrm{mg} / \mathrm{g} \mathrm{DM}$ of the different parts in Mansholts and Samourai under control and salt stress (200 mM $\mathrm{NaCl})$

\begin{tabular}{|c|c|c|c|c|}
\hline Genotypes & Mansholts & Mansholts & Samourai & Samourai \\
\hline Traits / treatments & control & salt & control & salt \\
\hline FW 1+2 (g) & 2.50 & 2.36 & 1.94 & 1.21 \\
\hline FW 3+4 (g) & 3.98 & 2.10 & 2.34 & 0.69 \\
\hline FW rest (g) & 3.41 & 0.17 & 0.97 & 0.25 \\
\hline FW stem (g) & 0.92 & 0.2 & 0.58 & 0.18 \\
\hline FW total Plant (g) & 11.02 & 4.82 & 5.80 & 2.32 \\
\hline DW 1+2 (g) & 0.21 & 0.26 & 0.17 & 0.12 \\
\hline DW 3+4 (g) & 0.35 & 0.29 & 0.19 & 0.06 \\
\hline DW rest (g) & 0.34 & 0.03 & 0.10 & 0.04 \\
\hline DW stem (g) & 0.10 & 0.04 & 0.06 & 0.04 \\
\hline DW total Plant (g) & 1.01 & 0.61 & 0.51 & 0.24 \\
\hline SPAD1 1+2 & 25.17 & 29.73 & 29.23 & 33.60 \\
\hline SPAD1 3+4 & 26.85 & 31.45 & 30.90 & 34.42 \\
\hline SPAD $21+2$ & 24.85 & 35.28 & 29.52 & 34.38 \\
\hline SPAD $23+4$ & 30.88 & 41.92 & 35.02 & 37.28 \\
\hline $\mathrm{Na}^{+} 1+2\left(\mathrm{Na}^{+} \mathrm{mg} / \mathrm{g} \mathrm{DM}\right)$ & 3.83 & 16.40 & 0.97 & 15.79 \\
\hline $\mathrm{Na}^{+} 3+4\left(\mathrm{Na}^{+} \mathrm{mg} / \mathrm{g} \mathrm{DM}\right)$ & 5.07 & 16.52 & 1.44 & 10.02 \\
\hline $\mathrm{Na}^{+}$rest $\left(\mathrm{Na}^{+} \mathrm{mg} / \mathrm{g} \mathrm{DM}\right)$ & 3.65 & 5.90 & 1.09 & 5.43 \\
\hline $\mathrm{Na}^{+}$stem $\left(\mathrm{Na}^{+} \mathrm{mg} / \mathrm{g} \mathrm{DM}\right)$ & 4.16 & 5.08 & 1.33 & 4.68 \\
\hline $\mathrm{Na}^{+}$total Plant $\left(\mathrm{Na}^{+} \mathrm{mg} / \mathrm{g} \mathrm{DM}\right)$ & 2.54 & 15.53 & 1.20 & 12.59 \\
\hline $\mathrm{K}^{+} 1+2\left(\mathrm{~K}^{+} \mathrm{mg} / \mathrm{g} \mathrm{DM}\right)$ & 20.98 & 6.61 & 12.39 & 11.80 \\
\hline $\mathrm{K}^{+} 3+4\left(\mathrm{~K}^{+} \mathrm{mg} / \mathrm{g} \mathrm{DM}\right)$ & 16.49 & 7.49 & 18.12 & 6.38 \\
\hline $\mathrm{K}^{+}$rest $\left(\mathrm{K}^{+} \mathrm{mg} / \mathrm{g} \mathrm{DM}\right)$ & 16.31 & 3.18 & 11.69 & 4.06 \\
\hline $\mathrm{K}^{+}$stem $\left(\mathrm{K}^{+} \mathrm{mg} / \mathrm{g} \mathrm{DM}\right)$ & 15.96 & 3.60 & 10.76 & 4.69 \\
\hline $\mathrm{K}^{+}$Total Plant (mg K$\left.{ }^{+} \mathrm{mg} / \mathrm{g} \mathrm{DM}\right)$ & 17.41 & 6.80 & 14.26 & 9.23 \\
\hline
\end{tabular}


Table II-2: Experiment 2: The mean values of fresh weight (g), dry weight (g), SPAD values, sodium content $\mathrm{Na}^{+} \mathrm{mg} / \mathrm{g} \mathrm{DM}$ and potassium content $\mathrm{K}^{+} \mathrm{mg} / \mathrm{g} \mathrm{DM}$ of the different parts in Sollux and Gaoyou under control and salt stress $(200 \mathrm{mM} \mathrm{NaCl})$

\begin{tabular}{|c|c|c|c|c|}
\hline Genotypes & Sollux & Sollux & Gaoyou & Gaoyou \\
\hline Traits / treatments & control & salt & control & salt \\
\hline FW 1+2 (g) & 4.93 & 1.90 & 3.44 & 1.88 \\
\hline FW 3+4 (g) & 5.19 & 2.02 & 3.67 & 2.35 \\
\hline FW rest (g) & 1.23 & 0.17 & 1.01 & 0.24 \\
\hline FW stem (g) & 1.42 & 0.34 & 1.21 & 0.41 \\
\hline FW total Plant (g) & 12.95 & 4.43 & 9.80 & 4.86 \\
\hline DW 1+2 (g) & 0.41 & 0.21 & 0.35 & 0.25 \\
\hline DW 3+4 (g) & 0.52 & 0.27 & 0.39 & 0.34 \\
\hline DW rest (g) & 0.14 & 0.04 & 0.17 & 0.05 \\
\hline DW stem (g) & 0.13 & 0.05 & 0.11 & 0.07 \\
\hline DW total Plant (g) & 1.24 & 0.56 & 1.08 & 0.69 \\
\hline SPAD1 1+2 & 26.95 & 35.47 & 27.88 & 32.58 \\
\hline SPAD1 3+4 & 28.47 & 34.92 & 27.25 & 35.62 \\
\hline SPAD $21+2$ & 28.40 & 40.10 & 30.17 & 38.62 \\
\hline SPAD $23+4$ & 34.35 & 44.80 & 35.25 & 40.62 \\
\hline $\mathrm{Na}^{+} 1+2\left(\mathrm{Na}^{+} \mathrm{mg} / \mathrm{g} \mathrm{DM}\right)$ & 1.38 & 14.95 & 4.31 & 17.69 \\
\hline $\mathrm{Na}^{+} 3+4\left(\mathrm{Na}^{+} \mathrm{mg} / \mathrm{g} \mathrm{DM}\right)$ & 1.36 & 17.15 & 3.40 & 14.59 \\
\hline $\mathrm{Na}^{+}$rest $\left(\mathrm{Na}^{+} \mathrm{mg} / \mathrm{g} \mathrm{DM}\right)$ & 1.20 & 3.09 & 2.51 & 4.05 \\
\hline $\mathrm{Na}^{+}$stem $\left(\mathrm{Na}^{+} \mathrm{mg} / \mathrm{g} \mathrm{DM}\right)$ & 2.33 & 8.64 & 4.57 & 10.67 \\
\hline $\mathrm{Na}^{+}$Total Plant $\left(\mathrm{Na}^{+} \mathrm{mg} / \mathrm{g} \mathrm{DM}\right)$ & 1.46 & 14.39 & 3.43 & 15.23 \\
\hline $\mathrm{K}^{+} 1+2\left(\mathrm{~K}^{+} \mathrm{mg} / \mathrm{g} \mathrm{DM}\right)$ & 22.77 & 7.60 & 18.65 & 12.04 \\
\hline $\mathrm{K}^{+} 3+4\left(\mathrm{~K}^{+} \mathrm{mg} / \mathrm{g} \mathrm{DM}\right)$ & 17.10 & 9.60 & 15.72 & 9.29 \\
\hline $\mathrm{K}^{+}$rest $\left(\mathrm{K}^{+} \mathrm{mg} / \mathrm{g} \mathrm{DM}\right)$ & 14.24 & 3.09 & 15.68 & 4.65 \\
\hline $\mathrm{K}^{+}$stem $\left(\mathrm{K}^{+} \mathrm{mg} / \mathrm{g} \mathrm{DM}\right)$ & 23.89 & 5.19 & 17.42 & 6.59 \\
\hline $\mathrm{K}^{+}$total Plant $\left(\mathrm{K}^{+} \mathrm{mg} / \mathrm{g} \mathrm{DM}\right)$ & 19.50 & 7.95 & 17.73 & 9.90 \\
\hline
\end{tabular}


Chapter II-

Table II-3: Experiment 2: The mean values of fresh weight $(\mathrm{g})$, dry weight $(\mathrm{g})$, SPAD values, sodium content $\mathrm{Na}^{+} \mathrm{mg} / \mathrm{g} \mathrm{DM}$ and potassium content $\mathrm{K}^{+} \mathrm{mg} / \mathrm{g} \mathrm{DM}$ of the different parts in Alesi and $\mathrm{H} 30$ under control and salt stress $(200 \mathrm{mM} \mathrm{NaCl})$

\begin{tabular}{|c|c|c|c|c|}
\hline Genotypes & Alesi & Alesi & H30 & $\mathrm{H} 30$ \\
\hline Traits / treatments & control & salt & control & salt \\
\hline FW 1+2 (g) & 2.35 & 1.67 & 2.47 & 1.27 \\
\hline FW 3+4 (g) & 5.73 & 2.69 & 4.97 & 2.24 \\
\hline FW rest (g) & 1.21 & 0.15 & 2.07 & 0.39 \\
\hline FW stem (g) & 1.24 & 0.31 & 0.52 & 0.19 \\
\hline FW total Plant (g) & 10.51 & 4.81 & 10.03 & 4.07 \\
\hline DW 1+2 (g) & 0.20 & 0.17 & 0.21 & 0.16 \\
\hline DW 3+4 (g) & 0.52 & 0.37 & 0.51 & 0.35 \\
\hline DW rest (g) & 0.13 & 0.03 & 0.25 & 0.08 \\
\hline DW stem (g) & 0.13 & 0.05 & 0.07 & 0.04 \\
\hline DW total Plant (g) & 0.97 & 0.60 & 1.03 & 0.62 \\
\hline SPAD1 1+2 & 28.50 & 30.67 & 26.35 & 32.00 \\
\hline SPAD1 3+4 & 28.65 & 34.25 & 28.30 & 34.28 \\
\hline SPAD $21+2$ & 29.25 & 35.97 & 26.35 & 35.75 \\
\hline SPAD $23+4$ & 32.97 & 43.97 & 40.00 & 45.30 \\
\hline $\mathrm{Na}^{+} 1+2\left(\mathrm{Na}^{+} \mathrm{mg} / \mathrm{g} \mathrm{DM}\right)$ & 2.59 & 10.60 & 2.84 & 12.98 \\
\hline $\mathrm{Na}^{+} 3+4\left(\mathrm{Na}^{+} \mathrm{mg} / \mathrm{g} \mathrm{DM}\right)$ & 3.07 & 16.47 & 2.48 & 11.47 \\
\hline $\mathrm{Na}^{+}$rest $\left(\mathrm{Na}^{+} \mathrm{mg} / \mathrm{g} \mathrm{DM}\right)$ & 2.07 & 2.88 & 1.50 & 5.89 \\
\hline $\mathrm{Na}^{+}$stem $\left(\mathrm{Na}^{+} \mathrm{mg} / \mathrm{g} \mathrm{DM}\right)$ & 3.15 & 6.87 & 2.15 & 3.35 \\
\hline $\mathrm{Na}^{+}$total Plant $\left(\mathrm{Na}^{+} \mathrm{mg} / \mathrm{g} \mathrm{DM}\right)$ & 2.83 & 14.14 & 2.41 & 10.68 \\
\hline $\mathrm{K}^{+} 1+2\left(\mathrm{~K}^{+} \mathrm{mg} / \mathrm{g} \mathrm{DM}\right)$ & 19.70 & 8.50 & 20.19 & 12.75 \\
\hline $\mathrm{K}^{+} 3+4\left(\mathrm{~K}^{+} \mathrm{mg} / \mathrm{g} \mathrm{DM}\right)$ & 17.52 & 9.22 & 19.10 & 11.47 \\
\hline $\mathrm{K}^{+}$rest $\left(\mathrm{K}^{+} \mathrm{mg} / \mathrm{g} \mathrm{DM}\right)$ & 15.05 & 1.93 & 16.84 & 8.50 \\
\hline $\mathrm{K}^{+}$stem $\left(\mathrm{K}^{+} \mathrm{mg} / \mathrm{g} \mathrm{DM}\right)$ & 21.55 & 6.40 & 12.61 & 3.23 \\
\hline $\mathrm{K}^{+}$total Plant $\left(\mathrm{mg} \mathrm{K}^{+} \mathrm{mg} / \mathrm{g} \mathrm{DM}\right)$ & 18.18 & 8.95 & 18.22 & 10.95 \\
\hline
\end{tabular}


2.4 Experiment 3: Testing the performance of Mansholts $\times$ Samourai and Sollux $\times$ Gaoyou under $200 \mathrm{mM} \mathrm{NaCl}$

\subsubsection{Material and Methods}

The experiment was conducted in the greenhouse from the $23^{\text {th }}$ of July until the $27^{\text {th }}$ of August, 2012. The methods and calculations were the same as the previously mentioned protocol for Experiment 1 (2.2). Two weeks after beginning the $200 \mathrm{mM}$ $\mathrm{NaCl}$ salt treatment, the plants were harvested and separated into $1^{\text {st }}$ and $2^{\text {nd }}$ leaves, and the remaining shoot system was labeled as "rest".

\subsubsection{Results}

There was a significant reduction in the total plant FW and the total plant FW of the tested genotypes. The reductions in FW for Samourai and Mansholts were $62 \%$ and $53 \%$, respectively. The reductions in DW for Samourai and Mansholts were $47 \%$ and $37 \%$, respectively (Table 4). In case of, Sollux and Gaoyou lines, the respective reductions in FW were $66 \%$ and 51\%, and were 52\% and $31 \%$ for the DW (Table 6 , and Figures 5 and 6).

\subsubsection{Conclusion}

There was a significant difference between Mansholts and Samourai and between Sollux and Gaoyou, but the performance of both couples was similar (Figures 3 and 4). Nevertheless, the parental lines Mansholts and Samourai were considered to be suitable parental lines based on the molecular markers set and the quality of the linkage map.

\subsection{General conclusion}

The difference between Mansholts and Samourai was similar to that between Sollux and Gaoyou. However, the $\mathrm{DH}$ population derived from the Sollux and Gaoyou parental lines includes $200 \mathrm{DH}$ lines, while that derived from the Mansholts and Samourai parental lines includes $150 \mathrm{DH}$ lines. After discussion with Dr. Ecke, Department of Crop Sciences, Georg-August-Universität Göttingen, we decided to continue with the $\mathrm{DH}$ population that was developed from the Mansholts and Samourai parental lines. The selection was based on the quality of the genotypic markers data (linkage map). The linkage map for the Mansholts and Samourai population is preferable because it is better covered by markers than that of Sollux and Gaoyou populations. This is because of the high percentage of markers that were not mapped for Sollux and Gaoyou population. Additionally, one of the linkage groups was lost for the Sollux and Gaoyou population. We found the evaluation parameters, " $\mathrm{Na}^{+}$content of the $1^{\text {st }}+2^{\text {nd }}$ leaves" and " $\mathrm{Na}^{+}$content of the total plant" to be relevant in testing for salt tolerance. However, so as to reduce labor during the evaluation of the mapping population, measurement of the $\mathrm{Na}^{+}$content of the $1^{\text {st }}+2^{\text {nd }}$ leaves was omitted. 


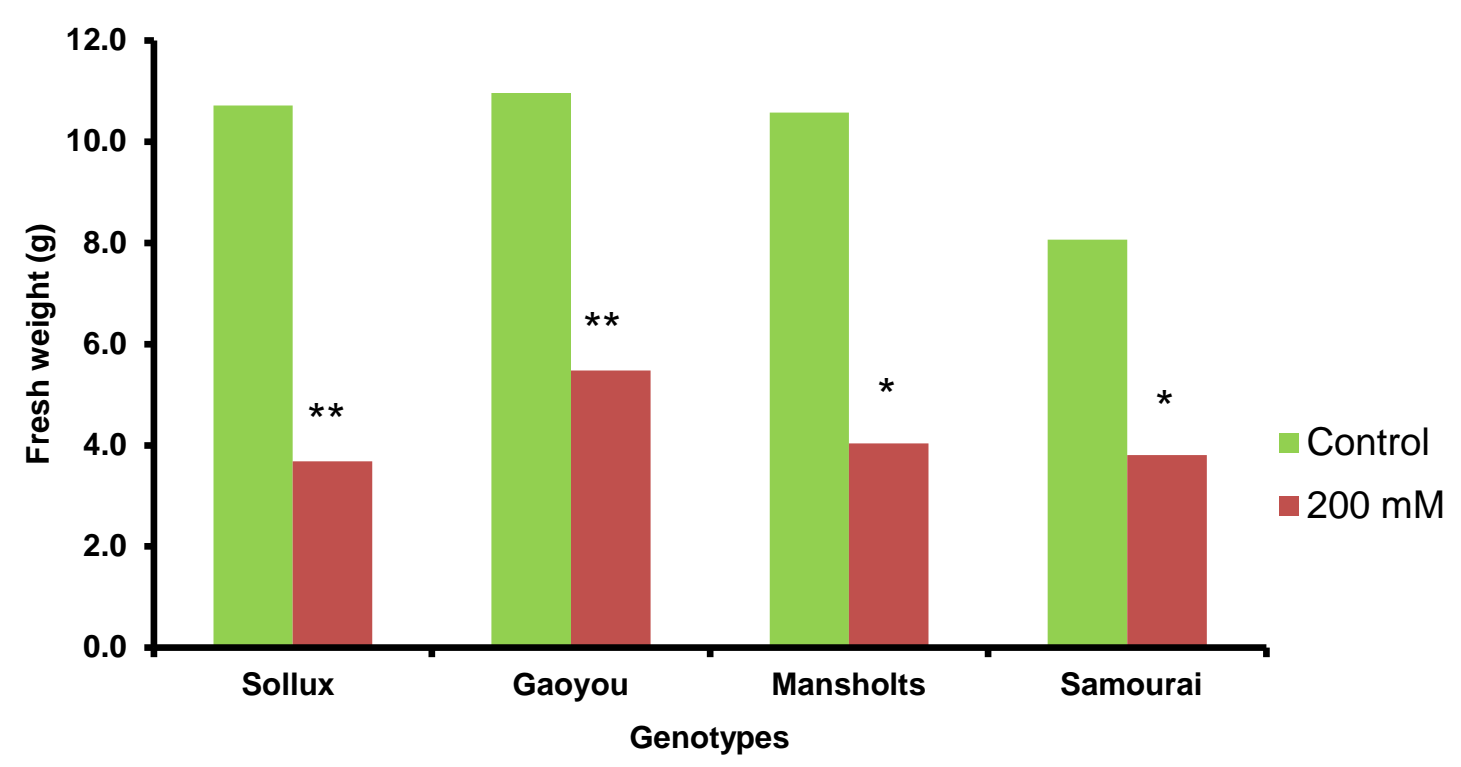

Figure II-5: Total plant fresh weight (g) mean values and signifcance levels of Mansholts, Samourai, Sollux and Gaoyou under control and salt stress

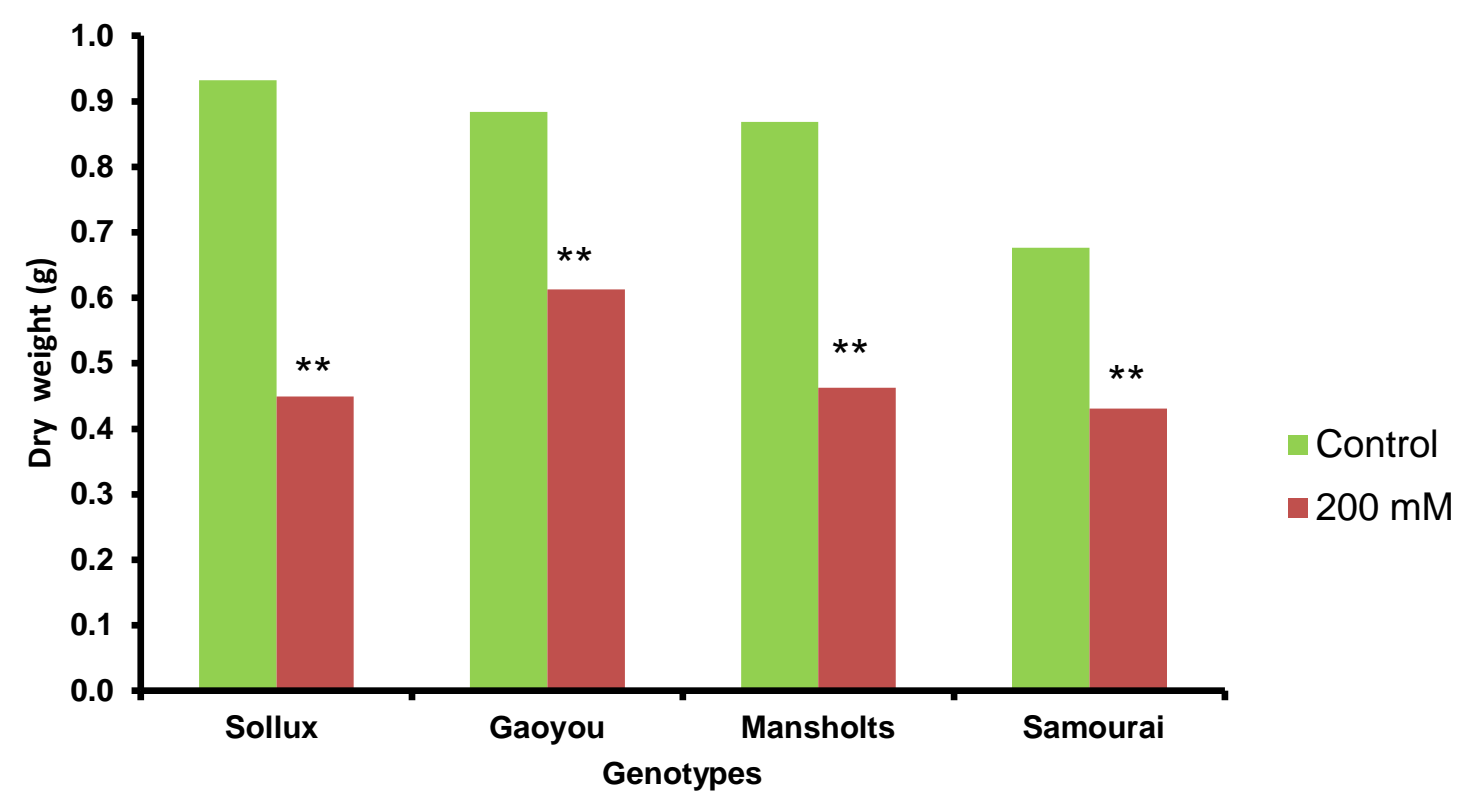

Figure II-6: Total plant dry weight (g) mean values and significance levels of Mansholts, Samourai, Sollux and Gaoyou under control and salt

** Significant at $P=0.01 ;$ * significant at $P=0.05,+$ significant at $P=0.1$ and ns $=$ nonsignificant. 
Chapter II-

Table II-4: Experiment 3: The mean values of fresh weight, dry weight, sodium content $\mathrm{Na}^{+} \mathrm{mg} /$ $\mathrm{g} \mathrm{DM}$ and potassium content $\mathrm{K}^{+} \mathrm{mg} / \mathrm{g} \mathrm{DM}$ of the different parts in Mansholts and Samourai under control and salt stress (200 mM NaCl)

\begin{tabular}{|c|c|c|c|c|}
\hline Genotypes & Samourai & Samourai & Mansholts & Mansholts \\
\hline Traits / treatments & control & salt & control & salt \\
\hline FW 1+2 (g) & 1.40 & 1.27 & 0.99 & 1.19 \\
\hline FW rest $(g)$ & 9.18 & 2.77 & 7.07 & 2.62 \\
\hline FW total Plant $(\mathrm{g})$ & 10.58 & 4.04 & 8.06 & 3.81 \\
\hline DW $1+2(g)$ & 0.09 & 0.14 & 0.07 & 0.14 \\
\hline DW rest (g) & 0.78 & 0.33 & 0.61 & 0.30 \\
\hline DW total Plant (g) & 0.87 & 0.46 & 0.68 & 0.43 \\
\hline $\mathrm{Na}^{+} 1+2\left(\mathrm{Na}^{+} \mathrm{mg} / \mathrm{g} \mathrm{DM}\right)$ & 4.47 & 20.34 & 5.55 & 24.06 \\
\hline $\mathrm{Na}^{+}$rest $\left(\mathrm{Na}^{+} \mathrm{mg} / \mathrm{g} \mathrm{DM}\right)$ & 3.11 & 18.91 & 3.94 & 20.99 \\
\hline $\mathrm{Na}^{+}$total Plant $\left(\mathrm{Na}^{+} \mathrm{mg} / \mathrm{g} \mathrm{DM}\right)$ & 3.24 & 19.30 & 4.11 & 21.85 \\
\hline $\mathrm{K}^{+} 1+2\left(\mathrm{~K}^{+} \mathrm{mg} / \mathrm{g} \mathrm{DM}\right)$ & 12.99 & 8.58 & 11.47 & 7.6 \\
\hline $\mathrm{K}^{+}$rest $\left(\mathrm{K}^{+} \mathrm{mg} / \mathrm{g} \mathrm{DM}\right)$ & 13.25 & 6.91 & 12.32 & 6.40 \\
\hline $\mathrm{K}^{+}$total Plant $\left(\mathrm{K}^{+} \mathrm{mg} / \mathrm{g} \mathrm{DM}\right)$ & 13.22 & 7.38 & 12.23 & 6.79 \\
\hline
\end{tabular}

Table II-5: Experiment 3: The mean values of fresh weight (g), dry weight (g), sodium content $\mathrm{Na}^{+} \mathrm{mg} / \mathrm{g} \mathrm{DM}$ and potassium content $\mathrm{K}^{+} \mathrm{mg} / \mathrm{g} \mathrm{DM}$ of the different parts in Sollux and Gaoyou under control and salt stress $(200 \mathrm{mM} \mathrm{NaCl})$

\begin{tabular}{lcccc}
\hline Genotypes & Samourai & Samourai & Mansholts & Mansholts \\
\hline Traits / treatments & control & salt & control & salt \\
\hline FW 1+2 (g) & 2.52 & 1.42 & 2.53 & 2.45 \\
FW rest (g) & 8.19 & 2.26 & 8.60 & 3.02 \\
FW total Plant (g) & 10.71 & 3.68 & 11.13 & 5.49 \\
DW 1+2 (g) & 0.18 & 0.17 & 0.18 & 0.27 \\
DW rest (g) & 0.76 & 0.29 & 0.71 & 0.36 \\
$\mathrm{DW}_{\text {total Plant (g) }}$ & 0.93 & 0.45 & 0.89 & 0.62 \\
$\mathrm{Na}^{+} 1+2\left(\mathrm{Na}^{+} \mathrm{mg} / \mathrm{g} \mathrm{DM}\right)$ & 3.75 & 16.15 & 5.75 & 18.11 \\
$\mathrm{Na}^{+}$rest (Na $\left.\mathrm{mg} / \mathrm{g} \mathrm{DM}\right)$ & 2.64 & 13.69 & 4.13 & 16.07 \\
$\mathrm{Na}^{+}$total Plant (Na mg/ g DM) & 2.85 & 14.60 & 4.45 & 16.93 \\
$\mathrm{~K}^{+} 1+2\left(\mathrm{~K}^{+} \mathrm{mg} / \mathrm{g} \mathrm{DM}\right)$ & 12.49 & 8.18 & 10.62 & 7.38 \\
$\mathrm{~K}^{+}$rest $\left(\mathrm{K}^{+} \mathrm{mg} / \mathrm{g} \mathrm{DM}\right)$ & 12.40 & 6.11 & 12.24 & 6.47 \\
$\mathrm{~K}^{+}$total Plant $\left(\mathrm{K}^{+} \mathrm{mg} / \mathrm{g} \mathrm{DM}\right)$ & 12.41 & 6.88 & 11.90 & 6.86 \\
\hline
\end{tabular}




\section{Chapter III}

\section{Mapping QTL for salt tolerance at seed germination in Brassica napus and Brassica oleracea doubled-haploid populations}

\subsection{Introduction}

Salinity is one of the most significant abiotic stresses that reduce crop productivity (Munns 1993). Timely germination is critical for the plant to commence a new life cycle. Seed germination starts when the dry seeds absorb the water and is completed when the radicle protrudes from the seed coat (Bewley 1997a). Physiologically, seed germination encompasses three consecutive phases; (I) rapid water uptake, (II) metabolic activity of enzymes to catalyze the utilization of stored nutrients and (III) embryo enlargement and radical protrusion (Bewley 1997a). As a consequence of imbibition, protein synthesis and DNA transcription are reactivated. The cell wallweakening enzymes facilitate the penetration of the radicle through the endosperm and seed coat, and the stored energy sources are remobilized to ensure a fast growth of the emerging seedling (Nonogaki 2006). High concentrations of salt impair seed germination and crop establishment (Flowers 1991). The loss of optimum plant germination causes a reduction in plant density, which may result in yield reduction. The germination rate and seedling establishment of $B$. napus is delayed and reduced by salinity (Zheng et al. 1998).

\section{QTL and genes related to salt tolerance at seed germination}

QTL associated with salt tolerance during seed germination have been detected in many plants such as tomato (Foolad and Jones 1993), barley (Mano and Takeda 1997), wheat (Ma et al. 2007) rice (Wang et al. 2011) and Arabidopsis (Quesada et al. 2002; Ren et al. 2010; Vallejo et al. 2010; Joosen et al. 2012). For salt tolerance, Ren et al. (2010) identified a premature stop codon in the RAS1 (RAS1; At1g09950) gene that acts as a negative regulator of salt tolerance during seed germination and early seedling growth by enhancing ABA sensitivity in Arabidopsis. In Arabidopsis, one major QTL has been detected that controls both the germination percentage and the germination rate. In addition, one of the genes that were identified in this QTL interval is a nicotinamidase gene (NIC2, At5g23230) (Joosen et al. 2012). The function of this gene is to repair DNA prior to germination. The mutant of this gene causes retarded germination and impaired germination potential (Hunt et al. 2007). Another strong QTL harboring two potential candidate genes involved in the osmotic stress pathway (NHX1; AT5G27150 and $\mathrm{H}^{+}$ATPase; AT5G08690) was localized on the top of chromosome 5 in Arabidopsis (Joosen et al. 2012).

\subsection{The objectives of this chapter are to}

1. assess the variation in germination under salt stress.

2. Identify the QTL that controls seed germination variation under control and salt stress conditions in Brassica napus and Brassica oleracea DH populations. 


\subsection{Materials and methods}

\subsubsection{Plant materials}

Three doubled-haploid (DH) mapping populations were investigated; two populations of $B$. napus and one of $B$. oleracea. The $B$. napus $\mathrm{DH}$ population consisted of $138 \mathrm{DH}$ lines derived from a cross between Alesi (winter oilseed rape cultivar) and H30 (resynthesized line). Alesi has 00 seed quality, a low glucosinolate content and zero erucic acid in the seeds, whereas $\mathrm{H} 30$ has ++ seed quality with high erucic acid and high glucosinolate content in the seeds. Doubled-haploid lines of this population were provided by KWS SAAT AG, Einbeck, Germany.

The second mapping population consisted of $138 \mathrm{DH}$ lines developed from a cross between two DH lines DH5.1 and DH5.2 from variety Mansholts Hamburger Raps and one $\mathrm{DH}$ line from the cultivar Samourai DH11.4. Mansholts Hamburger Raps is an old cultivar with ++ seed quality and Samourai is a modern French cultivar with 00 seed quality (Uzunova et al. 1995).

The third population is a $B$. oleracea Bo1TBDH population, which consisted of $145 \mathrm{DH}$ lines derived from a cross between $\mathrm{DH}$ rapid cycling cabbage line TO1000DH3 and $\mathrm{DH}$ broccoli line Early Big. The population was developed as a $B$. oleracea reference population. The parental line TO1000DH3 is the reference genome for the $B$. oleracea sequencing project (Iñiguez-Luy et al. 2009). The lines of this population were provided by Graham Teakle, Warwick Crop Centre, The University of Warwick, Wellesbourne, Warwick.

\subsubsection{Germination experiment}

For germination, ten seeds per genotype were placed in 9-cm-diameter Petri dishes on Whatman No1 paper moistened, in the case of the controls, with $5 \mathrm{ml}$ of tap water. For the salinity experiments the set-up was similar, except the paper was moistened with $5 \mathrm{ml}$ of $200 \mathrm{mM} \mathrm{NaCl}$ solution for the $B$. napus Alesi and $\mathrm{H} 30$, and Mansholts and Samourai populations, and with five $\mathrm{ml}$ of $100 \mathrm{mM} \mathrm{NaCl}$ solution for the $B$. oleracea (Bo1TBDH) population, respectively. The Petri dishes were placed in an incubator Rubarth Apparate Gmbh (Hannover, Germany) at $20^{\circ} \mathrm{C}$ under dark conditions. All $\mathrm{DH}$ lines and parental lines were tested in three replicates and in a complete randomized block design. Germination was scored at 24 hour intervals for up to eight days. The seeds were considered germinated when a complete radicle protrusion appeared through the seed coat (Bewley 1997a).

Three germination parameters were assessed; germination percentage (G\%), germination pace (GP) and the Salt Tolerance Index (STI).

$$
\mathrm{G} \%=\frac{\mathrm{n}}{\mathrm{N}} \times 100
$$

Where $\mathrm{n}$ is the number of germinated seeds at the end of the experiment and $\mathrm{N}$ is the number of total sown seeds. 


$$
\mathrm{GP}=\frac{\mathrm{N}}{\Sigma(\mathrm{n} \times \mathrm{g})} \times 100
$$

Where $\mathrm{N}$ is the total number of germinated seeds at the end of the experiment, $\mathrm{n}$ is the number of germinated seeds on day $\mathrm{g}$.

The salt tolerance index (STI) was calculated for G\% and GP, according to Cano et al. (1998).

$$
\begin{aligned}
& \mathrm{G} \% \mathrm{STI}=\frac{\mathrm{G} \% \text { under salt stress }}{\mathrm{G} \% \text { under control }} \times 100 \\
& \mathrm{GP} \mathrm{STI}=\frac{\mathrm{GP} \text { under salt stress }}{\mathrm{GP} \text { under control }} \times 100
\end{aligned}
$$

\subsubsection{Statistics}

The single values for each genotype of the three replicates were used for the analysis of variance, and the heritabilities were analyzed using PlabSTAT 3.0 software (Utz, 2003) according to the following model:

$$
Y_{i j}=\mu+g_{i}+r_{j}+(g r) i j
$$

where $Y_{i j}$ is the observation of genotype $i$ in replicate $j, \mu$ is the general mean, $g_{i}$ is the effect of genotype $i$ (for $i=1 \ldots, n), r_{j}$ is the replicate effect and $(g r) i j$ is the experimental error.

\subsubsection{Linkage maps}

To match with the QTL mapping software PlabMQTL requirements, we employ the Haldane's mapping function as default. The recombination frequencies between the markers on the full maps and the framework maps of all populations were transformed into mapping distances in centiMorgans (cM) with the Haldane's mapping function (Haldane 1919). In all populations: B. napus Alesi and H30, B. napus Mansholts and Samourai, and B. oleracea Bo1TBDH, the linkage groups (LGs) were named according to the Multinational Brassica genome project (MBGP), http://www.brassica.info/. Date of visiting January 15, 2014.

\section{The linkage map of $B$. napus mapping population (Alesi and $\mathrm{H} 30$ )}

The marker data for the DH population Alesi and H3O were developed by KWS SAAT AG, Einbeck, Germany and Sebastian Miersch, Department of Crop Sciences, GeorgAugust-Universität Göttingen. The full map was developed by Sebastian Miersch based on $139 \mathrm{DH}$ lines using 438 markers: 390 single nucleotide polymorphism markers (SNP) and 48 simple sequence repeat markers (SSR). The mapped markers were distributed on 22 linkage groups (LGs). The LG C4 was subdivided into C4a and C4b. Moreover, the LG C5 was subdivided into C5a and C5b, and four markers were mapped on the LG 22. The markers set covered $1483 \mathrm{cM}$ of the $B$. napus genome with an average marker density of one marker per $3.6 \mathrm{cM}$ (Table 1, and Appendix 2). 
For QTL mapping, a framework map was developed consisting of 188 markers for QTL mapping (Figure 4). A well-distributed, highly informative set of markers was selected to have one marker every $5 \mathrm{cM}$ to $10 \mathrm{cM}$ wherever possible. The order of the selected markers was verified using MAPMAKER/EXP 3.0 (Lincoln et al. 1993) and the command "ripple" with window six markers and threshold with a LOD score three.

\section{The linkage map of $B$. napus mapping population of Mansholts and Samourai}

The full map of Mansholts and Samourai population based on $177 \mathrm{DH}$ lines was an extended version of the map developed by Uzunova et al. (1995). The extended map consisted of 613 markers: 214 Restriction fragment length polymorphism markers (RFLP), 228 Amplified fragment length polymorphism markers (AFLP), 135 SSR, 35 Random amplified polymorphic DNA markers (RAPD), and one phenotypic marker (flower color). The mapped markers were distributed on 21 LGs, whereby the LG C8 was subdivided into $\mathrm{C} 8 \mathrm{a}$ and $\mathrm{C} 8 \mathrm{~b}$, and four markers were mapped on LG 21 . The markers set covered $2180 \mathrm{cM}$ of the $B$. napus genome with an average marker density of one marker per $3.6 \mathrm{cM}$ (Table 2 and Appendix 3). A framework map was developed for QTL mapping as described earlier. The framework map consists of 208 markers for QTL mapping.

\section{The linkage map of $B$. oleracea mapping population Bo1TBDH}

The full map was developed by Iñiguez-Luy et al. (2009) based on $155 \mathrm{DH}$ lines. This map consists of 279 markers; 155 RFLP, 122 SSR, one phenotypic marker (flower color), and one ispga PCR marker. The mapped markers were distributed on nine LGs, representing the nine chromosomes of $B$. oleracea according to the international nomenclature. The markers set covered $1012.7 \mathrm{cM}$ of the $B$. oleracea genome with an average marker density of one marker per $3.6 \mathrm{cM}$ (Table 3, and Appendix 4). Based on this map, a framework map of 128 markers was developed as described earlier

\subsubsection{QTL analysis protocol}

The means of the phenotypic data were analysed with the genetic markers using software QTLNetwork2.1 (Yang et al. 2008) and PlabMQTL (PLAnt-Breeding Meta QTL-analysis) Version 9 (Utz 2011). In the first analysis using QTLNetwork2.1, the significance level of QTL detection was fixed to $P=0.05$. QTL resulting from this analysis were considered to be "significant QTL". Additional non-significant QTL were defined as "putative QTL". The QTL analysis was repeated using PlabMQTL at $P=$ 0.05 .

PlabMQTL employs multiple regressions to perform composite interval mapping using cofactors. The QTL mapping takes place in two steps. First, the whole genome is scanned over to produce the LOD curves and to show the peaks where the QTL are located by composite interval mapping (CIM). Second, the set of QTL which were produced from the first step were verified by Bayesian information criterion (BIC) in a stepwise regression procedure to identify the most important QTL. To generate LOD scores corresponding to a significance level of $P=0.05$ the LOD threshold for each 
trait was calculated independently using a permutation test with 1000 replications according to Doerge and Churchill (1996) and use of software PlabMQTL.

Putative QTL were identified either in the QTL analysis by use of QTLNetwork2.1 or on the basis of the LOD score curves (PlabMQTL) as QTL that had low LOD scores, which were nevertheless below the significance threshold. The statistical parameters of these putative QTL were obtained by use of PlabMQTL (LOD 2.0).

Table III-1: Linkage group size, number of markers and marker density per linkage group of the full map of Brassica napus DH population Alesi $\times \mathrm{H} 30$

\begin{tabular}{cccc}
\hline Linkage group & Size (cM) & Marker number & Marker density \\
\hline A1 & 82.7 & 25 & 3.3 \\
A2 & 49.8 & 12 & 4.1 \\
A3 & 153.5 & 36 & 4.3 \\
A4 & 28.3 & 8 & 3.5 \\
A5 & 108.6 & 29 & 3.7 \\
A6 & 110.9 & 32 & 3.4 \\
A7 & 74.6 & 38 & 1.9 \\
A8 & 20.5 & 11 & 1.9 \\
A9 & 89.6 & 18 & 4.9 \\
A10 & 66.2 & 12 & 5.5 \\
C1 & 81.3 & 28 & 2.9 \\
C2 & 8.4 & 4 & 2.1 \\
C3 & 91.6 & 22 & 4.1 \\
C4a & 74.6 & 15 & 4.9 \\
C4b & 34 & 4.0 & 8.5 \\
C5a & 60 & 15 & 4.0 \\
C5b & 16.9 & 6 & 2.8 \\
C6 & 120.7 & 52 & 2.3 \\
C7 & 57.4 & 22 & 2.6 \\
C8 & 40.8 & 15 & 2.7 \\
C9 & 105.4 & 32 & 3.3 \\
Lg22 & 7.3 & 2 & 3.6 \\
\hline Total & 1483.1 & 438 & 3.4 \\
\hline
\end{tabular}

Table III-2: Linkage group size, number of markers and marker density per linkage group of the full map of Brassica napus DH population Mansholts $\times$ Samourai

\begin{tabular}{cccc}
\hline Linkage group & Size (cM) & Marker number & Marker density \\
\hline A1 & 85.8 & 30 & 2.8 \\
A2 & 147.8 & 21 & 7.0 \\
A3 & 125.4 & 54 & 2.4 \\
A4 & 67.2 & 20 & 3.3 \\
A5 & 161.2 & 47 & 3.4 \\
A6 & 88.3 & 27 & 3.2 \\
A7 & 77.9 & 35 & 2.2 \\
A8 & 78.5 & 21 & 3.7
\end{tabular}


Table 2 continued from page 33

\begin{tabular}{crrr} 
A9 & 117.0 & 34 & 3.4 \\
A10 & 72.1 & 39 & 1.8 \\
C1 & 126.6 & 37 & 3.0 \\
C2 & 135.1 & 26 & 5.1 \\
C3 & 176.0 & 53 & 3.3 \\
C4 & 154.1 & 45 & 3.4 \\
C5 & 108.6 & 12 & 9.0 \\
C6 & 104.6 & 30 & 3.4 \\
C7 & 110.8 & 19 & 5.8 \\
C8a & 76.2 & 22 & 3.4 \\
C8b & 5.3 & 10 & 0.5 \\
C9 & 141.1 & 27 & 5.22 \\
Lg21 & 20.2 & 4 & 5.0 \\
\hline Total & $\mathbf{2 1 8 0}$ & $\mathbf{6 1 3}$ & $\mathbf{3 . 6}$ \\
\hline
\end{tabular}

Table III-3: $\quad$ Linkage group size, number of markers, and marker density per linkage group of the full map of Brassica oleracea DH population Bo1TBDH

\begin{tabular}{cccc}
\hline Linkage group & Size (cM) & Marker number & Marker density \\
\hline C1 & 107.7 & 37 & 2.9 \\
C2 & 119.8 & 26 & 4.6 \\
C3 & 116 & 43 & 2.6 \\
C4 & 117.4 & 31 & 3.8 \\
C5 & 113.7 & 41 & 2.8 \\
C6 & 130 & 28 & 4.6 \\
C7 & 117.5 & 19 & 6.1 \\
C8 & 100.2 & 22 & 4.5 \\
C9 & 82 & 32 & 2.5 \\
\hline Total & $\mathbf{1 0 1 2 . 7}$ & $\mathbf{2 7 9}$ & $\mathbf{3 . 6}$ \\
\hline
\end{tabular}




\subsection{Results}

\subsubsection{Traits variations}

A large phenotypic variation was found in all populations. The mean, minimum, and maximum germination percentage, germination pace and respective salt tolerance indices determined in the three $\mathrm{DH}$ populations under control and salt treatment are summarized in Appendix 1.

In the $B$. napus $\mathrm{DH}$ population of Alesi and $\mathrm{H} 30$, the difference between parental lines was high for all traits under both control and salt stress, except for G\% under control, where both parents gave 100\%. For the $\mathrm{DH}$ lines under control conditions $\mathrm{G} \%$ ranged from $90 \%$ to $100 \%$. When they were treated with $200 \mathrm{mM} \mathrm{NaCl}$ solution, $\mathrm{G} \%$ varied from $10 \%$ to $100 \%$ (Figure $1 \mathrm{a}, \mathrm{b}$ ). Germination pace ranged from 0.18 to 0.62 under control conditions, whereas under salt stress there was a clear reduction extending from 0.11 to 0.35 (Figure 1c, d). A significant variation among the $\mathrm{DH}$ lines was found under control and salt stress conditions. For G\%, the variation under salt stress was higher than under control conditions. Conversely, for GP, the variation among $\mathrm{DH}$ lines was lower under salt stress. Heritability as an estimation of the repeatability of the experiment of G\% and GP under control was $57 \%$ and $85 \%$, respectively. On the other hand, under salt stress it was $74 \%$ and $75 \%$ for $\mathrm{G} \%$ and $\mathrm{GP}$, respectively. The mean squares and heritability of G\% and GP under both conditions are summarized in Table 4.

The salt tolerance index (STI) for G\% varied from $20 \%$ to $100 \%$ and for GP from $34 \%$ to $81 \%$. Significant differences were observed among the $\mathrm{DH}$ lines. The heritability of STI was high for G\% $\left(h^{2}=85 \%\right)$ and moderate for GP $\left(h^{2}=47 \%\right)$. The variation of G\%, STI and GPSTI was wide, whereby some DH lines showed salt tolerance indices higher than the parent, with high STI values and others were lower than the parent, with the lowest STI value(Figure 1e, f).

In the $B$. napus $\mathrm{DH}$ population of Mansholts and Samourai, the difference between the parental lines for all traits was non-significant under control conditions as well as under salt stress (Figure 2). In contrast, the $\mathrm{DH}$ lines showed wide variation in all traits, particularly under salt stress. The germination percentage varied from $90 \%$ to $100 \%$ and from $0 \%$ to $100 \%$ under control conditions and salt stress, respectively (Figure 2a, b). GP varied under control conditions from 0.21 to 0.61 and ranged from 0 to 0.32 under salt stress (Figure $2 \mathrm{c}, \mathrm{d}$ ). The genetic variation and heritability values for the $\mathrm{DH}$ lines were higher under salt stress than under control conditions. The heritability was moderate under control with $45 \%$ and $62 \%$ for G\% and GP, respectively, while it was much higher under salt stress, with 95\% and 96\% for G\% and GP, respectively.

The salt tolerance index for G\% varied from $20 \%$ to $100 \%$ and ranged from $20 \%$ to $100 \%$ for GP. A transgressive variation was observed in both directions among the $\mathrm{DH}$ lines. A set of $\mathrm{DH}$ lines exceeded the tolerant parent while others showed values lower than the susceptible parent (Figure 2e, f). Significant differences were found between 
the $\mathrm{DH}$ lines, though the difference between parental lines was not significant. The heritability of STI was high, with $96 \%$ and $85 \%$ for G\% and GP, respectively. Mean squares and heritability of G\%, STI and GPSTI are summarized (Table 5).

In the $B$. oleracea Bo1TBDH mapping population, the differences between the parental lines was small and non-significant under both conditions for all traits. In the $\mathrm{DH}$ lines, under salt stress the G\% ranged from $0 \%$ to $100 \%$ and from $60 \%$ to $100 \%$ under control (Figure $3 a, b)$. For GP, the variation under salt stress went from 0.00 to 0.35 and ranged from 0.13 to 0.40 under control (Figure $3 \mathrm{c}$ and $3 \mathrm{~d}$ ). These results indicate that a group of $\mathrm{DH}$ lines failed to germinate under the applied salt stress. The significant variation and heritability were higher under the salt treatment than under control. The heritability of G\% and GP for control was $86 \%$ and $74 \%$ and was $90 \%$ and $74 \%$ under salt, respectively (Table 5).

The salt tolerance index ranged from $0 \%$ to $100 \%$ for $\mathrm{G} \%$ as well as for GP (Figure $3 e$, 3f). The heritabilities for G\%STI and GPSTI were $83 \%$ and $20 \%$ respectively. The mean squares for the respective traits and heritability values are summarized (Table 6).

In all populations, under both conditions, there was a transgressive segregation in both sides, except for the $\mathrm{G} \%$ in the first population of Alesi and $\mathrm{H} 30$, where the parental line $\mathrm{H} 30$ displayed $100 \%$ seed germination. The observed transgressive segregation means that both parental lines in all populations could contribute positively to increasing the respective trait.

** The names of parents are abbreviated

$\mathrm{M}=$ Mansholts

$\mathrm{S}=$ Samourai

$\mathrm{TO}=\mathrm{TO} 1000 \mathrm{DH} 3$

$\mathrm{EB}=$ Early Big 


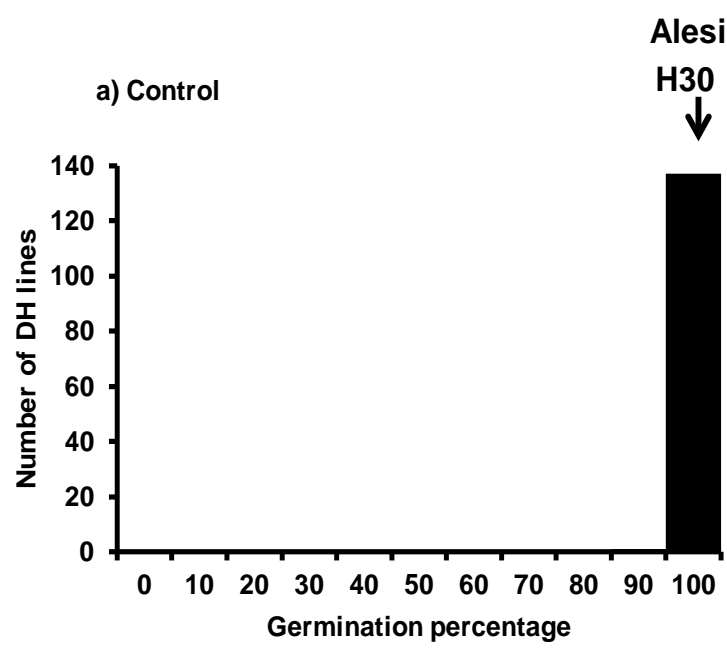

c) Control
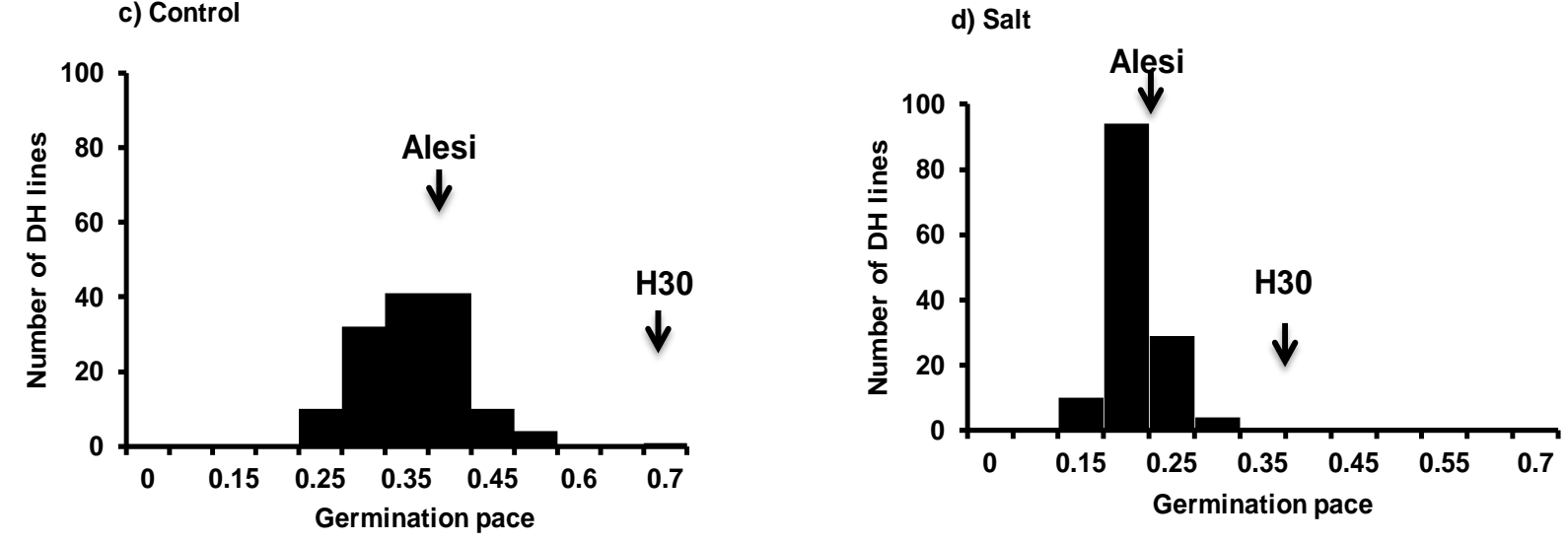

e)

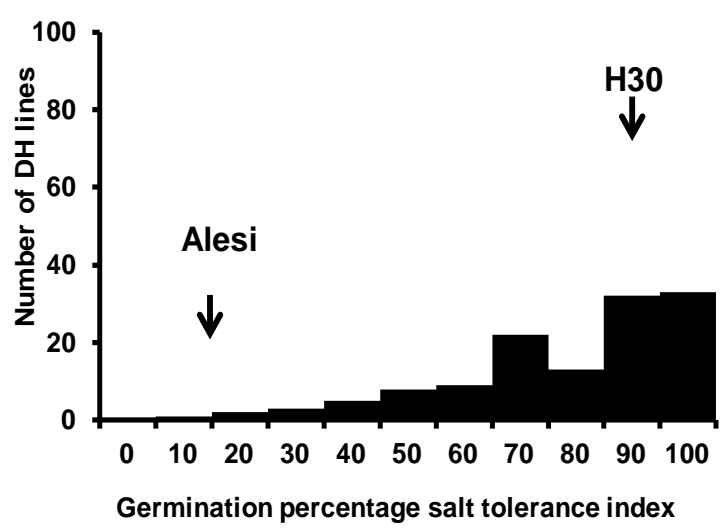

f)

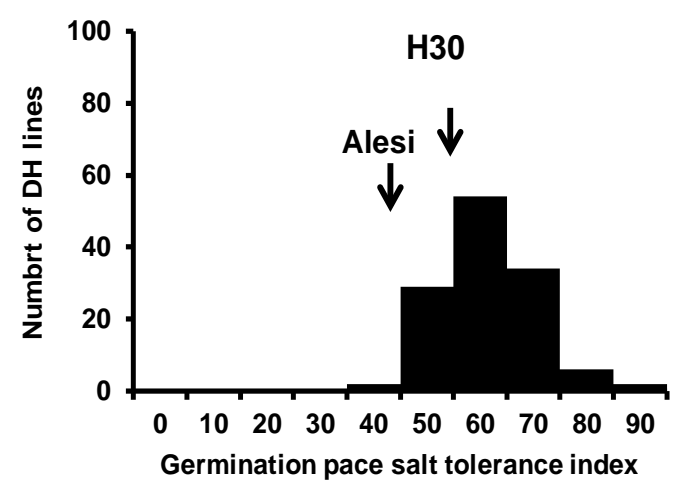

Figure III-1: Frequency distribution of germination parameters under control under salt stress conditions of Brassica napus mapping population Alesi $\times \mathrm{H} 30$; a) Germination percentage (\%) under control and b) Germination percentage under salt; c) Germination pace (\%) at control and d) Germination pace under salt, e) Salt tolerance index for germination percentage and f) Salt tolerance index for germination pace 


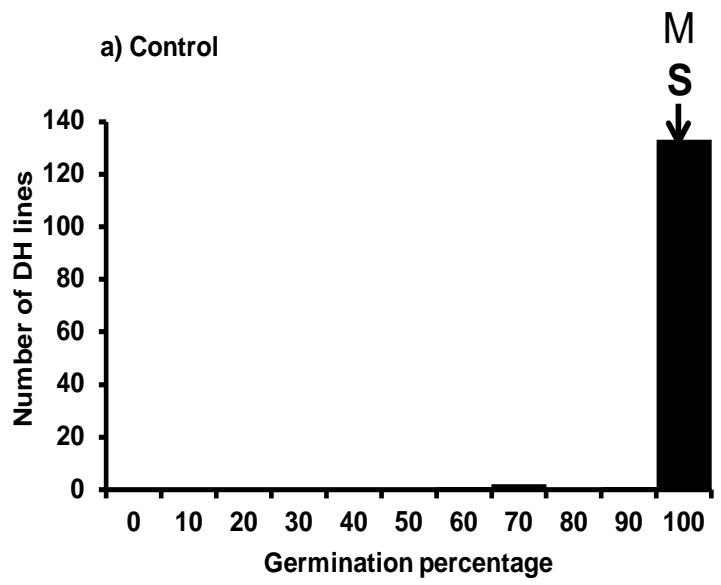

b) Salt
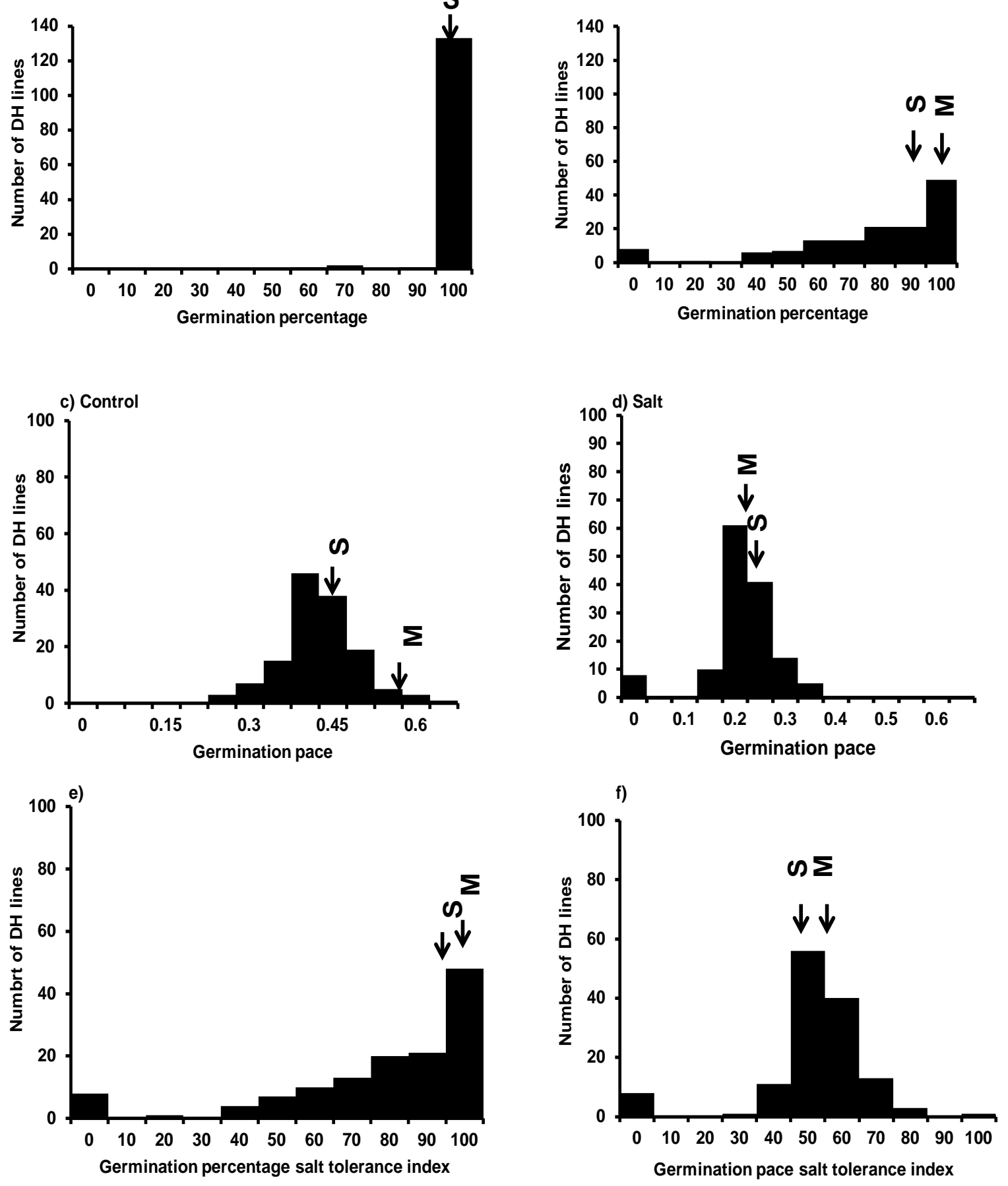

Figure III-2: Frequency distribution of germination parameters under control under salt stress conditions of Brassica napus mapping population Mansholts (M) $\times$ Samourai (S); a) Germination percentage (\%) under control and b) Germination percentage under salt; c) Germination pace (\%) under control and b) Germination pace under salt, d) Salt tolerance index for germination percentage and d) Salt tolerance index for germination 


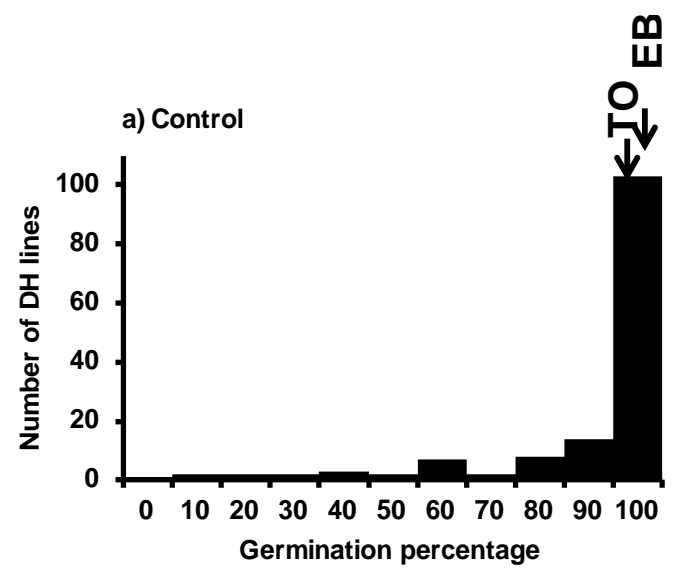

b) Salt

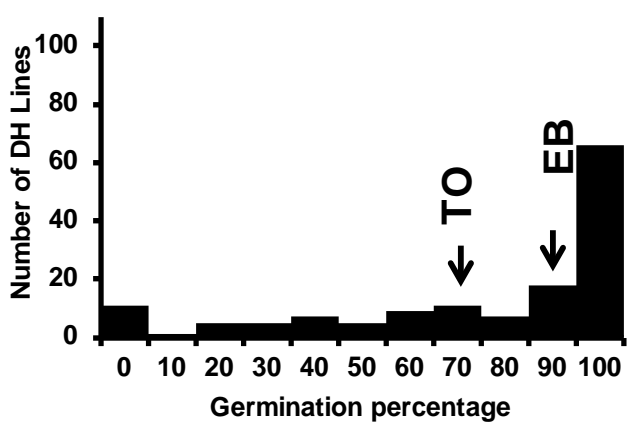

c) Control

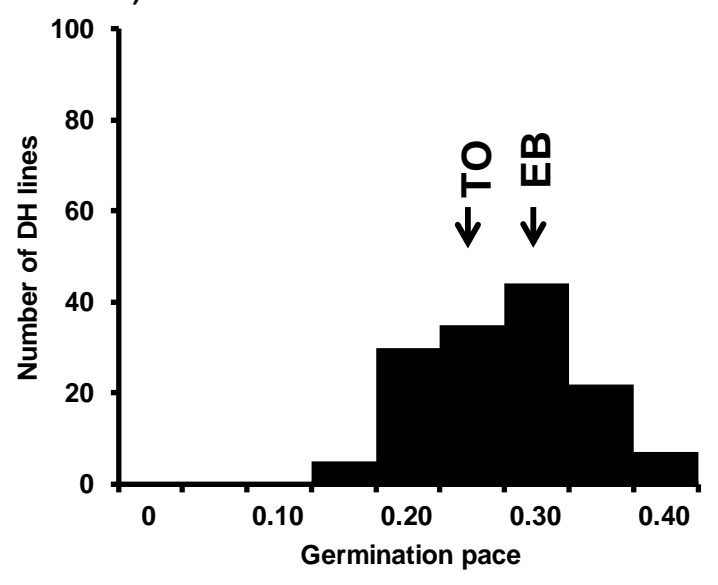

d) Salt
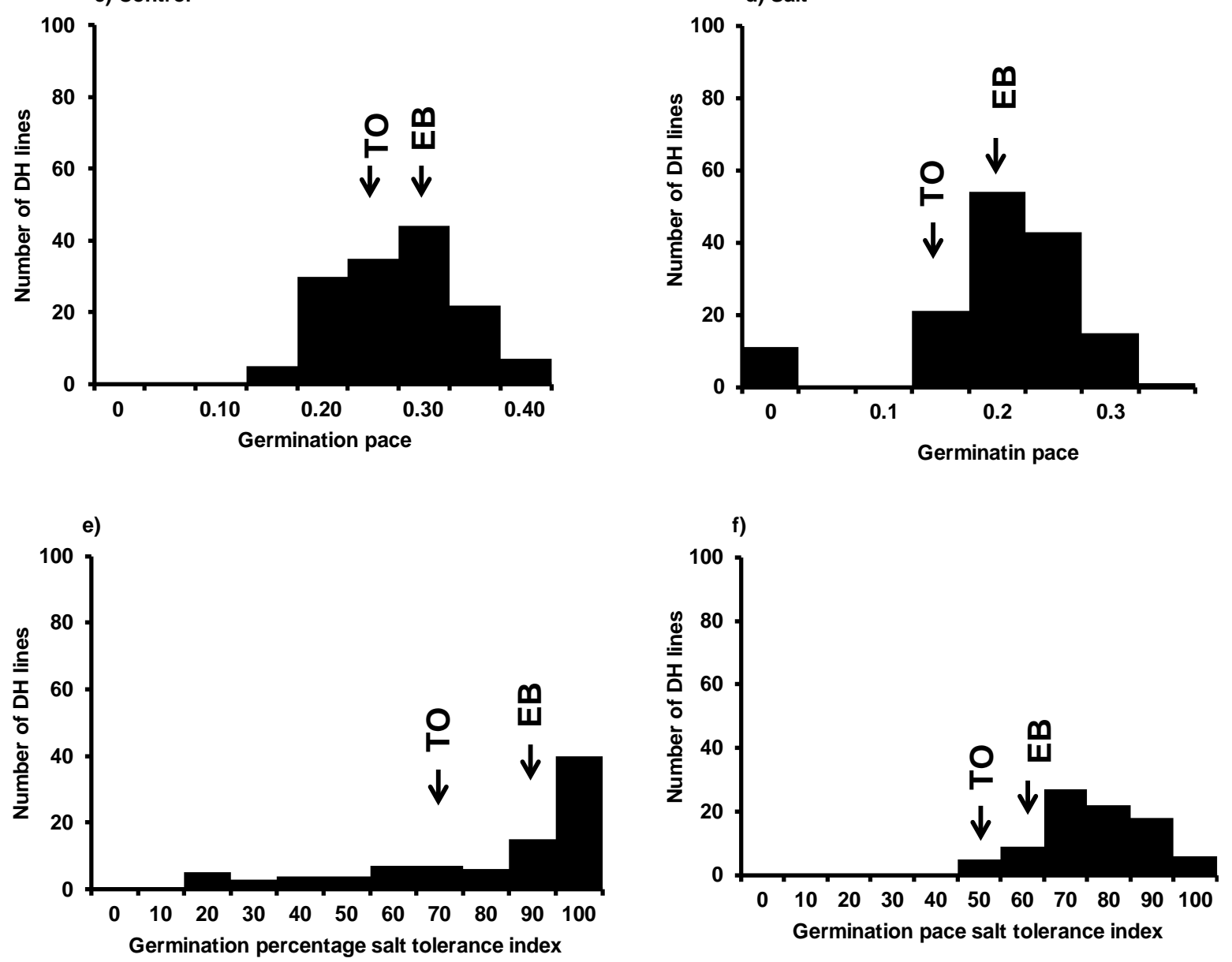

Figure III-3: Frequency distribution of germination parameters under control under salt stress conditions of Brassica oleracea mapping population Bo1TBDH; a) Germination percentage (\%) under control and b) Germination percentage under salt; c) Germination pace under control and d) Germination pace under salt, e) Salt tolerance index for germination percentage and f) Salt tolerance index for germination pace 
Table III-4: Mean squares, respective F tests, and heritabilities estimated from the ANOVA of Brassica napus DH population Alesi $\times \mathrm{H} 30,138 \mathrm{DH}$ lines were tested under control conditions and at salt treatment $(200 \mathrm{mM} \mathrm{NaCl})$

\begin{tabular}{|c|c|c|c|c|c|c|c|}
\hline \multirow[t]{2}{*}{ Sources of variance } & \multirow[t]{2}{*}{ DF } & \multicolumn{2}{|c|}{ Germination Percentage (G \%) } & \multicolumn{2}{|c|}{ Germination Pace (GP) } & \multirow[t]{2}{*}{$\mathrm{G} \% \mathrm{STI}$} & \multirow[t]{2}{*}{ GP STI } \\
\hline & & Control & Salt & Control & Salt & & \\
\hline Genotypes (G) & 137 & $6.72^{\star \star}$ & $12.76^{\star \star}$ & $0.93^{\star *}$ & $0.27^{\star \star}$ & $1269.35^{\star \star}$ & $205.17^{* *}$ \\
\hline Replicates (R) & 2 & $11.60 *$ & $11.27^{\star \star}$ & $2.93^{\star \star}$ & $1.16^{\star *}$ & $11881.38^{\star \star}$ & 129.13 \\
\hline $\mathrm{G} \times \mathrm{R}$ & 274 & 2.80 & 18.40 & 0.23 & 0.06 & 189.35 & 108.50 \\
\hline$h^{2}$ & & 57.86 & 85.62 & 74.22 & 75.15 & 85.08 & 47.12 \\
\hline
\end{tabular}

Table III-5: Mean squares, respective F tests, and heritabilities estimated from the ANOVA of Brassica napus DH population Mansholts $\times$ Samourai, $138 \mathrm{DH}$ lines were tested under control conditions and at salt treatment $(200 \mathrm{mM} \mathrm{NaCl})$

\begin{tabular}{|c|c|c|c|c|c|c|c|}
\hline Sources of variance & DF & \multicolumn{2}{|c|}{ Germination Percentage } & \multicolumn{2}{|c|}{ Germination Pace } & G\% STI & GP STI \\
\hline & & Control & Salt & Control & Salt & & \\
\hline Genotypes (G) & 137 & $9.0 * *$ & $20.31^{* *}$ & $0.02^{* *}$ & $0.01^{\star \star}$ & $2040.01^{\star \star}$ & $670.77^{\star \star}$ \\
\hline Replicates (R) & 2 & 2.80 & 1.60 & $0.09 * *$ & 0.00 & 39.65 & $637.67^{* *}$ \\
\hline$G \times R$ & 274 & 5.40 & 11.00 & 0.07 & 0.01 & 112.94 & 103.29 \\
\hline$h^{2}$ & & 44.66 & 94.57 & 61.90 & 95.79 & 94.46 & 84.60 \\
\hline
\end{tabular}

Table III-6: Mean squares, respective $F$ tests, and heritabilities estimated from the ANOVA of Brassica oleracea DH population Bo1TBDH, $145 \mathrm{DH}$ lines were tested under control conditions and at salt treatment $(100 \mathrm{mM} \mathrm{NaCl})$

\begin{tabular}{|c|c|c|c|c|c|c|c|}
\hline \multirow[t]{2}{*}{ Sources of variance } & \multirow[t]{2}{*}{$\mathrm{DF}$} & \multicolumn{2}{|c|}{ Germination Percentage } & \multicolumn{2}{|c|}{ Germination Pace } & \multirow[t]{2}{*}{ G\% STI } & \multirow[t]{2}{*}{ GP STI } \\
\hline & & Control & Salt & Control & Salt & & \\
\hline Genotypes (G) & 144 & $1331.07^{* *}$ & $1981.63^{\star *}$ & $0.01^{* *}$ & $0.05^{\star \star}$ & $1736.57^{\star \star}$ & $189.32+$ \\
\hline Replicates (R) & 2 & $4520.38^{\star \star}$ & $951.31^{\star *}$ & $0.24^{\star \star}$ & $0.04^{\star \star}$ & 523.30 & $4545.14^{\star \star}$ \\
\hline$G \times R$ & 288 & 184.40 & 199.83 & 0.001 & 0.001 & 297.87 & 150.10 \\
\hline$h^{2}$ & & 86.15 & 89.92 & 73.87 & 74.43 & 82.85 & 19.81 \\
\hline
\end{tabular}

** Significant at $P=0.01 ;$ * significant at $P=0.05$ and + significant at $P=0.1$ 


\subsubsection{Framework maps}

For the B. napus DH population of Alesi and H30, the framework map comprises 188 markers: 131 SNPs markers and 57 SSR markers were developed as described earlier in Chapter 3 (3.3.4). The mapped markers distributed on 22 LGs, with a marker density of one marker per $4.1 \mathrm{cM}$. The size of the LGs was unequal. The LG C2 presented the shortest LG with a length of $8.4 \mathrm{cM}$, while LG A3 was the longest LG with a length of $149.8 \mathrm{cM}$. The distribution of markers on LGs was uneven, ranging from only two markers on LGs: C4b and LG 22 to 18 on LG C6. Similarly, the marker density differed among the LGs from one marker per $2.8 \mathrm{cM}$ on LG C2 to one marker per $12.4 \mathrm{cM}$ on LG C4b. The set of markers that was mapped on the framework map of this population covered $1444 \mathrm{cM}$ of the $B$. napus genome (Table 7 and Figure 7 ).

In the $B$. napus $\mathrm{DH}$ population of Mansholts and Samourai, the framework map included 208 markers: 121 RFLP, 27 AFLP, 42 SSR, 17 RAPD and 1 phenotypic marker (flower color) was developed as reported before. The selected markers were mapped on 21 LGS, with a marker density of one marker per $10.4 \mathrm{cM}$. The length of LGs varied from $4.8 \mathrm{cM}$ for LG C8b to $173.6 \mathrm{cM}$ for LG C3. The number of markers mapped per LG varied from three markers on LG C8b to 17 markers on LGs C3 and C4. The marker density ranged from one marker per $1.6 \mathrm{cM}$ on LG C8b to one marker per $15.3 \mathrm{cM}$ on LG C5. This framework map covered $2179 \mathrm{cM}$ of the $B$. napus genome (Table 8 and Figure 8). In $B$. oleracea (Bo1TBDH population), the framework map consisted of 128 markers: 70 RFLP, 56 SSR, 1 phenotypic marker (flower color) and 1 ispga PCR marker was constructed using the protocol described in Chapter 3 (3.3.4). The selected markers were distributed on nine LGs with a marker density of one marker per $3.6 \mathrm{cM}$. The length of the LGs was longer than $100 \mathrm{cM}$, but LG C9 was $78.5 \mathrm{cM}$. All linkage groups were covered with more than 10 markers, except LG C9 with 9 markers. The highest marker density was on LG C1 with one marker per 5.7 $\mathrm{cM}$. The mapped markers on this framework map covered $1000 \mathrm{cM}$ of the $B$. oleracea genome (Table 9 and Figure 9). 
Table III-7: Linkage group size, number of markers, and marker density per linkage group of the framework map of Brassica napus $\mathrm{DH}$ population Alesi $\times \mathrm{H} 30$

\begin{tabular}{cccc}
\hline Linkage group & Size (cM) & Marker number & Marker density \\
\hline A1 & 78.6 & 14 & 5.6 \\
A2 & 53 & 5 & 10.6 \\
A3 & 149.8 & 17 & 8.7 \\
A4 & 28.2 & 5 & 5.6 \\
A5 & 103 & 13 & 7.9 \\
A6 & 110.6 & 10 & 11.0 \\
A7 & 75.5 & 14 & 5.3 \\
A8 & 20.8 & 5 & 4.1 \\
A9 & 89.5 & 9 & 9.9 \\
A10 & 66.1 & 8 & 8.2 \\
C1 & 79 & 9 & 8.7 \\
C2 & 8.4 & 3 & 2.8 \\
C3 & 89 & 9 & 9.8 \\
C4a & 74.6 & 6 & 12.4 \\
C4b & 35.9 & 3 & 11.9 \\
C5a & 54.2 & 5 & 10.8 \\
C5b & 14.4 & 4 & 3.6 \\
C6 & 118.8 & 18 & 6.6 \\
C7 & 58.3 & 10 & 5.83 \\
C8 & 41.2 & 7 & 5.88 \\
C9 & 88.5 & 12 & 7.3 \\
Lg22 & 7.3 & 2 & 3.6 \\
\hline Total & 1444.7 & & 7.6 \\
\hline
\end{tabular}

Table III-8: Linkage group size, number of markers, and marker density per linkage group of the framework map of Brassica napus DH population Mansholts $\times$ Samourai

\begin{tabular}{cccc}
\hline Linkage group & Size (cM) & Marker number & Marker density \\
\hline A1 & 78.5 & 9 & 8.7 \\
A2 & 148.6 & 12 & 12.3 \\
A3 & 131.3 & 15 & 8.7 \\
A4 & 69.3 & 8 & 8.6 \\
A5 & 161.1 & 11 & 14.6 \\
A6 & 87.2 & 7 & 12.4 \\
A7 & 75.5 & 11 & 6.8 \\
A8 & 78.7 & 8 & 9.8 \\
A9 & 119.5 & 10 & 10.8 \\
A10 & 72.6 & 8 & 8.8 \\
C1 & 127.9 & 10 & 12.7
\end{tabular}


Table 8 continued from page 42

\begin{tabular}{rrrr} 
C2 & 132.8 & 11 & 12.0 \\
C3 & 173.6 & 17 & 10.2 \\
C4 & 151.4 & 16 & 9.4 \\
C5 & 110.2 & 7 & 15.7 \\
C6 & 107.1 & 11 & 9.7 \\
C7 & 115.6 & 10 & 10.8 \\
C8a & 75.1 & 8 & 9.3 \\
C8b & 4.8 & 3 & 1.6 \\
C9 & 138.1 & 12 & 11.5 \\
Lg21 & 20.2 & 4 & 5.0 \\
\hline Total & $\mathbf{2 1 7 9 . 2}$ & $\mathbf{2 0 8}$ & $\mathbf{1 0 . 4}$ \\
\hline
\end{tabular}

Table III-9: Linkage group size, number of markers, and marker density per linkage group of the framework map of Brassica oleracea DH population Bo1TBDH

\begin{tabular}{cccc}
\hline Linkage group & Size (cM) & Marker number & Marker density \\
\hline C1 & 107.7 & 19 & 5.7 \\
C2 & 118.7 & 13 & 9.1 \\
C3 & 115.9 & 18 & 6.4 \\
C4 & 117 & 17 & 6.8 \\
C5 & 114.1 & 13 & 8.7 \\
C6 & 130 & 15 & 8.6 \\
C7 & 116.6 & 11 & 10.6 \\
C8 & 101.8 & 13 & 7.8 \\
C9 & 78.1 & 9 & 8.6 \\
\hline Total & $\mathbf{1 0 0 0}$ & $\mathbf{1 2 8}$ & 7.8 \\
\hline
\end{tabular}



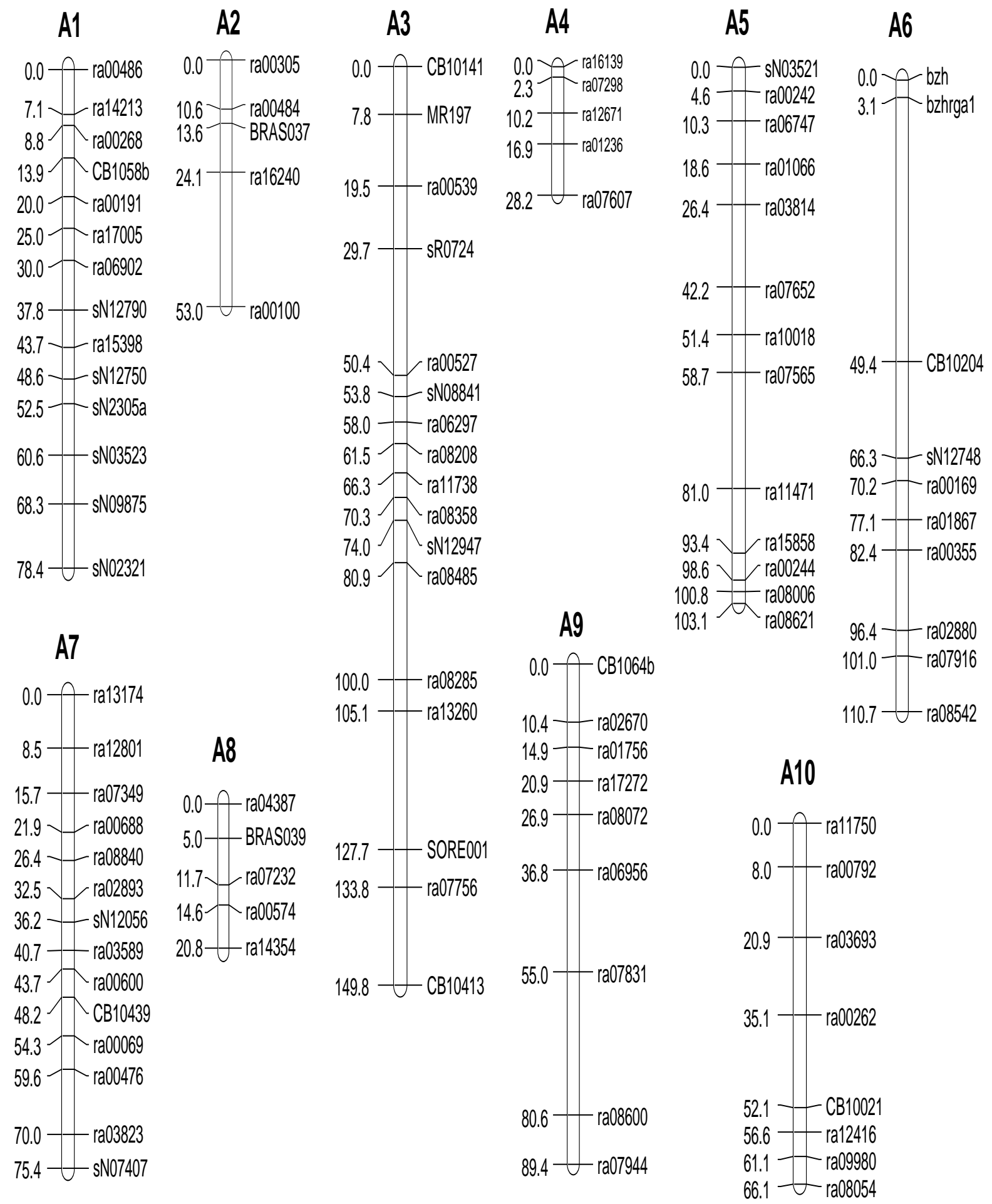

Figure III-4: Framework map of Brassica napus mapping population Alesi $\times \mathrm{H} 30$. The vertical bars are the linkage groups $\mathrm{N} 1-\mathrm{N} 10=\mathrm{A} 1-\mathrm{A} 10$ and $\mathrm{N} 11-\mathrm{N} 19=\mathrm{C} 1-\mathrm{C} 9$ (international nomenclature). Marker locus names and positions (cM) are located to the left and right of the vertical bars, respectively 
Figure III-1 continued from page 44

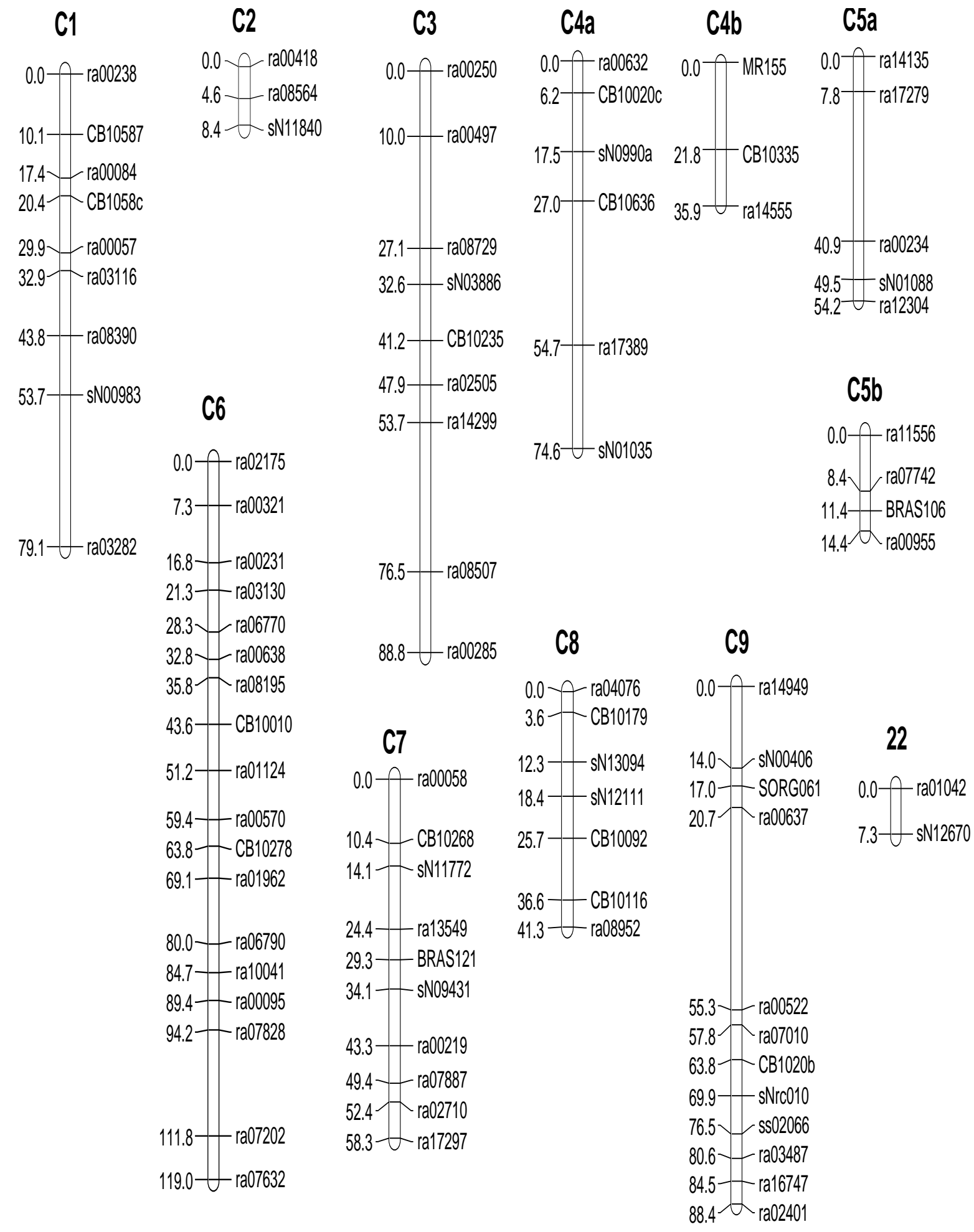




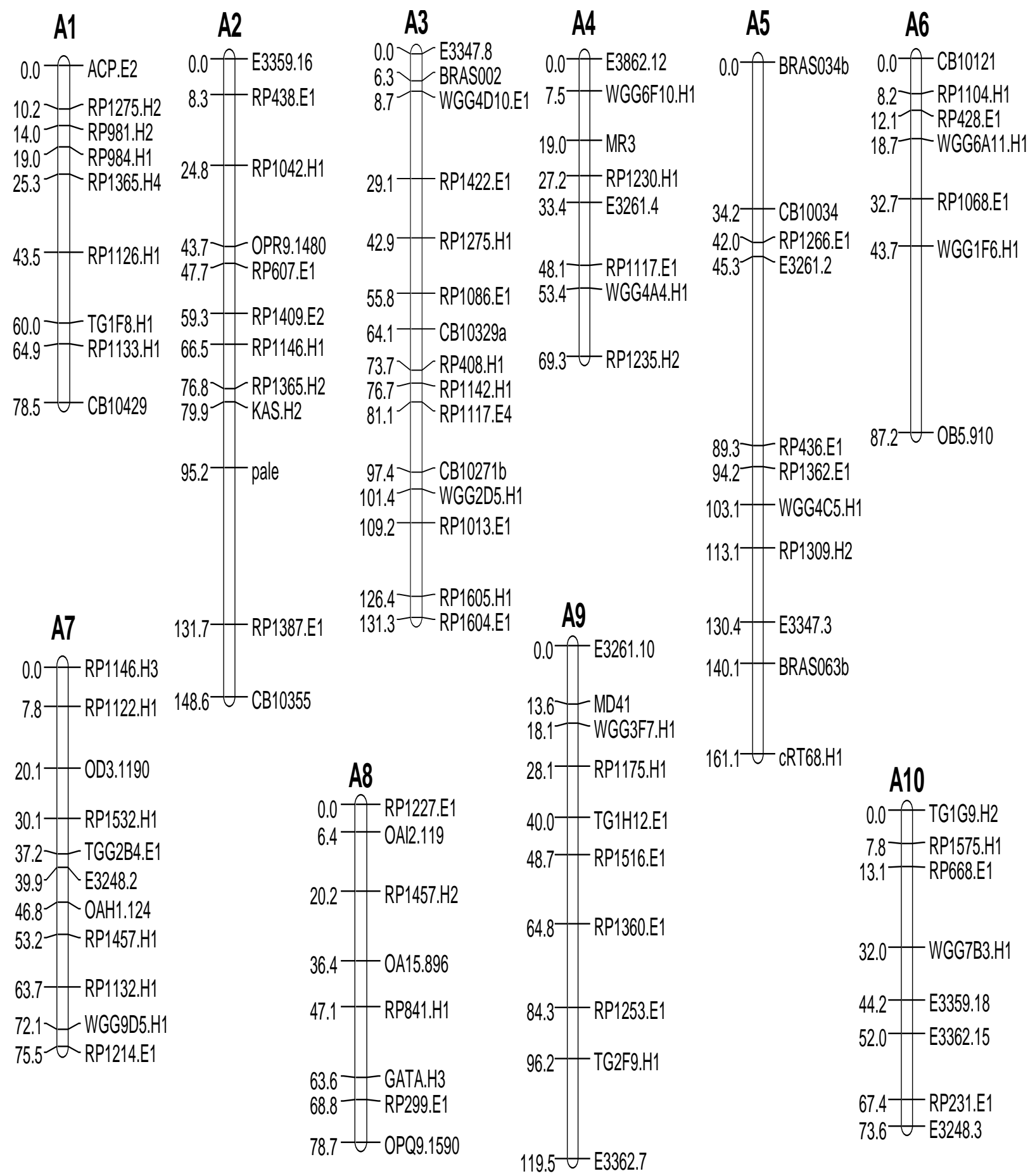

Figure III-5: Framework map of Brassica napus mapping population Mansholts $\times$ Samourai. The vertical bars represent linkage groups N1-N10 = A1-A10 and N11-N19 = C1-C9 (international nomenclature). Marker locus names and positions (cM) are located to the left and right of the vertical bars, respectively 
Figure 5 continued from page 46

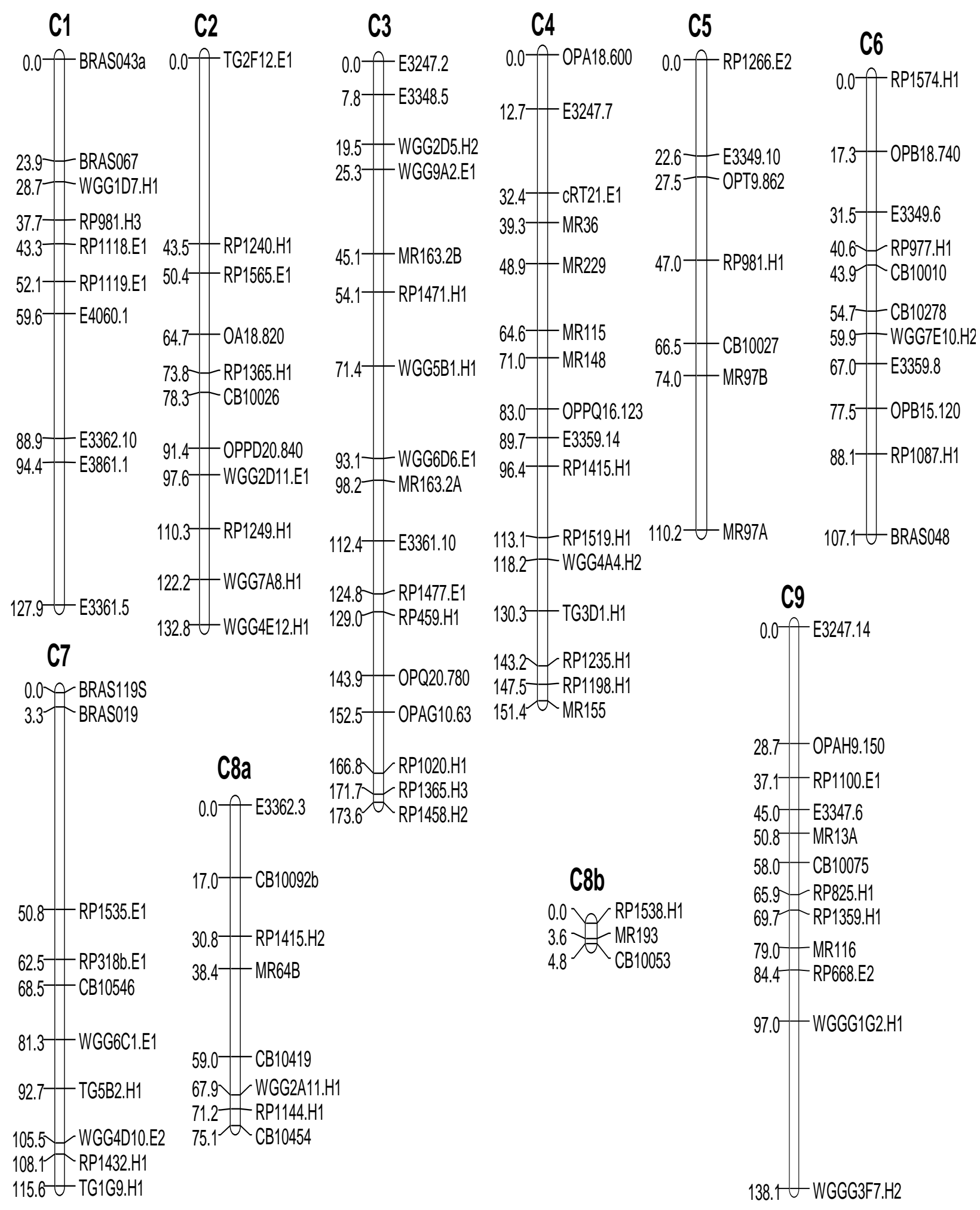


C1

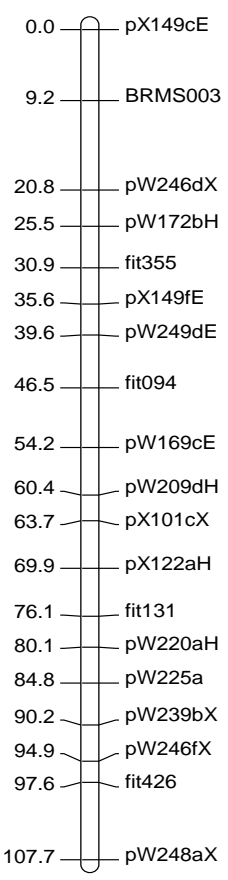

C6

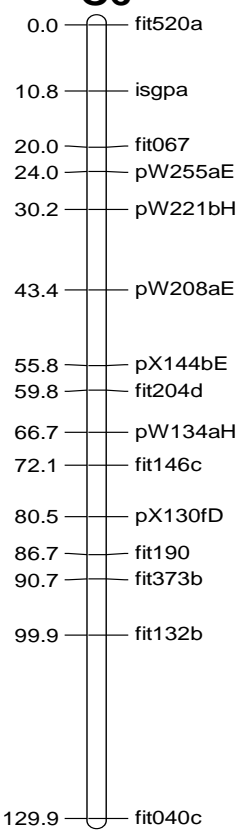

C2

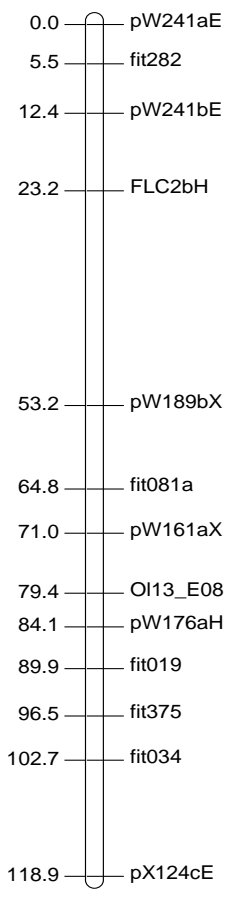

C3

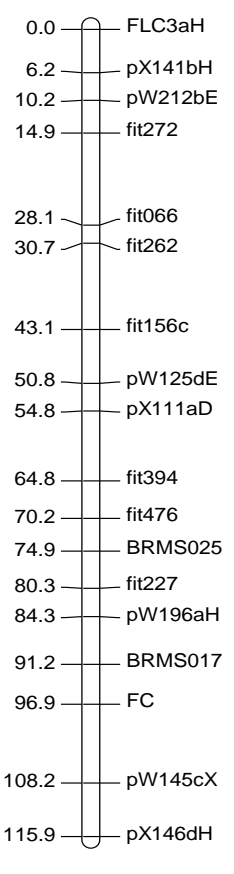

C4

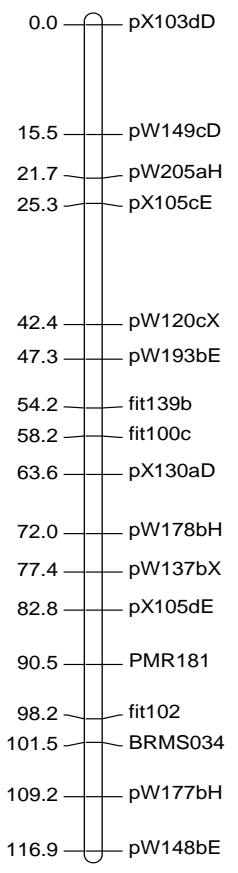

C5

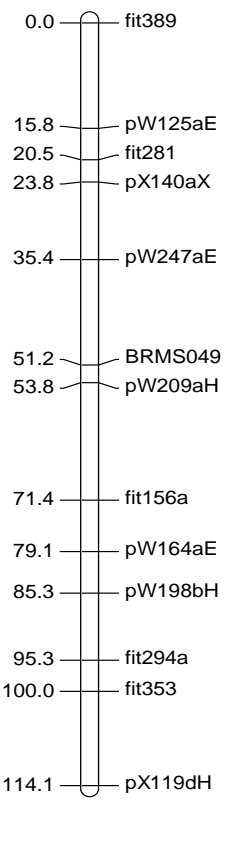

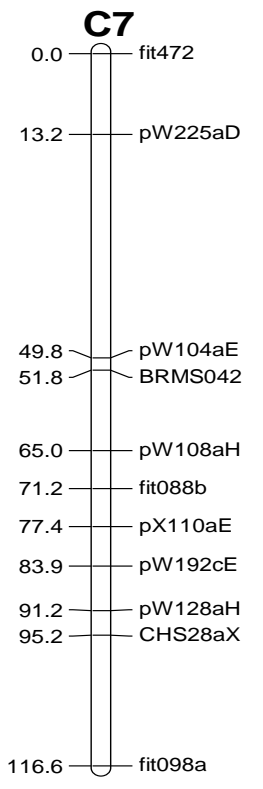

C8

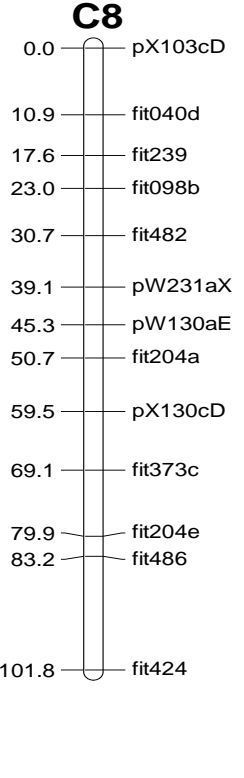

C9

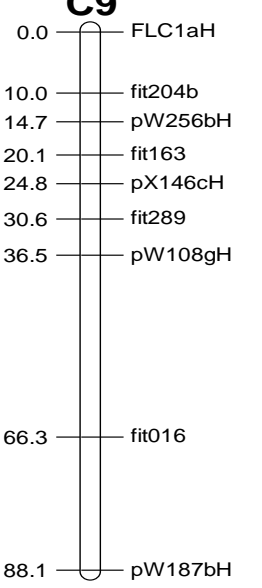

Figure III-6: Framework map of Brassica oleracea mapping population $\mathrm{Bo1TBDH}$. The vertical bars represent linkage groups N11-N19 = C1-C9 (international nomenclature). Marker locus names and positions (cM) are located to the left and right of the vertical bars, respectively 


\subsubsection{QTL analysis and localization}

For germination parameters under control and salt stress conditions, a total of 22 QTL were identified in the three tested populations. The full statistics data on the QTL detected in the three tested populations, additive effect, flanking markers, and the variation explained by each QTL and LOD score, are summarized in Tables 10, 11 and 12. The position of QTL on linkage groups (LG) is outlined in Figures 7, 8 and 9. Positive additive effect means that alleles of Alesi increase the threat while the negative additive effect means that the alleles of $\mathrm{H} 30$ increase the trait.

\section{Brassica napus DH population (Alesi $\times$ H30) Germination percentage}

No QTL were identified under control conditions. Under salt stress one putative QTL, G\%1S, was detected on LG C1. This QTL explains $6 \%$ of the phenotypic variation with a negative additive effect.

\section{Germination pace}

Under control, three QTL, GP-1C, GP-2C and GP-3C were detected on LGs A9, C1 and C4, respectively. They explain $37 \%$ of the phenotypic variance. Two QTL- GP-1C and GP-2C, show a negative additive effect. QTL GP-2C was identified at $P=0.05$ and alone explains $17 \%$ of the phenotypic variation. The third QTL, namely GP-3C, shows a positive additive effect. No QTL were identified for GP under salt stress.

\section{Salt tolerance index}

Three QTL were localized, i.e. G\%STI-1 was found on LG A3 which explains 6\% of the phenotypic variation with a negative additive effect. For GP, two QTL, GP-STI-1 and GPSTI-2, were detected on LGs A9 and A10, respectively. GP-STI-1S shows a positive additive effect and explains $7 \%$ of the phenotypic variation. In contrast, GP-STI-2 shows a negative additive effect and explains $8 \%$ of the phenotypic variation.

\section{Brassica napus DH population (Mansholts $\times$ Samourai) Germination percentage}

Two QTL, G\%-1C and G\%-2C, were identified on LG C1 at $24 \mathrm{cM}$ and $53 \mathrm{cM}$, respectively. Together they explain $17 \%$ of the genotypic variation. For both QTL G\%-1C and G\%-2C, the additive effect was negative. Under salt stress, one QTL was identified as G\%-1S on LG C5, explaining $4 \%$ of the phenotypic variation with a negative additive effect.

\section{Germination pace}

One QTL (GP-1C) was detected under control conditions on LG A9. This QTL explains $6 \%$ of the phenotypic variation with a positive additive effect. Under salt stress, one QTL GP-1S was detected on LG A8, explaining $6 \%$ of the phenotypic variation with a negative additive effect.

\section{Salt tolerance index}

No QTL were mapped for G\%-STI and only one QTL GP-STI-1 was identified on LG A8, which explains $5 \%$ of the phenotypic variation with a negative additive effect. 
Comparing the traits variation of the two $B$. napus populations, the mean values and distribution of the traits is quite similar under control and salt stress. The number of QTL was quite similar, with seven QTL for the $B$. napus $\mathrm{DH}$ population (Alesi and $\mathrm{H} 30$ ), and six QTL for B. napus DH population (Mansholts and Samourai).

\section{Brassica oleracea population Bo1TBDH}

\section{Germination percentage}

The QTL mapping resulted in three QTL: G\%-1C, G\%-2C and G\%-3C. G\%-1C was detected on LG C2, while G\%-2C and G\%-3C were found on the same LG C4 at $44 \mathrm{cM}$ and $99 \mathrm{cM}$, respectively. The QTL values account for $30 \%$ of the phenotypic variation. Only G\%-3C were mapped at $P=0.05$. G\%-1C and G\%-2C show a positive additive effect. Under salt treatment, one QTL was identified for G\%-1S on LG C1, which explains $7 \%$ of the phenotypic variation with a positive additive effect.

\section{Germination pace}

Under control, three QTL were mapped: GP-1C and GP-2C were found on LGs C4 at 40 cM and $102 \mathrm{cM}$, respectively. GP-3C was mapped on Lg C5. These three QTL together explain $30 \%$ of the phenotypic variation. The QTL GP-1C and GP-2C showed a positive additive effect. Conversely, the additive effect was negative for GP-3C. Under salt treatment, one QTL GP-1S was detected on LG C4, explaining 6\% of the phenotypic variation with a positive additive effect.

\section{Salt tolerance index}

One QTL for G\%: GP-STI-1 was detected on LG C3, which explains 8\% of the phenotypic variation with negative additive effect. 
Table III-10: QTL detected at LOD > 1.2 under control treatment (C) and Salt treatment (S) for germination percentage (G\%), germination pace (GP), and respective salt tolerance indices (G\%STI, GPSTI) in Brassica napus mapping population Alesi $\times$ H30. (QTL significant with $P=0.05$ are marked bold)

\begin{tabular}{|c|c|c|c|c|c|c|c|c|c|}
\hline Treatment & Trait & Name of QTL & LG & LOD & $\begin{array}{l}\text { Position } \\
\text { (cM) }\end{array}$ & interval & Flanking Markers & $\begin{array}{c}\text { Additive } \\
\text { Effect }\end{array}$ & $\begin{array}{c}\text { Phenotypic } \\
\text { Variation } \\
\text { explained (\%) }\end{array}$ \\
\hline \multirow{3}{*}{ C } & GP & GP-1C & A9 & 3.0 & 81 & $80-89$ & ra08600 -ra07944 & -0.03 & 10.45 \\
\hline & GP & GP-2C & C1 & 5.3 & 44 & $32-54$ & ra08390 -sN00983 & -0.04 & 17.5 \\
\hline & GP & GP-3C & $\mathrm{C} 4 \mathrm{~b}$ & 2.6 & 11 & $0-22$ & MR155 -CB10335 & 0.03 & 8.79 \\
\hline \multirow[t]{4}{*}{$\mathrm{S}$} & $\mathrm{G} \%$ & G\%-1S & $\mathrm{C} 1$ & 1.8 & 54 & $43-79$ & sN00983-ra03282 & -10.70 & 6.41 \\
\hline & G\%-STI & G\%-STI-1 & A3 & 1.8 & 51 & $50-54$ & ra00527-sN08841 & -10.56 & 6.31 \\
\hline & GP-STI & GP-STI-1 & A9 & 2.0 & 81 & $80-89$ & ra08600-ra07944 & 4.54 & 7.27 \\
\hline & GP-STI & GP-STI-2 & A10 & 2.2 & 56 & $35-57$ & CB10021-ra12416 & -4.66 & 7.59 \\
\hline
\end{tabular}

Table III-11: QTL detected at LOD > 1.2 under control treatment (C) and Salt treatment (S) for germination percentage (G\%), germination pace (GP), and respective salt tolerance indices (G\%STI, GPSTI) in Brassica napus mapping population Mansholts $\times$ Samourai. (QTL significant with $P=0.05$ are marked bold)

\begin{tabular}{|c|c|c|c|c|c|c|c|c|c|}
\hline $\begin{array}{c}\text { Treatmen } \\
\mathrm{t}\end{array}$ & Trait & Name of QTL & LG & LOD & $\begin{array}{l}\text { Position } \\
\text { (cM) }\end{array}$ & interval & Flanking Markers & $\begin{array}{c}\text { Additive } \\
\text { Effect }\end{array}$ & $\begin{array}{l}\text { Phenotypic } \\
\text { Variation } \\
\text { explained }\end{array}$ \\
\hline \multirow{3}{*}{$\mathrm{C}$} & G\% & G\%-1C & $\mathrm{C} 1$ & 1.8 & 24 & $8-27$ & BRAS067 - W1D7.H1 & 1.88 & 6.12 \\
\hline & G\% & G\%-2C & C1 & 3.4 & 53 & $52-58$ & RP1119.E1 -F4E4060.1 & -2.48 & 11.28 \\
\hline & GP & GP-1C & A9 & 1.8 & 14 & $13-16$ & MD41 - WG3F7.H1 & 0.02 & 6.06 \\
\hline \multirow{3}{*}{ S } & G\% & G\%-1S & $\mathrm{C5}$ & 1.2 & 107 & $90-110$ & MR97B $\quad$-MR97A & -5.99 & 4.31 \\
\hline & GP & GP-1S & A8 & 1.8 & 77 & $68-78$ & RP299.E1 -OPQ9.1590 & -0.02 & 6.27 \\
\hline & GP-STI & GP-STI & A8 & 1.5 & 77 & $68-78$ & RP299.E1 -OPO9.1590 & -3.80 & 5.15 \\
\hline
\end{tabular}

- The additive effect is calculated by subtracting Mansholts allele by Samourai allele. 
Table III-12: QTL detected at LOD >1.2 under control treatment (C) and salt treatment (S) for germination percentage (G\%), germination pace (GP), and respective salt tolerance indices (G\%STI, GPSTI) in Brassica oleracea mapping population Bo1TBDH. (QTL significant with $P=0.05$ are marked bold)

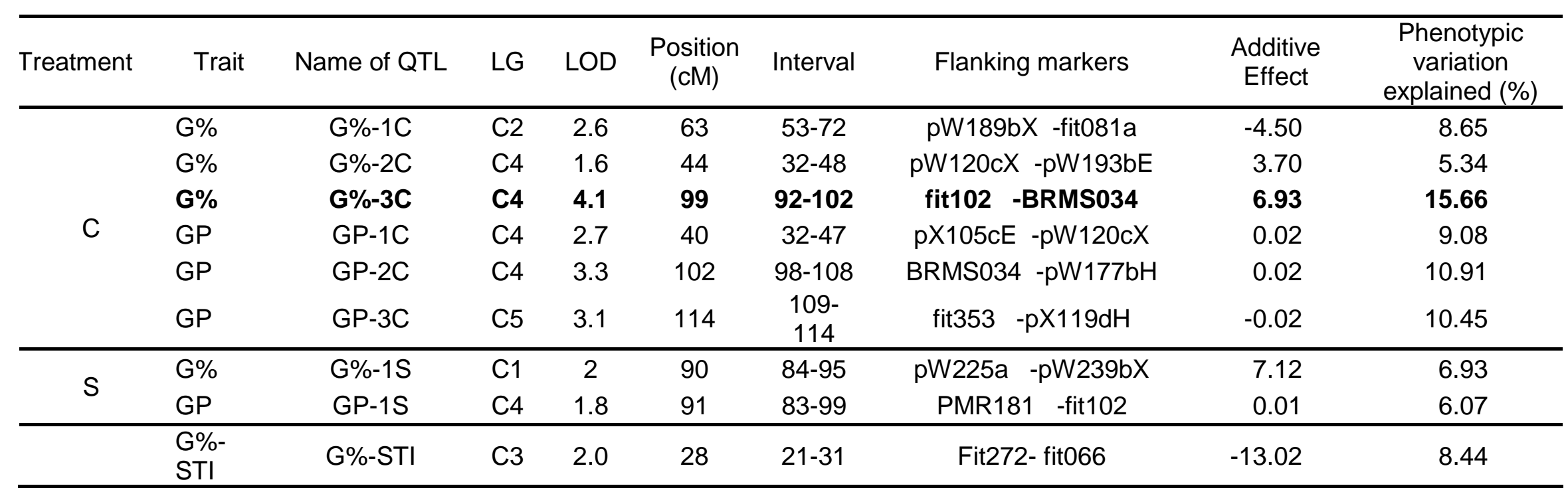

- The additive effect is calculated by subtraction TO1000DH3 allele by Early Big allele. 

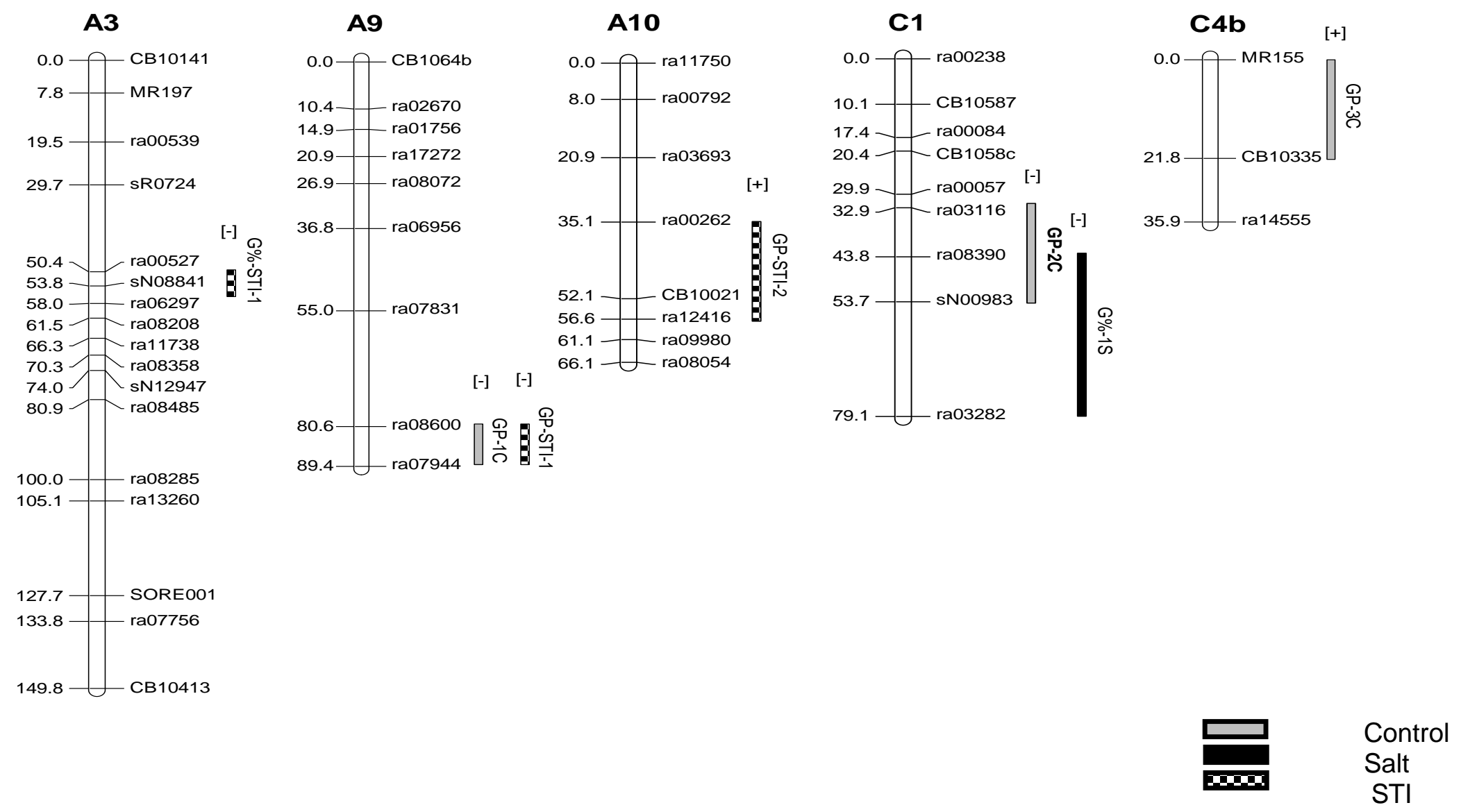

Figure III-7: Localization of QTL for germination parameters in Brassica napus DH population Alesi x H30. (QTL significant with $P=0.05$ are marked bold) 

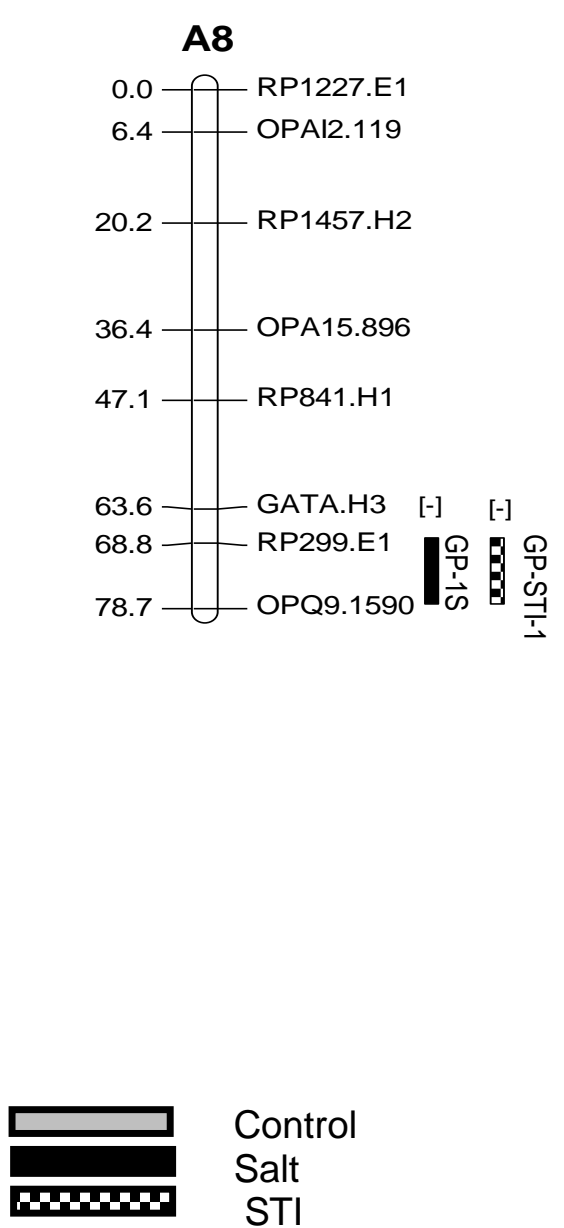
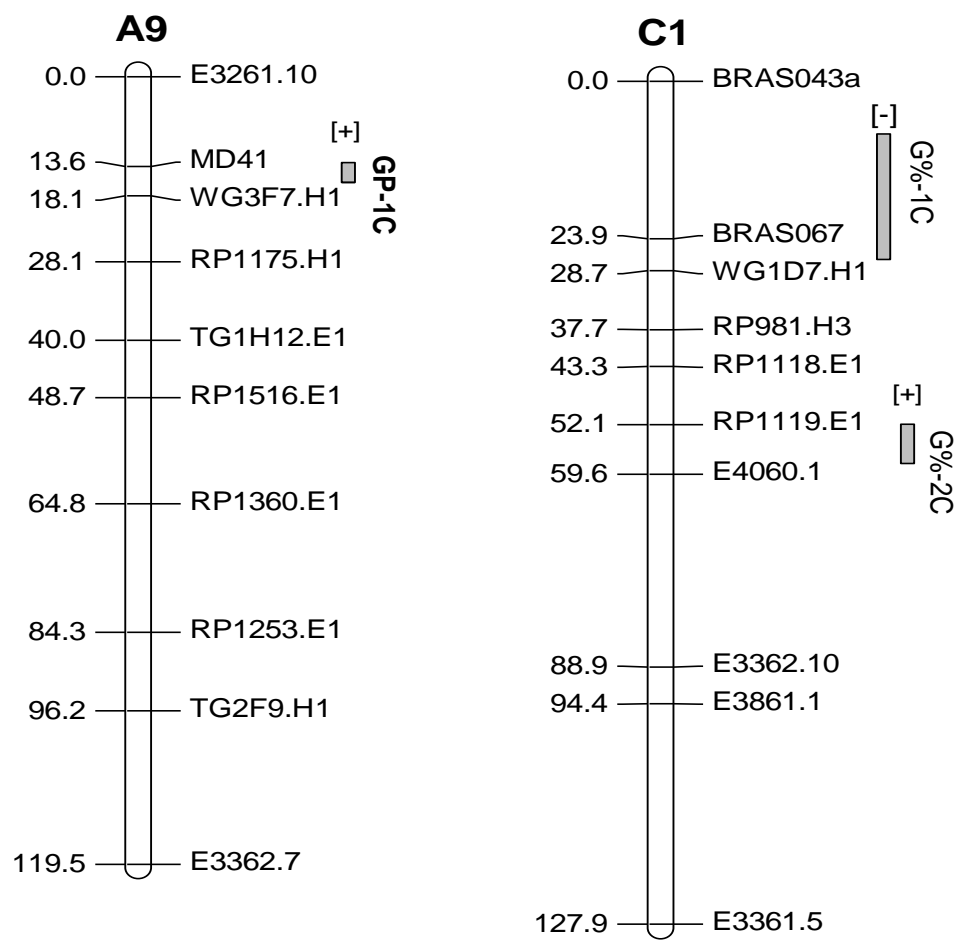

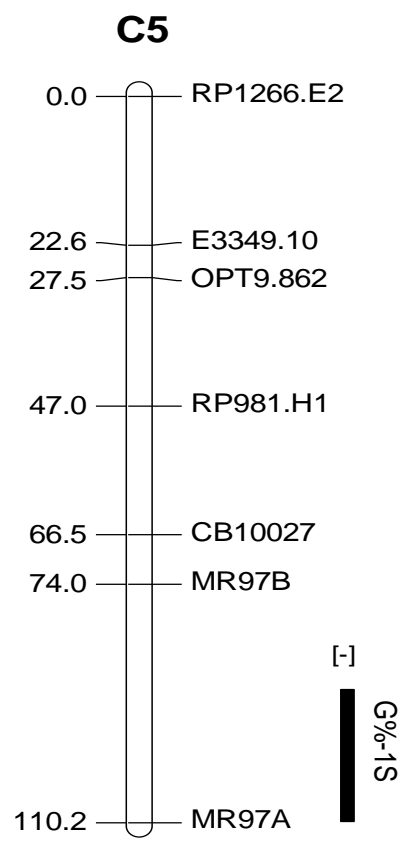

0
0
$\dot{1}$

Figure III-8: Localization of QTL for germination parameters in Brassica napus DH population Mansholts x Samourai. (QTL significant with $P=0.05$ are marked bold) 
C1

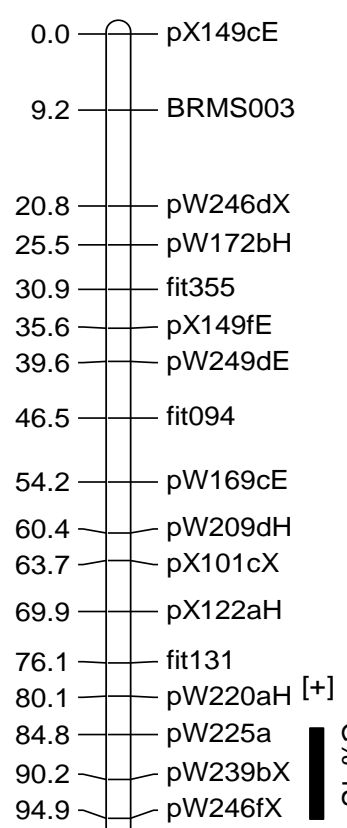

97.6 fit426

$107.7-\mathrm{pW} 248 \mathrm{ax}$

\section{C2}

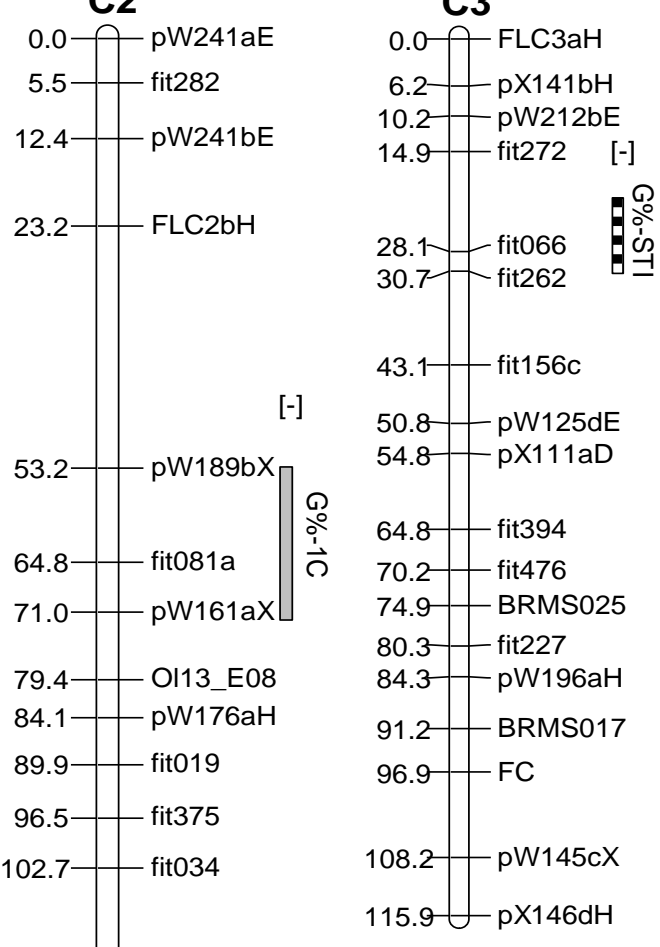

C4

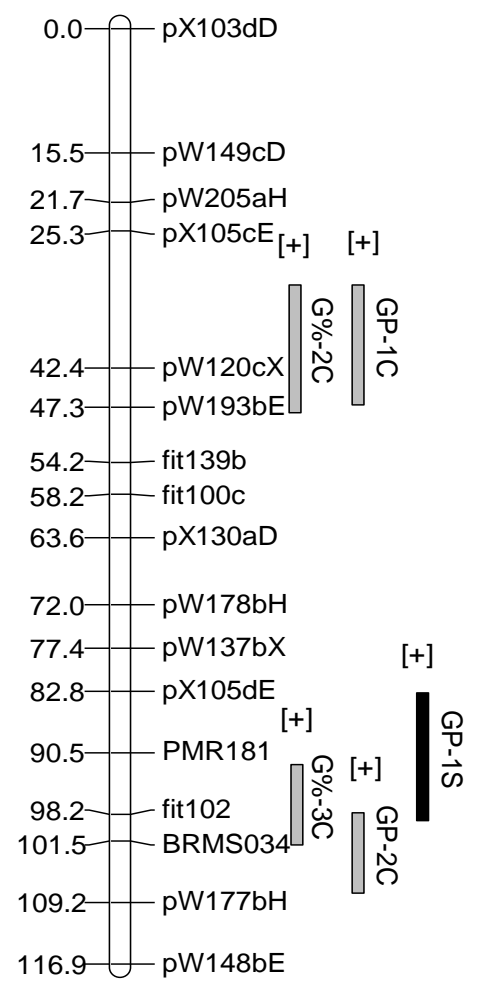

$116.9-p W 148 b E$
C5

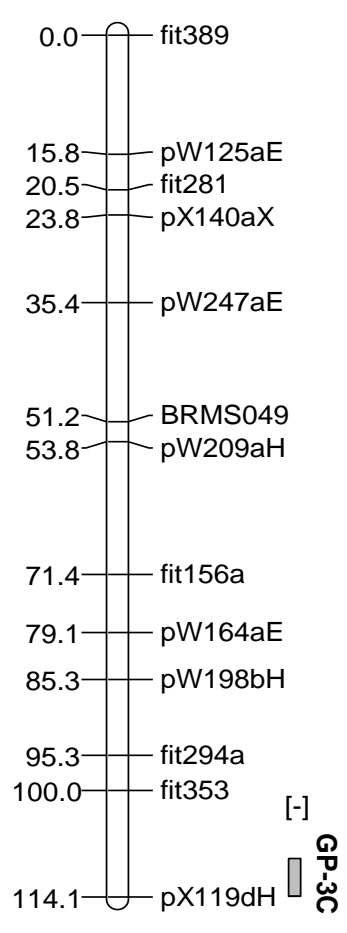

$118.9-p \times 124 c E$

\section{Control \\ Salt}

Figure III-9: Localization of QTL for germination parameters in Brassica oleracea Bo1TBDH population. (QTL significant with $P=0.05$ are marked bold) 


\subsection{Discussion}

\subsubsection{Traits variations}

In the present study, three traits were measured, namely germination percentage (G\%), germination pace (GP), and salt tolerance index (STI). Our results indicate that the impact of salt stress was higher on GP than on G\% because several $\mathrm{DH}$ lines germinated under salt stress with $100 \%$ germination. But the germination rate was slower in the salt stressed plants than in the controls. It is thus clear that no $\mathrm{DH}$ line showed the same GP under both treatments of control and salt. These findings were consistent with the results of Foolad and Jones (1991) in tomato. They found that salinity stress reduced the G\% and retarded the germination rate, which increased the time to complete germination. The variations in the responses of populations to stress depend on the magnitude of the stress and the genetic background of each population (Foolad et al. 1999). Zheng et al. (1998) reported that seed germination and seedling establishment of $B$. napus is delayed and reduced under salinity. In tomato and Arabidopsis, similar results were reported, where salt stress reduced the germination rate, though several genotypes showed the maximum germination level (Foolad et al. 1999; Galpaz and Reymond 2010). A reduction and retardation of germination are mainly due to the high osmotic pressure surrounding the seeds. The high osmotic pressure surrounding the germinated seeds causes water deficiency. The accumulation of $\mathrm{Na}^{+}$and $\mathrm{Cl}^{-}$induces nutrition deficiency, ion toxicity and catabolistic disturbance, or a combination of these; these hazards underlie the retardation of germination (Foolad 1999). Osmotic stress has more impact than ion toxicity. This assumption was strengthened by the findings of Huang and Redman (1995) report that polyethylene glycol (PEG) and $\mathrm{NaCl}$ equally affect equally the germination of $B$. napus. Similarly, in tomato, Foolad et al. (2003) proposed that osmotic pressure was more fatal than ion toxicity. They found a positive correlation between seed germination under both salt stress and drought stress. Furthermore, they found that the genotypes that were selected as salt tolerant also showed drought tolerance. These results suggest the presence of cross-talk between the mechanisms that regulate plant responses to the different abiotic stresses.

\subsubsection{QTL analysis and localization}

For each trait, one or more QTL were identified under control or stress conditions. For instance, in the population of Alesi and H30, two QTL, GP-1C and GP-STI-1, were colocalized on LG A9. Likewise, the two QTL, GP-2C and G\%-1S, were co-localized on LG C1 (Figure 7). This co-localization is expected because these traits are related. Furthermore, STI expresses performance under control and salt stress. This colocalization of QTL on LG A9 indicates that in this genomic region there may be one gene with a pleiotropic effect or two tightly linked genes independently responsible for the variation on these traits. In both cases, on LG A9 and LG C1, the additive effect of the QTL was negative, meaning that the alleles on each LG are in a couple phase. One adaptive QTL GP-3C, which controls the variation under control conditions, was mapped on LG C4b. This means in this genomic region, gene(s) govern (s) the GP variation only under control conditions. Additionally, two constitutive QTL, G\%-STI-1 and GP-STI-2 which regulate the variation of one trait under control and salt stress, 
were mapped on LGs, $A 3$ and A10, respectively. These results indicated that on LGs, A3 and A10, there are genomic regions that harbor gene(s) to control the GP variation under control and salt stress.

Similarly, in the Mansholts and Samourai population two QTL, GP-1S and GP-STI-1, were co-localized on LG A8 (Figure 8). Since, STI expresses the performance under control and salt stress, the QTL related to this trait were constitutive that regulate the variation of the corresponding trait under control and salt stress conditions. The overlapping of these QTL intervals suggests that one gene with pleiotropic effect lies behind the variation of this trait under control and salt stress conditions, or two closely linked genes that control the two traits independently. The additive effect of both QTL was negative. This means that these Mansholts alleles increase the corresponding traits and that they are in a couple phase. Additionally, four adaptive QTL were mapped on LGs; A9, C1 and C5, respectively.

No common QTL were mapped between the two populations of $B$. napus, which indicates that these QTL were population specific. The inconsistency in identifying QTL in different populations and in different environments can be attributed to a number of factors such as different sets of markers, genetic background of parental lines or population types (Collins et al. 2008). In the case of B. napus populations, the most likely explanation would be the difference in parental line sources: there was no common parental line between the two populations. This is consistent with the findings of Monforte et al. (1997) in tomato; they found that the QTL effect varies between populations, depending on the genetic background of the population. Moreover, the QTL effect changes in the presence/absence of salinity. This QTL explained 58\% of fruit fresh weight under non-stress conditions. Under salt stress, this QTL explain 14\% of the variation for the same trait.

In B. oleracea, the Bo1TBDH population the intervals of three constitutive QTL; G\%3C, GP-2C and GP-1S are overlapped on LG C4. Moreover, near the middle of this LG two adaptive QTL are co-localized, namely GP-1C and G\%-2C (Figure 9). In these genomic regions there might be one gene with a pleiotropic effect controlling the variation in these traits. Another possibility is that three genes underlie these trait variations; the alleles for increasing the GP and G\% are descended from TO1000DH3, which are in a couple phase because the additive effect of all QTL was positive. In $B$. oleracea, our results are in agreement with the results of Bettey et al. (2000), who detected four QTL under control condition on LGs: C1, C4, C5 and C6. They detected one QTL under stressful conditions, while we found two QTL; this discrepancy might be due to the different plant materials.

According to Collins et al. (2008), the QTL that were mapped in the three populations can be classified into two types; constitutive QTL, which exist and sustain their effect under both control and salt stress conditions, and adaptive QTL, which control the variation of one trait under either control or salt stress conditions. In all populations, both types were detected. These findings indicate that distinct genomic regions control 
germination both under non-stress and stress conditions, while other genomic regions affect germination either under control or under stress. Our results are in agreement with the findings of other authors for different crops; in tomato (Foolad et al. 1999), in Arabidopsis (Quesada et al. 2002; Clerkx et al. 2004; Galpaz and Reymond 2010) and in B. oleracea (Bettey et al. 2000). These authors speculate that some genomic regions regulate the germination event under control and stress conditions; these QTL are termed stress-nonspecific or constitutive QTL. They also found salt-specific (adaptive) QTL.

A transgressive distribution was found for all traits (Figures 4, 5 and 6). This transgressive segregation indicates that the alleles responsible for increasing or decreasing a particular trait are scattered in the parental lines of each mapping population. Similar results concerning the contribution of salt-sensitive parents in increasing salt tolerance were found in Arabidopsis (Quesada et al. 2002, Clerkx et al. 2004, Galpaz and Reymond 2010), and in tomato (Foolad et al. 1999).

\section{Conclusion}

We observed a large variation in all investigated traits in the tested populations. The effect of salinity on seed germination may be attributed to osmotic stress or ion-toxicity or a combination of both. Mostly, the distribution of the traits was normal, with a transgressive segregation, meaning that both parents could contribute positively to increasing a particular trait. We mapped several QTL underlying seed germination traits such as germination percentage, germination pace and the performance of genotypes under control and salt stress. These results might prove helpful in understanding the genetic and physiological mechanisms that control salt tolerance in the seed germination stage of Brassica species. The markers associated with the mapped QTL can be employed for selecting the best genotypes without further phenotyping evaluation.

Of great importance is the presence of stress-nonspecific QTL that control the seed germination under control and salt stress conditions. Also, the fine mapping of these QTL might help us to uncover the causal genes that reside within their intervals and to understand their contributions. 


\section{Chapter IV}

\section{Mapping QTL for salt tolerance at the young plant stage and leaf glucosinolates in a Brassica napus DH population}

\subsection{Introduction}

Brassica napus originated from interspecific hybridizations between turnip rape (Brassica rapa $\mathrm{AA}, 2 \mathrm{n}=20$ ) and cabbage (Brassica oleracea; CC, $2 \mathrm{n}=18$ ) that occurred spontaneously (Morinaga 1934; U 1935) during medieval times (Iñiguez-Luy and Federico 2011). It is thought to be a relatively new species, about 500 years old, and no wild populations have been recorded (Gómez-Campo and Prakash 1999). Brassica napus has been classified as a moderately salt tolerant plant (Mass and Hoffman 1977). Under salt stress, polyploid species of Brassica such as $B$. napus show superiority over diploid species (Mailk 1990; He and Carmer 1992; Ashraf et al. 2001). Several approaches have been pursued to enhance salinity tolerance in Brassica, such as conventional breeding, somaclonal variation and gene transfer (Purty et al. 2008). Until now, the QTL for salinity tolerance in Brassica species have never been reported, making it difficult to understand the genetic basis of salinity stress tolerance in Brassica species (Nayidu et al. 2013). A number of studies have reported successes in improving salt tolerance in $B$. napus by gene transfer (Huang et al. 2000; Prasad et al. 2000; Zhang et al. 2001; Srivastava et. al. 2004; Song et al. 2014). These reports demonstrate the considerable increase in salt tolerance that can be achieved by single gene overexpression, despite the fact that salt tolerance is a polygenic trait.

Brassica napus has a unique aliphatic glucosinolate profile (Mithen 2001). Our knowledge about the genetic control of leaf glucosinolates (GSL) variation in $B$. napus is rather limited compared to the genetic control of seed glucosinolates. The role of glucosinolates in biotic stresses such as insect attack and pathogens resistance has been energetically studied. In contrast, knowledge of the role of GSL under abiotic stressors such as light, drought, salinity and heat is still vague. Several environmental factors affect the concentration and composition of glucosinolates, such as light, drought, temperature and salinity (Qasim et al. 2003; Velasco et al. 2007; LópezBerenguer et al. 2008; Mewis et al. 2012).

\subsection{The objectives of this chapter are}

1. To analyze the genetic variation of the $B$. napus $\mathrm{DH}$ population under salt stress and to map the QTL which regulate salt tolerance in $B$. napus in the young plant stage.

2. To study the variations in leaf glucosinolates under control and salt stress and to identify the QTL that underlie these variations. 


\section{Part I}

\section{Mapping QTL for salt tolerance at the young plant stage in B. napus}

\subsection{Materials and Methods}

\subsubsection{Plant material}

The plant material consists of 138 doubled-haploid (DH) lines that were developed from crossing Mansholts Hamburger Raps (Mansholts) and Samourai. Mansholts has ++ quality, high erucic acid content and high glucosinolate content. Samourai has 00 quality, low erucic acid content and low glucosinolates content. A full description of this population is provided in Chapter 3 (3.3.1)

\subsubsection{Greenhouse experiment and treats assessment}

The $138 \mathrm{DH}$ lines and their two parents were tested in the greenhouse in two consecutive experiments. The first replicate was sown on October 3, 2012 and harvested on November 5, 2012. The second replicate was sown on November 14, 2012 and harvested on December 19, 2012. The fluctuation in temperature for each replicate and the mean overall temperature and time courses of the two replicates are shown in Appendix 7.

To guarantee homogenous germination, four seeds were sown in $7 \times 7 \mathrm{~cm}$ pots filled with $50 \%$ soil $50 \%$ sand mixture. Each genotype was represented by 5 adjacent pots. The temperature was automatically adjusted to $20^{\circ} \mathrm{C}$ during the day and $15^{\circ} \mathrm{C}$ at night. The relative humidity was approximately 47\%. Plants were exposed to long day conditions, i.e. $16 \mathrm{~h}$ light and $8 \mathrm{~h}$ dark. In addition to daylight, each table was illuminated by two 400-watt SON-T-Agro sodium vapor lamps (Phillips, Netherlands). The average light intensities were $244 \mu \mathrm{mol} / \mathrm{m}^{*}{ }^{*} \mathrm{~s}$ for experiment one and 203 $\mu \mathrm{mol} / \mathrm{m}^{*}{ }^{*} \mathrm{~s}$ for experiment two. The light intensity was measured with Sunscan SS1 (Delta-T, England). The pots were placed on ten tables in the greenhouse. Seven genotypes, namely the two parents and five $\mathrm{DH}$ lines were placed randomly on each table and used for checking. A single row of pots with the commercial cultivar Elektra was placed on along the edges of each table to avoid border effects.

\subsubsection{Germination and establishment}

After sowing, the pots were watered with $100 \mathrm{ml}$ tap water per pot. To keep the soils thoroughly moist and to avoid poor aeration conditions, they were watered by overhead spraying from days seven to day 12 . The first expanded leaf emerged 13 days after sowing (das). The seedlings were thinned into two seedlings per pot. On the $15^{\text {th }}$ das, the watering method was changed to the flooding method where plants received water from the underneath. Each table was filled with 60 I tap water; the water height was about $2 \mathrm{~cm}$ for 2 hours. The water was supplemented with $0.5 \mathrm{~g} / \mathrm{l}$ of the compound fertilizer Hakaphos blue (COMPO, Netherlands).

\subsubsection{Salt stress}

For the salinity treatment, the plants were placed on five tables and watered 23 das, once with a saline solution of $100 \mathrm{mM} \mathrm{NaCl}$, for acclimation. Each table was filled with 
60 I saline solution to a height of about $2 \mathrm{~cm}$. The saline solution was enriched with 1 $\mathrm{g} / \mathrm{l}$ of Hakaphos blue. At day 27, the concentration of the saline solution was increased to the final concentration of $200 \mathrm{mM} \mathrm{NaCl}$ enriched with $1 \mathrm{~g} / \mathrm{l}$ of Hakaphos blue and the plants were watered by flooding as described above twice a week until the end of the experiment at 35 das. Beginning on the $23^{\text {rd }}$ das, the plants on the five tables serving as a control group were watered with the same amount of tap water enriched with $1 \mathrm{~g} / \mathrm{l}$ of Hakaphos blue until the end of the experiment.

\subsubsection{Harvest and biomass}

Thirty-five das, the above-ground parts from four pots were harvested and bulked, and the fresh weight was recorded. All genotypes of each replicate were harvested on the same day. Dry weight was recorded after samples were dried an oven at $60^{\circ} \mathrm{C}$ for 72 hours.

\subsubsection{Relative water content}

The relative water content was calculated as

$$
\mathrm{RWC}=\frac{\mathrm{FW}-\mathrm{DW}}{\mathrm{FW}} \times 100
$$

\subsubsection{Chlorophyll content}

The chlorophyll content was measured twice with a SPAD-Meter Minolta 502 (Osaka, Japan). The first time was six days after start of salt stress (SPAD1) and the second was 12 days after start of salt stress (SPAD2).

\subsubsection{Sodium $\left(\mathrm{Na}^{+}\right)$and Potassium $\left(\mathrm{K}^{+}\right)$analysis}

For the sodium and potassium concentration measurements, the dried samples were pulverized using a coffee grinder (KRUPS 75, Germany). The dried samples of each genotype from replicate one and replicate two were combined. One day before digestion the samples were dried overnight at $100^{\circ} \mathrm{C}$. From each sample $300 \mathrm{mg}$ were placed in the cups of the MLS-MEGA II microwave system (Leutkirch, Germany). Four $\mathrm{ml} 65 \% \mathrm{HNO}_{3}$ and $2 \mathrm{ml} \mathrm{H} \mathrm{O}_{2} 30 \%$ (Roth, Germany) were added to each sample. The samples were placed in the microwave system at $200^{\circ} \mathrm{C}$ for 55 minutes under 15 atm (atmospheric pressure) and cooled for 20 minutes. After digestion, the samples were diluted up to $25 \mathrm{ml}$ using deionized and filtered Seralpur water. Samples were further diluted 1:10 $(0.5 \mathrm{ml}$ plant material extract $+4.5 \mathrm{ml}$ Seralpur water $) . \mathrm{Na}^{+}$and $\mathrm{K}^{+}$concentrations were measured using the flame photometer Eppendorf, Elex 6361 (Hamburg, Germany). The flame photometer was calibrated every ten samples using two calibration standards for both elements; low standard $\left(0 \mathrm{mg} / \mathrm{I} \quad \mathrm{Na}^{+}\right.$and $\left.0 \mathrm{mg} / \mathrm{I} \mathrm{K}^{+}\right)$ and high standard $\left(100 \mathrm{mg} / \mathrm{I} \mathrm{Na}^{+}\right.$and $100 \mathrm{mg} / \mathrm{I} \mathrm{K}$ ). The $\mathrm{Na}^{+}$and $\mathrm{K}^{+}$content were calculated as $\mathrm{mg} \mathrm{g}^{-1} \mathrm{DW}$, and then the $\mathrm{Na}^{+} / \mathrm{K}^{+}$ratio was calculated.

\subsubsection{Glucosinolates analysis}

At 34 das, one pot was harvested for leaf glucosinolates analysis. The leaves were frozen immediately in liquid nitrogen and stored at $-20^{\circ} \mathrm{C}$ until analysis. Leaf 
glucosinolate profile was measured by HPLC (High Pressure Liquid Chromatography) following the method of Kräling et al. (1990). The accuracy of the measurements was controlled by analyzing a seed sample from the standard cultivar Linetta once along with every 20 samples. Samples were lyophilized for $96 \mathrm{~h}$ in the freeze dryer Epsilon 2-40, Christ (Osterode, Germany). The samples were pulverized in a shaker with 4 2.3-mm balls; $200 \mathrm{mg}$ of the pulverized plant material were weighed in a $13 \mathrm{ml}$ polypropylene tube. For the extraction step, three $\mathrm{ml}$ of $70 \%$ methanol and $200 \mu \mathrm{l}$ of internal standard $\left(6 \mathrm{mmol} \mathrm{\textrm {L } ^ { - 1 }}\right)$ glucotropeolin were added. The tubes were vortexed and incubated $\left(10 \mathrm{~min}, 75^{\circ} \mathrm{C}\right)$ in a water bath. The samples were shaken occasionally. After extraction, samples were centrifuged (5 minutes; $4000 \mathrm{rpm}$ (rounds per minute)). The supernatants were transferred into empty labelled tubes. For the second extraction, two $\mathrm{ml}$ of $10 \%$ methanol were added to the pellets, and then the tubes were vortexed and incubated $\left(10 \mathrm{~min}, 75^{\circ} \mathrm{C}\right)$ in a water bath. The samples were shaken occasionally. After centrifugation (5 minutes, $4000 \mathrm{rpm}$ ), each supernatant was combined and mixed with the preceding one, and the pellets were discarded. After that, $500 \mu \mathrm{L}$ of the extract were pipetted on a column filled with $20 \mathrm{mg}$ DEAE Sephadex A-25(S 9626; Sigma-Aldrich, D-82024 Taufkirchen). The column was washed twice with one $\mathrm{ml}$ deionized water. For desuphatising, $100 \mu \mathrm{L}$ of sulphatase (Sigma- Aldrich) solution were added, and then the columns were incubated overnight at $39^{\circ} \mathrm{C}$. The columns were flushed 3 times with $500 \mu \mathrm{L}$ deionized water to elute the desulpho-glucosinolates in three $\mathrm{ml}$ polypropylene tube. $700 \mu \mathrm{L}$ were pipetted in the HPLC vials for HPLC (125 93 mm Nucleodur 100-3 C18ec column; Machery-Nagel $\mathrm{GmbH}$ \& Co KG, D-52313 Düren) analysis followed by UV detection (UV-VIS Detector L4250 Merck Hitachi).

\subsubsection{Statistics}

Before the analysis of variance, the value of each replicate's genotype, in the growth traits experiments as well as in the glucosinolate analyses, was adjusted using the moving average method implemented with the software PlabSTAT 3.0 (Utz, 2003). The model is described in Chapter 3 (3.5).

\section{Trait abbreviations}

Fresh weight (g) FW

Dry weight (g) DW

Relative water content RWC

Chlorophyll content measured by SPAD1 and SPAD2

Sodium content (mg/ g DM) $\mathrm{Na}^{+}$

Potassium content (mg/g DM) $\mathrm{K}^{+}$

Sodium /Potassium ratio $\mathrm{Na}^{+} / \mathrm{K}^{+}$

Dry matter DM

\section{Parental lines abbreviations}

$M=$ Mansholts $S=$ Samourai 


\subsection{Results I}

\subsubsection{Traits variations}

Minor differences were observed between the parental lines with regard to all of the traits measured: FW, DW, RWC, SPAD1, SPAD2, $\mathrm{Na}^{+} \mathrm{mg} / \mathrm{g} \mathrm{DM}, \mathrm{K}^{+} \mathrm{mg} / \mathrm{g} \mathrm{DM}$ and $\mathrm{Na}^{+} / \mathrm{K}^{+}$under both control and salt stress conditions, but these variations were notably wide in the $\mathrm{DH}$ population. Additionally, the variation in $\mathrm{DH}$ lines for the $\mathrm{FW}$ under salt stress was greater than that under the control. Under both conditions, a large number of $\mathrm{DH}$ lines showed lower biomass yield than the parental lines. Nevertheless, there was a transgressive segregation (Figure 1a, b, c, d, e, f). The genetic variance and the heritability estimated from the analysis of variance (ANOVA) for each trait under control and stress conditions are summarized in Table 1 and the maximum, minimum and mean values in Appendix 6.

\section{Fresh weight}

Under control conditions, out of $138 \mathrm{DH}$ lines, $11 \mathrm{DH}$ lines (7.9\%) had a higher biomass yield than the parent with the high biomass yield, namely Mansholts. A large number 117 (84\%) DH lines had lower values than the parent with the low biomass yield, i.e. Samourai. The minimum was $2.1 \mathrm{~g}$ and the maximum was $7.32 \mathrm{~g}$. Under salt stress, $26 \mathrm{DH}$ lines (18\%) produced higher FW than the high-FW-yielding parent, Mansholts, and $88 \mathrm{DH}$ lines (63\%) had FW values lower than the low-biomass-yielding parent, Samourai (Figure 1a, b).

\section{Dry weight}

Under control conditions, $126 \mathrm{DH}$ lines (91\%) showed a DW lower than the weaker parent, Samourai, whereas only $10 \mathrm{DH}$ lines $(7 \%)$ revealed a DW higher than the stronger parent, Mansholts. The DW values ranged from $0.34 \mathrm{~g}$ to $0.93 \mathrm{~g}$. Even with salt stress, the performance of seven $\mathrm{DH}$ lines (5\%) was better than that of the highperformance parent, Mansholts. $129 \mathrm{DH}$ lines (94\%) exhibited weak performance, giving a DW lower than that of the parent with low dry weight, i.e. Samourai (Figure 1c, d).

\section{Relative water content}

The distribution of RWC shows the presence of transgressive segregation (Figure 2a, b). Under control conditions, $42 \mathrm{DH}$ lines (30\%) had a higher RWC value than the parent with the high value, and $69 \mathrm{DH}$ lines (50\%) had lower values than the parent with the lower RWC. The values ranged from 82 to 92 . Under salt stress, only one genotype had a lower value than Samourai, whereas, a large number $(122=88 \%)$ of the $\mathrm{DH}$ lines had higher values than the tolerant parent, Mansholts.

\section{Chlorophyll content measured by SPAD}

Figure $3 a, b$, shows the distribution of chlorophyll content measured under control and salt stress conditions for SPAD1 six days after starting the salt stress. Under control conditions, $125 \mathrm{DH}$ lines (92\%) had lower values than Samourai and $3 \mathrm{DH}$ lines (2\%) showed values higher than Mansholts; the range was from 20 to 44 . Under salt stress, $113 \mathrm{DH}$ lines (81.8\%) showed values lower than Samourai and $8 \mathrm{DH}$ lines (6\%) 
exhibited values higher than Mansholts; the values varied from 36 to 49 . SAPD2 values were measured 12 days after applying salt stress. Regarding the controls, 79 $\mathrm{DH}$ lines (57\%) had SPAD values lower than Samourai and eight DH lines (6\%) showed values greater than Mansholts. The minimum and maximum values were 20 and 45, respectively. For salinity, the distribution was similar to that of the controls; with $79 \mathrm{DH}$ lines $(57 \%)$ having SPAD values lower than Samourai and eight DH lines (6\%) showing values greater than Mansholts. An increase in SPAD values under salt stress was observed, the SPAD2 values ranging from 36 to 53 (Figure 3c, d).

\section{Sodium content}

Figure $4 \mathrm{a}, \mathrm{b}$ shows the distribution of $\mathrm{Na}^{+} \mathrm{mg} / \mathrm{g}$ DM. A transgressive segregation was observed under control and salt stress. Regarding control, 48 (35\%) of the $\mathrm{DH}$ lines were lower than the parent with low $\mathrm{Na}^{+}$content (Mansholts) and 64 (46\%) of the $\mathrm{DH}$ lines had $\mathrm{Na}^{+}$content higher than the parent with high $\mathrm{Na}^{+}$content (Samourai). The values ranged from $0.76 \mathrm{mg} / \mathrm{g} \mathrm{DM}$ to $2.4 \mathrm{mg} / \mathrm{g}$ DM. Under salt stress, a dramatic increase in $\mathrm{Na}^{+}$was observed compared to the $\mathrm{Na}^{+}$content under control. Out of 138 $\mathrm{DH}$ lines, $56 \mathrm{DH}$ lines (41\%) had $\mathrm{Na}^{+}$content lower than Mansholts, and 70 (51\%) of the $\mathrm{DH}$ lines had a $\mathrm{Na}^{+}$content higher than Samourai. The range here was between $14.6 \mathrm{mg} / \mathrm{g} \mathrm{DM}$ and $36 \mathrm{mg} / \mathrm{g} \mathrm{DM}$.

\section{Potassium content}

Compared to the difference in sodium content between controls and salt stressed plants, the difference between the potassium levels of plants under control and salt stress conditions was small. For the controls, it varied from $34 \mathrm{mg} / \mathrm{g}$ DM to $81 \mathrm{mg} / \mathrm{g}$ $\mathrm{DM}$ and for plants under salt stress it ranged from $30 \mathrm{mg} / \mathrm{g} \mathrm{DM}$ to $63 \mathrm{mg} / \mathrm{g} \mathrm{DM}$. The distribution of $\mathrm{K}^{+}$content in the $\mathrm{DH}$ lines showed a transgressive segregation under control conditions, where $53 \mathrm{DH}$ lines (38\%) of the population showed values lower than Mansholts, the parent with the lower $\mathrm{K}^{+}$content. A set of $62 \mathrm{DH}$ lines (45\%) exhibited higher values than Samourai, the parent with the high $\mathrm{K}^{+}$content. Under salt stress, $65 \mathrm{DH}$ lines (47\%) exhibited a $\mathrm{K}^{+}$content lower than that of the parent with low $\mathrm{K}^{+}$content (Mansholts) and $64 \mathrm{DH}$ lines (46\%) exceeded the value of the parent with high $\mathrm{K}^{+}$content (Samourai) (Figure 4c, d).

\section{Sodium Potassium ratio}

Under control conditions, $42 \mathrm{DH}$ lines (30 \%) exhibited $\mathrm{Na}^{+} / \mathrm{K}^{+}$lower than Mansholts, the parent with low $\mathrm{Na}^{+} / \mathrm{K}^{+}$, whereas $77 \mathrm{DH}$ lines (55\%) had a higher $\mathrm{Na}^{+} / \mathrm{K}^{+}$than Samourai, the parent with high $\mathrm{Na}^{+} / \mathrm{K}^{+}$. Under salt stress, a group of $62 \mathrm{DH}$ lines (45\%) had lower values than Mansholts and $43 \mathrm{DH}$ lines, accounting for 31\%, showed $\mathrm{Na}^{+} / \mathrm{K}^{+}$values higher than Samourai (Figure 4e, f). Regarding the control, the differences between genotypes ranged from 0.02 to 0.07 . The variations between the $\mathrm{DH}$ lines under salt stress ranged between 0.27 and 0.76 .

\subsubsection{Correlations}

The developmentally related traits revealed positive and significant correlations. For example, the correlation between FW and DW was high and significant under both 
conditions $\left(r=0.75^{\star \star}\right)$ and $\left(r=0.86^{\star \star}\right)$ for control and salt conditions, respectively. Likewise, SPAD1 and SPAD2 were positively and significantly correlated $\left(r=0.67^{* *}\right)$, and $\left(r=0.72^{\star *}\right)$ under control and salt conditions, respectively (Tables 2 and 3 ). The correlation between $\mathrm{FW}$ and other traits was positive but non-significant with SPAD1, SPAD2, $\mathrm{K}^{+}$and $\mathrm{Na}^{+} / \mathrm{K}^{+}$under control conditions (Table 2 and 3). Under salt stress, the correlation of FW was negative and significant $\left(r=-0.21^{*}\right)$ and $\left(r=0.20^{\star}\right)$, for $\mathrm{Na}^{+}$and $\mathrm{Na}^{+} / \mathrm{K}^{+}$respectively. Under control conditions, DW correlated positively and significantly $\left(r=0.20^{*}\right)$ and $\left(r=0.20^{*}\right)$ for SPAD1 and SPAD2 respectively. Under salt stress, the correlation for DW was positive and significant $\left(r=0.33^{\star}\right)$ and $\left(r=0.24^{\star}\right)$ for SPAD1 and SPAD2, respectively. The remaining traits showed a negative significant correlation with DW, with the exception of $\mathrm{K}^{+}$, which showed a positive significant correlation under salt stress (Tables 2, and 3). The correlation between RWC and all traits was negative and significant, except for $\mathrm{Na}^{+}$, where it was positive $\left(r=0.44^{\star \star}\right)$ and $\left(r=0.34^{\star \star}\right)$ under control and salt stress, respectively. The RWC showed a positive and significant correlation with $\mathrm{K}^{+}\left(r=0.69^{* *}\right)$ and $\left(r=0.23^{\star *}\right)$ under control and salt stress, respectively (Tables 2 and 3). The correlation of SPAD1 and SPAD2 under control and under salt stress was significant and negative with the remaining traits. Under salt stress, the correlation of SPAD1 and SPAD2 was negative and significant only with RWC (Tables 2 and 3). Under control conditions, the correlation of $\mathrm{Na}^{+}$content was weak and positive with FW and DW, whereas the correlation of SPAD1 and SPAD2 was negative and significant. Under salt stress, the correlation between $\mathrm{Na}^{+}$content for the remaining traits was negative and significant, but for RWC, the correlation was positive and significant (Tables 2 and 3). Under control conditions, $\mathrm{K}^{+}$correlated positively and significantly with DW, RWC, and $\mathrm{Na}^{+}$content, but negatively and significantly with SPAD1 and SAPD2. Under salt stress, the correlation between $\mathrm{K}^{+}$and the remaining traits was positive, except for SPAD1 and $\mathrm{Na}^{+}$(Tables 2 and 3). 
Table IV-1: Mean squares and F test of significance from the ANOVA and heritabilities of fresh weight (FW), dry weight (DW), relative water content, chlorophyll content measured by SPAD (SPAD1, SPAD2) of Brassica napus DH population Mansholts $x$ Samourai, 138 $\mathrm{DH}$ lines were tested under control conditions and at salt treatment $(200 \mathrm{mM} \mathrm{NaCl})$

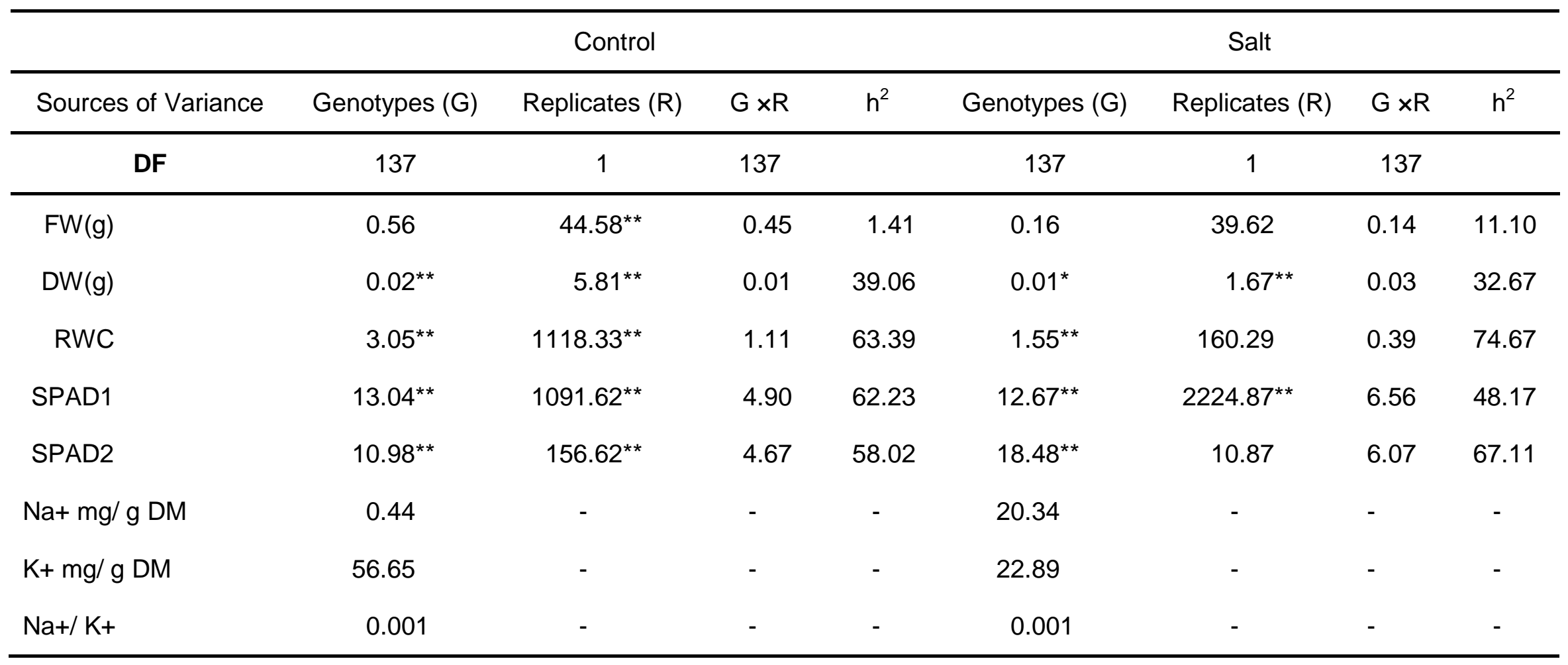

** Significant at $P=0.01 ;$ * significant at $P=0.05$ and + significant at $P=0.1$

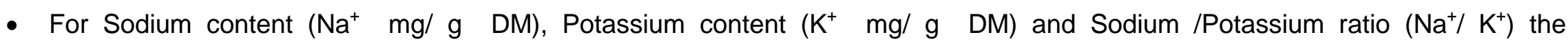
dry matter of each genotype of replicate one was combined with replicate two, therefore there were no replication and no heritability was calculated for these traits. 
a) Control

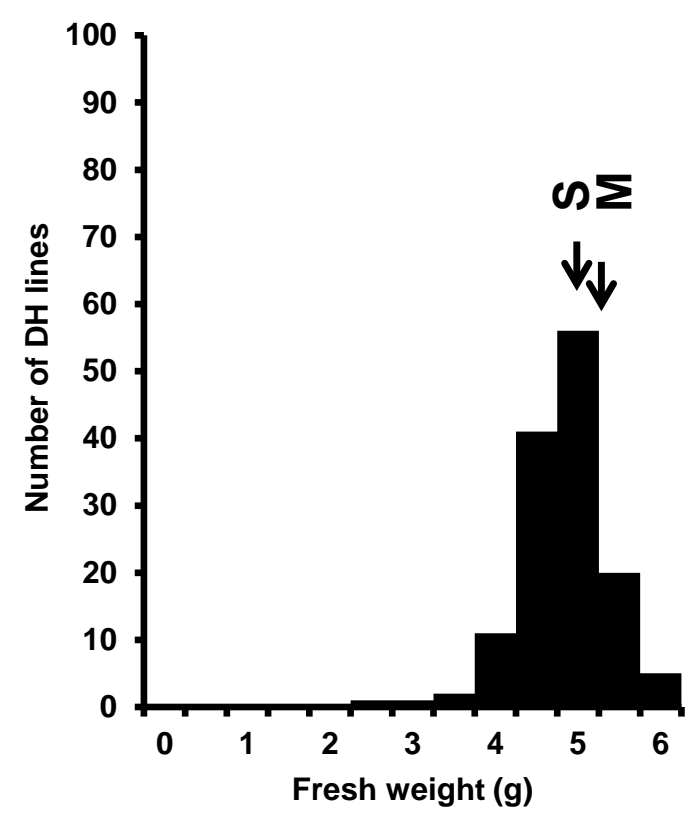

c) Control

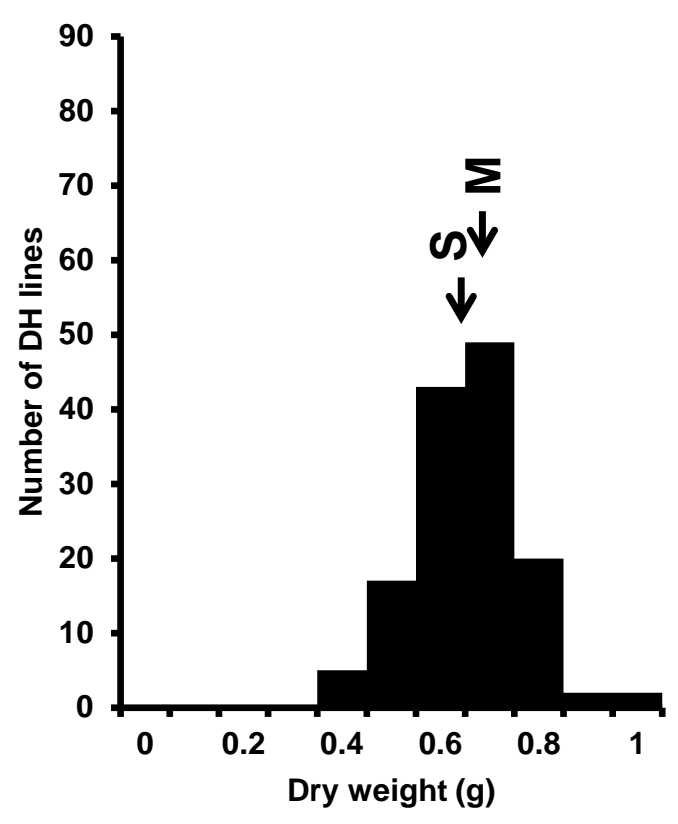

b) Salt

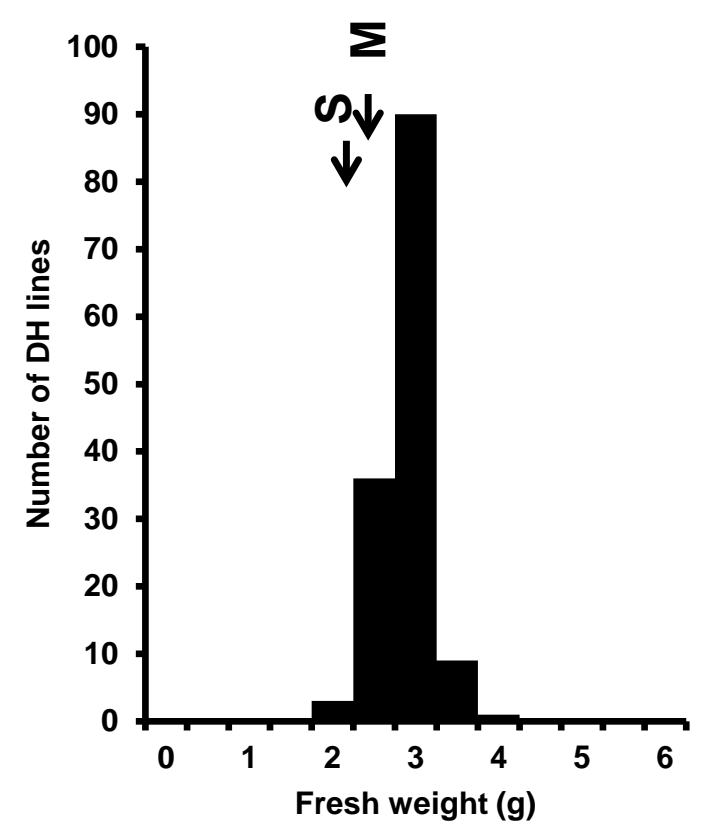

d) Salt

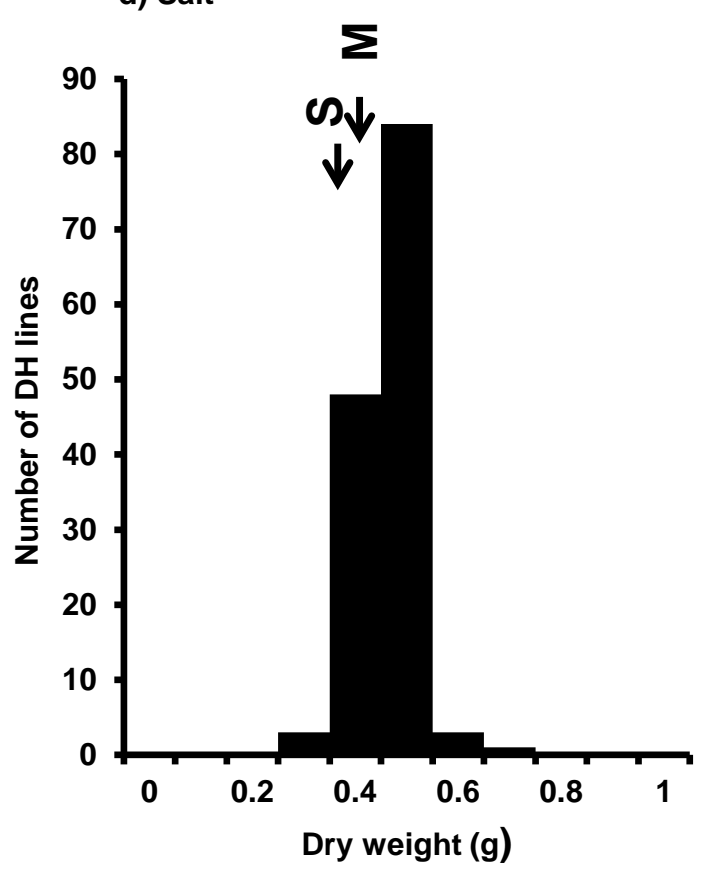

Figure IV-1: Frequency distribution of fresh and dry weight of Brassica napus DH population Mansholts $\times$ Samourai. a) Fresh weight under control, b) Fresh weight under salt stress, c) Drv weiaht under control and d) Drv weiaht under salt stress 
a) Control

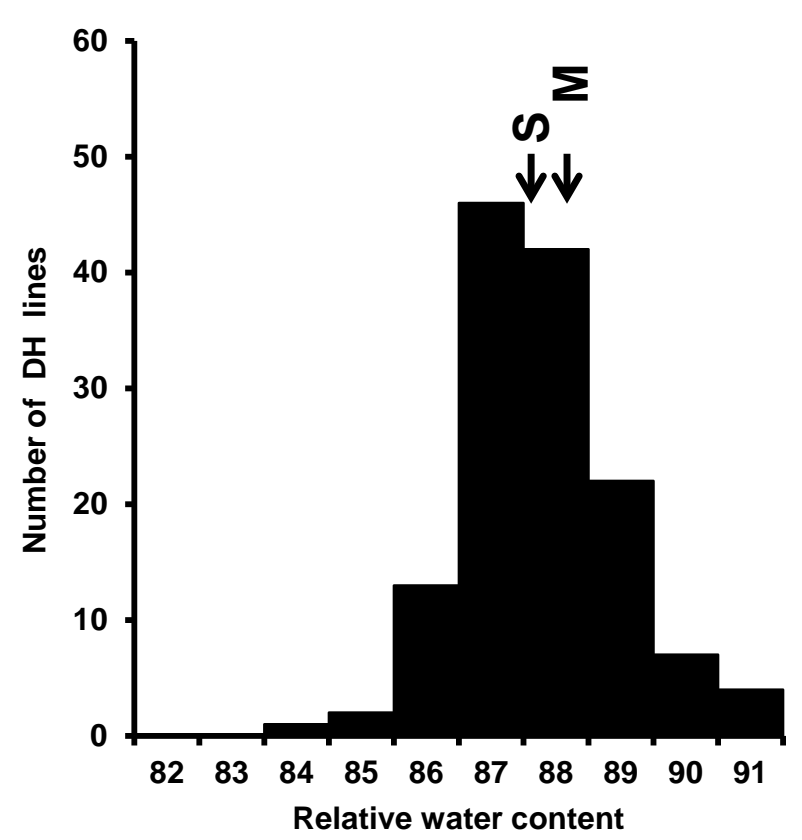

b) Salt

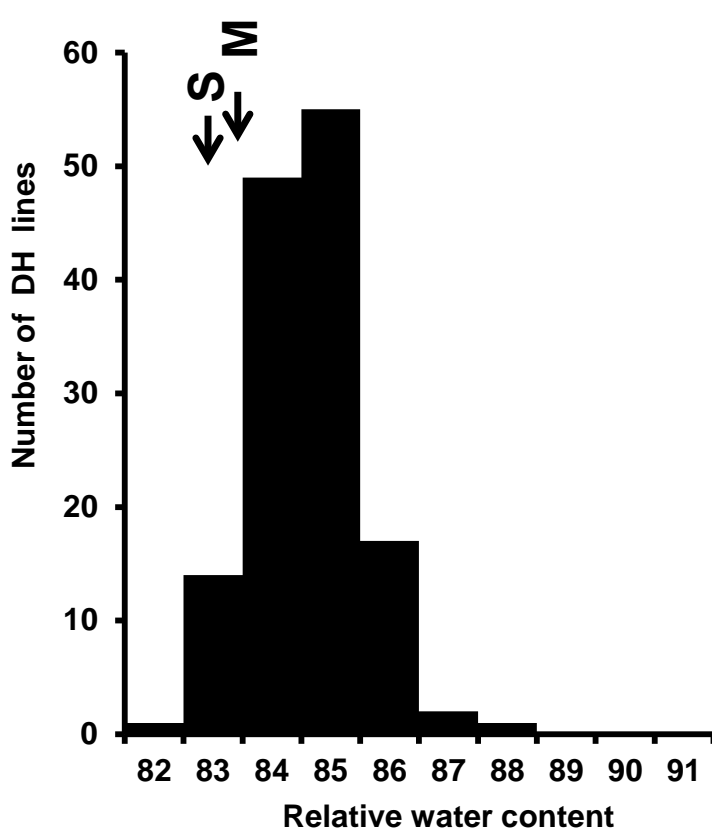

Figure IV-2: Frequency distribution of relative water content of Brassica napus $\mathrm{DH}$ population Mansholts $\times$ Samourai. a) Relative water content under control and b) Relative water content under salt stress 
a) Control

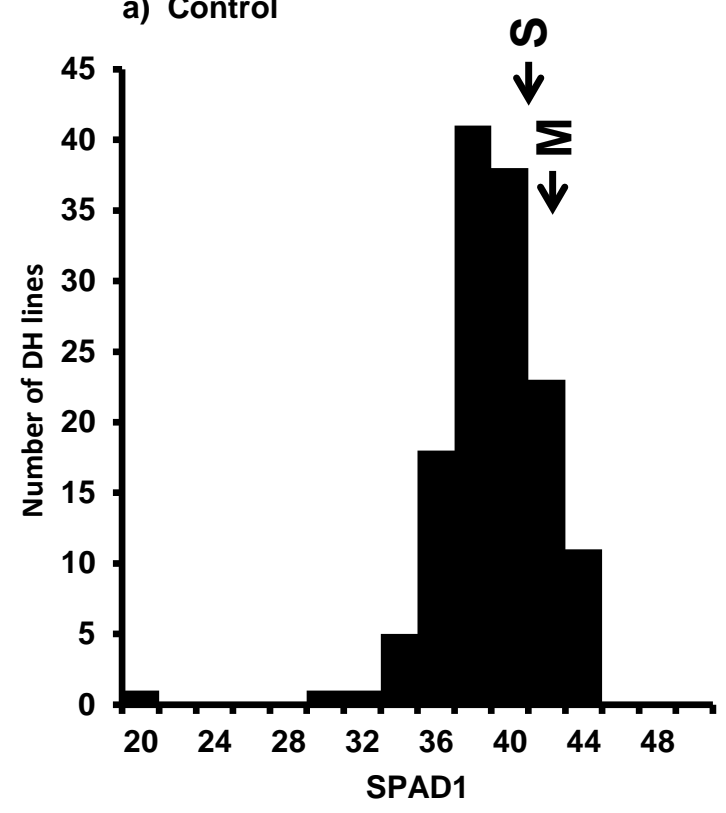

c) Control

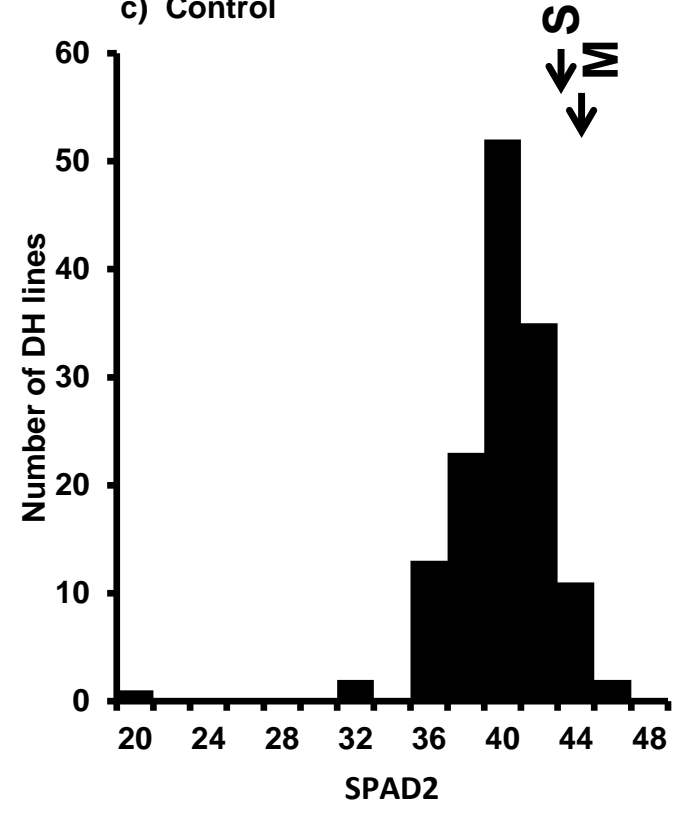

b) Salt

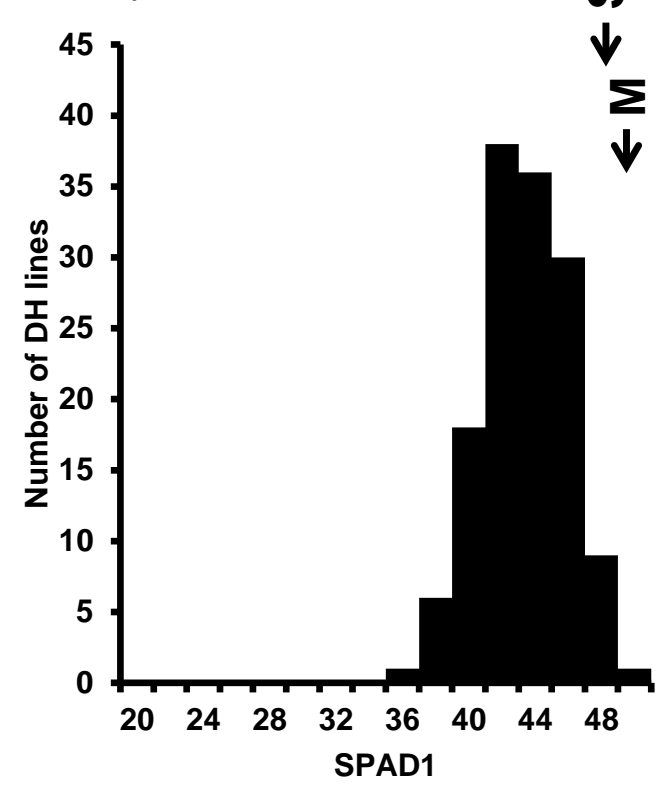

d) Salt

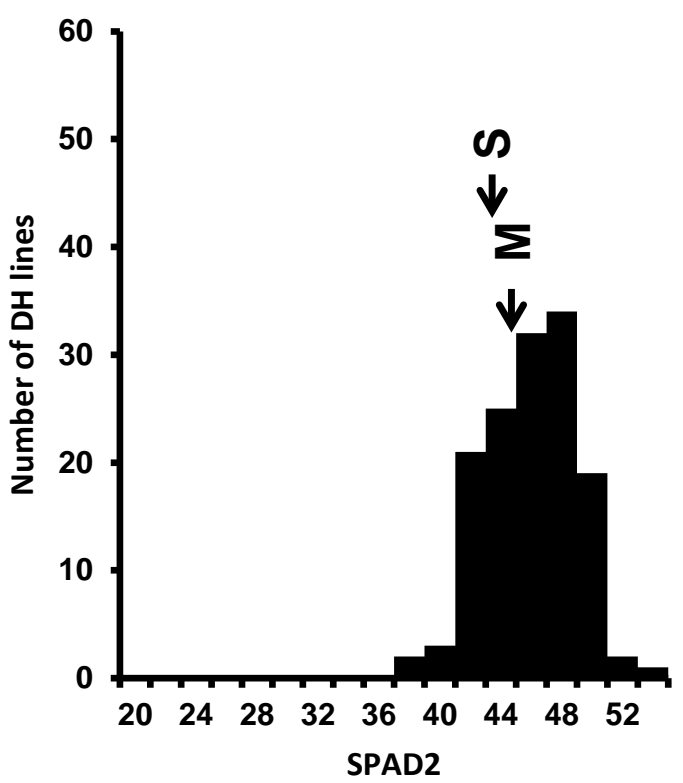

Figure IV-3: Frequency distribution of chlorophyll content measured by SPAD of Brassica napus DH population Mansholts $\times$ Samourai. a) SPAD1 under control and b) SPAD1 under salt stress, c) SPAD2 under control and d) SPAD2 under salt stress 
a) Control

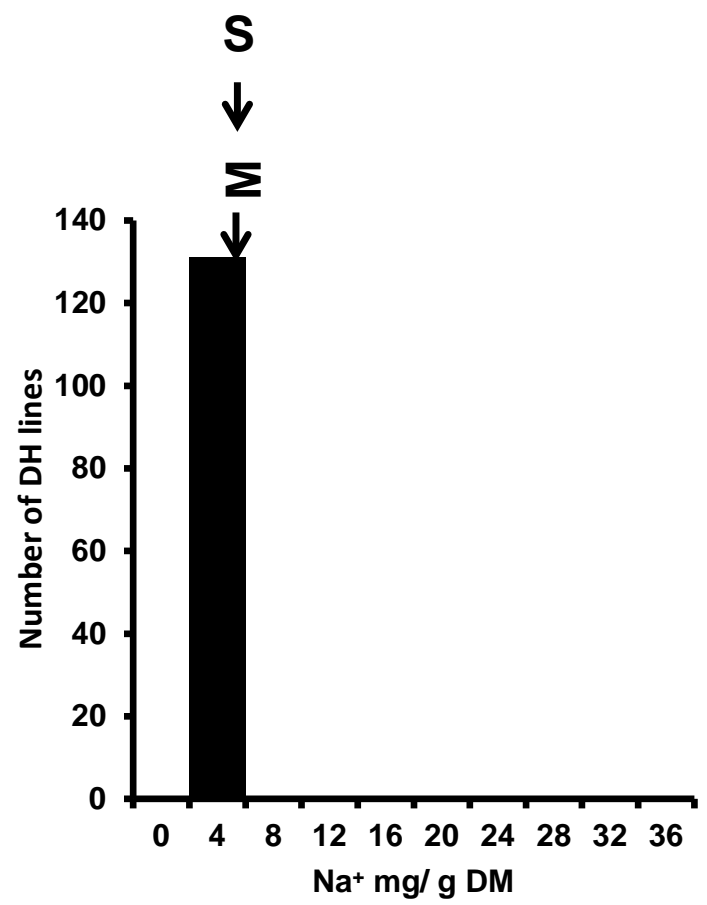

c) Control

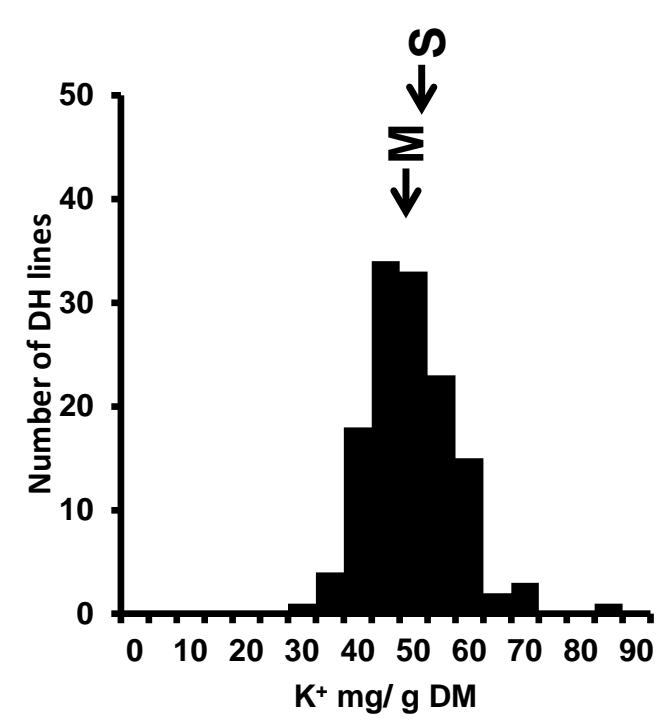

b) Salt

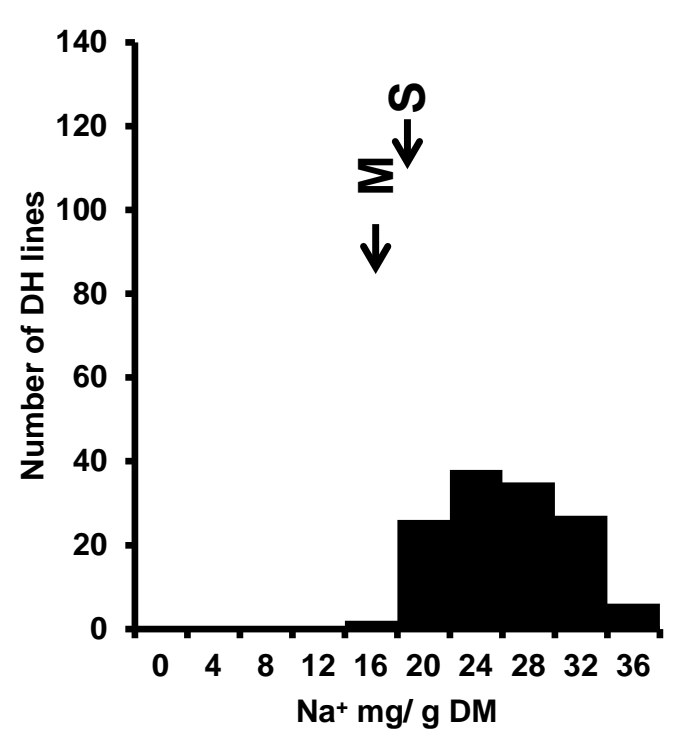

d) Salt

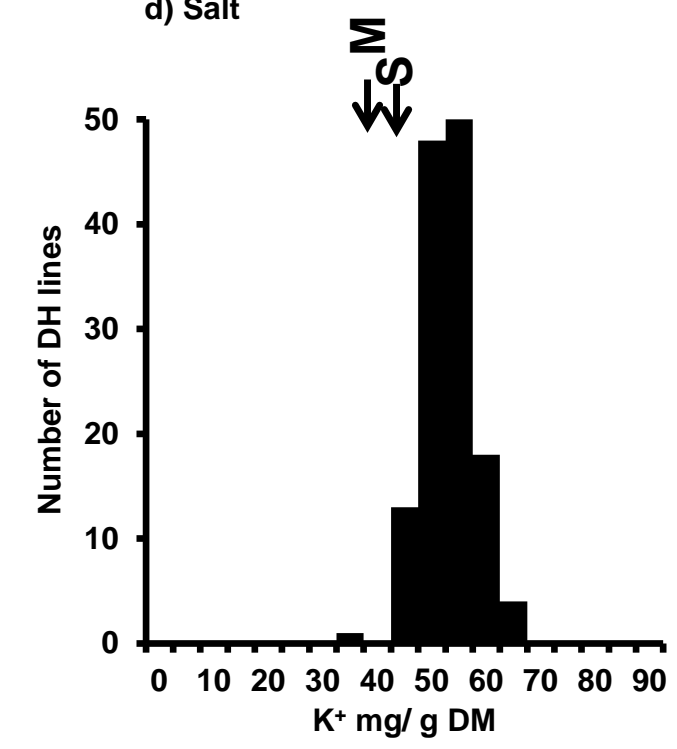

Figure IV-4: Frequency distribution of sodium content $\mathrm{Na}^{+} \mathrm{mg} / \mathrm{g} \mathrm{DM}$ and potassium content $\mathrm{K}^{+} \mathrm{mg} / \mathrm{g}$ DM of Brassica napus DH population Mansholts $\times$ Samourai. a) sodium content at control and b) Sodium content under salt stress, C) potassium content under control and d) Potassium content under salt stress, e) $\mathrm{Na} / \mathrm{K}$ ratio under control and f) $\mathrm{Na} / \mathrm{K}$ ratio under salt stress 
Figure IV-4 continued from page 70

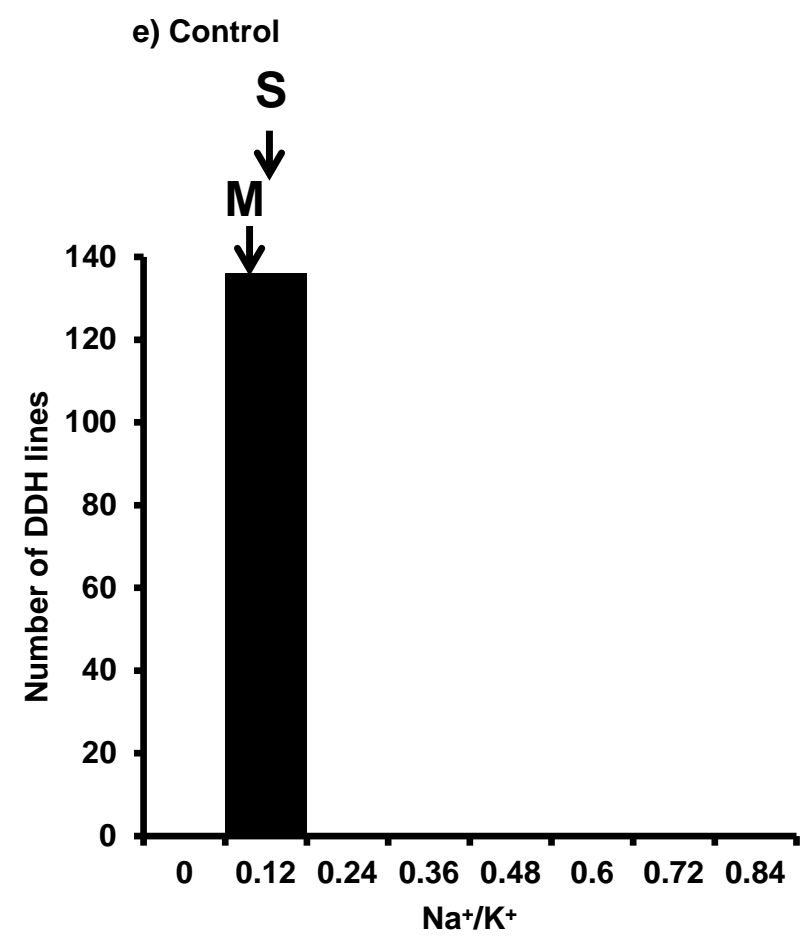

f) Salt

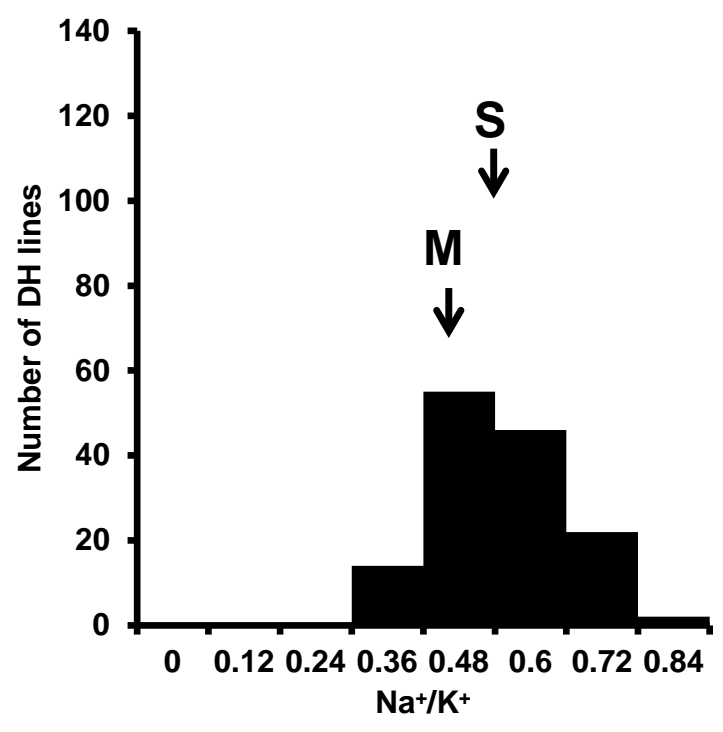


Table IV-2: Spearman's rank correlations of the estimated traits in Brassica napus mapping population Mansholts $\times$ Samourai under control

\begin{tabular}{|c|c|c|c|c|c|c|c|}
\hline & $F W(g)$ & Dw (g) & SPAD1 & SPAD2 & RWC & $\mathrm{Na}^{+} \mathrm{mg} / \mathrm{g} \mathrm{DM}$ & $\mathrm{K}^{+} \mathrm{mg} / \mathrm{g} \mathrm{DM}$ \\
\hline Dw (g) & $0.75^{\star \star}$ & & & & & & \\
\hline SPAD1 & 0.03 & $0.20 *$ & & & & & \\
\hline SPAD2 & 0.10 & $0.2^{*}$ & $0.69^{\star \star}$ & & & & \\
\hline RWC & -0.10 & $-0.61^{* *}$ & $-0.30 * \star$ & $-0.29 * *$ & & & \\
\hline $\mathrm{Na}^{+} \mathrm{mg} / \mathrm{g} \mathrm{DM}$ & -0.10 & 0.30 & $-0.29 * \star$ & $-0.18^{\star}$ & $0.43^{\star \star}$ & & \\
\hline $\mathrm{K}^{+} \mathrm{mg} / \mathrm{g} \mathrm{DM}$ & 0.13 & $0.58^{\star \star}$ & $-0.26^{\star *}$ & $-0.20 *$ & $0.68^{* *}$ & $0.67^{\star \star}$ & \\
\hline $\mathrm{Na}^{+} / \mathrm{K}^{+}$ & 0.001 & 0.06 & $-0.20^{*}$ & -0.10 & -0.03 & $0.60^{\star \star}$ & -0.10 \\
\hline
\end{tabular}

Table IV-3: Spearman's rank correlations of the estimated traits in Brassica napus mapping population Mansholts $\times$ Samourai under salt stress $(200 \mathrm{mM} \mathrm{NaCl})$

\begin{tabular}{|c|c|c|c|c|c|c|c|}
\hline & $F W(g)$ & Dw (g) & SPAD1 & SPAD2 & RWC & $\mathrm{Na}^{+} \mathrm{mg} / \mathrm{g} \mathrm{DM}$ & $\mathrm{K}^{+} \mathrm{mg} / \mathrm{g} \mathrm{DM}$ \\
\hline Dw & $0.86^{\star \star}$ & & & & & & \\
\hline SPAD1 & 0.14 & $0.32^{\star \star}$ & & & & & \\
\hline SPAD2 & 0.08 & $0.23^{\star \star}$ & $0.72^{\star \star}$ & & & & \\
\hline RWC & -0.05 & $-0.47^{\star *}$ & $-0.38^{\star \star}$ & -0.30 ** & & & \\
\hline $\mathrm{Na}^{+} \mathrm{mg} / \mathrm{g} \mathrm{DM}$ & $-0.20^{*}$ & $-0.34^{\star \star}$ & -0.04 & -0.12 & $0.33^{\star *}$ & & \\
\hline $\mathrm{K}^{+} \mathrm{mg} / \mathrm{g} \mathrm{DM}$ & 0.06 & $0.17^{*}$ & -0.08 & 0.03 & $0.28^{* *}$ & -0.11 & \\
\hline $\mathrm{Na}^{+} / \mathrm{K}^{+}$ & $-0.20^{*}$ & -0.03 & -0.01 & -0.11 & $0.18^{*}$ & $0.90^{\star *}$ & -0.50 ** \\
\hline
\end{tabular}




\subsubsection{QTL analysis and localization}

The framework maps and the QTL mapping protocol are described earlier in Chapter 3 (3.3.4).

Twenty-eight QTL were identified for FW, DW, RWC, SPAD1, SPAD2, $\mathrm{Na}^{+} \mathrm{mg} / \mathrm{g} \mathrm{DM}$, $\mathrm{K}^{+} \mathrm{mg} / \mathrm{g} \mathrm{DM}$ and $\mathrm{Na}^{+} / \mathrm{K}^{+}$. Under control conditions, $13 \mathrm{QTL}$ were identified for all traits and 15 for all traits under salt stress. The localization, additive effect, names of the mapped QTL on (LGs) for all traits under control and salt stress are shown in Figure 5. More details on the flanking markers, intervals, additive effect and logarithm of odds (LODs) are summarized in Tables 4 and 5 . Where the additive effect is positive, this means that the Mansholts alleles increase the corresponding trait, while a negative additive effect indicates that the Samourai alleles increase the trait.

\section{Fresh weight}

Two QTL were identified. One is the QTL under control conditions FW-1C on LG A6, which explains $5 \%$ of the phenotypic variation with a negative additive effect. The second QTL was scored under salt stress on LG C3, which explains $7 \%$ of the phenotypic variation with a positive additive effect.

\section{Dry weight}

Five QTL were detected; three of which were under control conditions: DW-1C, DW$2 \mathrm{C}$ and DW-3C on the LGs A5, C2 and C3, respectively, accounting for $31 \%$ of the phenotypic variation. DW-2C was mapped at a significance level of $P=0.05$ and explains $17 \%$ of the phenotypic variation. The additive effect was negative for DW-1C and positive for DW-2C and DW-3C. Under salt stress, two QTL, DW-1S and DW-2S, were localized on the LGs C3 and C6, respectively. They jointly explained $18 \%$ of the phenotypic variation. The two QTL were detected at significance level $P=0.05$ with a positive additive effect.

\section{Relative water content}

Under control conditions, two QTL, RWC-1C and RWC-2C, were identified on the LGs C2 and C3, respectively. Together, they explain $26 \%$ of the phenotypic variation with a negative additive effect for both of them. RWC-1C was recognized at a significance level $P=0.05$ and alone accounted for $17 \%$ of the explained phenotypic variation. Under salt stress, one QTL, namely RWC-1S, was found on LG C3, which explains $8 \%$ of the phenotypic variation with a negative additive effect.

\section{Chlorophyll content after six days of salt stress (SPAD1)}

QTL mapping for this trait identified six QTL. For the controls, three QTL, SPAD1-1C, SPAD1-2C and SPAD1-3C, were detected on the LGs A9, C2 and C6, respectively. The additive effects of all QTL were positive. These QTL jointly explain $43 \%$ of the phenotypic variation. SPAD1-1C, SPAD1-2C were mapped at $P=0.05$. Likewise, under salt stress, three QTL, SPAD1-1S, SPAD1-2S and SPAD1-3S, were mapped on the LGs $A 1, A 9$ and $C 2$, respectively. SPAD1-3S was localized at $P=0.05$ and explains $15 \%$ of the phenotypic variation. Collectively, these three QTL explain $37 \%$ of 
the phenotypic variation. SPAD1-2S and SPAD1-3S show a positive additive effect, while SPAD1-1S shows a negative additive effect.

\section{Chlorophyll content after 12 days of salt stress (SPAD2)}

The highest number of QTL was mapped for the chlorophyll content trait. Nine QTL were mapped, of which two QTL were for the controls and the remaining seven QTL for salt stress. For the controls, SPAD2-1C and SPAD2-2C were localized on the LGs A9 and C2, respectively. They explain $21 \%$ of the phenotypic variation, where SPAD22C was mapped at $P=0.05$ and accounts for $14 \%$ of the phenotypic variation. Both QTL had positive additive effects. Under salt stress, seven QTL were localized, namely SPAD2-1S, SPAD2-2S, SPAD2-3S, SPAD2-4S, SPAD2-5S, SPAD2-6S and SPAD2-7S. They collectively explain $93 \%$ of the phenotypic variation. Two QTL, SPAD2-4S and SPAD2-5S, were mapped at $P=0.05$ and disclose $47 \%$ of the phenotypic variation. These two QTL were identified at the LGs A9 and C2, respectively. Both of them had positive additive effects. The other five were mapped on the LGs A1, A3, A7, C3 and C3, respectively. They account for $46 \%$ of the phenotypic variation. The additive effects for the five QTL were negative.

\section{Sodium content}

No QTL were identified for under control conditions. Under salt stress, two QTL, Na1S and Na-2S, were mapped on the LGs A3 and C9. They explained $21 \%$ of the phenotypic variation, with negative additive effects.

\section{Potassium content}

Under control conditions, the two QTL, K-1C and K-2C, were mapped on the LGs C2 and $\mathrm{C} 3$, respectively. The QTL K-1C was mapped at $P=0.05$, which explains $18 \%$ of the phenotypic variation, while $\mathrm{K}-2 \mathrm{C}$ explains $7 \%$ of the phenotypic variation. The additive effects for both QTL were negative. Under salt stress, the three QTL, K-1S, K$2 \mathrm{~S}$ and K-3S were identified. They explain $24 \%$ of the phenotypic variation. K-2S has a positive additive effect. Conversely, K-1S and K-3S have negative additive effects.

\section{Sodium-potassium ratio}

No QTL were detected under the control regimen. Three QTL were mapped for salt stress: $\mathrm{Na} / \mathrm{K}-1 \mathrm{~S}, \mathrm{Na} / \mathrm{K}-2 \mathrm{~S}$ and $\mathrm{Na} / \mathrm{K}-3 \mathrm{~S}$ on the LGs A3, C9 and C8a. All of the QTL together explain $28 \%$ of the phenotypic variation. $\mathrm{Na} / \mathrm{K}-1 \mathrm{~S}$ was identified at $P=0.05$. The additive effect of $\mathrm{Na} / \mathrm{K}-1 \mathrm{~S}$ and $\mathrm{Na} / \mathrm{K}-2 \mathrm{~S}$ was negative, while it was positive for $\mathrm{Na} / \mathrm{K}-3 \mathrm{~S}$. 
Chapter IV

Table IV-4: QTL detected with LOD > 1.5 under control treatment (C) for fresh weight, dry weight, SPAD1, SPAD2, relative water content, sodium content $\mathrm{Na}^{+} \mathrm{mg} / \mathrm{g} \mathrm{DM}$ and potassium content $\mathrm{K}^{+} \mathrm{mg} / \mathrm{g} \mathrm{DM}$ in Brassica napus mapping population Mansholts $\times$ Samourai. (QTL significant with $P=0.05$ are marked bold)

\begin{tabular}{|c|c|c|c|c|c|c|c|c|}
\hline Trait & Name of QTL & LG & LOD & $\begin{array}{l}\text { Position } \\
\text { (cM) }\end{array}$ & Interval & Flanking Markers & $\begin{array}{c}\text { Additive } \\
\text { Effect }\end{array}$ & $\begin{array}{c}\text { Phenotypic } \\
\text { variation } \\
\text { explained (\%) }\end{array}$ \\
\hline FW & FW-1C & 6 & 1.59 & 10 & 8-18 & RP1104.H1 -RP428.E1 & -0.14 & 5.49 \\
\hline DW & DW-1C & 5 & 2.01 & 43 & $42-46$ & RP1266.E1 -E3261.2 & -0.02 & 6.86 \\
\hline DW & DW-2C & 12 & 5.36 & 74 & $69-77$ & RP1365.H1- CB10026 & 0.40 & 17.3 \\
\hline DW & DW-3C & 13 & 2.12 & 173 & $171-173$ & RP1365.H3- R1458.H2 & 0.02 & 7.25 \\
\hline RWC & RWC-1C & 12 & 5.14 & 98 & 91-109 & WG2D11.E1 -RP1249.H1 & -0.54 & 16.64 \\
\hline RWC & RWC-2C & 13 & 2.91 & 91 & $80-97$ & WG5B1.H1 - WG6D6.E1 & -0.40 & 9.8 \\
\hline SPAD1 & SPAD1-1C & 9 & 4.92 & 72 & $59-81$ & RP1360.E1- RP1253.E1 & 1.2 & 15.99 \\
\hline SPAD1 & SPAD1-2C & 12 & 5.6 & 66 & $60-73$ & OPA18.820- RP1365.H1 & 1.19 & 18.01 \\
\hline SPAD1 & SPAD1-3C & 16 & 2.78 & 57 & $54-68$ & CB10278- WG7E10.H2 & 0.83 & 9.37 \\
\hline SPAD2 & SPAD2-1C & 9 & 2.28 & 69 & $58-82$ & RP1360.E1- RP1253.E1 & 0.82 & 7.77 \\
\hline SPAD2 & SPAD2-2C & 12 & 4.14 & 98 & $93-105$ & WG2D11.E1- RP1249.H1 & 1.10 & 13.65 \\
\hline K mg / g DM & $\mathrm{K}-1 \mathrm{C}$ & 12 & 5.35 & 94 & $85-98$ & OPD20.840- WG2D11.E1 & -3.18 & 17.53 \\
\hline $\mathrm{K} \mathrm{mg} / \mathrm{g} \mathrm{DM}$ & $\mathrm{K}-2 \mathrm{C}$ & 13 & 2.16 & 129 & $125-130$ & RP1477.E1 -RP459.H1 & -1.87 & 7.49 \\
\hline
\end{tabular}

- The additive effect is calculated by subtracting Samourai allele by Mansholts allele.

- Interval is the start and end of the genetic distance where the maximal LOD of the QTL were identified. 
Chapter IV-

Table IV-5: QTL detected with LOD > 1.5 under salt treatment (S) for fresh weight, dry weight, SPAD1, SPAD2, relative water content, sodium content $\mathrm{Na}^{+} \mathrm{mg} / \mathrm{g} \mathrm{DM}$ and potassium content $\mathrm{K}^{+} \mathrm{mg} / \mathrm{g} \mathrm{DM}$ in Brassica napus mapping population Mansholts $\times$ Samourai. (QTL significant with $P=0.05$ are marked bold)

\begin{tabular}{|c|c|c|c|c|c|c|c|c|}
\hline Trait & Name of QTL & LG & LOD & $\begin{array}{l}\text { Position } \\
\text { (cM) }\end{array}$ & interval & Flanking Markers & $\begin{array}{c}\text { Additive } \\
\text { Effect }\end{array}$ & $\begin{array}{c}\text { Phenotypic } \\
\text { variation } \\
\text { explained (\%) }\end{array}$ \\
\hline FW & FW-1S & 13 & 2.13 & 152 & $144-158$ & OPQ20.780 -OPAG10.63 & 0.10 & 7.28 \\
\hline DW & DW-1S & 13 & 2.55 & 128 & $113-130$ & RP1477.E1 -RP459.H1 & 0.20 & 8.65 \\
\hline DW & DW-2S & 16 & 2.81 & 44 & $40-51$ & СВ10010 -СВ10278 & 0.20 & 9.48 \\
\hline RWC & RWC-1S & 13 & 2.5 & 128 & $124-130$ & RP1477.E1 -RP459.H1 & -0.26 & 8.47 \\
\hline SPAD1 & SPAD1-1S & 1 & 3.55 & 12 & $10-15$ & RP1275.H2 -RP981.H2 & -0.77 & 11.82 \\
\hline SPAD1 & SPAD1-2S & 9 & 2.84 & 29 & $19-37$ & RP1175.H1 -TG1H12.E1 & 0.69 & 9.58 \\
\hline SPAD1 & SPAD1-3S & 12 & 4.69 & 68 & $58-74$ & OPA18.820 -RP1365.H1 & 0.92 & 15.32 \\
\hline SPAD2 & SPAD2-1S & 1 & 2.34 & 15 & $10-20$ & RP981.H2 -RP984.H1 & -0.66 & 7.95 \\
\hline SPAD2 & SPAD2-2S & 3 & 2.17 & 101 & $97-102$ & CB10271b -W2D5.H1 & -0.65 & 7.41 \\
\hline SPAD2 & SPAD2-3S & 7 & 2.49 & 0 & $0-8$ & RP1146.H3 -RP1122.H1 & -0.68 & 8.46 \\
\hline SPAD2 & SPAD2-4S & 9 & 5.67 & 42 & $30-49$ & TG1H12.E1 -RP1516.E1 & 1.12 & 18.22 \\
\hline SPAD2 & SPAD2-5S & 12 & 9.55 & 74 & 71-75 & RP1365.H1 -CB10026 & 1.48 & 28.71 \\
\hline SPAD2 & SPAD2-6S & 13 & 3.29 & 0 & $0-2$ & E3247.2 -E3348.5 & -0.98 & 10.99 \\
\hline SPAD2 & SPAD2-7S & 13 & 3.27 & 167 & $160-171$ & RP1020.H1 -RP1365.H3 & -0.82 & 10.94 \\
\hline $\mathrm{Na} \mathrm{mg/g} \mathrm{DM}$ & Na-1S & 3 & 4.05 & 2 & $0-7$ & E3347.8 -BRAS002 & -2.17 & 13.37 \\
\hline $\mathrm{Na} \mathrm{mg} / \mathrm{g} \mathrm{DM}$ & $\mathrm{Na}-2 \mathrm{~S}$ & 19 & 2.29 & 2 & $0-12$ & E3247.14 -ОРАН9.150 & -1.77 & 7.79 \\
\hline $\mathrm{Kmg} / \mathrm{g} \mathrm{DM}$ & $\mathrm{K}-1 \mathrm{~S}$ & 5 & 1.88 & 96 & $94-114$ & RP1362.E1 -WG4C5.H1 & -1.21 & 6.45 \\
\hline $\mathrm{Kmg} / \mathrm{g} \mathrm{DM}$ & $\mathrm{K}-2 \mathrm{~S}$ & 9 & 3.23 & 57 & $42-65$ & RP1516.E1 -RP1360.E1 & 1.69 & 10.82 \\
\hline $\mathrm{Kmg} / \mathrm{g} \mathrm{DM}$ & K-3S & 13 & 2.02 & 94 & $88-98$ & WG6D6.E1 -MR163.2A & -1.25 & 6.91 \\
\hline $\mathrm{Na} / \mathrm{K}$ & $\mathrm{Na} / \mathrm{K}-1 \mathrm{~S}$ & 3 & 4.63 & 7 & $1-9$ & BRAS002 -WG4D10.E1 & -0.04 & 15.14 \\
\hline $\mathrm{Na} / \mathrm{K}$ & $\mathrm{Na} / \mathrm{K}-2 \mathrm{~S}$ & $18 a$ & 1.81 & 70 & $64-72$ & WG2A11.H1 -RP1144.H1 & 0.02 & 6.2 \\
\hline $\mathrm{Na} / \mathrm{K}$ & $\mathrm{Na} / \mathrm{K}-3 \mathrm{~S}$ & 19 & 2.16 & 0 & $0-8$ & E3247.14 -OPAH9.150 & -0.03 & 7.36 \\
\hline
\end{tabular}

- The additive effect is calculated by subtracting Samourai allele by Mansholts allele. 
A1

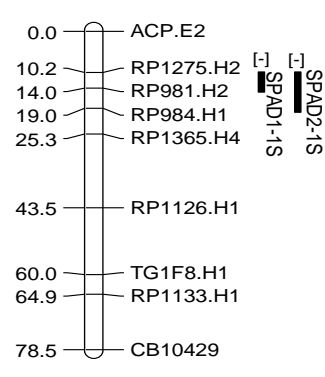

A7

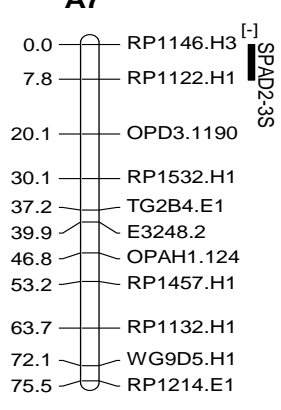

A3

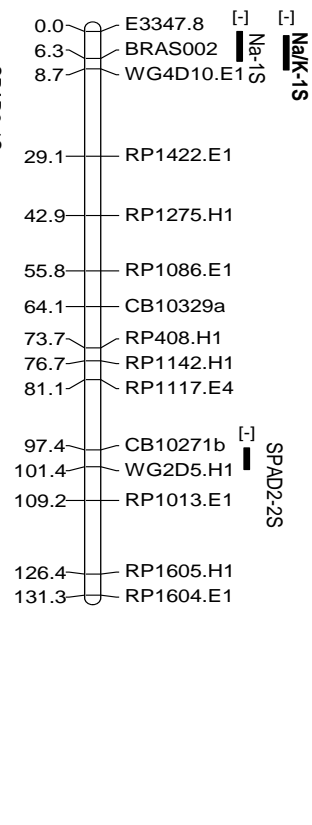

A5

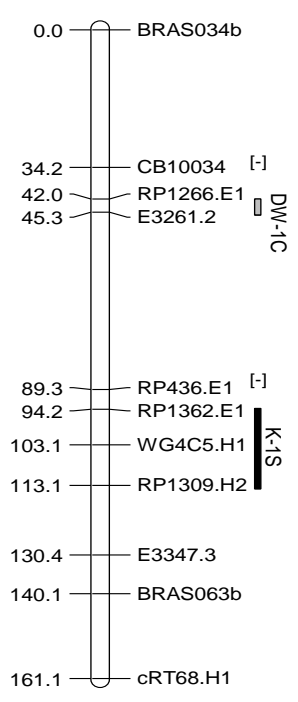

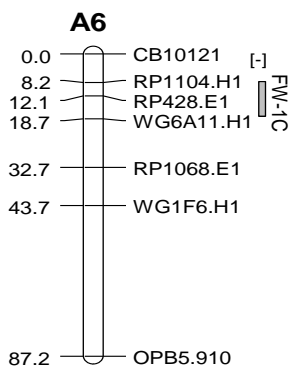

A9

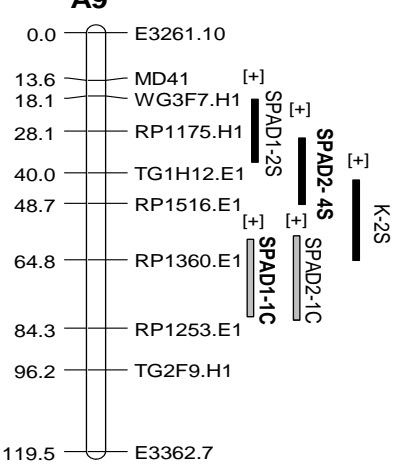

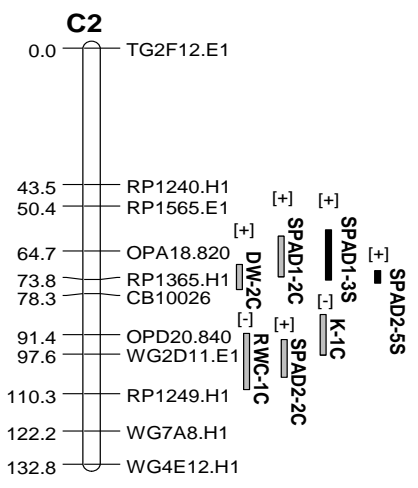

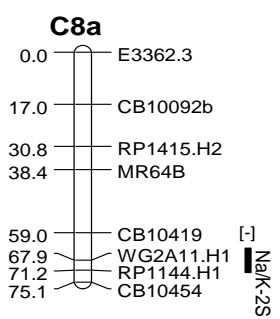

Control

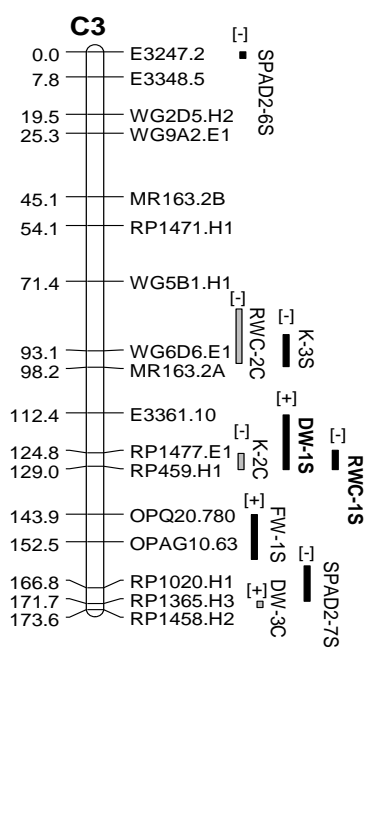

Salt

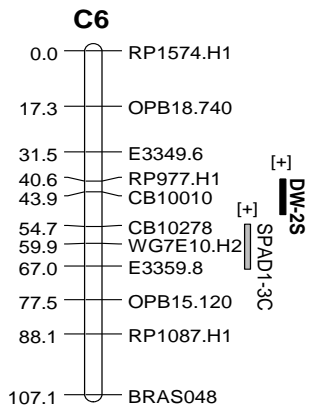

$107.1-$ BRAS048

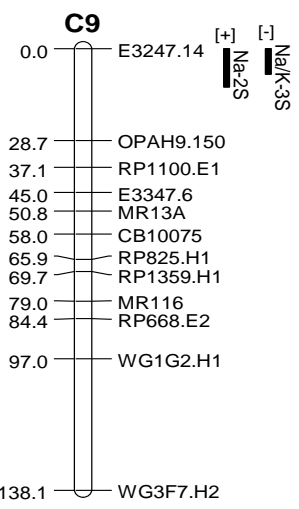

Figure IV-5: Localization of QTL for growth traits in Brassica napus DH population Mansholts $\times$ Samourai. (QTL significant with $P=0.05$ are marked bold) 


\subsection{Discussion I}

\subsubsection{Traits variations}

There was a clear reduction in the FW and DW yield under salt stress compared with the control growth conditions. Also, Liu et al. (2013) reported that $150 \mathrm{mM} \mathrm{Nacl}$ reduced dry matter in Brassica napus L. cv. Nanyanyou 1. The present study applied a high salt concentration of $200 \mathrm{mM} \mathrm{NaCl}$; hence the lower amount of fresh biomass and dry matter can be attributed to ion-specific toxicity, osmotic stress or a combination of these. Salt stress causes a reduction in leaf area, which consequently reduces the photosynthesis to such a low rate that it is inadequate to sustain growth (Munns 2002; Munns and Tester 2008). In the present study, the water relations parameter RWC showed a slight decline upon salt stress. One plausible explanation for this is that the high concentration of $\mathrm{Na}^{+}$and $\mathrm{K}^{+}$ions inside the cell ensured sufficient water uptake after all, the RWC showed positive and significant correlations with $\mathrm{Na}^{+}$and $\mathrm{K}^{+}$. Interestingly however, the correlation of RWC with $\mathrm{FW}$ and DW was negative under control and stress growth conditions (Tables 2 and 3). This it is more likely that the role of RWC was osmotic adjustment to avoid dehydration rather than blocking the lethal effect of the high dose of $\mathrm{Na}^{+}$. Similarly, Liu et al. (2013) reported that $150 \mathrm{mM}$ Nacl reduced the RWC in B. napus L. CV. Nanyanyou 1.

Under salt stress conditions, there was an increase in the chlorophyll content in the cases of SPAD1 and SAPD2. The high SPAD values for chlorophyll under salt stress are explained in part by anatomical modifications in the leaf area. The reduction of leaf area under salt stress makes the leaf smaller and thicker, which increases chloroplast density per leaf area (Fricke et al. 2004)). Munns et al. (2002) found that in wheat, under $150 \mathrm{mM} \mathrm{NaCl}$, the photosynthesis of the entire plant was reduced, though there was no change in the photosynthesis rate per unit leaf area. The correlation of SPAD1 and SPAD2 with DW was positive and significant, especially under salt stress, which indicates the crucial role of chlorophyll as a photosynthetic pigment for the capture of light energy and hence for carbon assimilation.

Under salt stress, a dramatic increase in $\mathrm{Na}^{+} \mathrm{mg} / \mathrm{g}$ DM was observed it was $210 \%$ compared to the control. The correlation between $\mathrm{Na}^{+}$and the remaining traits was negative, particularly, with FW, DW and also with $\mathrm{K}^{+}$. The excessive levels of $\mathrm{Na}^{+}$and $\mathrm{Cl}^{-}$induce nutrient deficiency as a result of the unbalanced ratio between $\mathrm{Na}^{+}$and $\mathrm{Cl}^{-}$ and other ions. This nutrient deficiency may be ascribed to a lack of nutrient uptake and an inactivation of the metabolic pathways that are mainly dependent on these nutrients. Additionally, these imbalances cause an unequal distribution and sequestering of the other nutrients inside the plant, leading to a further deficiency of essential nutrients (Grattan and Grieve 1999). The negative and significant correlation between $\mathrm{Na}^{+}$and $\mathrm{K}^{+}$shows an antagonism between $\mathrm{Na}^{+}$ions and $\mathrm{K}^{+}$. This antagonism is attributed to their similar physiochemical proprieties and atomic size (Shabala and Cuin 2007).

Unexpectedly, in the $\mathrm{DH}$ population, $\mathrm{K}^{+} \mathrm{mg} / \mathrm{g} \mathrm{DM}$ increased under salt stress by up to $50 \mathrm{mg} / \mathrm{g}$ DM compared to $48 \mathrm{mg} / \mathrm{g} \mathrm{DM}$ in the control with an increase of $5 \%$. The 
excess $\mathrm{K}^{+}$may be used for osmotic adjustment along with the high concentration of $\mathrm{Na}^{+}$. The explanation for this point was the positive and significant correlation between $\mathrm{K}^{+}$and relative water content. Furthermore, the correlation between $\mathrm{K}^{+}$and $\mathrm{FW}$ and DW was positive and significant, indicating that $\mathrm{K}^{+}$promotes plant growth even under salt stress. The capacity to maintain high $\mathrm{K}^{+}$is characteristic for salt-tolerant genotypes (Munns 2005). The contribution of $\mathrm{K}^{+}$in biochemical and physiological reactions of the cells includes charge equilibration with the negative charges on nucleic acids and proteins, and activation of important enzymes like those involved in pyruvate transport. Moreover, it acts as an osmoticum to ensure turgidity in case of water-deficiency (Maathuis and Amtmann 1999).

\subsubsection{QTL analysis and localization}

In the present study, we identified associations between different genomic regions and the variations in the measured traits. Several QTL hotspots for many traits were detected. These QTL hotspots for different traits were found on different LGs. For example, the largest hotspot was on LG C3, where QTL for DW, $\mathrm{K}^{+}$and RWC were clustered. This clustering is expected as $\mathrm{K}^{+}$is involved as an enzyme catalyst in many processes inside the plant cell. Moreover, $\mathrm{K}^{+}$acts as an osmoticum. This assumption is supported by the positive and significant correlation with RWC under either control or salt stress. These hotspots exist for these traits suggest two plausible explanations. The first is that the pleiotropic effect depends on one gene residing in this genomic region that controls the variation of these traits. The second is that the effect is due to different, tightly linked genes that control these traits variations independently. Since this hotspot involves three subgroups of QTL, at least three genes reside in these genomic regions. As the additive effects of $\mathrm{K}-2 \mathrm{C}$ and RWC-1S was negative, while the additive effect of DW-1S was positive, these alleles must be in repulsion phase. Another two groups of QTL were found to be proximal to this cluster. The first one was in the middle of LG C3, which includes two QTL for K-3S and RWC-2C. Both of them had negative effects, meaning that the alleles that underlie these traits are in couple phase. It is possible that either one gene with pleiotropic effect or two genes regulate these two traits. The second group was at the bottom of LG C3 and includes two QTL, indicating that they control these traits separately.

On LG C2, other QTL hotspots were observed. One of them involves three QTL, one for each of the traits $\mathrm{K}^{+}, \mathrm{SPAD}$ and RWC. The first and the third showed negative additive effect, whilst the second's additive effect was negative, meaning that these alleles are in a repulsion phase. In this region the QTL SPAD2-5S that explains 28\% of the phenotypic variance was mapped. It is more than likely that this QTL is a major gene controlling the chlorophyll content under salt stress.

On LG A9, another group of QTL showed interval overlapping. This group includes five QTL. Four of them corresponded to SPAD1 and SPAD2 and one for $\mathrm{K}^{+}$. The cosegregation of SPAD-related QTL is expected as they are for the same trait at different time intervals. The intervals of SPAD1-2S and SPAD2-4S overlap each other, suggesting that these genomic regions include genes that control chlorophyll content 
variation only under salt stress. Conversely, two QTL, SPAD1-1C and SPAD2-1C, revealed overlapping intervals, suggesting that the gene/genes residing in these QTL regulate(s) the chlorophyll trait only under control conditions. The fifth QTL in this hotspot was for $\mathrm{K}^{+}$, which overlaps with both groups of QTL for SPAD. This overlap might be due to the role of $\mathrm{K}^{+}$in protecting chlorophyll from oxidative damage caused by the reactive oxygen species (ROS) induced by salt stress in the chloroplast, which is the site for producing most of ROS.

Of high interest is the co-localization of $\mathrm{QTL}$ for $\mathrm{Na}^{+}$and $\mathrm{Na}^{+} / \mathrm{K}^{+}$on C9. Probably this region harbors a gene or genes coding for plasma membrane or vacuolar antiporters. The plasma membrane antiporter regulates the influx of $\mathrm{Na}^{+}$across the plasma membrane. The vacuolar antiporter controls $\mathrm{Na}^{+}$compartmentalization in the vacuole to relieve the detrimental effect of excess $\mathrm{Na}^{+}$ions in the cytoplasm. For this reason, fine mapping of this region is of great importance in discovering what type of antiporters is hidden here. Additionally, use of the flanking markers to select for lower $\mathrm{Na}^{+}$and $\mathrm{Na}^{+} / \mathrm{K}^{+}$may help in improving the salt tolerance. The association between $\mathrm{Na}^{+}$and $\mathrm{Na}^{+} / \mathrm{K}^{+}$on LG C9 is in agreement with the findings of Koyama et al. (2001) in rice, as they found an association between $\mathrm{QTL}$ for $\mathrm{Na}^{+}$and $\mathrm{Na}^{+} / \mathrm{K}^{+}$. Also, they found QTL for $\mathrm{Na}^{+}$and $\mathrm{K}^{+}$, which were mapped on different linkage groups, suggesting that these QTL independently control sodium and potassium uptake. The QTL mapped for $\mathrm{Na}^{+}$and $\mathrm{Na}^{+} / \mathrm{K}^{+}$were clustered together on the LGs A3 and C9 under salt stress only. It shows that these genomic regions are stress-specific, because no QTL were identified for both traits under control.

Our results agree with the findings of Collins et al. (2008), as they have classified the QTL into the two major groups (constitutive QTL) and (adaptive QTL). The constitutive QTL express themselves in a wide spectrum of different growth conditions. The adaptive QTL occur in a limited range of environmental conditions, either control conditions or salinity. An example for constitutive QTL on LG C2 is that the SPAD1-2C and SPAD1-3S were localized together. An example for adaptive QTL on LG A9 is that the SPAD1-1C and SPAD2-1C showed a strong overlap. In tomato, similar results were reported under salinity, where stress-nonspecific QTL were mapped (Foolad et al. 1999). Monforte et al. (1997) identified a major QTL in tomato, which explained $58 \%$ of fruit fresh weight under non-stress conditions. Under salt stress, this QTL explain $14 \%$ of the variation for the same trait. Regarding the adaptive QTL, our results are in harmony with the findings of Villalta et al. (2007), as they found saltspecific and control-specific QTL for fruit weight in two solanum F7 populations.

In the context of finding the co-localizations of QTL underlying different traits, results similar to ours have been reported. In B. napus, Basunanda et al. (2009) found QTL hotspots for some traits linked to heterosis, such as seed germination and seedling growth. This was expected as these traits are developmentally related. Moreover, they found co-localization between traits that seem to be developmentally unrelated, such as biomass yield, plant height and seed yield. In Arabidopsis, Ren et al. (2010) found QTL for different growth traits: green seedling as a marker for salt tolerance and root 
length sharing the same position on chromosome 1. In barley, Mano and Takeda (1997) mapped QTL for salt tolerance at the germination stage adjacent to the QTL that control the ABA response. Villalta et al. (2007) found co-localization between several QTL that control many traits, such as fruit weight and fruit number, in two solanum F7 population. Siahsar and Narouei (2010) found a co-localization of QTL for different traits in a barley Steptoe $x$ Morex doubled population. They detected a QTL hotspot for RWC, proline content and water soluble carbohydrates. In another study on the same population, a co-localization was observed between QTL for kernel weight and grain protein (Han and Ullric 1994). Ma et al. (2007) identified a cluster of QTL that control related traits such as the salt tolerance index for radicale and plumule.

\section{Conclusion}

To sum up, significant reductions in the FW and DW were observed. The remaining traits showed an increase, especially $\mathrm{Na}^{+} \mathrm{mg} / \mathrm{g}$ DM. Unexpectedly, $\mathrm{K}^{+} \mathrm{mg} / \mathrm{g} \mathrm{DM}$ showed an increase under salt stress. Consistent with previous studies, several nonstress-specific and stress-specific regions were identified. Both regions are important for selection, as the non-specific genomic regions might give insights into the performance of genotypes under control and salt stress conditions. The adaptive QTL (stress-specific) can be employed for the direct selection of salt-tolerant genotypes. Several QTL hotspots for several traits were identified for related traits like FW and DW, and for traits that seem to be unrelated, such as $\mathrm{K}^{+}$and chlorophyll content (SPAD). The co-localization of related and unrelated traits is a great advantage. The markers that are linked to these QTL will be helpful for selection aimed at improving more than one trait.

Because of the complexity of the salt tolerance trait, the polyploid nature of $B$. napus and the large QTL intervals, it was not possible to go further and look for candidate genes behind this variation. Additionally, the genome of $B$. napus is dynamic new homoeologous regions occur after each cross, rendering the positioning of candidate genes therefore very laborious (Wolfgang Ecke, personal communication). To reach this target, further steps are needed, such as testing for the presence of these QTL in different plant materials and fine mapping to precisely verify their position, because no studies have been hereto reported for this trait in $B$. napus.

Altogether, these results are basis from which to explore the salt tolerance of $B$. napus. This goal is closer than ever before, especially after the publication of the full sequences of the $B$. rapa and $B$. oleracea, the corresponding diploid ancestors of $B$. napus and the expected release of the complete sequence of $B$. napus in the next few years. 


\section{Part II}

Mapping QTL for glucosinolates variation under control and salt stress conditions in B. napus

In $B$. napus, very little is known about the genetic control of leaf GSL variation compared to the genetic control of GSL content in seed. Moreover, our knowledge of the effect of salinity on leaf GSL is much more limited due to the scarcity of studies on this issue.

Table IV-6: Systematic and common names of the glucosinolates detected in the leaf

\begin{tabular}{|c|c|c|c|c|}
\hline Systematic name & Trivial name & Group & Source & $\begin{array}{c}\text { Abbre } \\
\text { viatio } \\
\mathrm{n} \\
\end{array}$ \\
\hline (2R)2-Hydroxy-3-butenyl & Progoitrin & Aliphatic & Methionine & PRO \\
\hline 3-Butenyl & Gluconapin & Aliphatic & Methionine & GNA \\
\hline 4-Methylsulphinylbutyl & Glucoraphanin & Aliphatic & Methionine & RAA \\
\hline 4-Methylsulphinyl-3-butyl & Glucoraphenin & Aliphatic & Methionine & RAE \\
\hline 4-Pentenyl & Glucobrassicanapin & Aliphatic & Methionine & GBN \\
\hline 2-Hydroxy-4-pentenyl & Napoleiferin & Aliphatic & Methionine & GNL \\
\hline 3-Indolylmethyl & Glucobrassicin & Indolic & Tryptophan & GBC \\
\hline 4-Hydroxy-3-indolylmethyl & 4-Hydroxyglucobrassicin & Indolic & Tryptophan & $4 \mathrm{OH}$ \\
\hline 2-Phenylethyl & Gluconasturtiin & Indolic & Tryptophan & NAS \\
\hline 4-Methoxy-3-indolylmethyl & 4-Methoxyglucobrassicin & Indolic & Tryptophan & $4 \mathrm{ME}$ \\
\hline N-Methoxy-3-indolmethyl & Neoglucobrassicin & Aromatic & $\begin{array}{c}\text { Tyrosine, } \\
\text { Phenylalan } \\
\text { ine }\end{array}$ & NEO \\
\hline
\end{tabular}

To make the description of GSL content understandable, it will be described according to three main classes: aliphatic GSL, indolic GSL and aromatic GSL, in both parents and the $\mathrm{DH}$ population under control and salt stress conditions. 


\subsection{Results II}

\subsubsection{Parents' GSL profile and content under control conditions}

We observed wide variations in total leaf glucosinolate content and in the individual glucosinolates between the parental lines Mansholts and Samourai. This was also the case in the DH population. Mansholts showed higher GSL than Samourai under control and salt stress. Noteworthy is that under salt stress Mansholts showed an increase in total GSL due to the increase in aliphatic GSL.

\section{Mansholts GSL content under control conditions}

Under control conditions, the total GSL content of Mansholts was $9.59 \mu \mathrm{mol} / \mathrm{g}$ DM (Table 7). The aliphatic GSL concentration was $7.6 \mu \mathrm{mol} / \mathrm{g} \mathrm{DM}$, which accounts for $79 \%$ of the total GSL (Table 8). The main compositions were PRO, GBN and GNA. The concentrations of these components were $4 \mu \mathrm{mol} / \mathrm{g} \mathrm{DM}, 2.10 \mu \mathrm{mol} / \mathrm{g}$ DM and $1.20 \mu \mathrm{mol} / \mathrm{g} \mathrm{DM}$, respectively. The proportions of these components in the aliphatic GSL are $53 \%, 28 \%$ and $15 \%$, respectively. Their contributions to the total GSL are $42 \%, 22 \%$ and 12\%, respectively. The minor ingredients, GNL, RAA and RAE amount to $0.08 \mu \mathrm{mol} / \mathrm{g} \mathrm{DM}, 0.03 \mu \mathrm{mol} / \mathrm{g} \mathrm{DM}$ and $0.18 \mu \mathrm{mol} / \mathrm{g} \mathrm{DM}$, respectively. Together, they represent $4 \%$ of aliphatic GSL and $3 \%$ of total GSL (Table 7, and Figures $6 a$, b, and $7 \mathrm{a}, \mathrm{b})$.

The indolic GSL concentration was $1.8 \mu \mathrm{mol} / \mathrm{g}$ DM, which accounts for $20 \%$ of the total GSL (Figure 6a and Table 8). Four components were detected: GBC, NAS, 4OH and $4 \mathrm{ME}$. The concentrations of these were $1 \mu \mathrm{mol} / \mathrm{g} \mathrm{DM}, 0.51 \mu \mathrm{mol} / \mathrm{g} \mathrm{DM}, 0.17$ $\mu \mathrm{mol} / \mathrm{g} \mathrm{DM}$ and $0.14 \mu \mathrm{mol} / \mathrm{g} \mathrm{DM}$, respectively. These components share 55\%, 28\%, $9 \%$ and $8 \%$, respectively of the total indolic GSL. Their contributions to the total GSL are 10\%, 5\%, 1.6\% and 1.4\%, respectively (Figures 6a, b and $8 a$, b, and Table 7).

The aromatic GSL group is represented by NEO with $0.17 \mu \mathrm{mol} / \mathrm{g} \mathrm{DM}$, with a share of $2 \%$ of total GSL (Figures 6a, b and 9, and Tables 7 and 8).

\section{Samourai GSL content under control conditions}

Under control conditions, Samourai showed a total GSL content of as high as 6.4 $\mathrm{mmol} / \mathrm{g}$ DM. The aliphatic GSL were the predominant class, with $4.25 \mu \mathrm{mol} / \mathrm{g} \mathrm{DM}$, which accounts for $66 \%$ of the total GSL (Table 8). The major components are PRO, GBN and GNA. The absolute values of these components were $1.9 \mu \mathrm{mol} / \mathrm{g}$ DM, 1.4 $\mu \mathrm{mol} / \mathrm{g} \mathrm{DM}$ and $0.67 \mu \mathrm{mol} / \mathrm{g} \mathrm{DM}$, respectively. The shares of these components in the aliphatic GSL are $46 \%, 34 \%$ and $16 \%$, respectively. Their contributions to the total GSL are $30 \%, 22 \%$ and 10\%, respectively (Figure $6 a, b$, Figure $7 a, b$ ). The remaining components of the aliphatic class are GNL, RAA and RAE. Their concentrations are rather low in comparison to the major components. All of them together represent $3 \%$

of the aliphatic GSL and $2.8 \%$ of the total GSL content (Figures $6 a, b$ and $7 a, b$, and Table 7). 
a)

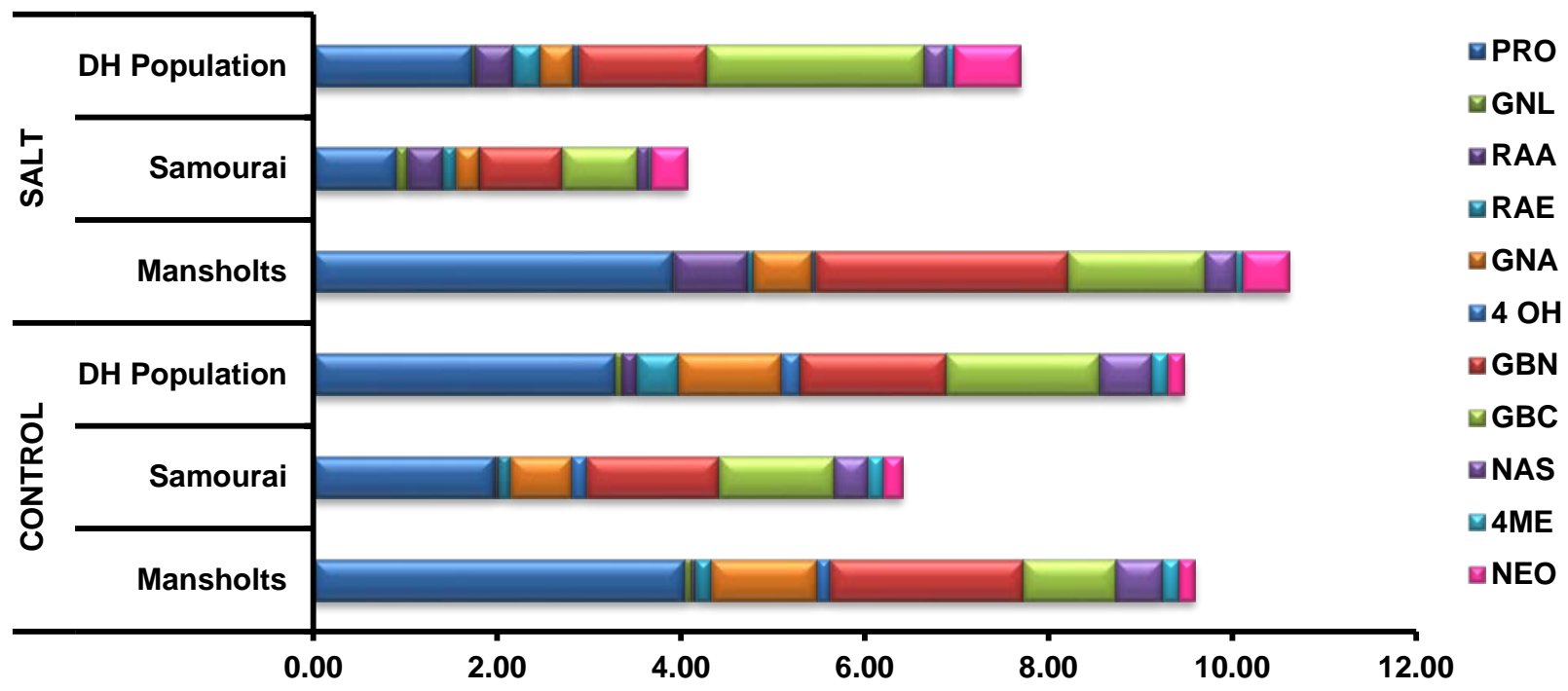

Absolute cocentration of total GSL components $\mu \mathrm{mol} / \mathrm{g}$ DM

b)

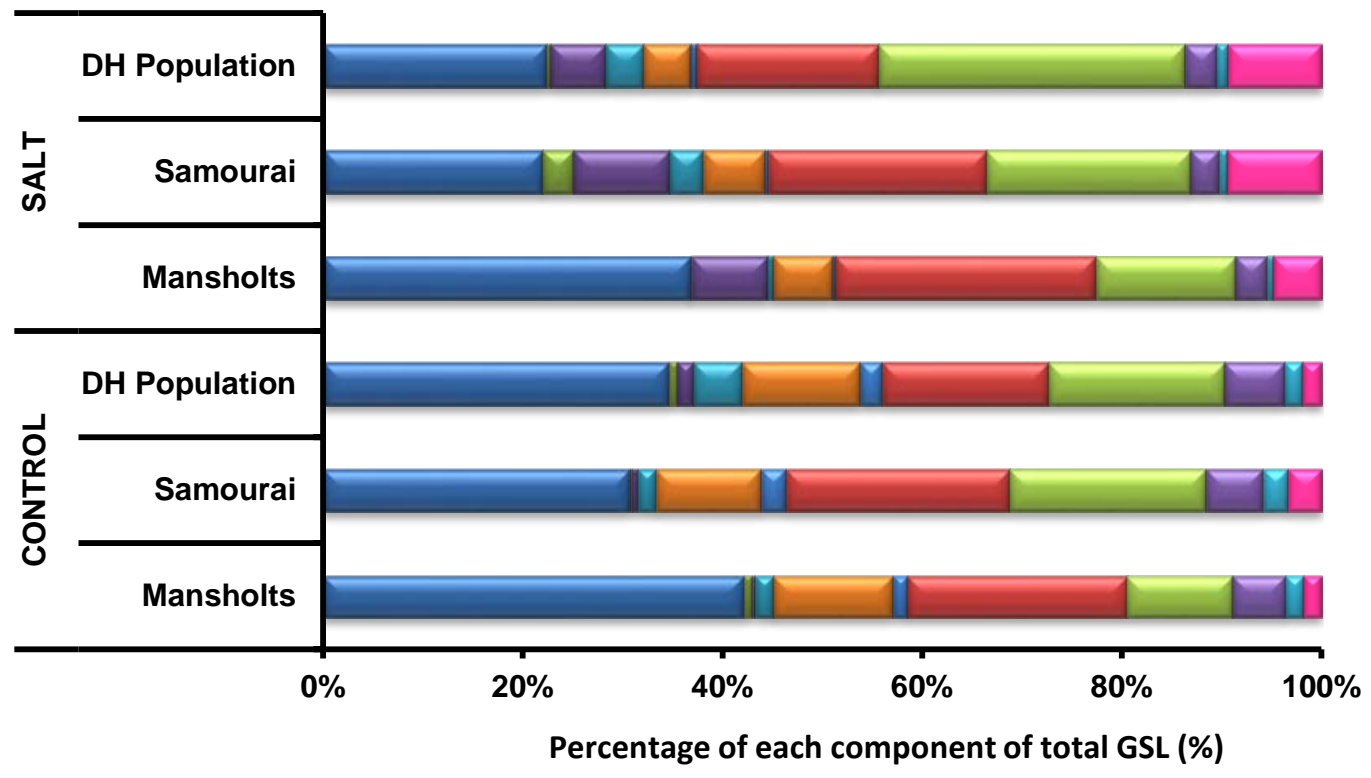

- PRO

$\square \mathrm{GNL}$

IRAA

IRAE

$\square$ GNA

$\square 4 \mathrm{OH}$

$\square \mathrm{GBN}$

$\square \mathrm{GBC}$

$\square$ NAS

$\square$ पME

口NEO

Figure IV-6: (a) Total glucosinolate content $\mu \mathrm{mol} / \mathrm{g}$ DM of each component in parents and the $\mathrm{DH}$ population under control and salt, (b) Percentage of each component relative to the total GSL content in parents and the $\mathrm{DH}$ population under control and salt 
a)

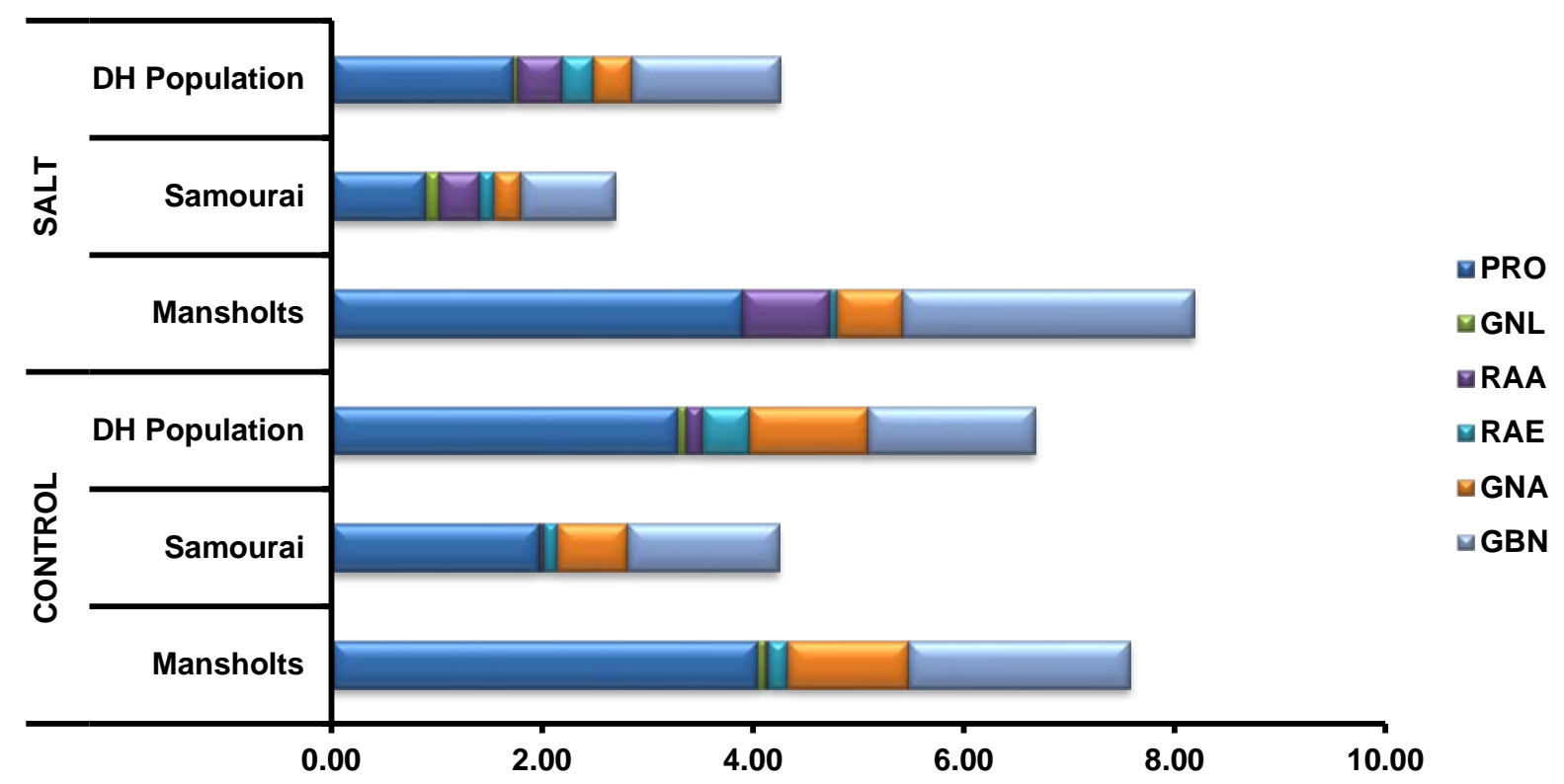

Aliphatic GSL $\mu \mathrm{mol} / \mathrm{g}$ DM

b)

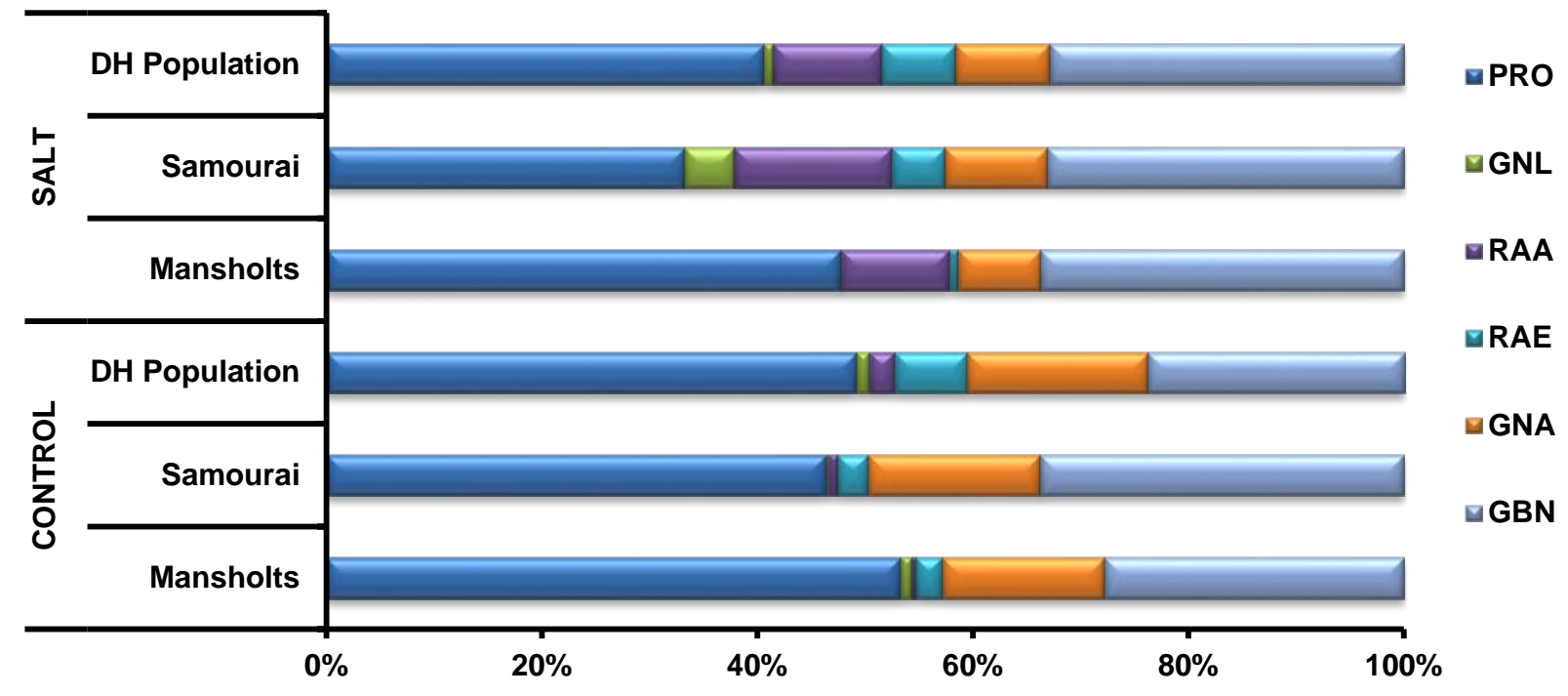

Percentage of each component of aliphatic GSL (\%)

Figure IV-7: a) Absolute values of aliphatic GSL components $\mu$ mol/ $g$ DM in the parents and the $\mathrm{DH}$ population under control and salt, b) Percentage of each ingredient of the aliphatic GSL in the aliphatic GSL content in parents and the $\mathrm{DH}$ population under control and salt 
a)

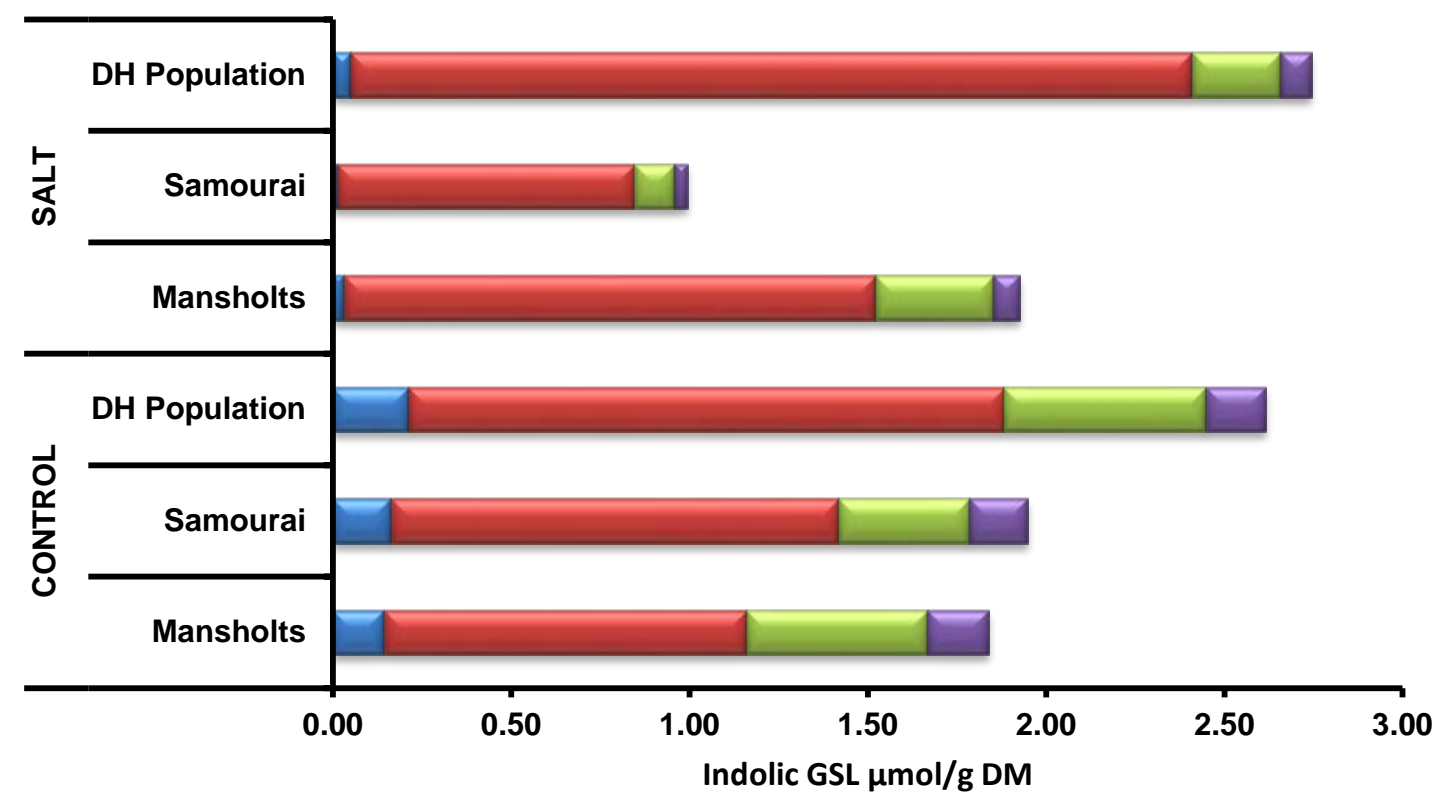

$\square 4 \mathrm{OH}$

$\square \mathrm{GBC}$

$\square$ NAS

$\square 4 \mathrm{ME}$

b)

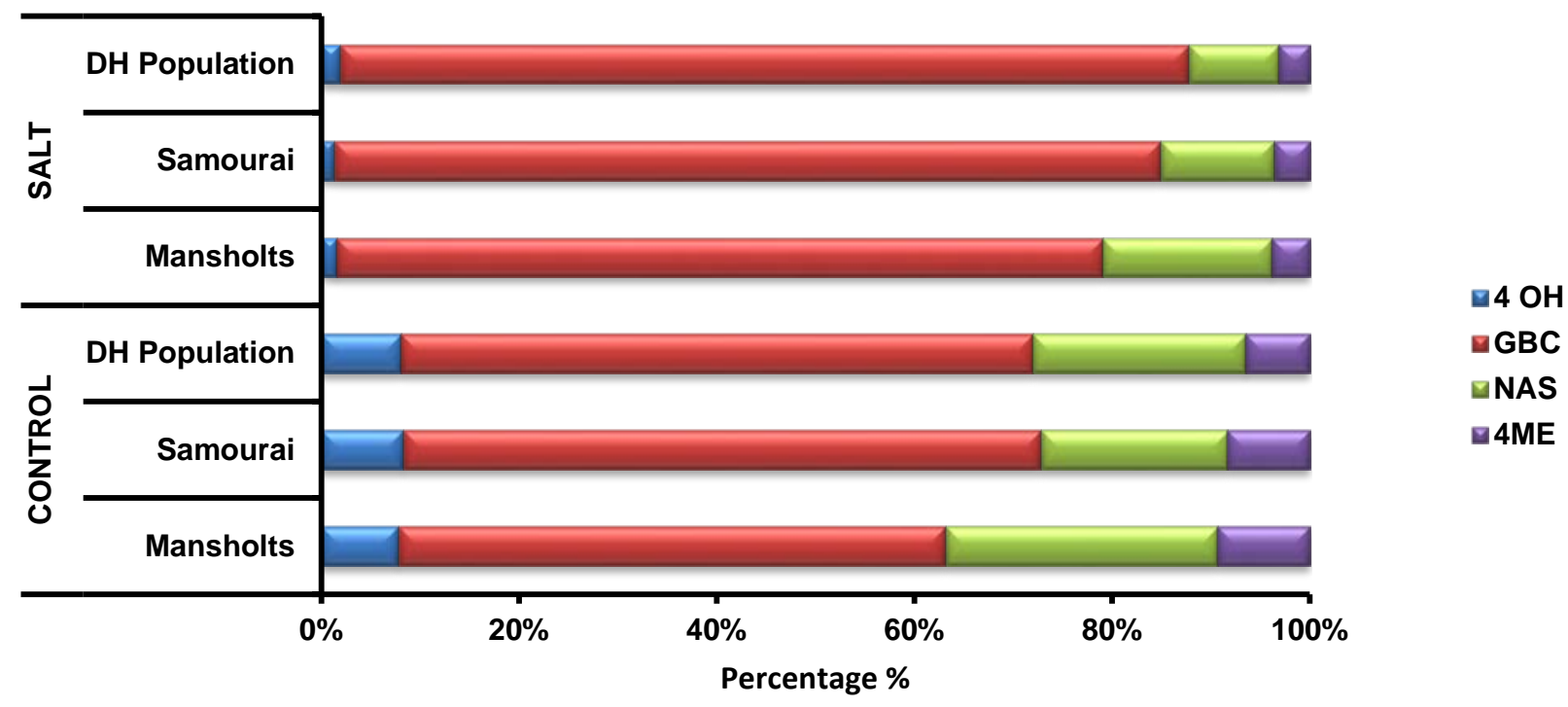

percentage of each component in the indolic GSL

Figure IV-8: a) Absolute values of indolic GSL components $\mu \mathrm{mol} / \mathrm{g} \mathrm{DM}$ in the parents and the $\mathrm{DH}$ population under control and salt, b) Percentage of each ingredient of indolic GSL in the indolic GSL content in parents and the $\mathrm{DH}$ population under control and salt 


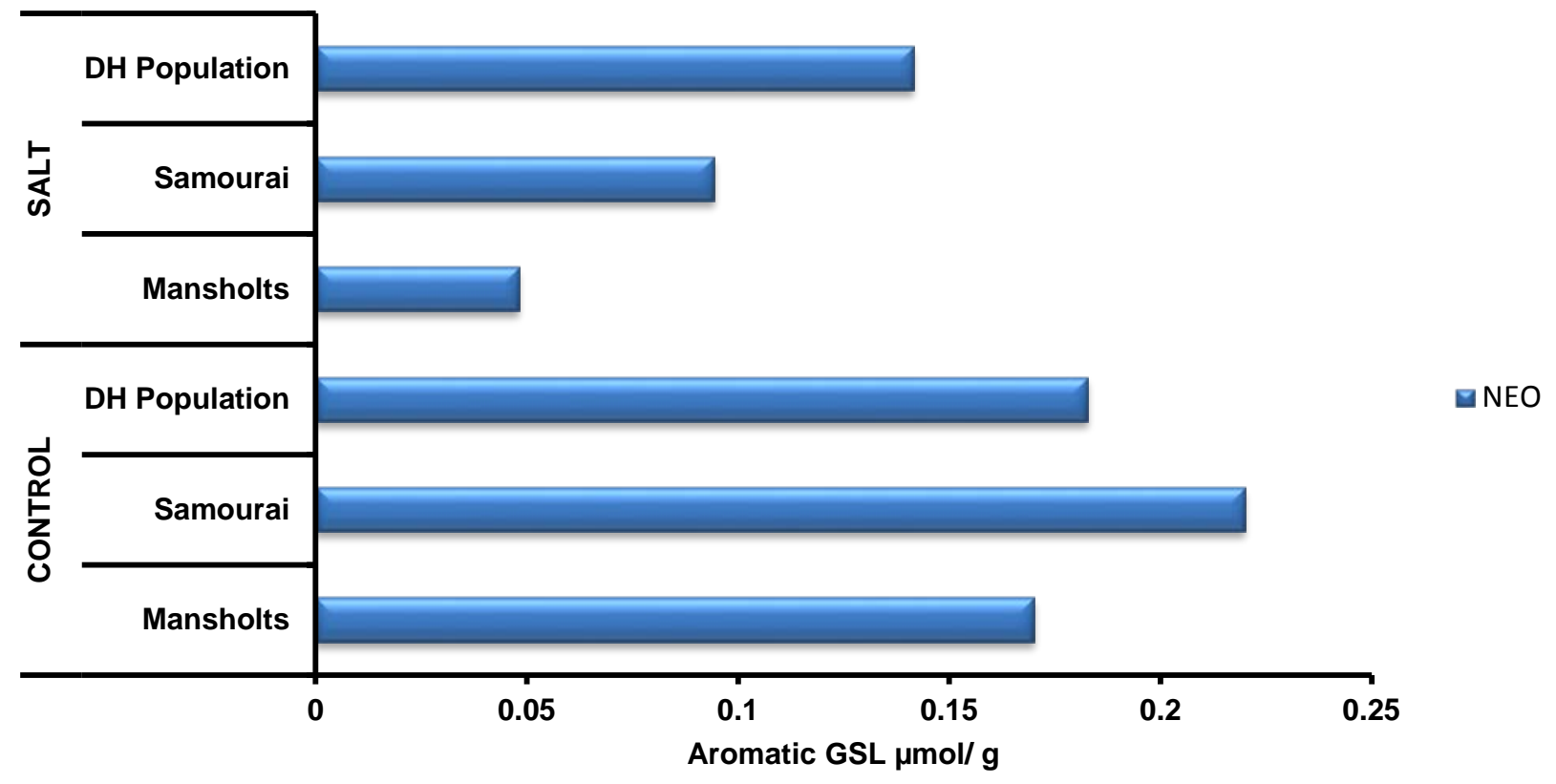

Figure IV-9: Absolute values of aromatic GSL components $\mu \mathrm{mol} / \mathrm{g} \mathrm{DM}$ in the parents and the $\mathrm{DH}$ population under control and salt

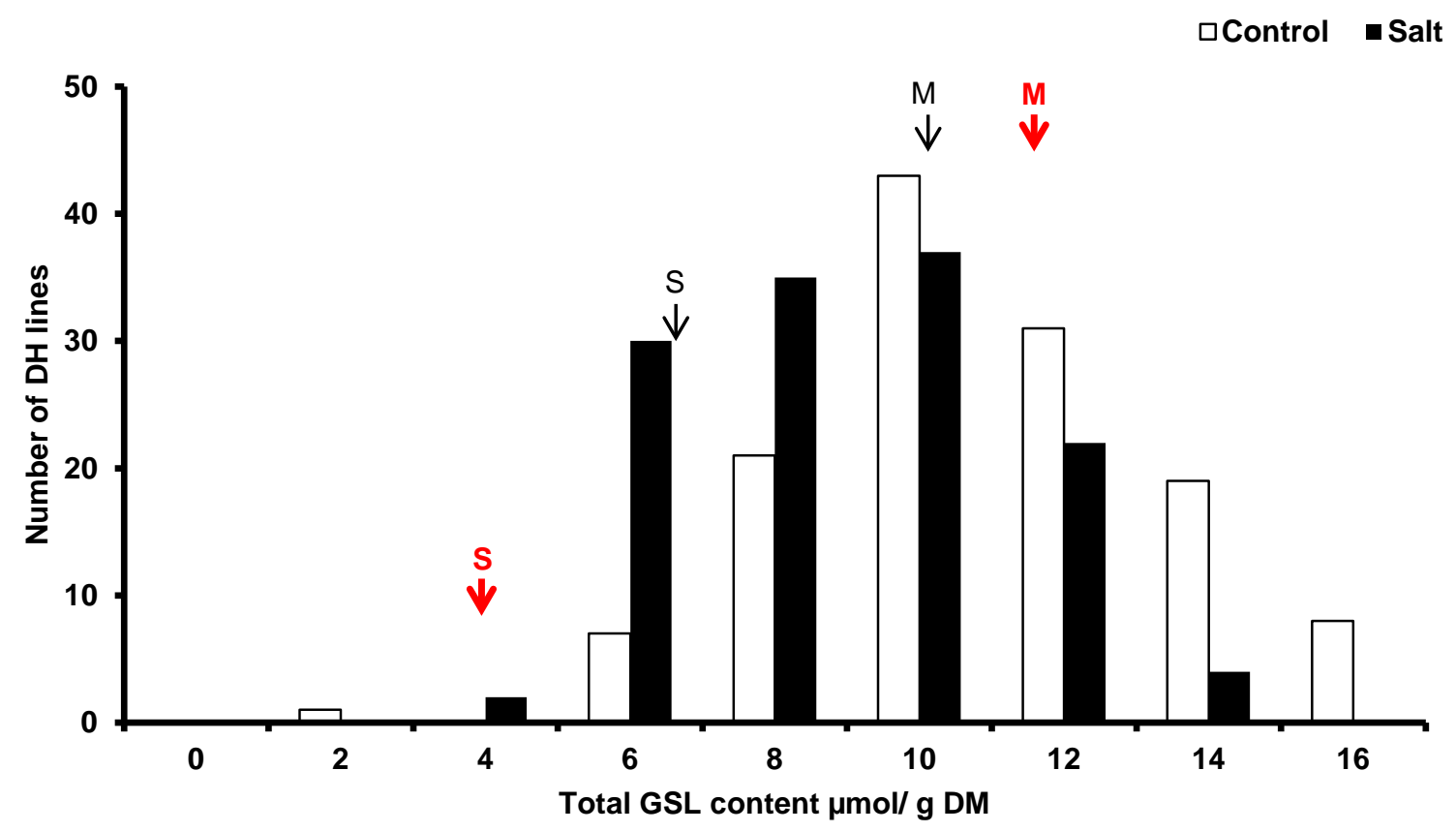

Figure IV-10: Distribution of total GSL $\mu \mathrm{mol} / \mathrm{g}$ DM of Brassica napus DH population Mansholts $\times$ Samourai under control and salt stress

- $\quad$ Red and bold arrows refers to parents GSL content under salt stress 
The indolic GSL represented $30 \%$ of the total GSL, with $1.95 \mu \mathrm{mol} / \mathrm{g}$ DM (Table 8). GBC and NAS are the major components with $1.3 \mu \mathrm{mol} / \mathrm{g} \mathrm{DM}$ and $0.37 \mu \mathrm{mol} / \mathrm{g} \mathrm{DM}$, respectively; their shares in the indolic GSL are $64 \%$ and $19 \%$, respectively. These components share $20 \%$ and $60 \%$ of the total GSL, respectively. The minor components, $4 \mathrm{OH}$ and $4 \mathrm{ME}$ have the same concentration of $0.16 \mu \mathrm{mol} / \mathrm{g} \mathrm{DM}$; collectively they share $16 \%$ of the GSL and $3 \%$ of the total GSL (Figures $6 a, b$ and $7 a$, b, and Tables 7 and 8).

The NEO concentration was $0.22 \mu \mathrm{mol} / \mathrm{g}$ DM, which represents less than $4 \%$ of the total GSL (Figure 6a, b, Figure 9, and Table 7).

The ratios of the GSL content of Mansholts relative to Samourai are $151 \%, 180 \%$, $94 \%$ and 77\%, and for total GSL, aliphatic, aromatic and indolic GSL, respectively. These findings declare that Mansholts have a high aliphatic GSL content compared to Samourai. Nevertheless, Samourai show high indolic and aromatic GSL. Regarding the individual components, Mansholts dominated Samourai in all GSL component categories, except RAA, 4OH and GBC (Figure 6a, b, and Table 7).

\subsubsection{Parents' GSL profiles and content under salt conditions}

We observed a modification of the total GSL content in the parental lines under salt stress conditions. Mansholts exhibited an increase in the total GSL, while Samourai showed a reduction in the total GSL content.

\section{Mansholts GSL profile and content under salt}

Mansholts' total GSL increased by $9 \%$, from $9.7 \mu \mathrm{mol} / \mathrm{g} \mathrm{DM}$ under control conditions to $10.6 \mu \mathrm{mol} / \mathrm{g}$ DM under salt stress. The aliphatic GSL increased by $8 \%$, from 7.6 umol/ $\mathrm{g}$ DM under control conditions to $8.2 \mu \mathrm{mol} / \mathrm{g} \mathrm{DM}$, which equals $77 \%$ of total GSL (Tables 7 and 8). GBN increased to $2.8 \mu \mathrm{mol} / \mathrm{g} \mathrm{DM}$, which comes to $34 \%$ of aliphatic GSL and $26 \%$ of total GSL. RAA increased to $0.89 \mu \mathrm{mol} / \mathrm{g}$ DM, representing $10 \%$ of aliphatic GSL and $7 \%$ of total GSL (Figure $7 a, b$, and Table 7 ). The remaining components decreased. PRO and GNA were the major components with $3.9 \mu \mathrm{mol} / \mathrm{g}$ $\mathrm{DM}$ and $0.63 \mu \mathrm{mol} / \mathrm{g} \mathrm{DM}$, respectively. These concentrations represent $48 \%$ and $8 \%$ of the aliphatic GSL, respectively. The shares of the major components in the total GSL are $37 \%$ and $5 \%$, respectively. RAE was found in small amounts, and GNL completely disappeared.

Indolic GSL increased by 4\%, from $1.84 \mu \mathrm{mol} / \mathrm{g} \mathrm{DM}$ to $1.92 \mu \mathrm{mol} / \mathrm{g} \mathrm{DM}$, thus accounting for $18 \%$ of total GSL. GBC increased to $1.5 \mu \mathrm{mol} / \mathrm{g} \mathrm{DM}$, which was $77 \%$ of the total indolic GSL and $14 \%$ of the total GSL. The remaining $4 \mathrm{OH}$, NAS and $4 \mathrm{ME}$ decreased relative to their concentrations under control conditions. Together they represent $23 \%$ of the indolic GSL and less than $3 \%$ of the total GSL (Figure $8 \mathrm{a}, \mathrm{b}$, and Table 8). Despite the increase in the indolic GSL under salt stress, their contribution to the total GSL fell from $30 \%$ under control to $18 \%$ under salt stress conditions (Table 8). The aromatic GSL component, NEO, significantly decreased to be $0.5 \mu \mathrm{mol} / \mathrm{g} \mathrm{DM}$, sharing $5 \%$ of the total GSL. 


\section{Samourai GSL profile and content under salt stress conditions}

Samurai's total GSL content fell by $34 \%$, from $6.4 \mu \mathrm{mol} / \mathrm{g}$ DM to $4.1 \mu \mathrm{mol} / \mathrm{g} \mathrm{DM}$. The aliphatic GSL dropped by 37\%, from $4.2 \mu \mathrm{mol} / \mathrm{g}$ DM to $2.7 \mu \mathrm{mol} / \mathrm{g}$ DM (Figure 6a, b). Nevertheless, the aliphatic GSL represents $66 \%$ of the total GSL content (Table 8). RAA, RAE and GNL increased. The highest increase was scored for RAA, which was $0.39 \mu \mathrm{mol} / \mathrm{g} \mathrm{DM}$, accounting for $15 \%$ of aliphatic GSL and $9.5 \%$ of total GSL. Similarly, RAE and GNL accreted, but their contributions were much less than the other components, with contributions of $10 \%$ and $3 \%$ of aliphatic and total GSL, respectively (Figures $6 \mathrm{a}, \mathrm{b}$ and $7 \mathrm{a}, \mathrm{b}$ and Table 7). The major aliphatic components, PRO, GBN and GNA, decreased dramatically relative to their concentrations under control. PRO, GNA and GBN were estimated at $0.89 \mu \mathrm{mol} / \mathrm{g} \mathrm{DM}, 0.89 \mu \mathrm{mol} / \mathrm{g}$ DM and $0.25 \mu \mathrm{mol} / \mathrm{g} \mathrm{DM}$, respectively. The contributions of these three components in the aliphatic GSL were 33\%, 33\% and 9\%, respectively. Their shares in the total GSL were $22 \%, 22 \%$ and $6 \%$, respectively (Figures $6 a, b$ and $7 a, b$, and Table 7 ).

The total indolic GSL declined extremely, by up to $49 \%$, from $1.95 \mu \mathrm{mol} / \mathrm{g}$ DM under control conditions to $0.99 \mu \mathrm{mol} / \mathrm{g}$ DM under salinity. The indolic GSL contribution to the total GSL content was 24\% (Table 8). All ingredients declined: GBC, NAS were quantified as $0.83 \mu \mathrm{mol} / \mathrm{g} \mathrm{DM}$ and $0.11 \mu \mathrm{mol} / \mathrm{g} \mathrm{DM}$, respectively. The shares of these constituents in the indolic GSL are $83 \%$ and $11 \%$, respectively. The contributions of GBC and NAS to the total GSL are $20 \%$ and $3 \%$, respectively. The remaining types, $4 \mathrm{OH}$ and $4 \mathrm{ME}$ were detected in rather small amounts. Their shares represent $6 \%$ of the indolic GSL and $2 \%$ of the total GSL (Figures $6 a, b$ Figure $8 a, b$, and Tables 8 and 7).

The aromatic GSL decreased significantly, by $59 \%$ to $0.1 \mu \mathrm{mol} / \mathrm{g} \mathrm{DM}$, representing the smallest portion of the total GSL, i.e. $10 \%$ (Figures $6 a, b$, and 9 and Table 8).

Under salt stress, the ratio of Mansholts GSL content to Samourai GSL content became much higher compared to the ratio under control. The ratios were $260 \%$, $320 \%, 98 \%$ and 55\%, corresponding to the total GSL content, aliphatic GSL content, indolic and aromatic GSL, respectively. Similar to the results under control conditions, Mansholts dominated Samourai in the total GSL content, though Samourai dominated Mansholts in in terms of the indolic and the aromatic GSL content.

\subsubsection{Glucosinolate profile and content of the $\mathrm{DH}$ population under control conditions}

Control versus salt stress conditions produced a significant difference in the total GSL content and the single components (Appendix 10). Under control and salt stress, a transgressive distribution was observed in the $\mathrm{DH}$ population for all single components. The main aliphatic, indolic and aromatic groups as well as the total GSL showed a similar pattern (Appendices 10 and 11, and Figure 10). These data reveal that the total GSL content of some DH lines exceeded that of the parent with high GSL content (Mansholts), while others showed GSL content lower than that of the parent with the lower GSL content (Samourai). 
A large variation in the total GSL was observed in the $\mathrm{DH}$ population under control or salt stress. Under control conditions, it ranged from $1.7 \mu \mathrm{mol} / \mathrm{g} \mathrm{DM}$ to $16 \mu \mathrm{mol} / \mathrm{g} \mathrm{DM}$ with a mean value of $9.8 \mu \mathrm{mol} / \mathrm{g} \mathrm{DM}$. Under salt treatment, the total GSL content ranged from $2.5 \mu \mathrm{mol} / \mathrm{g}$ DM to $13.3 \mu \mathrm{mol} / \mathrm{g} \mathrm{DM}$ with a mean of $7.2 \mu \mathrm{mol} / \mathrm{g} \mathrm{DM}$ (Figure 6a, b, and Table 7).

\section{Aliphatic GSL under control conditions}

Aliphatic GSL represented the main portion, ranging from $0.63 \mu \mathrm{mol} / \mathrm{g}$ DM to 13.5 $\mu \mathrm{mol} / \mathrm{g}$ DM with a mean value of $6.7 \mu \mathrm{mol} / \mathrm{g}$ DM. The share of aliphatic GSL in the total GSL was 70\% (Table 8). The major constituents, PRO, GBN and GNA, were found to have the concentrations $3.3 \mu \mathrm{mol} / \mathrm{g} \mathrm{DM}, 1.6 \mu \mathrm{mol} / \mathrm{g} \mathrm{DM}$ and $1.1 \mu \mathrm{mol} / \mathrm{g} \mathrm{DM}$, respectively. The shares of the major components in the aliphatic GSL are $49 \%, 24 \%$ and $11 \%$, respectively. Their contributions to the total GSL are $33 \%, 17 \%$ and $11 \%$, respectively (Figure $6 \mathrm{a}, \mathrm{b}$ and Table 7). The remaining minor GSL types, RAE, RAA and GNL, were quantified at $0.45 \mu \mathrm{mol} / \mathrm{g}$ DM, $0.15 \mu \mathrm{mol} / \mathrm{g}$ DM $0.08 \mu \mathrm{mol} / \mathrm{g}$ DM, respectively. Together, they represent $10 \%$ of the aliphatic GSL and $7 \%$ of the total GSL content (Figure 6a, b and Table 7).

\section{Indolic GSL under control conditions}

Indolic GSL represented the second largest portion, ranging from $1.6 \mu \mathrm{mol} / \mathrm{g}$ DM to $4.9 \mu \mathrm{mol} / \mathrm{g}$ DM, with an average of $2.6 \mu \mathrm{mol} / \mathrm{g}$ DM. The indolic GSL accounted for $28 \%$ of the total GSL (Table 8). The superabundant constituents, GBC and NAS, were detected in the concentrations $1.2 \mu \mathrm{mol} / \mathrm{g} \mathrm{DM}$ and $0.56 \mu \mathrm{mol} / \mathrm{g} \mathrm{DM}$, respectively. They are $64 \%$ and $22 \%$ of the indolic GSL, respectively. The shares of GBC and NAs in the total GSL come to $18 \%$ and $6 \%$, respectively. The minor constituents, $4 \mathrm{OH}$ and 4ME, were detected in $0.21 \mu \mathrm{mol} / \mathrm{g} \mathrm{DM}$ and $0.17 \mu \mathrm{mol} / \mathrm{g} \mathrm{DM}$, respectively. Collectively, $4 \mathrm{OH}$ and $4 \mathrm{ME}$ represent $14 \%$ of the indolic GSL and $4 \%$ of the total GSL (Figures 6a, b, and 8a, b, and Table 8).

\section{Aromatic GSL under control conditions}

Only one component NEO was quantified. It varied from $0 \mu \mathrm{mol} / \mathrm{g}$ DM to $0.48 \mu \mathrm{mol} / \mathrm{g}$ with a mean of $0.18 \mu \mathrm{mol} / \mathrm{g} \mathrm{DM}$, and a share of $2 \%$ of the total GSL (Figures $6 \mathrm{a}, \mathrm{b}$, and 9, and Tables 7 and 8).

\subsubsection{Glucosinolate profile and content of the DH population under salt stress}

The average total GSL content of the $\mathrm{DH}$ population declined by $20 \%$ from $9.5 \mu \mathrm{mol} / \mathrm{g}$ DM under control conditions to $7.7 \mu \mathrm{mol} / \mathrm{g}$ DM under salt stress (Table 7).

\section{Aliphatic GSL under salt stress}

Under salt stress, the aliphatic GSL ranged from $0.33 \mu \mathrm{mol} / \mathrm{g}$ to $8.59 \mu \mathrm{mol} / \mathrm{g}$. They declined by 39\%, from $7 \mu \mathrm{mol} / \mathrm{g}$ DM under control conditions to $4.31 \mu \mathrm{mol} / \mathrm{g} \mathrm{DM}$ under salt stress, representing $60 \%$ of total GSL (Table 8). All types showed a dramatic decrease except RAA, which significantly increased to $0.43 \mu \mathrm{mol} / \mathrm{g} \mathrm{DM}$. The proportion of RAA is $13 \%$ of the aliphatic GSL and $6 \%$ of the total GSL, respectively. The major components, PRO, GBN and GNA, were found in values of $1.7 \mu \mathrm{mol} / \mathrm{g} \mathrm{DM}$, 
$1.4 \mu \mathrm{mol} / \mathrm{g}$ DM and $0.37 \mu \mathrm{mol} / \mathrm{g} \mathrm{DM}$, respectively. The shares of PRO, GBN and GNA in the aliphatic GSL are $40 \%, 32 \%$ and $9 \%$, respectively, and their ratios in the total GSL are $24 \%, 19 \%$ and $5 \%$, respectively. The respective concentrations of RAE and GNL are $0.29 \mu \mathrm{mol} / \mathrm{g}$ DM and $0.04 \mu \mathrm{mol} / \mathrm{g}$ DM. Together; they represent less than $8 \%$ of the aliphatic GSL content and less than $5 \%$ of the total GSL content (Figure 6a, b and Table 7). Interestingly, under salt stress the parental lines Mansholts and Samourai and the DH population showed an increase in RAA.

\section{Indolic GSL under salt stress}

The indolic GSL increased by 5\% from $2.6 \mu \mathrm{mol} / \mathrm{g}$ DM under control conditions to 2.7 $\mu \mathrm{mol} / \mathrm{g}$ DM under salt stress (Table 8). The minimum and the maximum values were $0.98 \mu \mathrm{mol} / \mathrm{g} \mathrm{DM}$ to $5.88 \mu \mathrm{mol} / \mathrm{g} \mathrm{DM}$, respectively, with an average of $2.7 \mu \mathrm{mol} / \mathrm{g} \mathrm{DM}$. The indolic GSL are $38 \%$ of the total GSL (Table 8). The concentration of the dominant component $\mathrm{GBC}$ is $2.36 \mu \mathrm{mol} / \mathrm{g} \mathrm{DM}$, which represents $86 \%$ of the indolic GSL and $33 \%$ of the total GSL. The amounts of NAS, $4 \mathrm{OH}$ and $4 \mathrm{ME}$ were $0.49,0.77$ and 0.25 respectively. Altogether, the minor components share $14 \%$ of the indolic class and $5 \%$ of the total GSL content (Figures $6 a, b$ and $8 a, b$, and Table 7).

\section{Aromatic GSL under salt stress}

The single component NEO showed a dramatic increase of $75 \%$. NEO ranged from $0.07 \mu \mathrm{mol} / \mathrm{g} \mathrm{DM}$ to $4.55 \mu \mathrm{mol} / \mathrm{g} \mathrm{DM}$, with an average of $0.72 \mu \mathrm{mol} / \mathrm{g} \mathrm{DM}$, which represents $10 \%$ of total GSL (Figures $6 a$, b and 9 and Table 8).

\subsubsection{Correlations}

Under control conditions, the aliphatic GSL components correlate positively and significantly with each other in most cases; this is expected because they share the same precursor. The correlations of the aliphatic GSL components with the indolic ones were positive. Nevertheless, the correlation between GNA and GBC was negative and significant $\left(r=-0.24^{\star *}\right)$. Similarly, $4 \mathrm{OH}$ correlated negatively and significantly with GNA RAA $\left(r=-0.23^{\star \star}\right)$. As to the indolic GSL, the correlations were positive and significant between all components except $4 \mathrm{OH}$, which correlated negatively with the remaining indolic ingredients, where the correlation was negative and significant with $4 \mathrm{ME}\left(r=-0.18^{\star}\right)$, (Table 9).

Similarly, under salt stress, the aliphatic components correlated positively with each other. Likewise, the correlations among the different indolic GSL constituents were positive except $4 \mathrm{OH}$, which revealed a weak and negative correlation with $\mathrm{GBC}$ and NAS. In the context of correlation between the aliphatic and the indolic GSL components, PRO and GBN exhibited negative correlations with all the indolic GSL components except NAS. Surprisingly, the correlations of NEO as an aromatic GSL with the individuals of the aliphatic and the indolic GSL were negative, especially with the major aliphatic GSL components (Table 10). 
Table IV-7: Minimum maximum and mean of GSL content $\mu$ Mol/g DM of Brassica napus mapping population Mansholts $\times$ Samourai and parents under control and salt treatment $(200 \mathrm{mM} \mathrm{NaCl})$

\begin{tabular}{|c|c|c|c|c|c|c|c|c|c|c|}
\hline \multirow[t]{3}{*}{ Traits } & \multicolumn{6}{|c|}{ DH population } & \multirow{2}{*}{\multicolumn{2}{|c|}{$\frac{\text { Mansholts }}{\text { Mean }}$}} & \multirow{2}{*}{\multicolumn{2}{|c|}{$\frac{\text { Samourai }}{\text { Mean }}$}} \\
\hline & \multicolumn{2}{|c|}{ Min } & \multicolumn{2}{|c|}{ Max } & \multicolumn{2}{|c|}{ Mean } & & & & \\
\hline & Control & Salt & Control & Salt & Control & Salt & Control & Salt & Control & Salt \\
\hline PRO & 0.40 & 0.00 & 6.56 & 4.88 & 3.28 & 1.73 & 4.04 & 3.91 & 1.97 & 0.89 \\
\hline GNL & 0.00 & 0.00 & 0.24 & 0.78 & 0.08 & 0.04 & 0.08 & 0.00 & 0.01 & 0.12 \\
\hline RAA & 0.00 & 0.00 & 0.72 & 1.77 & 0.15 & 0.43 & 0.03 & 0.82 & 0.04 & 0.39 \\
\hline RAE & 0.00 & 0.00 & 1.03 & 1.39 & 0.45 & 0.29 & 0.18 & 0.07 & 0.12 & 0.13 \\
\hline GNA & 0.00 & 0.00 & 4.66 & 1.87 & 1.12 & 0.37 & 1.15 & 0.63 & 0.67 & 0.25 \\
\hline $4 \mathrm{OH}$ & 0.00 & 0.00 & 1.23 & 0.49 & 0.21 & 0.05 & 0.14 & 0.03 & 0.16 & 0.01 \\
\hline GBN & 0.18 & 0.00 & 3.62 & 3.48 & 1.58 & 1.40 & 2.10 & 2.76 & 1.44 & 0.89 \\
\hline GBC & 0.24 & 0.65 & 3.58 & 5.72 & 1.67 & 2.36 & 1.02 & 1.49 & 1.26 & 0.83 \\
\hline NAS & 0.00 & 0.00 & 1.34 & 0.77 & 0.56 & 0.25 & 0.51 & 0.33 & 0.37 & 0.11 \\
\hline $4 \mathrm{ME}$ & 0.00 & 0.00 & 0.30 & 0.60 & 0.17 & 0.09 & 0.17 & 0.07 & 0.16 & 0.04 \\
\hline NEO & 0.00 & 0.00 & 0.48 & 2.58 & 0.18 & 0.72 & 0.17 & 0.51 & 0.22 & 0.38 \\
\hline SUM & 1.71 & 2.50 & 16.00 & 13.33 & 9.47 & 7.69 & 9.59 & 10.62 & 6.41 & 4.06 \\
\hline
\end{tabular}

- $C=$ Control $S=$ Salt 
Table IV-8: Minimum, maximum and mean values of the major categories; aliphatic, indolic and aromatic GSL $\mu \mathrm{mol} / \mathrm{g} \mathrm{DM}$ of Brassica napus mapping population Mansholts $\times$ Samourai and parents under control and salt treatment $(200 \mathrm{mM} \mathrm{NaCl})$

\begin{tabular}{|c|c|c|c|c|c|c|c|c|c|c|c|c|c|c|c|c|}
\hline \multirow[t]{3}{*}{ Traits } & & & \multicolumn{6}{|c|}{ DH population } & \multicolumn{4}{|c|}{ Mansholts } & \multicolumn{4}{|c|}{ Samourai } \\
\hline & \multicolumn{2}{|c|}{ Min } & \multirow{2}{*}{$\frac{\operatorname{Max}}{\mathrm{C}}$} & \multicolumn{3}{|c|}{ Mean } & \multicolumn{2}{|c|}{ Percentage } & \multicolumn{2}{|c|}{ Mean } & \multicolumn{2}{|c|}{ Percentage } & \multicolumn{2}{|c|}{ Mean } & \multicolumn{2}{|c|}{ Percentage } \\
\hline & $\mathrm{C}$ & $\mathrm{S}$ & & $\mathrm{S}$ & $\mathrm{C}$ & $\mathrm{S}$ & C & $\mathrm{S}$ & C & $\mathrm{S}$ & $\mathrm{C}$ & $\mathrm{S}$ & C & $\mathrm{S}$ & $\mathrm{C}$ & $\mathrm{S}$ \\
\hline Aliphatic & 0.63 & 0.33 & 13.50 & 8.59 & 6.67 & 4.23 & $70 \%$ & $55 \%$ & 7.58 & 8.18 & $80 \%$ & $77 \%$ & 4.24 & 2.68 & $66 \%$ & $66 \%$ \\
\hline Indolic & 1.63 & 0.98 & 4.88 & 5.98 & 2.62 & 2.74 & $28 \%$ & $35 \%$ & 1.84 & 1.62 & $18 \%$ & $18 \%$ & 1.95 & 0.99 & $30 \%$ & $24 \%$ \\
\hline Aromatic & 0.00 & 0.07 & 0.48 & 4.55 & 0.18 & 0.72 & $2 \%$ & $10 \%$ & 0.17 & 0.05 & $2 \%$ & $5 \%$ & 0.16 & 0.38 & $34 \%$ & $10 \%$ \\
\hline
\end{tabular}

- $C=$ Control $S=$ Salt 
Table IV-9: Spearman's rank correlations of glucosinolates in Brassica napus mapping population Mansholts $\times$ Samourai under control condition

\begin{tabular}{|c|c|c|c|c|c|c|c|c|c|c|c|}
\hline & PRO & GNL & RAA & RAE & GNA & $4 \mathrm{OH}$ & GBN & GBC & NAS & $4 \mathrm{ME}$ & NEO \\
\hline GNL & 0.16 & & & & & & & & & & \\
\hline RAA & $0.36^{\star *}$ & 0.02 & & & & & & & & & \\
\hline RAE & $0.39 * *$ & 0.06 & 0.002 & & & & & & & & \\
\hline GNA & $0.62^{* *}$ & 0.10 & 0.13 & 0.15 & & & & & & & \\
\hline $4 \mathrm{OH}$ & 0.10 & $-0.26 \star *$ & $-0.23^{\star *}$ & -0.10 & 0.29 ** & & & & & & \\
\hline GBN & $0.75^{\star \star}$ & 0.16 & $0.43^{* *}$ & $0.36^{* *}$ & $0.60^{\star \star *}$ & -0.11 & & & & & \\
\hline GBC & 0.05 & 0.16 & $0.20 *$ & 0.02 & $-0.24^{\star \star}$ & -0.15 & 0.06 & & & & \\
\hline NAS & $0.28 * \star$ & $0.24^{\star \star}$ & $0.54^{\star *}$ & $0.17^{*}$ & $0.18^{*}$ & -0.17 & $0.41^{* *}$ & $0.26^{\star \star}$ & & & \\
\hline $4 \mathrm{ME}$ & 0.06 & $0.29 * \star$ & $0.31^{\star *}$ & 0.07 & -0.13 & $-0.18^{*}$ & 0.16 & $0.58^{\star *}$ & $0.36^{\star \star}$ & & \\
\hline NEO & 0.07 & $0.25^{\star \star}$ & 0.16 & 0.03 & -0.10 & $-0.19 *$ & 0.10 & 0.50 ** & $0.18^{*}$ & $0.57^{\star \star}$ & \\
\hline SUM & $0.84^{\star *}$ & $0.21^{*}$ & $0.38^{\star \star}$ & $0.37^{* *}$ & $0.62^{\star \star}$ & 0.09 & $0.81^{\star *}$ & 0.30 ** & $0.49 * *$ & $0.29 * *$ & $0.20^{*}$ \\
\hline
\end{tabular}

Table IV-10: Spearman's rank correlations of glucosinolates in Brassica napus mapping population Mansholts $\times$ Samourai under salt stress $(200 \mathrm{mM} \mathrm{NaCl})$ condition

\begin{tabular}{|c|c|c|c|c|c|c|c|c|c|c|c|}
\hline & PRO & GNL & RAA & RAE & GNA & $4 \mathrm{OH}$ & GBN & GBC & NAS & $4 \mathrm{ME}$ & NEO \\
\hline GNL & -0.10 & & & & & & & & & & \\
\hline RAA & $0.55^{\star \star}$ & -0.005 & & & & & & & & & \\
\hline RAE & $0.21^{*}$ & 0.04 & -0.05 & & & & & & & & \\
\hline GNA & $0.55^{\star \star}$ & -0.40 & $0.47^{\star *}$ & 0.10 & & & & & & & \\
\hline $4 \mathrm{OH}$ & -0.10 & $0.17^{*}$ & 0.12 & $0.24^{\star \star}$ & 0.05 & & & & & & \\
\hline GBN & $0.64^{* *}$ & -0.06 & $0.52^{\star \star}$ & 0.05 & $0.66^{\star *}$ & -0.004 & & & & & \\
\hline
\end{tabular}


Chapter IV

Table 10 continued from page 94

\begin{tabular}{|c|c|c|c|c|c|c|c|c|c|c|c|}
\hline GBC & -0.07 & -0.12 & 0.004 & -0.01 & $-0.24^{\star \star}$ & -0.003 & $-0.28 * \star$ & & & & \\
\hline NAS & $0.46^{\star *}$ & -0.06 & $0.57^{\star \star}$ & -0.04 & 0.39 ** & -0.01 & $0.49^{\star \star}$ & -0.07 & & & \\
\hline $4 \mathrm{ME}$ & -0.14 & -0.06 & 0.02 & 0.15 & $-0.18^{*}$ & $0.26^{\star \star}$ & -0.29 ** & $0.39 * \star$ & -0.02 & & \\
\hline NEO & $-0.19 *$ & -0.08 & -0.15 & 0.05 & $-0.22^{\star \star}$ & 0.01 & 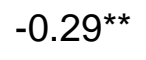 & 0.29 ** & -0.12 & $0.37^{\star *}$ & \\
\hline SUM & $0.73^{* *}$ & -0.10 & $0.55^{\star \star}$ & $0.22^{*}$ & $0.45^{\star *}$ & 0.08 & $0.52^{\star \star}$ & $0.37^{\star *}$ & $0.46^{\star *}$ & $0.19 *$ & 0.17 \\
\hline
\end{tabular}




\subsubsection{QTL analysis and localization}

The QTL mapping produced ten putative QTL under control and 26 QTL under salt stress conditions. The full description of all mapped QTL, flanking markers, additive effects, and positions is shown in Tables 11 and 12. The QTL localizations and their distribution on linkage groups (LGs) are summarized in Figure 11. A positive QTL additive effect means that Mansholts alleles are increasing the GSL content and a negative additive effect means that Samourai alleles are increasing the GSL content.

\section{QTL associated with the aliphatic GSL under control and salt stress conditions}

For the aliphatic GSL, 13 QTL were mapped, five QTL under control and eight QTL under salt stress conditions. All of the QTL described in this paragraph show positive additive effects, indicating that the alleles for increasing the corresponding component are inherited from the parent with high GSL content, i.e. Mansholts. In the case of PRO under control conditions, one QTL, PRO-1C, was detected on LG C3, which explains 5\% of the phenotypic variation. Under salt stress, two QTL, PRO-1S and PRO-2S, were mapped on LGs A9 and C2, respectively. PRO-1S was mapped at a significance level $P=0.05$ and alone explains solely $29 \%$ of the phenotypic variation. PRO-2S explains $6 \%$ of the phenotypic variation. In the case of GNL, one QTL, GNL-1C, was identified on LG A3 at a significance level of $P=0.05$, which explains $6 \%$ of the phenotypic variation. No QTL were mapped for GNL under salt stress. Under control conditions, one QTL, RAA-1C, was mapped for RAA on LG C6, which explains $4 \%$ of the phenotypic variation. Likewise, under salt stress, one QTL: RAA-1S was detected on LG A9, which accounts for 8\% of the phenotypic variation. The QTL RAA-1S was identified at $P=0.05$. Regarding GNA, one QTL, GNA-1C, was mapped on LG A9, which explains $9 \%$ of the phenotypic variation.

For RAE under control conditions, one QTL, RAE-1C, was mapped on LG C8a, which governs 8\% of the variation; this QTL was identified at $P=0.05$ with a negative additive effect. No QTL for RAE were detected under salt stress. For GBN under control conditions, one QTL, GBN-1C, was identified on LG A4, explaining $5 \%$ of the variation with a negative additive effect. Under salt stress, four QTL GBN-1S, GBN-2S, GBN-3S and GBN-4S were detected on LGs, A8, C2, C5 and C9, respectively. Altogether they account for 42\% of the phenotypic variation. The first three QTL exhibit positive additive effects, while GBN-4S show a negative additive effect.

With regard to total aliphatic GSL, two QTL, Aliphatic-1C and Aliphatic-2C, were identified on LGs, i.e. A4 and A5, respectively. They together explain $12 \%$ of the observed phenotypic variation. The additive effect of Aliphatic-1C is negative, while the additive effect of Aliphatic-2C is positive. Three QTL were mapped for the total aliphatic GSL content under salt stress. Two QTL, Aliphatic-1S and Aliphatic-2S, were mapped on LG A9 at $34 \mathrm{cM}$ and $134 \mathrm{cM}$, respectively. The third QTL, Aliphatic-3S, was identified on LG C2. The additive effects of the three QTL are positive. These three QTL explain a large portion of the phenotypic variation of about 44\%. The two QTL, Aliphatic-1S and Aliphatic-3S, were mapped at $P=0.05$. 
QTL associated with the indolic GSL under control and salt stress conditions

Surprisingly, under control conditions, no QTL were mapped for GBC, NAS and 4ME. One QTL, $4 \mathrm{OH}-1 \mathrm{C}$, was positioned for $4 \mathrm{OH}$ on LG A3, which explains $5 \%$ of the phenotypic variation, with a negative additive effect. For $4 \mathrm{OH}$ under salt stress, two QTL, $4 \mathrm{OH}-1 \mathrm{~S}$ and $4 \mathrm{OH}-2 \mathrm{~S}$, were located on LGs C3 and C7, respectively. They collectively explain $17 \%$ of the observed phenotypic variation. The additive effects of both QTL were positive. For GBC, three QTL, i.e. GBC-1S, GBC-2S and GBC-3S, were detected on LGs A3, C2 and C7, respectively. These QTL explain $27 \%$ of the phenotypic variation; all of them exhibited positive additive effects. In the case of NAS, two QTL, NAS-1S and NAS-2S, were localized adjacent to the same LG C9 at $41 \mathrm{cM}$ and $52 \mathrm{cM}$, respectively. These two QTL explain in total $25 \%$ of the observed phenotypic variation. NAS-1S has a positive effect, while NAS-2S has a negative additive. In the case of 4ME, one QTL, 4ME-1S, was mapped on LG C4, which explains $4 \%$ of the phenotypic variation with a negative additive effect. No QTL was identified for the total indolic GSL under control conditions. Under salt stress, three QTL, Indolic-1S, Indolic-2S and Indolic-3S, were detected on LGs A3, C2 and $\mathrm{C} 7$, respectively. The QTL Indolic-3S was identified at $P=0.05$. The three $\mathrm{QTL}$ account for $25 \%$ of the phenotypic variation; for all QTL the additive effects were positive.

\section{QTL associated with the aromatic GSL under control and salt conditions}

Under control conditions, one QTL, NEO-1C, was mapped on LG A3; this QTL explains $5 \%$ of the phenotypic variation, with a negative additive effect. Under salt stress, two QTL, NEO-1S and NEO-2S, were mapped on LGs C2 and C4, respectively. Both QTL together explain $23 \%$ of the observed phenotypic variation. NEO-2S was identified at $P=0.05$ and alone accounts for $16 \%$ of the observed phenotypic variation. The additive effects of both QTL were negative.

\section{QTL associated with the total GSL content under control and salt conditions}

Under control conditions, one QTL, SUM-1C, was mapped on LG A9, which explains 4\% of the variation, with a positive additive effect. Under salt stress, two QTL; SUM-1S and SUM-2S, were mapped on LGs A3 and A9, respectively. These two QTL explain 34\% of the variation of the total GSL content. SUM-1S and SUM-2S show positive additive effects. The QTL SUM-2S was mapped at significance level $P=0.05$ and show a remarkable effect, accounting for $27 \%$ of the variation.

It is important to mention that the total GSL content data for seed were provided by Dr. Ecke, Department of Crop Sciences, Division of plant Breeding, Georg-August Universität, Göttingen. These data have been published (Uzunova et al. 1995). We have included the data of total seed GSL as a check in the QTL analysis. 
Chapter IV

Table IV-11: QTI detected at LOD > 1.2 under control treatment (C) for glucosinolates $\mu \mathrm{mol} / \mathrm{g}$ DM in Brassica napus mapping population Mansholts $\times$ Samourai. (QTL significant with $P=0.05$ are marked bold)

\begin{tabular}{|c|c|c|c|c|c|c|c|c|}
\hline Trait & Name of QTL & Chrom & LOD & $\begin{array}{l}\text { Position } \\
\text { (cM) }\end{array}$ & Intervals & Flanking markers & $\begin{array}{c}\text { Additive } \\
\text { Effect }\end{array}$ & $\begin{array}{c}\text { Phenotypic variation } \\
\text { explained (\%) }\end{array}$ \\
\hline GNL & GNL-1C & A3 & 1.5 & 9 & $6-19$ & WG4D10.E1 -RP1422.E1 & 0.01 & 5.6 \\
\hline RAE & RAE-1C & C8a & 2.2 & 72 & $71-75$ & RP1144.H1 -CB10454 & -0.06 & 7.9 \\
\hline $4 \mathrm{OH}$ & $4 \mathrm{OH}-1 \mathrm{C}$ & C3 & 1.9 & 0 & $0-5$ & E3247.2 -E3348.5 & 0.10 & 7.0 \\
\hline GBN & GBN-1C & A4 & 1.2 & 55 & $53-61$ & WG4A4.H1 -RP1235.H2 & -0.15 & 4.5 \\
\hline Aliphatic & Aliphatic-2C & A5 & 1.7 & 134 & $130-146$ & E3347.3 -BRAS063b & 0.58 & 6.1 \\
\hline SUM & SUM-1C & A9 & 1.1 & 115 & $96-119$ & TG2F9.H1 -E3362.7 & 0.65 & 4.0 \\
\hline SEED & SEED-1 & A9 & 13.9 & 24 & $19-29$ & WG3F7.H1 -RP1175.H1 & 7.96 & 43.5 \\
\hline SEED & SEED-2 & $\mathrm{C} 2$ & 2.3 & 111 & $101-121$ & RP1249.H1 -WG7A8.H1 & 2.89 & 9.1 \\
\hline SEED & SEED-3 & C6 & 3.4 & 55 & $54-60$ & CB10278 -WG7E10.H2 & 3.49 & 13.0 \\
\hline
\end{tabular}

- $\quad$ Additive effect was calculated by subtracting Samourai alleles by Mansholts alleles.

- The seed glucosinolates data are provided by Dr. Ecke; the data came from two experiments conducted $1992 / 1993$ as field experiments in Reinshof, Göttingen. 
Table IV-12: QTL detected at LOD > 1.2 under salt treatment (S) for glucosinolates $\mu$ mol/g DM in Brassica napus DH population Mansholts $\times$ Samourai. (QTL significant with $P=0.05$ are marked bold)

\begin{tabular}{|c|c|c|c|c|c|c|c|c|}
\hline Trait & Name of QTL & LG & LOD & $\begin{array}{l}\text { Position } \\
\text { (cM) }\end{array}$ & Intervals & Flanking markers & $\begin{array}{l}\text { Additive } \\
\text { Effect }\end{array}$ & $\begin{array}{c}\text { Phenotypic variation } \\
\text { explained (\%) } \\
\end{array}$ \\
\hline PRO & PRO-2S & $\mathrm{C} 2$ & 1.7 & 122 & $115-127$ & RP1249.H1 - WG7A8.H1 & 0.21 & 6.2 \\
\hline GNA & GNA-1S & A9 & 2.6 & 16 & $13-19$ & MD41 $\quad-W 3 F 7 . H 1$ & 0.08 & 9.1 \\
\hline $4 \mathrm{OH}$ & $4 \mathrm{OH}-1 \mathrm{~S}$ & C3 & 2.3 & 125 & $113-130$ & RP1477.E1 -RP459.H1 & 0.20 & 8.3 \\
\hline $4 \mathrm{OH}$ & $4 \mathrm{OH}-2 \mathrm{~S}$ & C7 & 2.6 & 91 & $81-105$ & WG6C1.E1 -TG5B2.H1 & 0.01 & 9.1 \\
\hline GBN & GBN-3S & $\mathrm{C} 5$ & 1.8 & 47 & $41-51$ & OPT9.862 -RP981.H1 & 0.17 & 6.7 \\
\hline GBN & GBN-4S & $\mathrm{C9}$ & 3.4 & 97 & $91-98$ & RP668.E2 -WG1G2.H1 & -0.24 & 12.1 \\
\hline GBC & GBC-1S & A3 & 1.9 & 109 & $106-116$ & WG2D5.H1 -RP1013.E1 & 0.24 & 7.1 \\
\hline GBC & GBC-2S & $\mathrm{C} 2$ & 3.4 & 113 & $110-119$ & RP1249.H1 -WG7A8.H1 & -0.34 & 12.1 \\
\hline GBC & GBC-3S & $\mathrm{C7}$ & 2.1 & 67 & $62-77$ & RP318b.E1 -CB10546 & 0.28 & 7.7 \\
\hline NAS & NAS-1S & $\mathrm{C9}$ & 4.9 & 41 & $37-44$ & RP1100.E1 -E3347.6 & 0.12 & 16.4 \\
\hline NEO & NEO-2S & C4 & 4.6 & 119 & $116-123$ & WG4A4.H2 -TG3D1.H1 & -0.23 & 15.7 \\
\hline Aliphatic & Aliphatic-1S & A9 & 8.4 & 17 & 13-19 & MD41 - WG3F7.H1 & 1.30 & 26.8 \\
\hline Aliphatic & Aliphatic-2 S & A9 & 1.9 & 96 & $91-97$ & RP1253.E1- TG2F9.H1 & 0.54 & 9.1 \\
\hline Aliphatic & Aliphatic-3S & $\mathrm{C} 2$ & 2.6 & 106 & $100-111$ & WG2D11.E1- RP1249.H1 & 0.48 & 7.8 \\
\hline Indolic & Indolic-1 S & A3 & 1.9 & 110 & $105-118$ & RP1013.E1- RP1605.H1 & 0.249 & 7.0 \\
\hline Indolic & Indolic-2 S & $\mathrm{C} 2$ & 3.5 & 111 & $110-117$ & RP1249.H1- WG7A8.H1 & -0.34 & 12.0 \\
\hline Indolic & Indolic-3 S & C7 & 1.7 & 66 & $62-74$ & RP318b.E1- CB10546 & 0.31 & 7.4 \\
\hline SUM & SUM-1S & A3 & 2.0 & 120 & $109-131$ & RP1013.E1 -RP1605.H1 & 0.57 & 7.3 \\
\hline SUM & SUM-2S & A9 & 8.4 & 21 & $18-26$ & WG3F7.H1 -RP1175.H1 & 1.19 & 26.7 \\
\hline
\end{tabular}



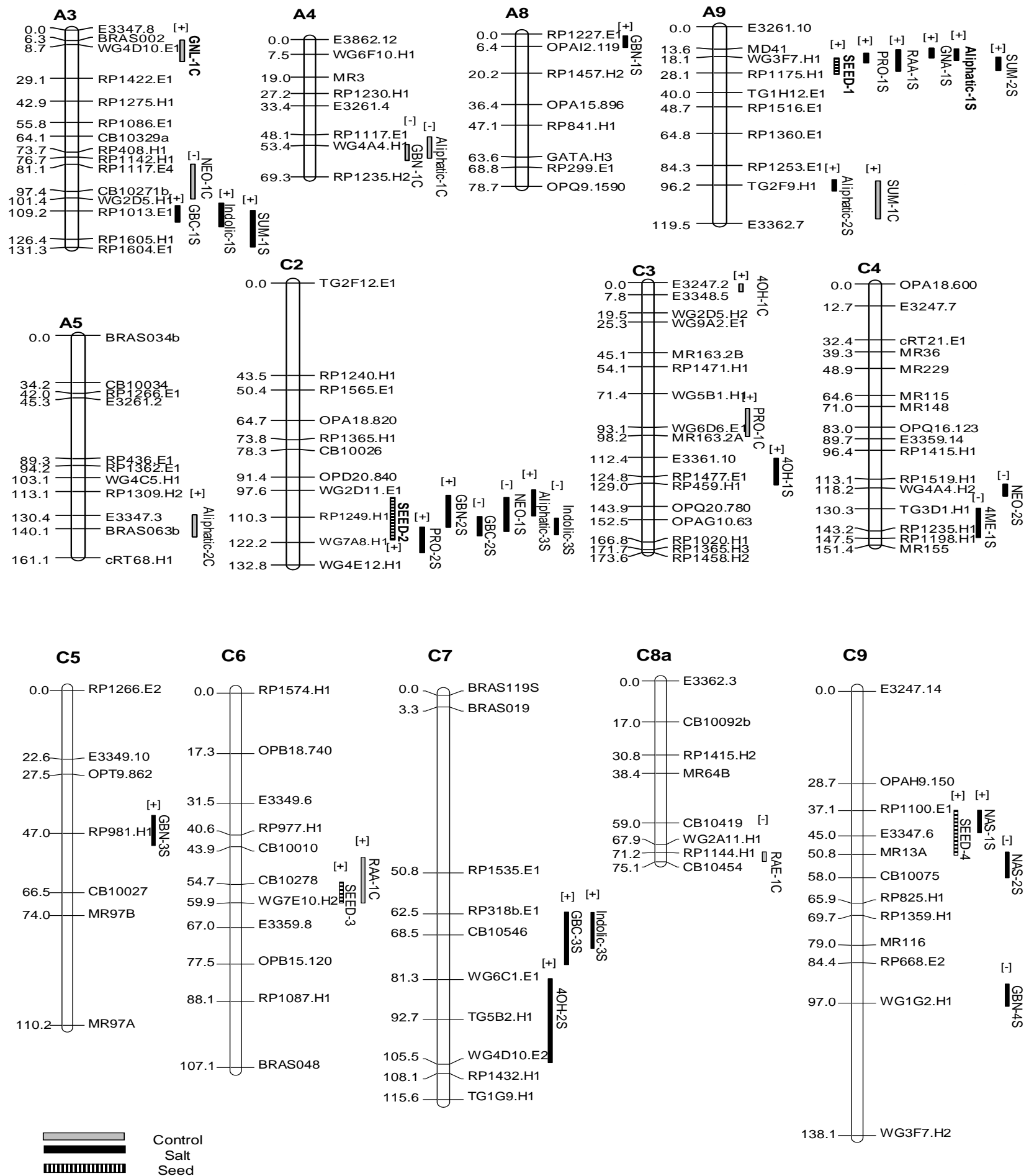

Figure IV-11: Localization of QTL for glucosinolates $\mu \mathrm{Mol} / \mathrm{g}$ DM in Brassica napus $\mathrm{DH}$ population Mansholts $\times$ Samourai. (QTL significant with $P=0.05$ are marked bold) 


\subsection{Discussion II}

\subsubsection{Variation of GSL under control conditions and salt stress conditions}

The aliphatic GSL were predominant in both parental lines and DH populations. Among them, the alkenyl GSL: PRO, GBN and GNA dominated under control and salt conditions. These findings are in harmony with the results of Mithen (1992), who found alkenyl GSL were abundant in $B$. napus leaves, while indolic GSL were the dominant ones in the roots and stem (Mithen 1992). Two aliphatic GSL types are known to be present in lower concentrations, RAA and ALY. Under control conditions, the former was found in a concentration of $0.08 \mu \mathrm{mol} / \mathrm{g} \mathrm{DM}$, and the second was absent. This finding is consistent with data reported by (Mithen 1992). Under control conditions, the correlation between PRO and its precursor GNA was positive and significant, which can be explained by the high activity of the hydroxylation enzymes in converting GNA to PRO. GNA is derived from RAA through desaturation and loss of the methylsulphinyl moiety by the GS-ALK gene; GNA is hydroxylated by the gene GS-OH to PRO (Li and Quiros 2003). This assumption is supported by taking into consideration that the hydroxylation step under optimal growth conditions is accelerated due to the availability of nitrogen (Yan and Chen 2007). The negative and significant correlation between GNA and GBC might be due to the fact that both are substrates for the hydroxylation enzymes. This negative correlation indicates that there is cross-talk between the biosynthesis cascades of the aliphatic GSL and the indolic GSL. Under salt stress, the correlation of PRO with all the indolic GSL was negative; this is most likely due to the alteration in the GSL biosynthesis to increase the indolic GSL and to decrease the aliphatic GSL. The elevation of GBC under salt stress could be attributed to a decline in the hydroxylation event to produce the hydroxylated indolyl GSL component (McDanell et al. 1988). This hypothesis is supported by the negative correlation between $\mathrm{GBC}$ and $4 \mathrm{OH}$.

Under salt stress, the total GSL content of the $\mathrm{DH}$ population decreased. Our results agree with the findings of Pang et al. (2012) in the salt-tolerant Thellungiella halophila, where the GSL content decreased to under $300 \mathrm{mM} \mathrm{NaCl}$. In contrast to the reduction in total GSL, the indolic GSL exhibited an increase, which agrees with the results of Xin et al. (2008), who found an increase in the total indolic and aromatic GSL in Arabidopsis under $150 \mathrm{mM} \mathrm{NaCl}$. Troufflard et al. (2010) stated that in Arabidopsis, the indolic GSL increased under K-deficiency growth conditions. Therefore, we can conclude that the increase in the indolic GSL in this population is attributed to $\mathrm{K}$ deficiency, which is a consequence of salt stress. The cross-talk between the biosynthesis of aliphatic and indolic GSL was evident in Arabidopsis (Gigolashvili et al. 2009), and in Brassica rapa ssp. Pekinensis (Kim et al. 2013). These authors reported that several transcription factors belonging to the cytochrome 450 family are involved in the biosynthesis of both the indolic and aliphatic GSL. The reduction or blocking of the biosynthesis of the aliphatic GSL is accompanied by an increase in the indolic GSL and vice versa (Grubb and Abel 2006).

Notably, GBC and RAA show an increase, suggesting that they are involved in salt tolerance. In accordance with our results, Guo et al. (2013) observed a 2.1-fold 
increase in sulforaphane, which is one of the products of glucoraphanin hydrolysis under $100 \mathrm{mM} \mathrm{NaCl}$ in Brassica oleracea var. italica cv. Youxiu. The aliphatic GSL RAA possesses three Sulfur atoms. After RAA degradation the released sulfur atoms are responsible for the antioxidant leverage of RAA. Probably, plants tend to accumulate RAA, to hydrolyze it under the sub-optimal growth conditions and to use these three Sulfur atoms to cope with salt stress (reviewed by Falk et al. 2007). Traka et al. (2013) report that in broccoli the accumulation of RAA might due to the steering of assimilates to enrich methionine-derived GSL biosynthesis. The increase in GBC indicates that it acts as an antioxidant. Furthermore, GBC drives the biosynthesis of auxin, which stimulates root growth in Arabidopsis thaliana under sub-optimal growth conditions, aiding the plant to look for more nutrients (reviewed by Falk et al. 2007). López-Berenguer et al. (2008) proposed that GSL under salt stress play a role in osmotic adjustment. This conclusion is doubtful because the concentration of GSL is much lower than other the components involved in the osmotic adjustment, such as $\mathrm{K}^{+}, \mathrm{N}^{+}$and organic metabolites like proline and glycine betaine. The plausible function of glucosinolates under salt stress might be to overcome the deleterious effects of the reactive oxygen species (ROS) that were generated under salt stress.

Several scenarios have been proposed to explain the reduction in total GSL under salt stress. Under salt stress, plants tend to reduce the biosynthesis of some metabolites, including GSL (Pang et al. 2012, López-Berenguer et al. 2009). This assumption was supported by the findings of Steinbrenner et al. (2012) in B. rapa, where they found that temporal stresses like salinity delayed the accumulation of some metabolites, including GSL. Under unfavorable conditions, the biosynthesis of GSL is costly (Textor and Gershenzon 2009). A reduction in GSL under salt stress might result from the leakage of GSL from the vacuole to the cytosol where they are hydrolyzed by myrosinase (Pang et al. 2012). Additionally, it has been reported that GSL are a reservoir for nutrients, like Nitrogen and Sulfur. One of the effects of salinity is to cause nutrient deficiency; therefore, plants hydrolyze GSL and benefit from the released elements as an alternative, so as to ensure the primary stages of metabolism such as protein biosynthesis (reviewed by Martinez-Ballesta et al. 2013).

\subsubsection{QTL analysis and localization}

In the case of $B$. napus, much less is known about the genetic control of leaf GSL compared to seed glucosinolates. Under control conditions, almost none of the aliphatic-specific QTL and indolic-specific QTL showed intervals of overlapping. This finding suggests that different genomic regions control the biosynthesis of both classes individually. Most likely, the genes that reside in these regions are involved in side chain modification. Two QTL, GNL-1C on LG A3 and GBN-1C on LG A4, were mapped for the aliphatic 5C hydroxylated forms, which suggests the presence of two genes. The first one catalysis the side chain elongation, such as GS-Elong, and the second controls the hydroxylation step, like the GS-OH gene (Li and Quiros 2003, Kliebenstein et al. 2001a). The interval of this QTL GBN-1C overlaps with the QTL for the sum of the aliphatic GSL. This is expected because GBN is one of the major aliphatic components. Two QTL, PRO-1C and GNL-1C, were mapped on LGs: C3 and 
A3, respectively, this result shows that two homologous genes are controlling the hydroxylation step one in the A genome and the second in the $\mathrm{C}$ genome. In agreement with this, Howell et al. (2003) found that the loci on A9, C2 and C9 were homoeologous loci.

QTL for aliphatic GSL were identified in the A genome on LGs A3, A4, A5. These findings support those of Lou et al. (2008) and Feng et al. (2012), they found QTL for the aliphatic GSL on LGs A3 and A4, however, they used different plant material. These results suggest that the QTL that have been identified in these different studies on these LGs are major QTL that control leaf GSL variation. The QTL for RAA was mapped on LG C6 in the C genome. This is not totally unexpected because it was evident that the members with the $C$ genome have high concentrations of $R A A$. For total leaf GSL content, one QTL, SUM-1C, was detected on LG A9. Notably, this QTL was mapped at the bottom of the linkage group, while a major QTL for total seed GSL was mapped at the top of this LG. This means the presence a novel locus uniquely controlling the leaf GSL variation.

Twenty-six QTL were identified under salt stress. Of special importance is the presence of two hotspots encompassing 11 QTL: five QTL on A9 and six QTL on C2, where two major QTL for seed GSL were mapped earlier by Uzunova et al. (1995). The hotspot on A9 includes five QTL for different kinds of aliphatic GSL and one QTL for total GSL. This finding suggests that many genes are included in the aliphatic GSL biosynthesis of this genomic region. This co-localization is expected because all of them are methionine-derived GSL. It is likely that this genomic region harbors genes involved in the aliphatic GSL biosynthesis, such as GSL-Elong converting 4methylthiobutyl into RAA and GS-ALK converting RAA in to GNA after which GNA undergoes a hydroxylation step to PRO (Li and Quiros 2003). The co-localization of QTL for total seed GSL and QTL for leaves on LGs: A9, C2 and C9 is consistent with the results of Harper et al. (2012) in B. napus. the gene expression marker (GEM) and SNP leaves associated well with the genes underlying the seed GSL accumulation. Interestingly, of the 11 QTL, five QTL for the aliphatic GSL co-localize with the major QTL for seed GSL on A9 and six QTL coincide with the second major seed GSL QTL on C2, while only one QTL co-localizes with the third major seed GSL on C9. Strong support for our results came from those of Harper et al. (2012), who found that the gene expression marker (GEM) and SNP QTL associated strongly with the previously detected seed QTL on C2, and A9, while the association on C9 was the weakest. These loci may harbor specific genes, transcription factors or enzymes independently regulating the accumulation of methionine-derived GSL. In Arabidopsis transcription factors MYB28 (At5g61420), MYB29 (At5g07690) and MYB76 (At5g07700) increase only the accumulation of the aliphatic GSL (Gigolashvili et al. 2007b, Sønderby et al. 2007). The overexpression of these transcription factors is induced by abiotic stressors like wounding (Gigolashvili et al. 2008).

On LG C2, two QTL for kinds other than methionine-derived GSL were clustered with QTL of the aliphatic GSL, which suggests the presence of genes that induce the 
biosynthesis of indolic and aromatic GSL. The more plausible explanation is that the salt stress reduces the biosynthesis of aliphatic GSL and induces the biosynthesis of indolic and aromatic GSL. There is evidence that in $B$. napus leaf treatment with Jasmonic acid (JA) or methyljasmonate (MeJA) strongly induced the biosynthesis of indolic GSL (Bodnaryk 1994). Mikkelsen et al. (2003) demonstrated in Arabidopsis that indolic GSL increased 3- to 4-fold after treatment with methyljasmonate (MeJA) or after wounding. This elevation in the indolic GSL was owing to the overexpression of the genes CYP79B2 and CYP79B3, which regulate the indolyl GSL biosynthesis. Most likely, the genes in these genomic are involved in the GSL core structure formation. Otherwise, these regions harbor an orthologous of the gene, At1g18570, which encodes the transcription factor HIG1 (high indolic glucosinolates1), the over expression of this gene increased indolyl GSL biosynthesis and reduced the levels of aliphatic GSL in Arabidopsis thaliana (Gigolashvili et al. 2007b).

The additive effects of the QTL, which were mapped earlier for seed total GSL and leaf aliphatic GSL on A9, were positive, suggesting that the alleles that increase seed and leaf GSL are inherited from Mansholts, the parent with the high seed and leaf GSL content. On LG C2 the additive effect of QTL for indolic and aromatic QTL was negative, while QTL for the aliphatic GSL showed positive additive effects. This means the alleles for increasing aliphatic GSL were inherited from Mansholts and alleles for indolyl GSL were passed on by Samourai. The increase in the indolic and aromatic GSL may be attributed to the decoding of some genes that regulate the rate of indolic and aromatic GSL biosynthesis. One of them is the gene CYP83B1, which catalyzes the transformation of aromatic and indolic aldoximes into their corresponding GSL class (reviewed by Halkier and Gershenzon 2006).

\section{Conclusion}

Worth mentioning is that under salt stress, the two GSL type, RAA and GBC, which are known as antioxidants, showed significant increases. Based on these outcomes, our results are in harmony with several results that were reported earlier. The reduction in total GSL in the $\mathrm{DH}$ population may be added to a reduction in the biosynthesis of several secondary products, among them GSL degradation by myrosinase or GSL redistribution. Interestingly, the major two QTL hotspots include the major two QTL for seed GSL and the QTL for leaf GSL. On A9, all QTL that were co-localized with the QTL for seed GSL were mapped for aliphatic GSL. The second hotspot on C2 includes QTL for aliphatic and indolic GSL, suggesting an intercross between the accumulations of both classes. The impact of salinity on GSL biosynthesis and accumulation is still an open question. Further work on leaf GSL content is of great importance to come to a comprehensive understanding of the genetic and metabolic mechanisms that lie behind the variation of GSL under salt stress 


\section{Chapter V}

\section{Mapping QTL for salt tolerance at the young plant stage and leaf glucosinolates in a Brassica oleracea DH population}

\subsection{Introduction}

Brassica oleracea is a diploid plant species $(2 n=18)$ and is one of the major edible vegetable crops worldwide. There are mainly six prominent groups. Kales (var. acephala) include green kale, marrow stem kale and collards. Other forms are widely used as edible forage. Cabbages (var. capitata, var. sabauda, var. bullata) include headed cabbages, brussel sprouts, savoy cabbage, and others, as well as kohlrabi (var. gongylodes). Inflorescence kales (var. botrytis, var. italica) include cauliflower, broccoli, sprouting broccoli, and others, as well as branching bush kales (var. fruticosa) and Chinese kale ( $B$. alboglabra), which are used as leafy vegetables (Rakow 2004). The large number of morphotypes developed by human selection reflects their malleability to be differentiated into distinctive crops in their growth habits and morphological features (Branca and Careta 2011). In the context of salt tolerance, broccoli and cauliflower were ranked as moderately salt tolerant, while cabbage and brussels sprouts were classified as moderately salt-sensitive (reviewed by Shannon and Grieve 1998). Brassica oleracea was classified as salt-sensitive compared with B. rapa and B. napus (Ashraf et al. 2001). The salt tolerance of Brassica oleracea var. capitata cultivar 'Golden Acre' was improved significantly by metabolic engineering via transformation with a bacterial betA gene (Bhattacharya et al. 2004).

Brassica oleracea has a distinctive glucosinolate profile with significant quantities of methylthioalkyl and methylsulphinylalkyl. This seems to be plentiful within the cultivated forms of $B$. oleracea (Magrath et al 1993). López-Berenguer et al. (2008) hypothesized that the accumulation of GSL in $B$. oleracea under salt stress plays a role in the osmotic adjustment. Likewise, Guo et al. (2013) observed a 2.1-fold increase in sulforaphane under $100 \mathrm{mM} \mathrm{NaCl}$ in Brassica oleracea var. italica cv. Youxiu.

\subsection{The objectives of this chapter are}

1. To assess the effect of salinity on growth at the young plant stage in a $B$. oleracea, and to map the QTL that control salt tolerance.

2. To study the variation in leaf glucosinolate under control and salt stress conditions and to identify the QTL underlying these. 


\section{Part I}

\section{Mapping QTL for salt tolerance at the young plant stage in B. oleracea}

\subsection{Materials and methods}

\subsubsection{Plant material}

A doubled-haploid (DH) population of Brassica oleracea Bo1TBDH of $138 \mathrm{DH}$ lines was tested in the greenhouse. This population was derived from a F1 individual, which was in turn derived by crossing a $\mathrm{DH}$ rapid cycling TO1000DH3 line and a $\mathrm{DH}$ broccoli line Early Big (Iñiguez-Luy et al. 2009). The full description of this population is summarized in Chapter 3 (3.3.1).

\subsubsection{Greenhouse experiment}

The parental lines plus $138 \mathrm{DH}$ lines were tested in the greenhouse at the Department of Crop Sciences, Division of Plant Breeding, Georg-August Universität, Göttingen. The first replicate was sown December 3, 2012 and harvested January 25, 2013. The second replicate started on January 28, 2013 and harvested on March 4, 2013. The experimental design and salt application method are described in details in Chapter 4 (4.1). The soil mixture, number of seeds per pot, number of pots for each genotype and lightning regime are also described in Chapter 4 (4.2). The fluctuation in temperature for each replicate and the mean of temperature over the time course of the two replicates are in Appendix 7. The average light intensities were $197 \mu \mathrm{mol} / \mathrm{m}^{\star}{ }^{*} \mathrm{~s}$ for experiment one and $260 \mu \mathrm{mol} / \mathrm{m}^{*}{ }^{*} \mathrm{~s}$ for experiment two. The light intensity was measured with Sunscan SS1 (Delta-T, England). The relative humidity was $35 \%$. The salt treatment was started on day 25 , with $50 \mathrm{mM} \mathrm{NaCl}$ for the first application and increased to a final concentration of $100 \mathrm{mM} \mathrm{NaCl}$ on day 30 . Seven genotypes were placed randomly on each table as checks. The traits measured and the methods used are given in Chapter 4 (3.2). The chlorophyll content was measured by a SPAD-meter Minolta 502 (Osaka, Japan). The leaf GSL content analysis is described in detail in Chapter 4 (4.4). For the statistical analysis, the values of each trait were adjusted as described above and the software and model are described in Chapter 4 (4.5).

\section{Trait abbreviations}

Fresh weight $(\mathrm{g})=\mathrm{FW}$

Dry weight $(\mathrm{g}) \quad=\mathrm{DW}$

Relative water content $=$ RWC

Chlorophyll content measured by SPAD1 and SPAD2

Sodium content (mg/ g DM) $\mathrm{Na}^{+}$

Potassium content (mg/g DM) $\mathrm{K}^{+}$

Sodium /Potassium ratio $\mathrm{Na}^{+} / \mathrm{K}^{+}$

Dry matter DM

Parental lines names abbreviations in figures;

$\mathrm{EB}=$ Early Big $\quad \mathrm{TO}=\mathrm{TO} 1000 \mathrm{DH}$ 


\subsection{Results I}

\subsubsection{Traits variations}

The fresh weight (FW), dry weight (DW) relative water content (RWC), chlorophyll content were measured by (SPAD), sodium content $\left(\mathrm{Na}^{+} \mathrm{mg} / \mathrm{g} \mathrm{DM}\right)$, potassium content $\left(\mathrm{K}^{+} \mathrm{mg} / \mathrm{g} \mathrm{DM}\right)$ and sodium/potassium ratio $\left(\mathrm{Na}^{+} / \mathrm{K}^{+}\right)$were recorded. The parental lines show little variation for the traits fresh biomass and dry biomass under both control and salt treatments (Appendix 7). In contrast, a large genetic variation was observed among the $\mathrm{DH}$ lines. The genotypic variation, heritabilities calculated from the analysis of variance (ANOVA) for all traits under control and salt treatment are summarized in Table 1. The minimum and maximum ranges of the above mentioned traits and mean values are given in Appendix 5. A transgressive segregation was observed for all treats under both growing conditions (Figures 1, 2, 3 and 4)

\section{Fresh weight}

Under control conditions, $86(62 \%)$ of the $\mathrm{DH}$ lines exhibited high FW compared to Early Big, the parent with the higher FW. On the other hand, $24 \mathrm{DH}$ lines (17\%) produced a lower FW than TO1000DH3, the parent with low FW. The range of FW varied from $2.7 \mathrm{~g}$ to $6.8 \mathrm{~g}$. Under salt treatment, most of the $\mathrm{DH}$ lines $(112=81 \%)$ showed better performance than Early Big (Figure 1a, b). Only nine DH lines (7\%) produced less fresh biomass than TO1000DH3, the parent with low FW. The minimum and the maximum values were $0.96 \mathrm{~g}$ and $3.7 \mathrm{~g}$, respectively.

\section{Dry weight}

Under control conditions, out of $138 \mathrm{DH}$ lines, 17 (12\%) showed lower DW compared with TO1000DH3, the parent with low DW, while $90 \mathrm{DH}$ lines (65\%) displayed DW higher than Early Big, the superior parent. The DW values varied from $0.11 \mathrm{~g}$ to 0.58 g. Likewise, under salt stress, few genotypes showed a DW lower than the weak parent, whereas five $\mathrm{DH}$ lines (4\%) produced a DW less than TO1000DH3. A large set comprises $115 \mathrm{DH}$ lines (83\%) produced DW higher than Early Big. The minimum and maximum values were $0.11 \mathrm{~g}$ and $0.35 \mathrm{~g}$, respectively (Figure $1 \mathrm{c}, \mathrm{d}$ ).

\section{Relative water content}

Under control conditions, a set of $27 \mathrm{DH}$ lines (20\%) revealed RWC lower than TO1000DH3, the parent with low RWC, whereas $69 \mathrm{DH}$ lines (50\%) showed RWC higher than Early Big, the parent with high RWC. The $\mathrm{DH}$ population values ranged from 87 to 95. Under salt treatment, RWC was lower than TO1000DH3 in only nine $\mathrm{DH}$ lines and higher than Early Big in 112 lines (81\%) (Figure 2a, b).

\section{Chlorophyll content measured by SPAD}

Figure $3 a, b$ shows the segregation under control conditions, where $27 \mathrm{DH}$ lines (20\%) had a chlorophyll content lower than TO1000DH3, the parent with low SPAD values. A large set of $\mathrm{DH}$ lines $(74=52 \%)$ exhibit SPAD values higher than Early Big, the parent with the high SPAD values. The lowest value was 34 and the highest 62 . Under salt stress, $12 \mathrm{DH}$ lines (9\%) exhibited SPAD values lower than TO1000DH3, while $72 \mathrm{DH}$ 
lines (52\%) showed SPAD values higher than Early Big (Figure 3a, b); the average ranged from 34 to 67.

\section{Sodium content}

A dramatic increase in the $\mathrm{Na}^{+}$content under salt stress was observed relative to the $\mathrm{Na}^{+}$content under control. Under control conditions, $59 \mathrm{DH}$ lines (43\%) showed a lower $\mathrm{Na}^{+}$content than Early Big, the parent with the lower $\mathrm{Na}^{+}$content, while, $67 \mathrm{DH}$ lines (49\%) revealed a higher $\mathrm{Na}^{+}$content than $\mathrm{TO} 1000 \mathrm{DH} 3$, the parent with the high $\mathrm{Na}^{+}$content. The range was between $1.43 \mathrm{Na}^{+} \mathrm{mg} / \mathrm{g} \mathrm{DM}$ and $4.44 \mathrm{Na}^{+} \mathrm{mg} / \mathrm{g} \mathrm{DM}$. Under salinity stress, TO1000DH3 showed $\mathrm{Na}^{+}$content higher than Early Big. A group of $14 \mathrm{DH}$ lines (10\%) exhibited a $\mathrm{Na}^{+}$content lower than Early Big and larger group of $\mathrm{DH}$ lines 73 (53\%) had sodium content higher than TO1000DH3 (Figure 4a, b). The lowest and the highest values were $17.5 \mathrm{mg} / \mathrm{g}$ DM and $54.3 \mathrm{mg} / \mathrm{g}$, respectively.

\section{Potassium content}

Out of the $138 \mathrm{DH}$ lines, four genotypes (3\%) under control conditions showed a $\mathrm{K}^{+}$ content lower than Early Big, the parent with the low $\mathrm{K}^{+}$content, while, $77 \mathrm{DH}$ lines (56\%) had a $\mathrm{K}^{+}$content higher than TO1000DH3, the parent with the high $\mathrm{K}^{+}$content,. The values ranged from $57.67 \mathrm{mg} / \mathrm{g}$ DM to $81.61 \mathrm{mg} / \mathrm{g} \mathrm{DM}$. Surprisingly, under salt stress, the $\mathrm{K}^{+}$content of $\mathrm{TO} 1000 \mathrm{DH} 3$ was higher than Early Big. A large set encompassing $115 \mathrm{DH}$ lines (83\%) showed a lower $\mathrm{K}^{+}$content than Early Big. At the same time, a small set of nine $\mathrm{DH}$ lines (7\%) exhibited a higher $\mathrm{K}^{+}$content than to TO1000DH3 (Figure 4c, d). The minimum and maximum values were $22.3 \mathrm{mg} / \mathrm{g}$ DM to $59.61 \mathrm{mg} / \mathrm{g}$ DM.

\section{Sodium and potassium ratio}

Under control conditions, $64 \mathrm{DH}$ lines (46\%) had a lower $\mathrm{Na}^{+} / \mathrm{K}^{+}$ratio than Early Big, the parent with the low $\mathrm{Na}^{+} / \mathrm{K}^{+}$ratio, and 40 genotypes (28\%) showed a higher $\mathrm{Na}^{+} / \mathrm{K}^{+}$ratio than TO1000DH3, the parent with high $\mathrm{Na}^{+} / \mathrm{K}^{+}$. The minimum and maximum values lie between 0.03 and 0.06 . Under salinity stress, only $3(2 \%) \mathrm{DH}$ lines showed a lower $\mathrm{Na}^{+} / \mathrm{K}^{+}$than Early Big. A large set of $105 \mathrm{DH}$ lines $(76 \%)$ showed a $\mathrm{Na}^{+} / \mathrm{K}^{+}$ratio higher than $\mathrm{TO} 1000 \mathrm{DH} 3$ (Figure $4 \mathrm{e}, \mathrm{f}$ ). The values ranged from 0.31 to 1.26 .

\subsubsection{Correlations}

The related traits, such as $\mathrm{FW}$ and $\mathrm{DW}$ or $\mathrm{Na}^{+}$content and $\mathrm{Na}^{+} / \mathrm{K}^{+}$ratio show significant positive correlations with each other. There is a positive correlation between FW and DW under control $\left(r=0.85^{\star \star}\right)$ and salt $\left(r=0.83^{\star *}\right)$ conditions. Likewise, $\mathrm{Na}^{+}$content and $\mathrm{Na}^{+} / \mathrm{K}^{+}$are positively correlated under control and salt conditions, with $\left(r=0.89^{\star \star}\right)$ and $\left(r=0.87^{\star *}\right)$, respectively (Tables 2 and 3). The correlations of FW and DW with $\mathrm{Na}^{+}$content and $\mathrm{Na}^{+} / \mathrm{K}^{+}$are negative and insignificant under control conditions, whereas a significant negative correlation can be observed under salt (Tables 2 and 3). There are significant positive correlations between RWC and all traits under control and salt conditions, except with DW and SPAD. Under control and salt stress, the correlation of SPAD with the remaining traits is negative, 
Chapter V

except for FW and DW, which is positive (Table 2 and 3). A significant positive correlation can be observed between $\mathrm{K}^{+}$content and all traits except RWC, $\mathrm{Na}^{+}$ content and the $\mathrm{Na}^{+} / \mathrm{K}^{+}$ratio, which is negative and significant under control as well as salt stress (Tables 2 and 3 ).

a) Control

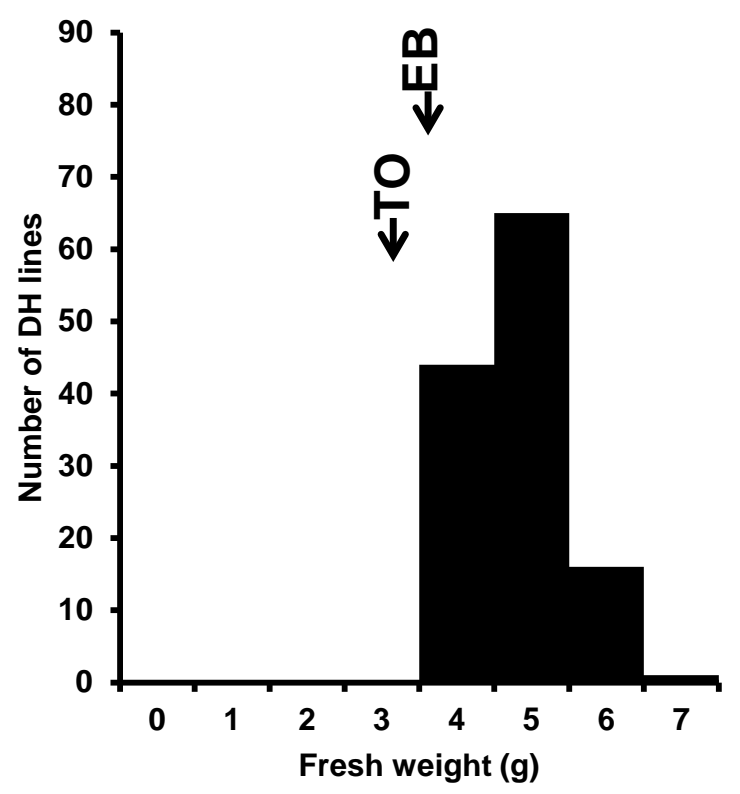

c) Control

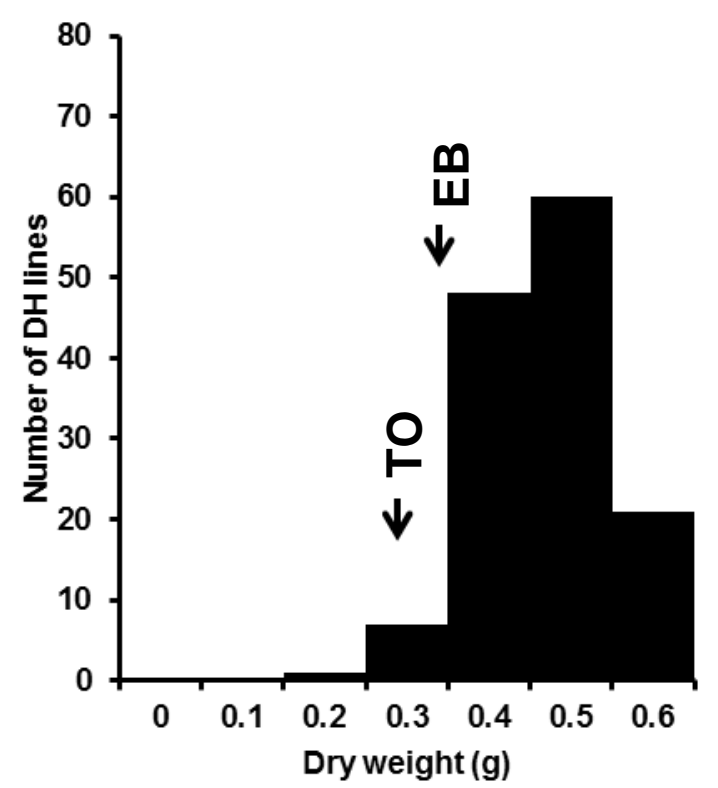

b) Salt

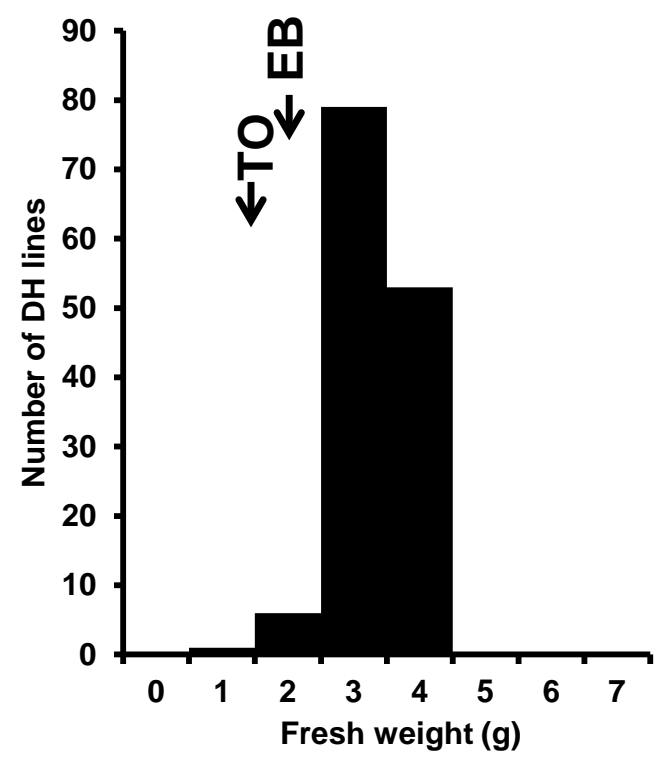

d) Salt

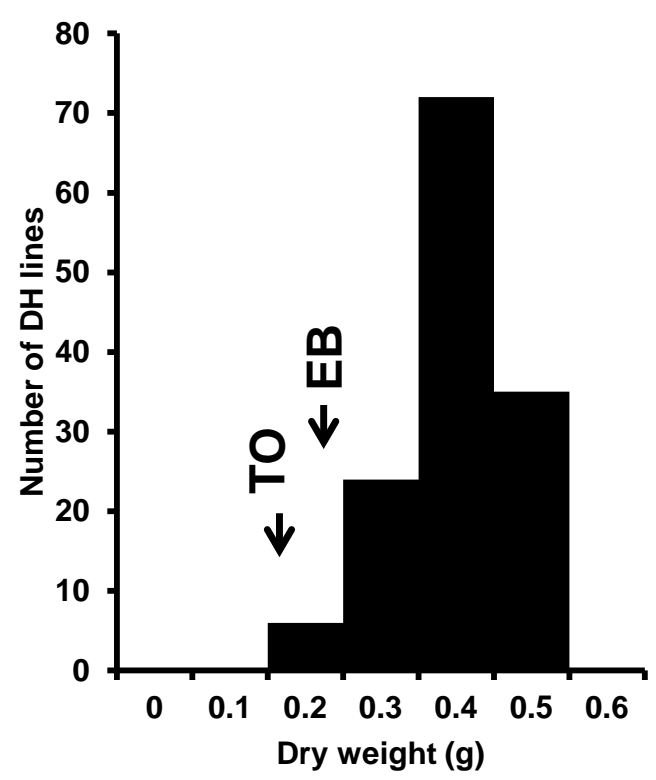

Figure V-1: Frequency distribution of fresh weight and dry weight of Brassica oleracea Bo1TBDH population a) Fresh weight under control, b) Fresh weight under salt stress, c) Dry weight under control and d) Dry weight at salt stress 

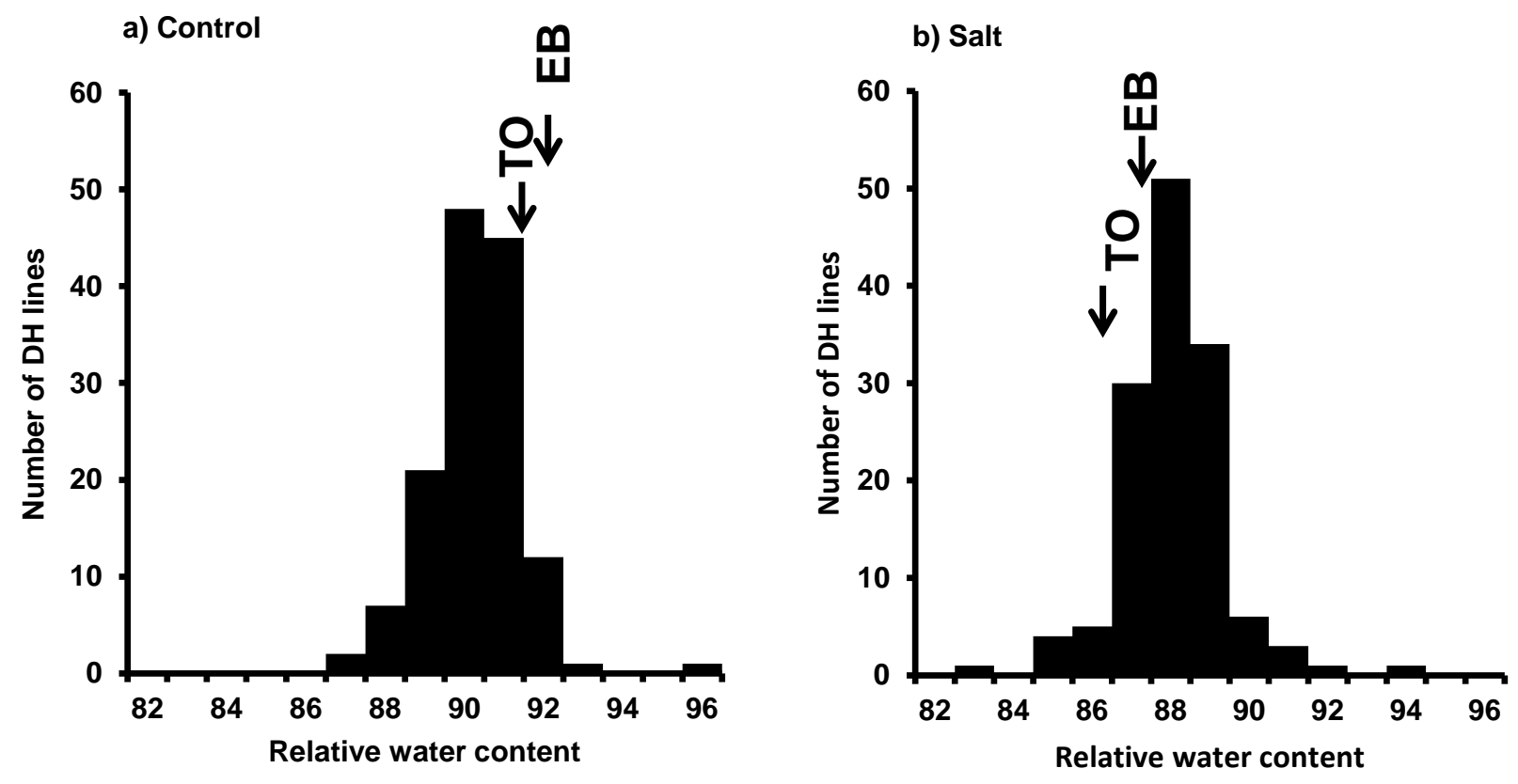

Figure V-2: Frequency distribution of relative water content of Brassica oleracea Bo1TBDH population a) Relative water content under control and b) Relative water

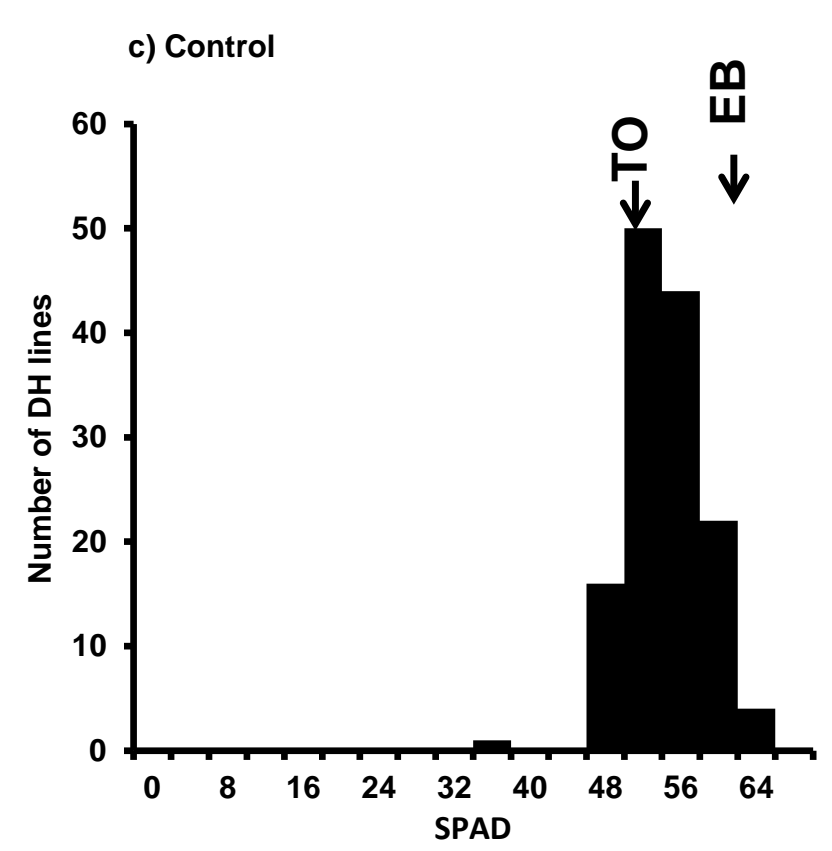

d) Salt

$\stackrel{\circ}{\vdash} \underset{w}{m}$

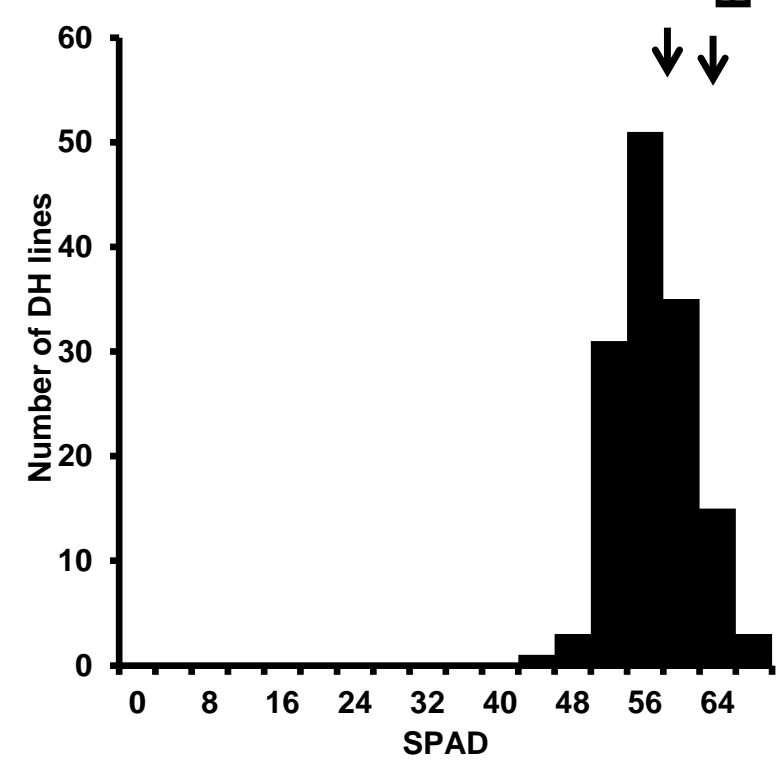

Figure V-3: Frequency distribution of chlorophyll content measured by SPAD of Brassica oleracea Bo1TBDH population a) SPAD under control and b) SPAD under salt stress 
Table V-1: Mean squares, respective F tests, and heritabilities estimated from the ANOVA of Brassica oleracea mapping population $\mathrm{Bo1TBDH}, 138 \mathrm{DH}$ lines were tested under control conditions and at salt treatment $(100 \mathrm{mM} \mathrm{NaCl})$

\begin{tabular}{|c|c|c|c|c|c|c|c|c|}
\hline & & Control & & & & Salt & & \\
\hline $\begin{array}{c}\text { Sources of } \\
\text { Variance }\end{array}$ & Genotypes (G) & Replicates (R) & $\mathbf{G} \times \mathbf{R}$ & $h^{2}$ & Genotypes (G) & Replicates (R) & $\mathbf{G} \times \mathbf{R}$ & $\mathbf{h}^{2}$ \\
\hline DF & 137 & 1 & 137 & & 137 & 1 & 137 & \\
\hline$F W(g)$ & $1.32^{\star \star}$ & $5.31^{\star \star}$ & 0.28 & 78.52 & $0.59 * \star$ & $11.45^{\star \star}$ & $0.17^{\star \star}$ & 70.90 \\
\hline $\mathrm{DW}(\mathrm{g})$ & $0.01^{\star \star}$ & $0.021^{*}$ & 0.004 & 70.6 & $0.010 * \star$ & $0.003^{\star *}$ & 0.003 & 71.37 \\
\hline RWC & 36.56 ** & $388.33^{\star *}$ & 9.126 & 75.04 & $36.25 * \star$ & $372.17^{\star *}$ & 6.90 & 80.95 \\
\hline SPAD1 & $2.47^{* *}$ & $54.90 * *$ & 1.1632 & 52.96 & $6.48^{\star *}$ & $185.34^{\star \star}$ & 3.97 & 38.75 \\
\hline $\mathrm{Na}^{+} \mathrm{mg} / \mathrm{g} \mathrm{DM}$ & 0.26 & - & - & - & 35.5 & - & - & - \\
\hline $\mathrm{K}^{+} \mathrm{mg} / \mathrm{g} \mathrm{DM}$ & 60.90 & - & - & - & 43.6 & - & - & - \\
\hline $\mathrm{Na}^{+} / \mathrm{K}^{+}$ & 0.001 & - & - & - & 0.03 & - & - & - \\
\hline
\end{tabular}

- ** Significant at $P=0.01 ;{ }^{*}$ significant at $P=0.05$ and + significant at $P=0.1$

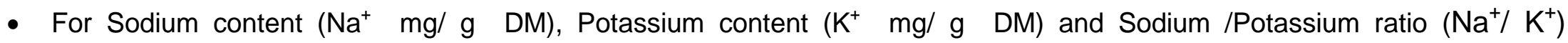
the dry matter of each genotype of replicate one was combined with replicate two, therefore there were no replication and no heritability was calculated for these traits. 
a) Control

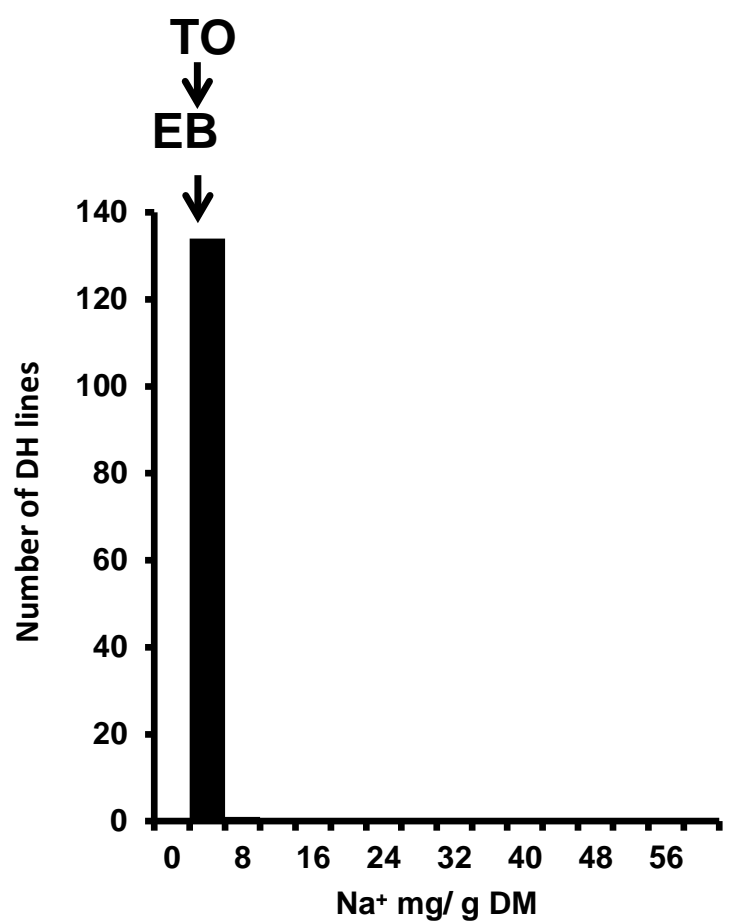

c) Control

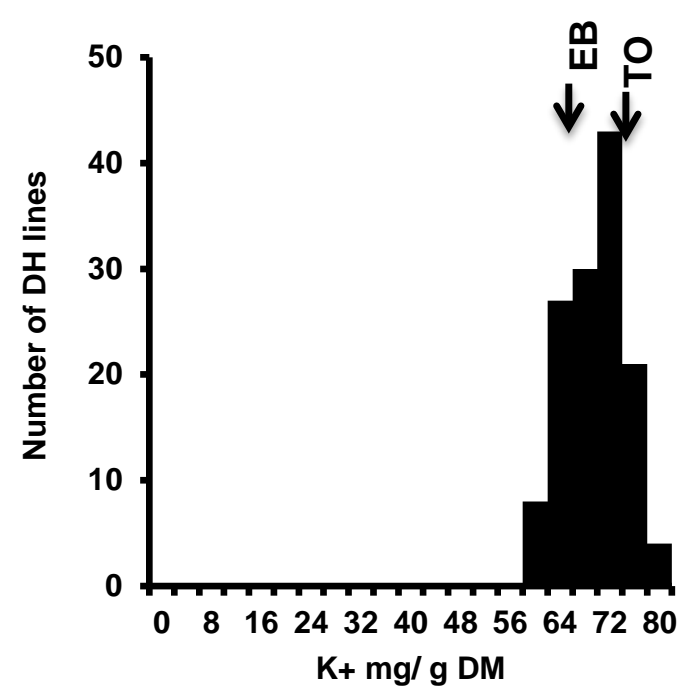

b) Salt

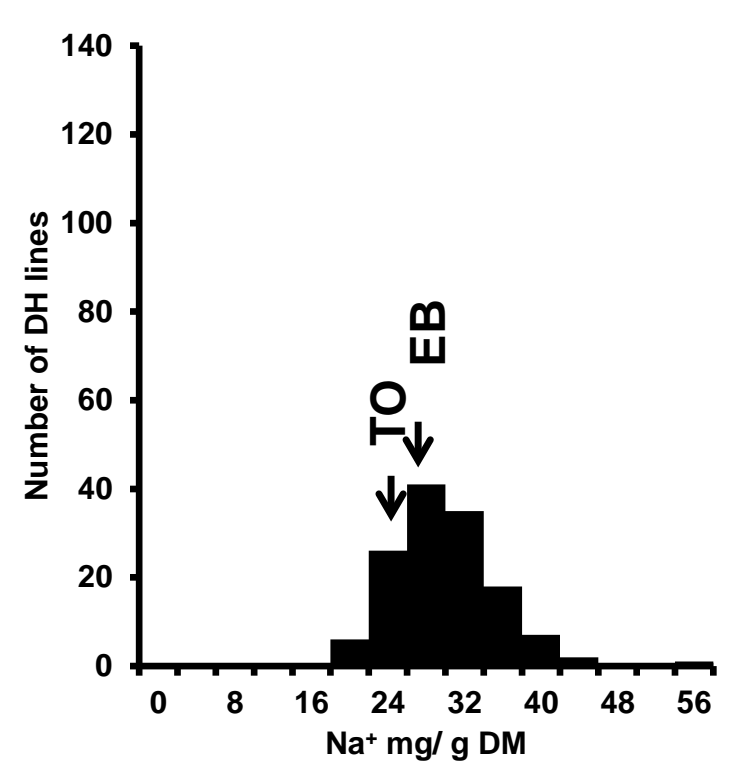

d) Salt

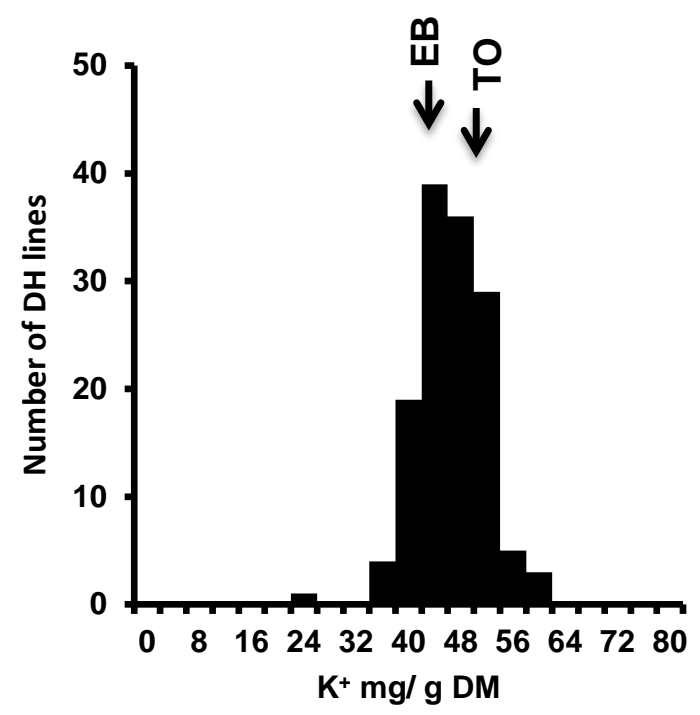

Figure V-4: Frequency distribution of sodium content $\mathrm{Na}^{+} \mathrm{mg} / \mathrm{g} \mathrm{DM}$ and potassium content $\mathrm{K}^{+} \mathrm{mg} / \mathrm{g}$ DM of Brassica oleracea Bo1TBDH population a) Sodium content under control, b) Sodium content under salt stress , C) Potassium content under control, d) Potassium content under salt stress, e) $\mathrm{Na}^{+} / \mathrm{K}^{+}$ratio under control and f) $\mathrm{Na/K}$ ratio under salt stress 
Figure V-4 continued from page 112

e) Control

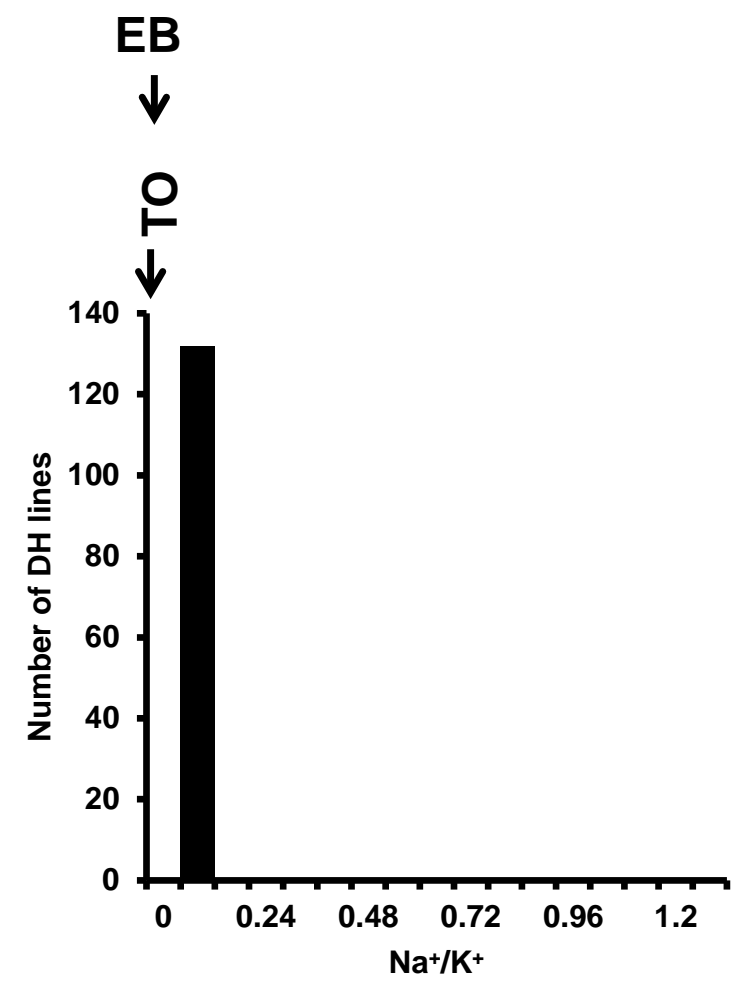

f) Salt

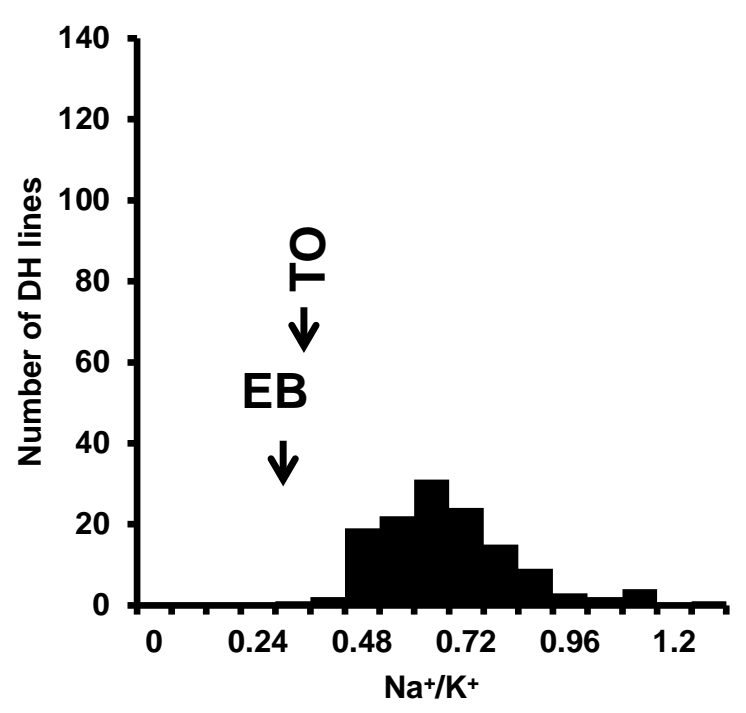


Table V-2: Spearman's rank correlation of growth traits for Brassica oleracea Bo1TDH under control conditions

\begin{tabular}{|c|c|c|c|c|c|c|}
\hline & FW (g) & DW (g) & RWC & SPAD & $\mathrm{Na}^{+} \mathrm{mg} / \mathrm{g} \mathrm{DM}$ & $\mathrm{K}^{+} \mathrm{mg} / \mathrm{g} \mathrm{DM}$ \\
\hline Dw (g) & $0.85^{\star \star}$ & & & & & \\
\hline RWC & $0.33^{\star *}$ & -0.13 & & & & \\
\hline SPAD & 0.12 & $0.20 *$ & -0.11 & & & \\
\hline $\mathrm{Na}^{+} \mathrm{mg} / \mathrm{g} \mathrm{DM}$ & -0.14 & -0.30 & $0.17^{*}$ & $-0.23^{\star *}$ & & \\
\hline $\mathrm{K}^{+} \mathrm{mg} / \mathrm{g} \mathrm{DM}$ & $0.20 *$ & 0.01 & $0.32^{\star *}$ & $-0.27^{\star \star}$ & $0.23^{* *}$ & \\
\hline $\mathrm{Na}^{+} / \mathrm{K}^{+}$ & $-0.21^{*}$ & $-0.30 * *$ & 0.02 & -0.11 & $0.88^{* *}$ & $-0.20^{\star}$ \\
\hline
\end{tabular}

Table V-3: Spearman's rank correlation of growth traits for Brassica oleracea Bo1TDH under salt stress (100 mM NaCl) conditions

\begin{tabular}{|c|c|c|c|c|c|c|}
\hline & FW (g) & $\mathrm{DW}(\mathrm{g})$ & RWC & SPAD & $\mathrm{Na}^{+} \mathrm{mg} / \mathrm{g} \mathrm{DM}$ & $\mathrm{K}^{+} \mathrm{mg} / \mathrm{g} \mathrm{DM}$ \\
\hline Dw (g) & $0.83^{\star *}$ & & & & & \\
\hline RWC & $0.226^{\star *}$ & $-0.21^{*}$ & & & & \\
\hline SPAD & 0.041 & $0.17^{*}$ & -0.12 & & & \\
\hline $\mathrm{Na}^{+} \mathrm{mg} / \mathrm{g} \mathrm{DM}$ & -0.161 & $-0.04^{\star \star}$ & $0.20 *$ & $-0.30 * \star$ & & \\
\hline $\mathrm{K}^{+} \mathrm{mg} / \mathrm{g} \mathrm{DM}$ & $0.332^{\star \star}$ & $0.20 *$ & $0.27^{\star \star}$ & -0.08 & $-0.25^{\star \star}$ & \\
\hline $\mathrm{Na}^{+} / \mathrm{K}^{+}$ & -0.053 & -0.06 & 0.03 & -0.20 & $0.87^{\star \star}$ & $-0.63^{\star \star}$ \\
\hline
\end{tabular}




\subsubsection{QTL analysis and localization}

A full map consisting of 279 markers was developed by Iñiguez-Luy et al. (2009), (Appendix 4). A framework with a sub-set of markers was constructed from the full map so as to have one marker per five to ten cM wherever possible. Thirty-one QTL were mapped on all LGs under control and salt stress conditions. Information about the logarithms of odds, intervals and flanking markers of the mapped QTL is summarized in Tables 4 and 5. Figure 5 shows the localization of the QTL mapped under control and salt stress. A positive additive effect means that the Early Big alleles increase the corresponding trait, while a negative additive effect means that the TO1000DH3 alleles increase the corresponding trait

\section{Fresh weight}

Four QTL were mapped under control conditions: FW-1C, FW-2C, FW-3C and FW4C. FW-3C was detected on LG C3 with significance level $P=0.05$. This QTL alone explains $19 \%$ of the phenotypic variation with a negative additive effect. The remaining three QTL together explain 32\% of the phenotypic variation and were detected on LGs C1, C3 and C7, respectively. QTL FW-1C has a positive additive effect, while the remaining two QTL have negative additive effects (Table 4). Under salt stress, two QTL, FW-1S and FW-2S, were identified on LGs C1 and C3, respectively. FW-1S explains $6 \%$ of the phenotypic variation with a positive additive effect. FW-2S explains $17 \%$ of the phenotypic variation and shows a negative additive effect (Table 5).

\section{Dry weight}

Under control conditions, one QTL, DW-1C was mapped at $P=0.05$ on LG C3. This QTL explains $9 \%$ of the phenotypic variation. Similarly, under salt stress, one QTL, DW-1S, was mapped on the same LG C3 at $P=0.05$, which explains $16 \%$ of the phenotypic variation. The two QTL, DW-1C and DW-1S show negative additive effects (Tables 4 and 5).

\section{Relative water content}

One QTL, RWC-1C, was identified under control conditions on LG C3 at $P=0.05$, which explains $8 \%$ of the phenotypic variation with a negative additive effect (Table 4). No QTL were mapped under salt stress.

\section{Chlorophyll content}

Nine QTL were mapped for the SPAD trait. Under control conditions, four QTL SPAD1C, SPAD-2C, SPAD-3C and SPAD-4C were mapped on the LGs C2, C4 and C8, respectively. SPAD-1C and SPAD-2C were localized on LG C2 at $67 \mathrm{cM}$ and $52 \mathrm{cM}$, respectively. Collectively, they explain $38 \%$ of the phenotypic variation. SPAD-1C, SPAD-2C and SPAD-3C show negative additive effects. SPAD-4C exhibits a positive additive effect (Table 4). Under salt stress, five QTL SPAD-1S, SPAD-2S, SPAD-3S, SPAD-4S and SPAD-5S were mapped. All of them are at $P=0.05$. They explain $80 \%$ of the phenotypic variation. SPAD-1S, SPAD-2S and SPAD-4S were localized on LGs C3, C4, and C6, respectively, with negative additive effects. SPAD-3S and SPAD-5S were mapped on LGs C4 and C8 with positive additive effects (Table 5). 


\section{Sodium content}

Under the control conditions, one QTL, Na-1C was detected on LG C9, which explains $16 \%$ of the phenotypic variation with a positive additive effect. Four QTL were mapped under salt stress, i.e. Na-1S, Na-2S, Na-3S and Na-4S on LGs: C1, C5, C8 and C9, respectively. Overall, they explain $38 \%$ of the phenotypic variation. For all of them the additive effects are negative. All of these QTL were mapped at $P=0.05$ (Tables 4 and 5).

\section{Potassium content}

Three QTL, K-1C, $\mathrm{K}-2 \mathrm{C}$ and $\mathrm{K}-3 \mathrm{C}$, were mapped under control treatment on the respective LGs C1, C3 and C8. They explain 26\% of the phenotypic variation. K-2C was mapped at $P=0.05$ with a negative effect. $\mathrm{K}-1 \mathrm{C}$ and $\mathrm{K}-3 \mathrm{C}$ show positive additive effects (Table 4). Two QTL, K-1S and K-2S, were mapped under salt treatment on LGs C1 and C8, respectively. K-1S and K-2S explain $16 \%$ of the phenotypic variation, whereas $\mathrm{K}-1 \mathrm{~S}$ showed a negative additive effect. The QTL, K-2S was mapped at $P=$ 0.05. This QTL exhibits a positive additive effect (Table 5).

\section{Sodium- potassium ratio}

No QTL were found for $\mathrm{Na}^{+} / \mathrm{K}^{+}$under control conditions, while three QTL under salt stress were mapped: $\mathrm{Na} / \mathrm{K}-1 \mathrm{~S}, \mathrm{Na} / \mathrm{K}-2 \mathrm{~S}$ and $\mathrm{Na} / \mathrm{K}-3 \mathrm{~S}$ were localized on LGs C1, C8 and C9, respectively. They account for $28 \%$ of the phenotypic variation. The QTL $\mathrm{Na} / \mathrm{K}-2 \mathrm{~S}$ was mapped at $P=0.05$. The $\mathrm{QTL} \mathrm{Na}^{+} / \mathrm{K}^{+}-1 \mathrm{~S}$ and $\mathrm{Na}^{+} / \mathrm{K}^{+}-2 \mathrm{~S}$ show negative additive effects, while $\mathrm{Na} / \mathrm{K}-3 \mathrm{~S}$ shows a positive additive effect (Table 5 ). 
Table V-4: QTL detected at LOD > 2 under control treatment (C) for fresh weight, dry weight, SPAD1, SPAD2, relative water content, Sodium content $\mathrm{Na}^{+} \mathrm{mg} / \mathrm{g}$ DM and Potassium content $\mathrm{K}^{+} \mathrm{mg} / \mathrm{g}$ DM in Brassica oleracea mapping population Bo1TBDH. (QTL significant with $P=0.05$ are marked bold)

\begin{tabular}{|c|c|c|c|c|c|c|c|c|}
\hline Trait & Name of QTL & LG & LOD & $\begin{array}{l}\text { Position } \\
\text { (cM) }\end{array}$ & Interval & Flanking markers & $\begin{array}{c}\text { Additive } \\
\text { Effect }\end{array}$ & $\begin{array}{c}\text { Phenotypic } \\
\text { variation explained } \\
(\%) \\
\end{array}$ \\
\hline FW & FW-1C & 1 & 3.9 & 64 & $60-70$ & pX101cX -pX122aH & 0.24 & 12.5 \\
\hline FW & $\mathrm{FW}-2 \mathrm{C}$ & 3 & 2.8 & 31 & $28-39$ & fito262 -fito156c & -0.27 & 9.0 \\
\hline FW & FW-3C & 3 & 6.0 & 57 & $51-63$ & pX111aD -fito394 & -0.39 & 18.5 \\
\hline FW & FW-4C & 7 & 3.1 & 96 & 91-109 & CHS28aX -fito098a & -0.21 & 10.0 \\
\hline DW & DW-1C & 3 & 2.9 & 59 & $52-64$ & pX111aD -fit394 & -0.03 & 9.3 \\
\hline RWC & RWC-1C & 3 & 2.5 & 39 & $32-48$ & fito262 -fito156c & -0.44 & 8.1 \\
\hline SPAD & SPAD-1C & 2 & 2.4 & 67 & $64-80$ & fito081a -pW161aX & -1.07 & 7.8 \\
\hline SPAD & SPAD-2C & 4 & 3.7 & 52 & $47-59$ & pW193bE -fito139b & -1.67 & 13.4 \\
\hline SPAD & SPAD-3C & 4 & 2.5 & 108 & $101-116$ & BRMS034 -pW177bH & -1.14 & 8.0 \\
\hline SPAD & SPAD-4C & 8 & 3.6 & 31 & $25-36$ & fito482 -pW231aX & 1.41 & 11.4 \\
\hline $\mathrm{Na} \mathrm{mg/g} \mathrm{DM}$ & $\mathrm{Na}-1 \mathrm{C}$ & 9 & 5.1 & 15 & $12-21$ & pW256bH -fito163 & 0.20 & 16.3 \\
\hline K mg/ g DM & $\mathrm{K}-1 \mathrm{C}$ & 1 & 2.2 & 40 & $37-47$ & pW249dE -fito094 & 1.33 & 7.4 \\
\hline $\mathrm{K} \mathrm{mg/g} \mathrm{DM}$ & $\mathrm{K}-2 \mathrm{C}$ & 3 & 3.4 & 65 & $58-70$ & fito394 -fito476 & -1.92 & 11.0 \\
\hline $\mathrm{K}$ mg/ g DM & $\mathrm{K}-3 \mathrm{C}$ & 8 & 2.3 & 69 & $60-77$ & pX130cD -fito373c & 1.42 & 7.8 \\
\hline
\end{tabular}

- $\quad$ Linkage group = LG

- $\quad$ Additive effect was calculated by subtracting TO1000DH3 allele by Early Big allele. 
Table V-5: QTL detected at LOD > 2 under salt treatment (S) for fresh weight, dry weight, SPAD1, SPAD2, relative water content, Sodium content $\mathrm{Na}^{+} \mathrm{mg} / \mathrm{g}$ DM and Potassium content $\mathrm{K}$ mg/ g DM in Brassica oleracea mapping population Bo1TBDH. (QTL significant with $P=0.05$ are marked bold)

\begin{tabular}{|c|c|c|c|c|c|c|c|c|}
\hline Trait & Name of QTL & LG & LOD & $\begin{array}{c}\text { Positio } \\
n \\
\text { (cM) } \\
\end{array}$ & Intervals & Flanking Markers & $\begin{array}{c}\text { Additive } \\
\text { Effect }\end{array}$ & $\begin{array}{c}\text { Phenotypic } \\
\text { variation explained } \\
(\%) \\
\end{array}$ \\
\hline FW & FW-1S & 1 & 2.0 & 87 & $80-91$ & pW225a $-p W 239 b X$ & 0.13 & 6.6 \\
\hline FW & FW-2S & 3 & 5.3 & 52 & $43-55$ & pW125dE -pX111aD & -0.25 & 16.4 \\
\hline DW & Dw-1S & 3 & 5.2 & 37 & $31-43$ & fito262 -fito156c & -0.04 & 16.0 \\
\hline SPAD & SPAD-1S & 3 & 3.0 & 95 & 91-104 & BRMS017 -FC & -1.30 & 9.8 \\
\hline SPAD & SPAD-2S & 4 & 9.3 & 72 & $66-76$ & pX130aD -pW178bH & -1.93 & 26.9 \\
\hline SPAD & SPAD-3S & 5 & 3.4 & 74 & $71-85$ & fito156a -pW164aE & 1.16 & 10.7 \\
\hline SPAD & SPAD-4S & 6 & 4.0 & 11 & $4-20$ & isgpa -fito067 & -1.21 & 12.6 \\
\hline SPAD & SPAD-5S & 8 & 6.6 & 51 & $48-56$ & fito204a -pX130cD & 1.60 & 19.8 \\
\hline Na mg/g DM & Na-1S & 1 & 3.5 & 32 & $25-36$ & fito355 -pX149fE & -1.68 & 11.3 \\
\hline Na mg/g DM & $\mathrm{Na}-2 \mathrm{~S}$ & 5 & 2.9 & 84 & $79-90$ & pW164aE -pW198bH & -1.62 & 9.4 \\
\hline Na mg/g DM & Na-3S & 8 & 1.8 & 82 & $72-84$ & fito204e -fito486 & -1.19 & 6.0 \\
\hline $\mathrm{Na} \mathrm{mg/g} \mathrm{DM}$ & $\mathrm{Na}-4 \mathrm{~S}$ & 9 & 3.7 & 15 & $14-18$ & pW256bH -fito163 & 1.71 & 11.9 \\
\hline K $\mathrm{mg} / \mathrm{g} \mathrm{DM}$ & $\mathrm{K}-1 \mathrm{~S}$ & 3 & 3.6 & 64 & $57-69$ & pX111aD -fito394 & -2.10 & 11.6 \\
\hline K $\mathrm{mg} / \mathrm{g} \mathrm{DM}$ & $\mathrm{K}-2 \mathrm{~S}$ & 8 & 4.5 & 72 & $60-80$ & fito373c -fito204e & 2.15 & 14.3 \\
\hline $\mathrm{Na}^{+} / \mathrm{K}^{+}$ & $\mathrm{Na} / \mathrm{K}-1 \mathrm{~S}$ & 1 & 2.3 & 31 & $25-36$ & fito355 -pX149fE & -0.04 & 7.6 \\
\hline $\mathrm{Na}^{+} / \mathrm{K}^{+}$ & $\mathrm{Na} / \mathrm{K}-2 \mathrm{~S}$ & 8 & 2.7 & 78 & $70-84$ & fito373c -fito204e & -0.04 & 8.8 \\
\hline $\mathrm{Na}^{+} / \mathrm{K}^{+}$ & $\mathrm{Na} / \mathrm{K}-3 \mathrm{~S}$ & 9 & 3.7 & 1 & $0-10$ & FLC1aH -fito204b & 0.05 & 11.9 \\
\hline
\end{tabular}




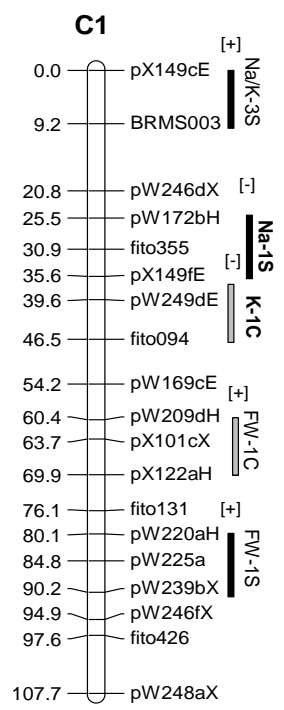

C5

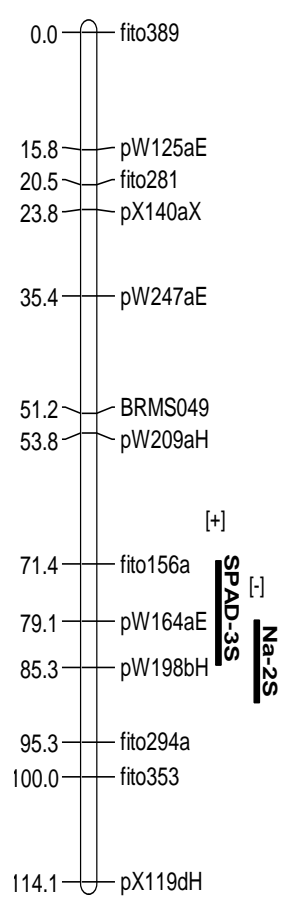

C2

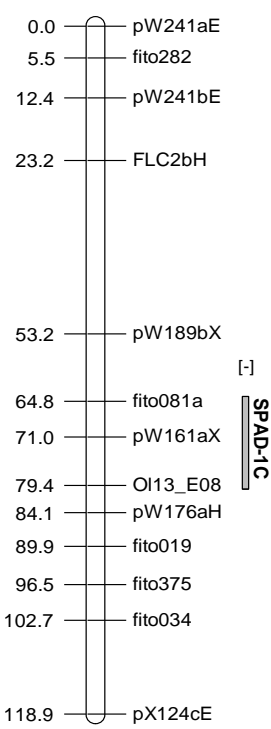

C3

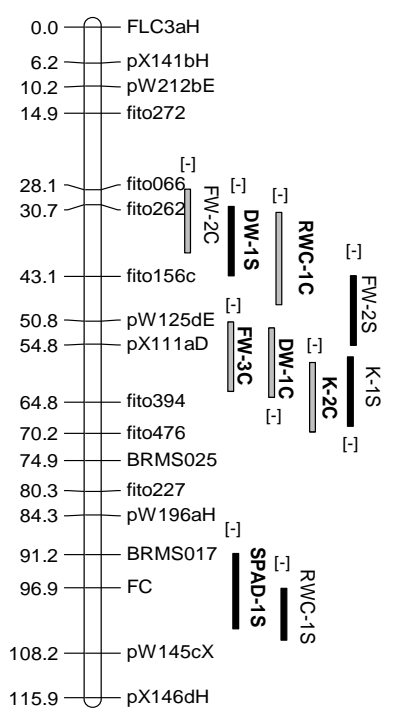

C4

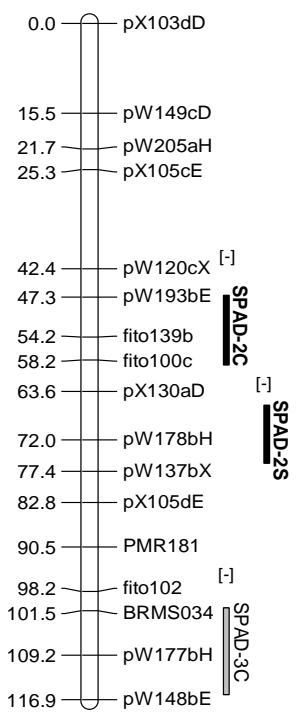

C7

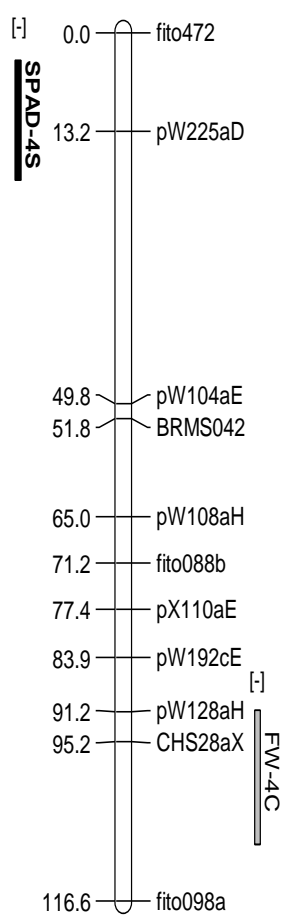

C9

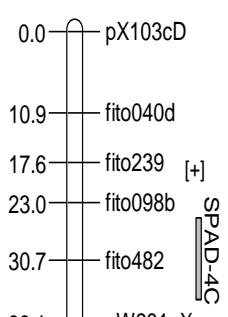

39.1 - pw231aX

$50.7-\mid \begin{array}{lll}45 \\ \text { fito204a }\end{array}$

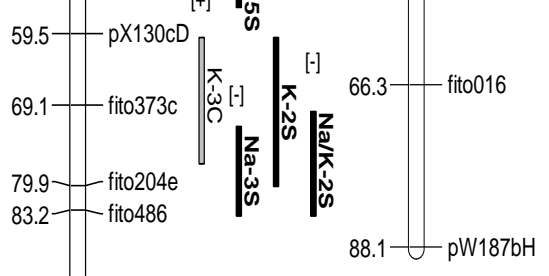

86.7 - fito190

90.7 - fito373b

$99.9-$ fito132b

i $101.8 \bigcup_{\text {fito424 }}$

$129.9-$ fito040c

Control

Salt

Figure V-5: Localization of QTL for growth traits in Brassica oleracea B01TBDH population. (QTL significant with $P=0.05$ are marked bold) 


\subsection{Discussion I}

\subsubsection{Traits variations}

The reduction in $\mathrm{FW}$ and DW was $32 \%$ and $17 \%$, respectively. The reduction in $\mathrm{FW}$ and DW is mainly due to the deleterious effect of osmotic stress and ion-toxicity. The correlation of $\mathrm{Na}^{+}$with $\mathrm{FW}$ and DW is negative and significant, which explains the significant reduction in $\mathrm{FW}$ and DW. The reduction was $3 \%$ in the case of RWC, which means that plants could maintain turgidity even under intensive salt stress by accumulating inorganic solutes such as $\mathrm{Na}^{+}$and $\mathrm{K}^{+}$. This is supported by the positive and significant correlation between RWC and $\mathrm{Na}^{+}$and $\mathrm{K}^{+}$upon control and salt stress.

Physiologically, the reason for this dramatic decrease is probably engendered by osmotic stress, which causes an immediate stomatal closure. Consequently, there is a reduction in the $\mathrm{CO} 2$ concentration, which is an essential compound for photosynthesis (Munns and Tester 2008). Osmotic stress is a tentative event plants can recover from within few hours. For example, in barely under salt stress, $150 \mathrm{mM}$ $\mathrm{NaCl}$; plants took one hour to generate osmotic adjustment (Munns 2002). However, with time, the $\mathrm{Na}^{+}$level increases to toxic levels. The overloading of ions, especially, $\mathrm{Na}^{+}$and $\mathrm{Cl}^{-}$is catastrophic either in the cell wall or inside the cell, causing cell dehydration (Munns 2002). When the rate of $\mathrm{Na}^{+}$and $\mathrm{Cl}^{-}$sequestering becomes lower than the rate of influx of $\mathrm{Na}^{+}$and $\mathrm{Cl}^{-}$, the accumulation will be higher in cytoplasm because the size of cytoplasm is small compared with the vacuole size (Munns 2002). This high rate of $\mathrm{Na}^{+}$and $\mathrm{Cl}^{-}$accumulation in cytoplasm is toxic for several enzymes, in particular, those that are K-dependent. Under these conditions, $\mathrm{Na}^{+}$acts as a competitive inhibitor for $\mathrm{K}^{+}$on the active sites of these enzymes (Munns 2002; Shabala and Cuin 2007).

In our experiment, chlorophyll content measured by SPAD increased by $6 \%$. This increase in SPAD values is mainly due to a reduction of leaf area, which in turn increases the number of chloroplasts per unit area (Fricke et al. 2004). The correlation of SPAD with FW and DW was positive and significant for both control and salt stress conditions. As it was expected, the correlation between SPAD and the traits related to $\mathrm{Na}^{+}$was negative and significant, which reflects the negative effect of the high levels of $\mathrm{Na}^{+}$in chloroplasts on photosynthesis.

Under salt stress, a dramatic increase of about $130 \%$ in $\mathrm{Na}^{+}$was observed. The correlation of $\mathrm{Na}^{+}$with FW and DW was negative and significant, which explains the significant reduction in $\mathrm{FW}, \mathrm{DW}$ and $\mathrm{K}^{+}$traits. This reduction in plant growth may be due to the replacement of $\mathrm{K}^{+}$ions by $\mathrm{Na}^{+}$ions, which break down the activities of the $\mathrm{K}$-dependent enzymes (Munns and Tester 2008). Noteworthy is that $\mathrm{K}^{+}$negatively and significantly correlated with SPAD under control conditions, probably because the concentration of $\mathrm{K}^{+}$exceeded the optimal limits (Subbarao et al. 2003). These authors reported that the optimal concentration for enzymes' maximum activity varies from 10$50 \mathrm{mM}$. Another possibility for this reduction is the accumulation of $\mathrm{Na}^{+}$and $\mathrm{Cl}^{+}$in the chloroplasts, which hinders photosynthesis. Contrarily, the correlation of $\mathrm{K}^{+}$was positive and significant with FW, DW and RWC, particularly under salt stress. This 
correlation means that $\mathrm{K}^{+}$is involved in several metabolic pathways such as the activation of various enzymes and $\mathrm{K}^{+}$-non-specific action as an osmoticum.

The physiological effects of salinity on plant growth are intensively discussed in Chapter 4 (4.5).

\subsubsection{QTL analysis and localization}

Fourteen QTL were identified under control growth conditions. Several QTL hotspots for different traits were detected on different LGs such as LGs C3, C8 and C9. The major hotspot was observed on LG C3. This hotspot comprises ten QTL for different traits. There are three points of overlapping QTL intervals (Figure 5). There is a major cluster in the middle of LG C3 comprised of the QTL FW-3C, FW-2S, DW-1C, K-2C and K-1S. The cluster of the first three QTL is expected because they are developmentally related traits, as is demonstrated by their positive and significant correlation under both treatments. Similarly, the overlap of the last two QTL is highly expected because they are for the same trait. The interference of the QTL intervals for the morphological traits such as FW and DW with QTL for physiological traits like $\mathrm{K}^{+}$ indicates that $\mathrm{K}^{+}$contributes positively to plant growth. This is supported by the positive and significant correlation between $\mathrm{FW}, \mathrm{DW}$ and $\mathrm{K}^{+}$, especially under salt stress. The clustering of these traits can be explained in two possible ways: a pleiotropic effect of one gene that controls the variation of these traits or the effects of tightly linked genes, regulating these traits independently. The second overlapping point was observed at the bottom of this LG, between SPAD-1S and RWC-1S; however, they are negatively and significantly correlated. Probably one gene with pleiotropic effect resides in this genomic region. This gene may increase one trait and decrease the second. Another possibility is the presence of two genes that control the variation of the two traits independently. The third site of overlapping QTL intervals was observed at the top of the LG, which includes the QTL FW-1C, DW-1S and RWC1C. Based on their positive and significant correlation, the clustering of these QTL is expected. Since, three QTL subgroups were identified on this LG; at least three major genes that govern the variation of these traits are hidden in these genomic regions.

Since the QTL FW-1C and RWC-1C were mapped under control conditions, while DW-1S was mapped under salt stress, the genome harbors gene(s) that control(s) the variation of more than one trait under different growth conditions. Additionally, there are genomic regions where gene(s) that exclusively control(s) the variation of one trait under control and salt, such as $\mathrm{K}-2 \mathrm{C}$ and $\mathrm{K}-1 \mathrm{~S}$. They are stress-non-specific regions or constitutive QTL. Other genomic regions harbor genes that control the variation of different traits under salt stress, like SPAD-1S and RWC-1S. On the other hand, QTL that exclusively regulate the variation of one trait or more under salt stress are stressspecific or adaptive QTL.

Remarkably, the additive effects of all QTL mapped on LG C3 were negative, indicating that the alleles for increasing these traits were transmitted by the same parent; in this case it was TO1000DH3. 
Another QTL hotspot was found on LG C8 where six QTL were located. Out of these four QTL are associated with $\mathrm{Na}^{+}$and $\mathrm{K}^{+}$-related traits. $\mathrm{K}-3 \mathrm{C}$ and $\mathrm{K}-2 \mathrm{~S}$ show positive additive effects, while the additive effects of $\mathrm{Na} / \mathrm{K}-2 \mathrm{~S}$ and $\mathrm{Na}-3 \mathrm{~S}$ are negative. The opposite additive effects of these QTL suggest that the alleles that control these trait variations are in a repulsion phase. The co-localization of $\mathrm{K}-2 \mathrm{~S}, \mathrm{Na} / \mathrm{K}-2 \mathrm{~S}$ is of great importance. They show a significant and negative correlation under salt stress, which means that $\mathrm{K}^{+}$and $\mathrm{Na}^{+} / \mathrm{K}^{+}$are inversely proportionate. Thus the flanking markers that are associated with these QTL can be harnessed for selection to increase $\mathrm{K}$ content and to decrease $\mathrm{Na}^{+} / \mathrm{K}^{+}$.

Another QTL hotspot was mapped on LG C9 for $\mathrm{Na}^{+}$- and $\mathrm{K}^{+}$-related traits. Three QTL were mapped on the top part of LG C9. Na-1C and Na-4S share the same interval. The third QTL, Na/K-3S, is salt-specific and regulates the variation of $\mathrm{Na}^{+} / \mathrm{K}^{+}$under salt stress. This genomic region probably harbors plasma membrane antiporters or vacuolar antiporters. The former governs $\mathrm{Na}^{+}$exclusion from the cell into the soil solution, the later manages the influx of excessive $\mathrm{Na}^{+}$into the vacuole to be sequestered. Most likely, this QTL is a major gene that controls the $\mathrm{Na} / \mathrm{K}$ ratio, since this QTL explains $12 \%$ of the phenotypic variation. Similarly, QTL for $\mathrm{Na}^{+}$and $\mathrm{K}^{+}$were mapped for $\mathrm{Na}^{+}$- and $\mathrm{K}^{+}$-related traits on LG C9 in the $B$. napus mapping population of Mansholts and Samourai as discussed in Chapter 4 (4.5).

The smallest QTL hotspot was observed on LG C5, where the SPAD-3S and Na-2S QTL overlapped; they are significantly and negatively correlated. This co-localization is of high value because a selection for improving SPAD will be associated with a reduction in $\mathrm{Na}^{+}$content.

\section{Conclusion}

In conclusion, wide variations were observed in the $\mathrm{DH}$ population in all traits. The FW and DW deceased considerably under salt stress. This reduction is imposed by $\mathrm{NaCl}$ in two phases, osmotic stress and ion toxicity. The QTL analysis spotted several genomic regions of high interest. In this context, two types of QTL were identified, the stress-specific (adaptive QTL), which explain the variance of one trait or more under either control or salt, and the stress-non-specific (constitutive QTL), were identified. These QTL control the variations in single traits or more under control and salt stress conditions. Of high importance are the QTL that underlie the variations of more than one trait, in particular when the correlation between them is negative. Thus, selection for increasing a desired trait can be achieved along with reducing an undesired trait. 


\section{Part II}

\section{Mapping QTL for leaf glucosinolates variation under control and salt stress conditions}

\section{in B. oleracea}

The experimental design and protocol of GSL analysis are described in detail in Chapter 4 (4.3) and growth conditions earlier in Chapter 5 (5.3.2).

The systematic and common names, the abbreviations and the precursor amino acids of each GSL constituent are listed in Chapter 4 (Table 1). The parents and GSL profiles of the $\mathrm{DH}$ populations will be described separately for the control and salt treatment.

\subsection{Results II}

The parents and the DH population were tested for GSL variation under control conditions and under salt stress with $100 \mathrm{mM} \mathrm{NaCl}$, in order to elucidate the effect of salinity under both growth conditions. The parents of population TO1000DH3 and Early Big showed broad GSL variation. TO1000DH3 had high GSL content compared to Early Big.

\subsubsection{Parents' GSL profile and content under control conditions}

There was a considerable difference in GSL content between TO1000DH3 and Early Big. The total GSL concentrations of the parental lines were $11.3 \mu \mathrm{mol} / \mathrm{g} \mathrm{DM}$ for TO1000DH3 and $4.67 \mu \mathrm{mol} / \mathrm{g}$ for Early Big. Unfortunately, as a result of poor germination of Early Big under salt stress, we could not determine its GSL content, but we could measure a total GSL content of $6.7 \mu \mathrm{mol} / \mathrm{g}$ DM for TO1000DH3 (Table 6, Figure 6a).

\section{T01000DH3 GSL content under control conditions}

Under control conditions, TO1000DH3 exhibited a total GSL content of $11.3 \mu \mathrm{mol} / \mathrm{g}$ DM. The major GSL constituents belong to the aliphatic class with $8.9 \mu \mathrm{mol} / \mathrm{g} \mathrm{DM}$, which represent $79 \%$ of the total GSL (Table 8). Four aliphatic GSL components were identified: GNA GNL, IBE and PRO. GNA dominated the other individuals with of 5.7 $\mu \mathrm{mol} / \mathrm{g}$ DM with contributions of $63 \%$ and $50 \%$ in the indolic and the total GSL, respectively. The remaining components, GNL, IBE and $\mathrm{PRO}$, were detected in concentrations of $1.8 \mu \mathrm{mol} / \mathrm{g} \mathrm{DM}, 0.94 \mu \mathrm{mol} / \mathrm{g} \mathrm{DM}$ and $0.5 \mu \mathrm{mol} / \mathrm{g} \mathrm{DM}$, respectively, representing a respective $20 \%, 10 \%$ and $6 \%$ of the aliphatic GSL. The contributions of these components to the total GSL content are $16 \%, 8 \%$ and $4 \%$, respectively (Table 6, Figure 6a, b).

Indolic GSL represent the smallest class. It is much lower than the aliphatic class, with $10 \%$ of the total GSL and a concentration of $1.2 \mu \mathrm{mol} / \mathrm{g} \mathrm{DM}$ (Figures $6 \mathrm{a}, \mathrm{b}$ and $7 \mathrm{a}, \mathrm{b}$ and Table 7). Three constituents were detected: GBC is the dominant component with $1.1 \mu \mathrm{mol} / \mathrm{g}$ DM, representing $89 \%$ of the indolic GSL and 9\% of the total GSL content. Concentrations of the remaining components $4 \mathrm{OH}$ and NAS are 
rather low with $0.015 \mu \mathrm{mol} / \mathrm{g} \mathrm{DM}$ and $0.11 \mu \mathrm{mol} / \mathrm{g} \mathrm{DM}$, respectively. The contributions of both components are $11 \%$ and $1 \%$ in the indolic GSL and the total GSL (Figures $6 b$ and $7 \mathrm{~b}$ and table 7$)$.

The aromatic GSL is represented by a single component, NEO, with a concentration of $1.3 \mu \mathrm{mol} / \mathrm{g} \mathrm{DM}$, equaling $11 \%$ of the total GSL (Figures $6 \mathrm{~b}$ and 9 and Tables 6, Table 7).

\section{Early Big GSL content under control conditions}

Unexpectedly, under control conditions, a single aliphatic component, GNL, was detected. The GNL concentration is $1 \mu \mathrm{mol} / \mathrm{g} \mathrm{DM}$. The ratio of aliphatic GSL to total GSL is $22 \%$ of the total GSL (Figure $6 \mathrm{~b}$ and Table 7 ).

The indolic GSL are the most abundant, with $3.13 \mu \mathrm{mol} / \mathrm{g}$ DM. This amount accounts for $67 \%$ of the total GSL. Only two constituents were detected, GBC and $4 \mathrm{OH}$, in concentrations of $3.1 \mu \mathrm{mol} / \mathrm{DM}$ and $0.03 \mu \mathrm{mol} / \mathrm{g} \mathrm{DM}$, respectively. Their respective shares in the total GSL are $66 \%$ and less than $1 \%$ (Figure $6 a, b$ and Table 7).

In the case of aromatic GSL, one component (NEO) was measured in a concentration of $0.5 \mu \mathrm{mol} / \mathrm{g} \mathrm{DM}$, which represents $11 \%$ of the total GSL amount (Figure 9 and Table 7).

Overall, TO1000DH3 shows higher GSL content than Early Big, with ratios of 240\%, $870 \%, 37 \%$ and 252\%, for total GSL content, aliphatic GSL, indolic and aromatic GSL, respectively. These findings reveal that Early Big dominates TO1000DH3 only in indolic GSL content.

\subsubsection{Parents' GSL profile and content under salts tress conditions}

\section{T01000DH3 GSL content under salt stress}

Under salt stress, total GSL in TO1000DH3 declined considerably, by $41 \%$ relative to the concentration under control, being $6.8 \mu \mathrm{mol} / \mathrm{g}$ DM (Figure 6a and Table 7). The aliphatic GSL concentration was 3.96 with $59 \%$ of the total GSL. A new GSL component was estimated under salt stress GBN in a low concentration of $0.03 \mu \mathrm{mol} /$ $g$ DM, which represents less than $1 \%$ of the aliphatic GSL. Reductions in single individuals were significant. PRO disappeared completely. The major ingredients GNA and IBE were found in concentrations of $3.15 \mu \mathrm{mol} / \mathrm{g} \mathrm{DM}$ and $0.72 \mu \mathrm{mol} / \mathrm{g}$ DM. Their shares in the aliphatic GSL were $79 \%$ and $18 \%$, respectively. They contributed a respective $47 \%$ and $11 \%$ to the total GSL (Figure $6 a$ and Table 6). The minor constituents GNL and GBN were found in rather low concentrations of $3 \%$ in the aliphatic GSL and less than 1\% of the total GSL (Figure 6b and Table 7).

In contrast, indolic GSL increased from $1.2 \mu \mathrm{mol} / \mathrm{g}$ DM under control conditions to 1.5 $\mu \mathrm{mol} / \mathrm{g} \mathrm{DM}$, an increase of $22 \%$. They represent $22 \%$ of the total GSL content (Figure $6 \mathrm{a}, \mathrm{b}$ and Table 7). Three components were identified: $\mathrm{GBC}, \mathrm{NAS}$ and $4 \mathrm{OH}$. The 
absolute concentrations of these ingredients are $1.2 \mu \mathrm{mol} / \mathrm{g} \mathrm{DM}, 0.34 \mu \mathrm{mol} / \mathrm{g} \mathrm{DM}$, respectively. $4 \mathrm{OH}$ was estimated in a much lower concentration of $0.03 \mu \mathrm{mol} / \mathrm{g} \mathrm{DM}$ (Figure $7 \mathrm{a}$ and Table 6). The contributions of these components to the indolic GSL are $76 \%, 22 \%$ and $2 \%$, respectively (Figure $7 \mathrm{~b}$ ). Their percentages of the total GSL are $17 \%$ for GBC and $5 \%$ for NAS and less than $1 \%$ for $4 \mathrm{OH}$ (Figure $6 \mathrm{~b}$ ).

The single aromatic GSL component, NEO, slightly increased by $2 \%$ being $1.3 \mu \mathrm{mol} / \mathrm{g}$ DM, which represented 19\% of the total GSL (Figure 9 and Table 7)

\section{Early Big GSL content under salt stress}

Regrettably, we cannot report on the GSL profile under salt stress of the second parent, Early Big, due to the lack of analyzable plant material as a consequence of poor germination. Therefore, we could not count how many DH lines showed GSL content lower than Early Big under salt stress.

\subsubsection{Glucosinolates' profile and content of the DH population under control conditions}

In the $\mathrm{DH}$ population, a significant difference in the glucosinolate profile and content was observed under control and salt stress conditions. The total glucosinolate content varied from $2.3 \mu \mathrm{mol} / \mathrm{g}$ DM to $15.7 \mu \mathrm{mol} / \mathrm{g}$ DM with an average of $8.5 \mu \mathrm{mol} / \mathrm{g} \mathrm{DM}$ under control. Under the salt regimen, total GSL concentrations varied from $0.92 \mu \mathrm{mol} /$ $\mathrm{g} \mathrm{DM}$ to $10.8 \mu \mathrm{mol} / \mathrm{g} \mathrm{DM}$, with a mean value of $4.4 \mu \mathrm{mol} / \mathrm{g} \mathrm{DM}$ (Tables 5 and 6). The distribution of the total GSL content under control and salt stress conditions showed a transgressive segregation (Figure 10). Mostly, the single constituents showed normal distributions (Appendix 13). Under salt stress, no lines with a lower GSL content than Early Big, the parent with low GSL content, could be identified (Figure 10). A significant genotypic variation was observed among the $\mathrm{DH}$ lines; the genotypic variation and heritabilities are outlined in Appendix 12.

\section{Aliphatic GSL under control conditions}

With a contribution of $37 \%$ to the total GSL, the aliphatic GSL class is not the largest. The mean value of the aliphatic GSL is $2.6 \mu \mathrm{mol} / \mathrm{g}$ DM ranges between $0 \mu \mathrm{mol} / \mathrm{g} \mathrm{DM}$ and $10.8 \mu \mathrm{mol} / \mathrm{g}$ DM (Table 7). The main components, GNA, PRO, IBE and GNL, were detected in concentrations of $1.2 \mu \mathrm{mol} / \mathrm{g} \mathrm{DM}, 0.58 \mu \mathrm{mol} / \mathrm{g} \mathrm{DM}, 0.57 \mu \mathrm{mol} / \mathrm{g} \mathrm{DM}$ and $0.26 \mu \mathrm{mol}$, respectively. The proportions of these components in the aliphatic GSL are $46 \%, 22 \%, 22 \%$ and $10 \%$, respectively. Their contributions to the total GSL are $13 \%, 8 \%, 8 \%$ and 4\%, respectively (Table 6, Figures 6a, b). RAA was much lower than the remaining components, with $0.02 \mu \mathrm{mol} / \mathrm{g}$ DM (Figure 6a, b Table 6).

\section{Indolic GSL under control conditions}

Indolic GSL class represents the highest portion of total GSL, with $40 \%$. The mean value is $2.8 \mu \mathrm{mol} / \mathrm{g}$ DM (Table 7). The $\mathrm{DH}$ line values range from $0.32 \mu \mathrm{mol} / \mathrm{g} \mathrm{DM}$ to $9.26 \mu \mathrm{mol} / \mathrm{g}$ DM. The superabundant ingredient is GBC, with $2.5 \mu \mathrm{mol} / \mathrm{g}$ DM. The percentages of GBC are $91 \%$ of indolic GSL and $36 \%$ of the total GSL. The remaining components, NAS, $4 \mathrm{ME}$ and $4 \mathrm{OH}$, show mean values as high as $0.13 \mu \mathrm{mol} / \mathrm{g} \mathrm{DM}$, 
$0.11 \mu \mathrm{mol} / \mathrm{g} \mathrm{DM}$ and 0.03 respectively. The contributions of these components together are $9 \%$ indolic GSL and 5\% total GSL.

\section{Aromatic GSL under control conditions}

As usual, the aromatic GSL class is represented by one constituent, NEO, with a value of $1.6 \mu \mathrm{mol} / \mathrm{g} \mathrm{DM}$, equaling $23 \%$ of the total GSL content. The values of NEO range from $0.25 \mu \mathrm{mol} / \mathrm{g}$ DM to $6.7 \mu \mathrm{mol} / \mathrm{g}$ DM (Figure 9 and Table 7).

\subsubsection{Glucosinolates' profile and content of the DH population under salt stress conditions}

Total GSL concentration and composition were found to be modified under salt stress with $100 \mathrm{mM} \mathrm{NaCl}$. Under salt stress, the total GSL content significantly declined by 49\%. Total GSL concentrations varied from $0.92 \mu \mathrm{mol} / \mathrm{g}$ DM to $10.8 \mu \mathrm{mol} / \mathrm{g} \mathrm{DM}$, with a mean value of $4.4 \mu \mathrm{mol} / \mathrm{g}$ DM (Table 6).

\section{Aliphatic GSL under salt stress conditions}

Aliphatic GSL fell by $32 \%$ to $1.8 \mu \mathrm{mol} / \mathrm{g}$ DM, which represents $42 \%$ of total GSL content (Table 6). The aliphatic GSL measurements range from $0 \mu \mathrm{mol} / \mathrm{g}$ DM to 10.8 $\mu \mathrm{mol} / \mathrm{g}$ DM. The concentrations of the major components, GNA, IBE and PRO, are $0.93 \mu \mathrm{mol} / \mathrm{g} \mathrm{DM}, 0.38 \mu \mathrm{mol} / \mathrm{g} \mathrm{DM}$, and $0.33 \mu \mathrm{mol} / \mathrm{g} \mathrm{DM}$, respectively. The shares of these components in the aliphatic GSL are 53\%, 22\% and $18 \%$, and their constituents represent $23 \%, 9 \%$ and $8 \%$ of the total GSL, respectively. The minor components, with much lower concentrations, are GNL, RAA and GBN. Collectively, they share $7 \%$ of the aliphatic GSL and 3\% of the total GSL content (Table 6 and Figure 6b, and 7b).

\section{Indolic GSL under salt stress conditions}

The total concentration of indolic GSL fell significantly by $48 \%$ to $1.5 \mu \mathrm{mol} / \mathrm{g} \mathrm{DM}$, is $35 \%$ of the total GSL content (Table 7). The concentration of indolic GSL ranges from $0.24 \mu \mathrm{mol} / \mathrm{g}$ DM to $3.8 \mu \mathrm{mol} / \mathrm{g}$ DM (Table 6). Four constituents were quantified. The effect of salinity on the analyzed species differed: while two, GBC and 4ME, decreased, NAS showed no change and $4 \mathrm{OH}$ increased. The two major components, GBC and NAS, were detected in values of $1.2 \mu \mathrm{mol} / \mathrm{g} \mathrm{DM}, 0.13 \mu \mathrm{mol} / \mathrm{g} \mathrm{DM}$, respectively. Their contributions to the indolic GSL were $86 \%$ and $9 \%$, and their shares in the total GSL were $30 \%$ and $3 \%$, respectively. The two minor components, $4 \mathrm{ME}$ and $4 \mathrm{OH}$, were detected in much lower concentrations with less than $6 \%$ of the indolic GSL and less than 3\% of the total GSL (Figure 8a, b, and Table 6).

\section{Aromatic GSL under salt stress conditions}

The aromatic GSL are represented by NEO, a single component with a value of 0.87 $\mu \mathrm{mol} / \mathrm{g}$ DM, i.e. $22 \%$ of the total GSL. The drop of $47 \%$ in absolute concentration is dramatic. The values of NEO range from $0.19 \mu \mathrm{mol} / \mathrm{g}$ to $4.04 \mu \mathrm{mol} / \mathrm{g}$ DM (Figure 9 and Table 7). 
a)

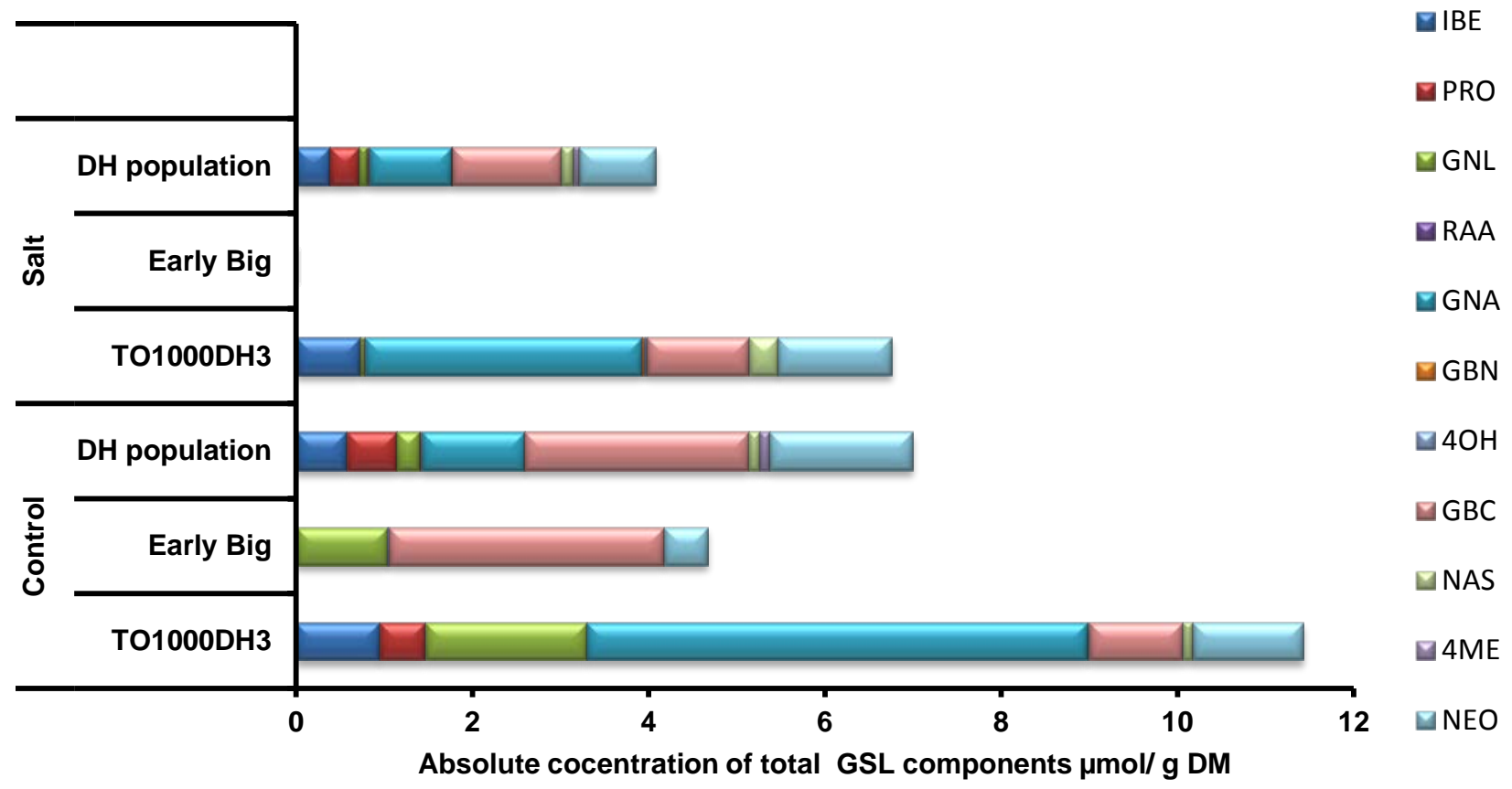

b)

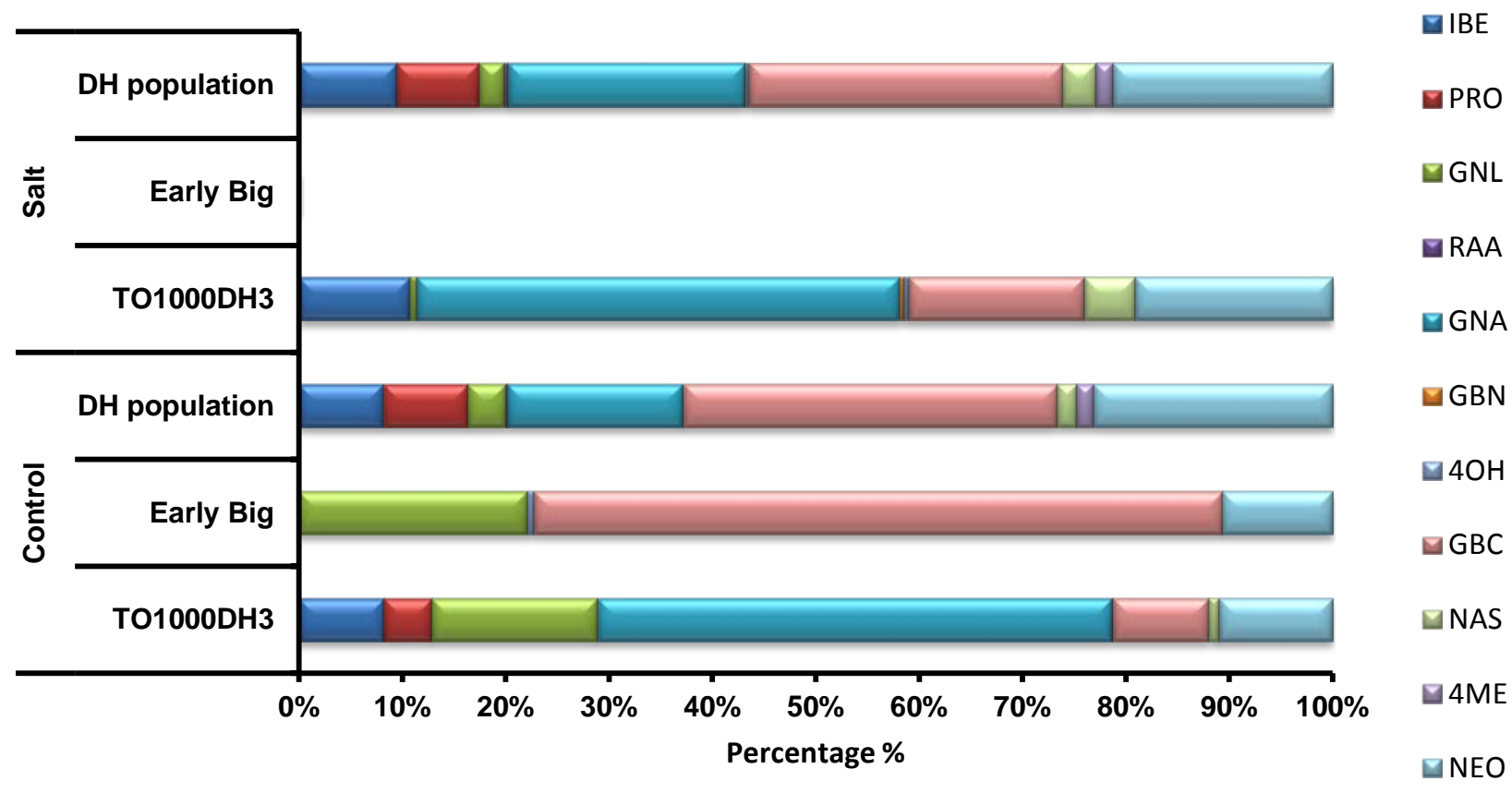

Figure V-6: (a) Total glucosinolate content $\mu \mathrm{mol} / \mathrm{g} \mathrm{DM}$ of each component in parents and the $\mathrm{DH}$ population under control and salt, (b) Percentage of each component relative to the total GSL content in parents and the $\mathrm{DH}$ population under control and salt 
a)

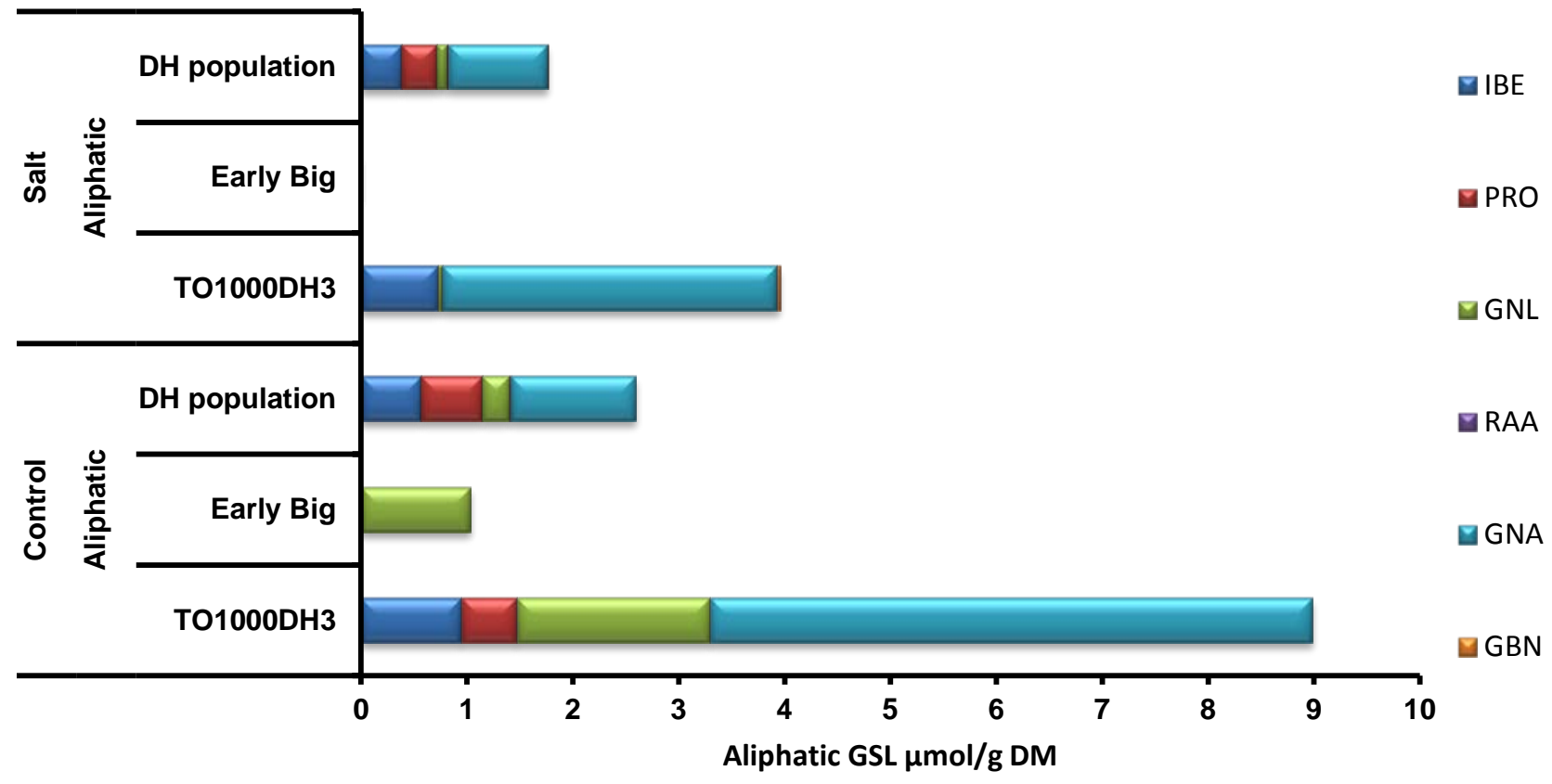

b)

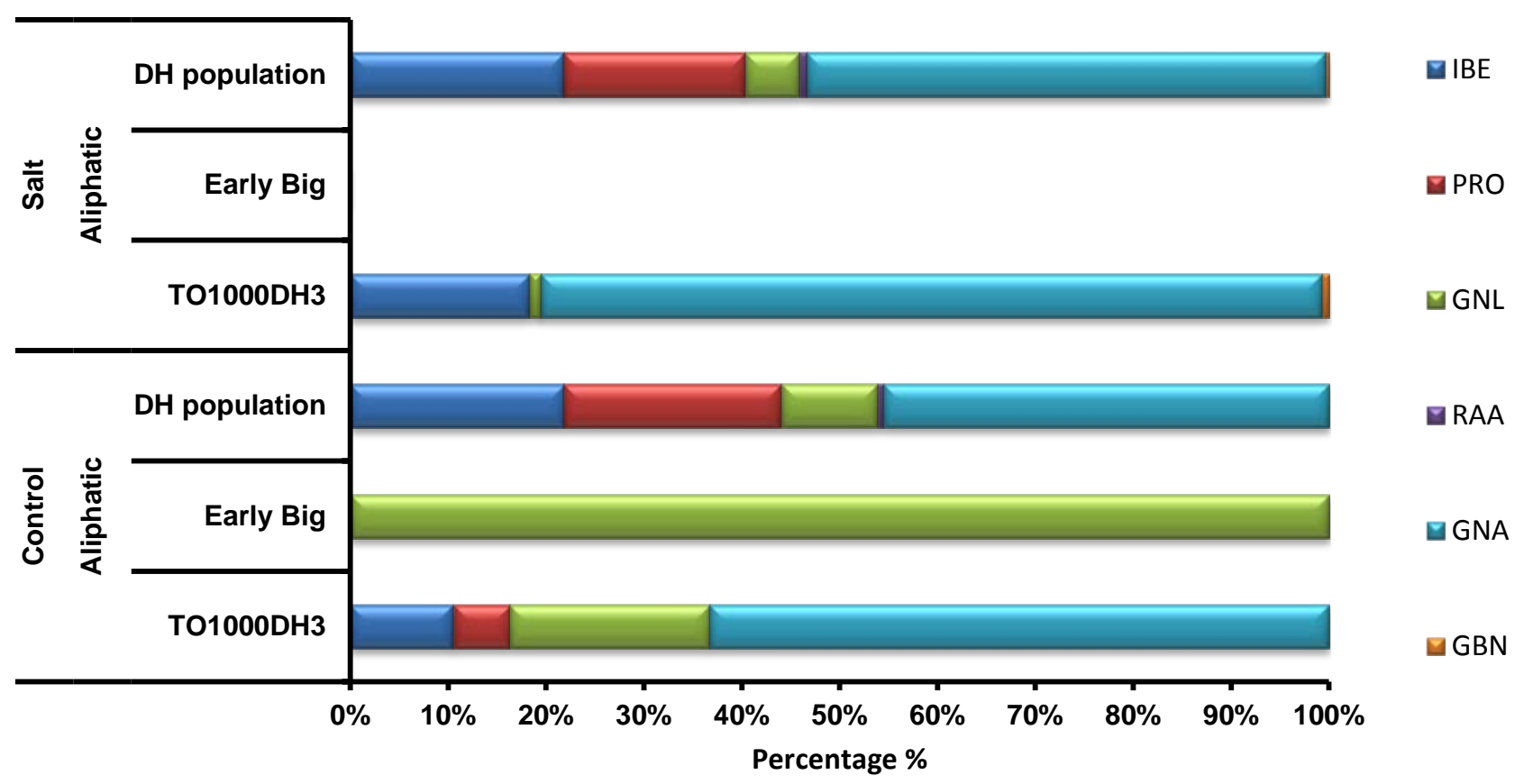

Figure V-7: Absolute values of aliphatic GSL components $\mu \mathrm{mol} / \mathrm{g}$ DM in the parents and the DH population under control and salt, b) Percentage of each ingredient of the aliphatic GSL in the aliphatic GSL content in parents and the $\mathrm{DH}$ population under control and salt 
a)

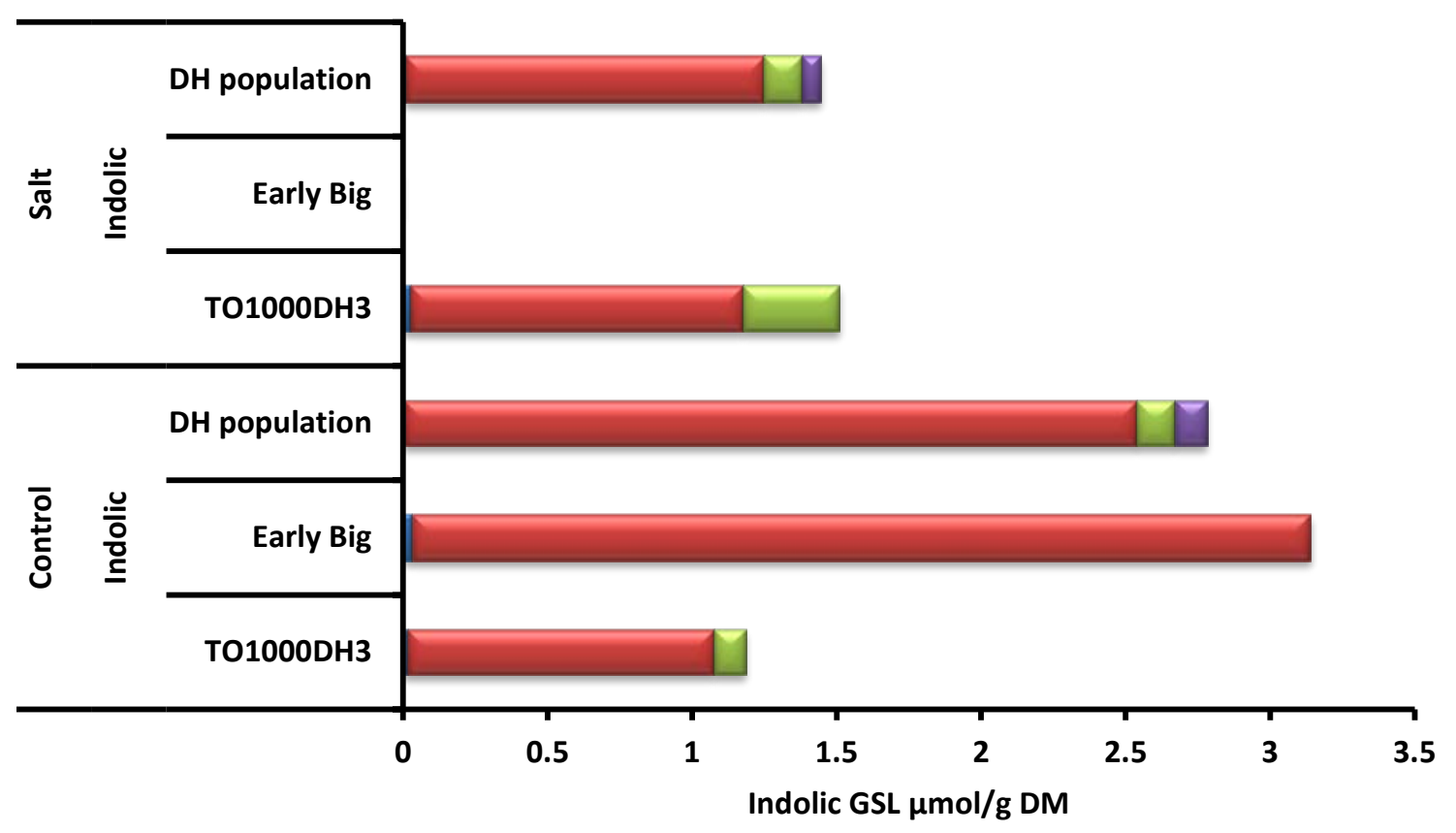

$\square$ 40H

口 GBC

$\nabla$ NAS

$\square$ 4ME

b)

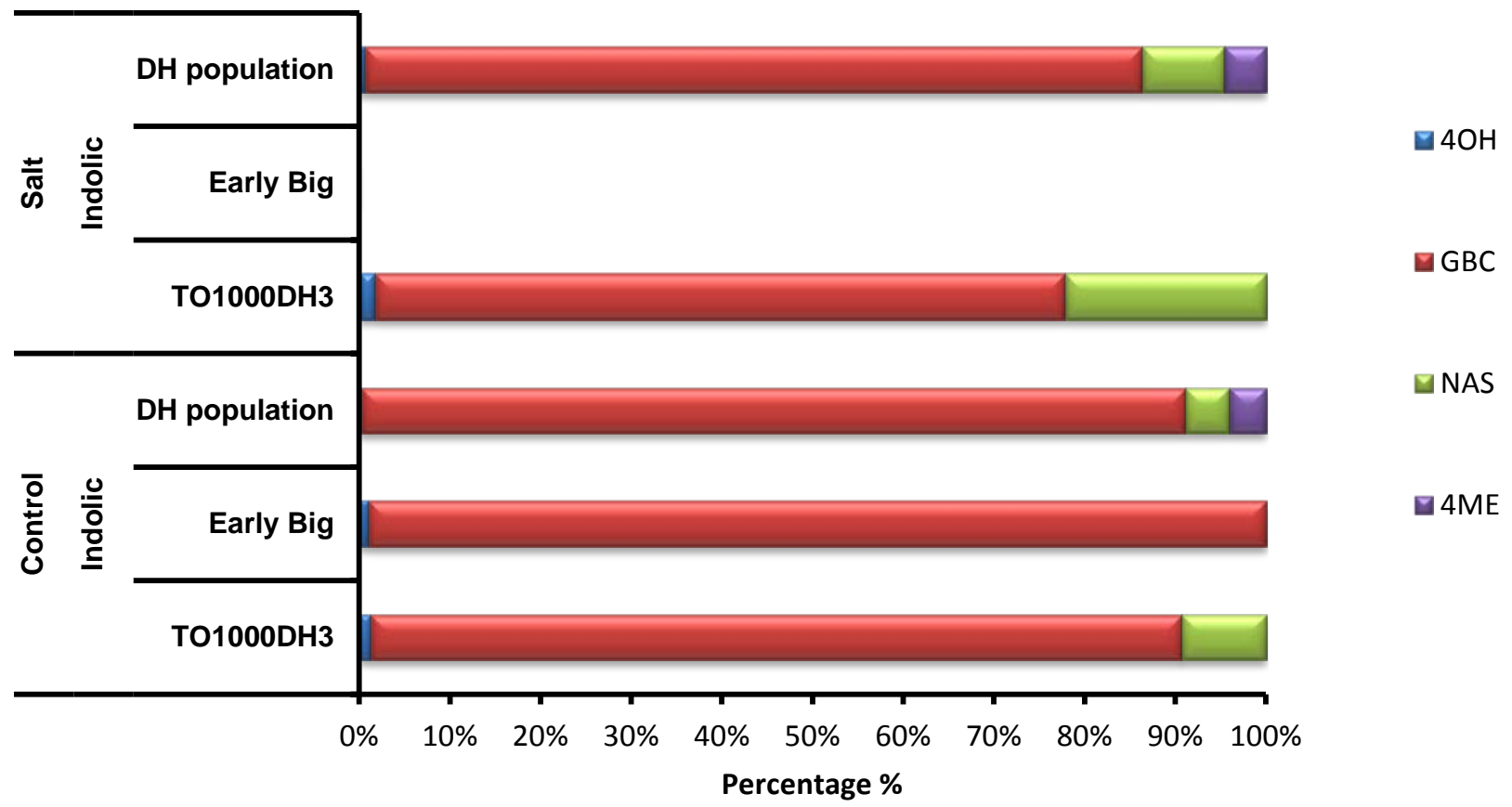

Figure V-8: Absolute values of indolic GSL components $\mu \mathrm{mol} / \mathrm{g} \mathrm{DM}$ in the parents and the $\mathrm{DH}$ population under control and salt, b) Percentage of each ingredient of indolic GSL in the total indolic GSL content in parents and the $\mathrm{DH}$ population under control and salt 


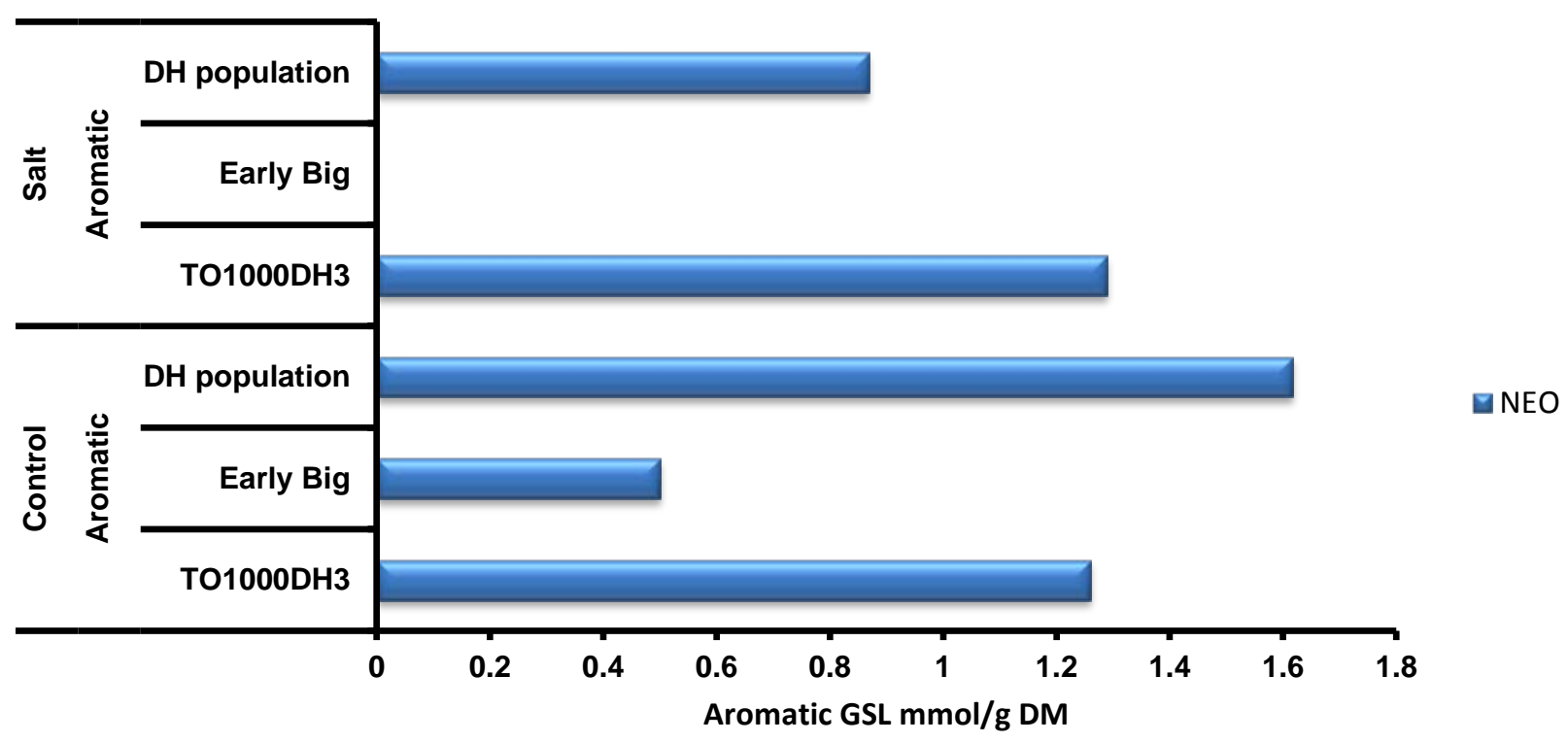

Figure V-9: The aromatic GSL content $\mu \mathrm{mol} / \mathrm{g} \mathrm{DM}$ in parents and the $\mathrm{DH}$ population under control and salt

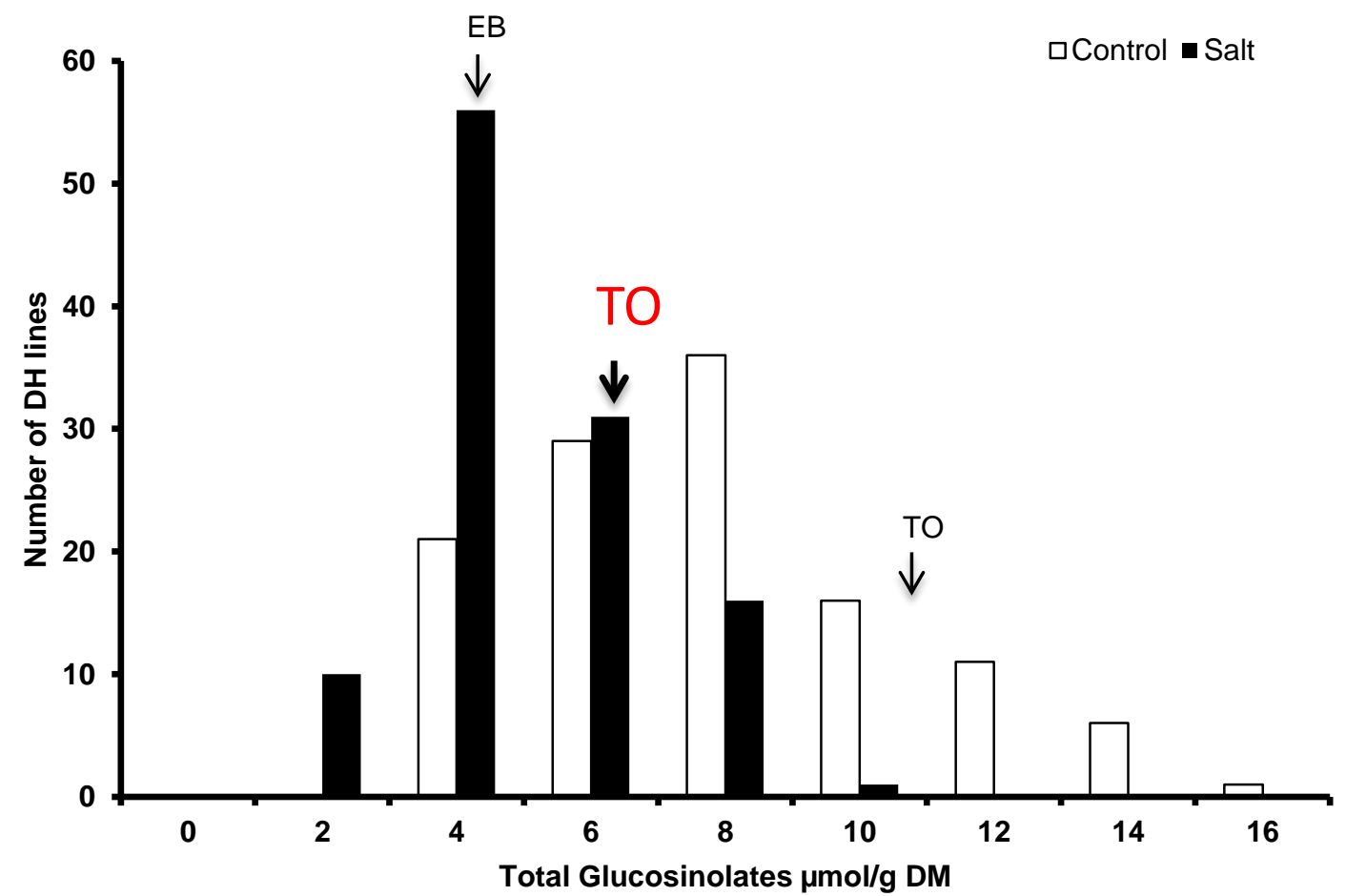

Figure V-10: Distribution of total GSL $\mu \mathrm{mol} / \mathrm{g}$ DM of Brassica oleracea DH population under control and salt stress 
Table V-6: Minimum, maximum and mean of glucosinolate content $\mu \mathrm{Mol} / \mathrm{g}$ DM of Brassica oleracea mapping population Bo1TBDH and parents under control and salt treatment $(100 \mathrm{mM} \mathrm{NaCl})$

\begin{tabular}{lcccccccccc}
\hline & \multicolumn{2}{c}{ Minimum } & \multicolumn{2}{c}{ Maximum } & \multicolumn{2}{c}{ Mean } & \multicolumn{2}{c}{ TO1000DH3 } & \multicolumn{2}{c}{ Early big } \\
\hline Traits & control & salt & control & salt & control & salt & Control & salt & control & salt \\
\hline IBE & 0.00 & 0.00 & 2.74 & 1.51 & 0.57 & 0.38 & 0.94 & 0.72 & 0.00 & - \\
PRO & 0.00 & 0.00 & 6.39 & 2.45 & 0.58 & 0.33 & 0.53 & 0.00 & 0.00 & - \\
GNL & 0.00 & 0.00 & 3.25 & 1.89 & 0.26 & 0.01 & 1.83 & 0.045 & 1.03 & - \\
RAA & 0.00 & 0.00 & 0.22 & 0.16 & 0.02 & 0.01 & 0.00 & 0.00 & 0.00 & - \\
GNA & 0.00 & 0.00 & 9.17 & 5.44 & 1.18 & 0.93 & 5.69 & 3.15 & 0.00 & - \\
4OH & 0.00 & 0.00 & 0.11 & 0.15 & 0.003 & 0.01 & 0.02 & 0.03 & 0.03 & - \\
GBN & 0.00 & 0.00 & 0.00 & 0.09 & 0.00 & 0.01 & 0.00 & 0.03 & 0.00 & - \\
GBC & 0.15 & 0.14 & 8.30 & 3.49 & 2.53 & 1.24 & 1.10 & 1.15 & 3.11 & - \\
NAS & 0.00 & 0.00 & 0.86 & 0.67 & 0.13 & 0.13 & 0.11 & 0.33 & 0.00 & - \\
4ME & 0.00 & 0.00 & 0.65 & 0.32 & 0.11 & 0.08 & 0.00 & 0.00 & 0.00 & - \\
NEO & 0.04 & 0.19 & 6.66 & 4.03 & 1.62 & 0.90 & 1.26 & 1.30 & 0.50 & - \\
SUM & 2.30 & 0.92 & 15.70 & 10.19 & 8.50 & 4.41 & 11.42 & 6.80 & 4.67 & - \\
\hline
\end{tabular}

Table V-7: Minimum, maximum and mean values of the major categories; aliphatic, indolic and aromatic GSL $\mu$ mol/ $\mathrm{g}$ DM of Brassica oleracea mapping population Bo1TBDH under control condition and salt treatment (100 mM NaCl)

\begin{tabular}{|c|c|c|c|c|c|c|c|c|c|c|c|c|c|c|c|c|}
\hline \multirow[t]{3}{*}{ Traits } & & & \multicolumn{6}{|c|}{ DH population } & \multicolumn{4}{|c|}{ TO1000DH3 } & \multicolumn{4}{|c|}{ Early Big } \\
\hline & \multicolumn{2}{|c|}{ Minimum } & \multicolumn{2}{|c|}{ Maximum } & \multicolumn{2}{|c|}{ Mean } & \multicolumn{2}{|c|}{ Percentage } & \multicolumn{2}{|c|}{ Mean } & \multicolumn{2}{|c|}{ Percentage } & \multicolumn{2}{|c|}{ Mean } & \multicolumn{2}{|c|}{ Percentage } \\
\hline & C & $\mathrm{S}$ & C & $\mathrm{S}$ & C & $S$ & C & $\mathrm{S}$ & C & $S$ & C & $\mathrm{S}$ & C & $\mathrm{S}$ & C & $\mathrm{S}$ \\
\hline Aliphatic & 0.00 & 0.00 & 10.76 & 6.03 & 2.59 & 1.77 & $37 \%$ & $43 \%$ & 8.98 & 3.96 & $79 \%$ & $59 \%$ & 1.03 & - & $22 \%$ & - \\
\hline Indolic & 0.32 & 0.22 & 9.26 & 3.76 & 2.78 & 1.45 & $40 \%$ & $35 \%$ & 1.19 & 1.51 & $10 \%$ & $22 \%$ & 3.14 & - & $67 \%$ & - \\
\hline Aromatic & 0.25 & 0.19 & 6.66 & 4.04 & 1.62 & 0.87 & $23 \%$ & $22 \%$ & 1.26 & 1.29 & $11 \%$ & $19 \%$ & 0.50 & - & $11 \%$ & - \\
\hline
\end{tabular}

- C: Control S: Salt 


\subsubsection{Correlations}

Under control conditions, the correlations between the individuals belonging to the aliphatic class are positive, except the correlation between IBE and GNA, which is negative and significant $\left(r=-0.25^{\star \star}\right)$ and PRO $\left(r=-0.24^{\star \star}\right)$, (Table 8). In the case of indolic GSL, the correlations between all components are positive, except between $\mathrm{GBC}$ and $4 \mathrm{OH}$, where it is negative and significant $\left(r=-0.22^{*}\right)$. Mostly, the correlation is negative between aliphatic GSL components with the indolic GSL components (Table 8). The aromatic GSL single component shows positive correlations with all aliphatic and indolic types; the only exceptions is with IBE $(r=-0.19 *)$.

Under salt stress, the correlations are positive among the different aliphatic GSL components (Table 9). Likewise, the indolic GSL constituents reveal positive correlations, except between NAS and 4ME, where the correlation is negative and significant $\left(r=-0.62^{\star *}\right)$. The aliphatic components correlate positively and significantly with the indolic ones, except between NAS and PRO, where it is negative and significant correlation $\left(r=0.20^{*}\right)$. The aromatic GSL ingredient NEO correlates positively with all indolic and aliphatic components, except with GNL and GNA, where it is negative and non-significant (Table 9). 
Table V-8: Spearman's rank correlations of glucosinolates in Brassica oleracea mapping population Bo1TBDH under control condition.

\begin{tabular}{|c|c|c|c|c|c|c|c|c|c|c|}
\hline & IBE & PRO & GNL & RAA & GNA & $40 \mathrm{H}$ & GBC & NAS & 4ME & NEO \\
\hline PRO & $-0.24^{\star \star}$ & & & & & & & & & \\
\hline GNL & 0.01 & 0.14 & & & & & & & & \\
\hline RAA & -0.03 & -0.07 & 0.13 & & & & & & & \\
\hline GNA & $-0.25^{\star \star}$ & $0.61^{\star \star}$ & 0.30 ** & 0.07 & & & & & & \\
\hline $4 \mathrm{OH}$ & 0.01 & 0.07 & 0.10 & $0.43^{\star *}$ & 0.04 & & & & & \\
\hline GBC & 0.06 & -0.16 & -0.02 & 0.061 & -0.11 & $-0.22^{*}$ & & & & \\
\hline NAS & -0.03 & -0.14 & 0.06 & $0.20^{*}$ & 0.06 & 0.15 & 0.06 & & & \\
\hline $4 \mathrm{ME}$ & 0.07 & 0.03 & 0.01 & 0.16 & -0.01 & -0.07 & $0.18^{*}$ & -0.31 & & \\
\hline NEO & $-0.18^{*}$ & 0.09 & 0.04 & 0.09 & 0.04 & 0.001 & 0.092 & 0.05 & -0.004 & \\
\hline SUM & 0.01 & $0.38^{\star *}$ & $0.24^{\star \star}$ & 0.10 & 0.49 ** & 0.13 & $0.52^{\star \star}$ & 0.10 & 0.10 & $0.42^{\star \star}$ \\
\hline
\end{tabular}

Table V-9: Spearman's rank correlations of glucosinolates in Brassica oleracea mapping population Bo1TBDH under salt stress $(100 \mathrm{mM} \mathrm{NaCl})$

\begin{tabular}{|c|c|c|c|c|c|c|c|c|c|c|c|}
\hline & IBE & PRO & GNL & RAA & GNA & GBN & $40 \mathrm{H}$ & GBC & NAS & 4ME & NEO \\
\hline PRO & 0.15 & & & & & & & & & & \\
\hline GNL & 0.05 & 0.07 & & & & & & & & & \\
\hline RAA & 0.001 & -0.16 & 0.05 & & & & & & & & \\
\hline GNA & 0.04 & 0.11 & 0.08 & 0.03 & & & & & & & \\
\hline GBN & 0.05 & $0.22^{*}$ & 0.06 & $0.29 * *$ & -0.02 & & & & & & \\
\hline $4 \mathrm{OH}$ & 0.20 & 0.12 & 0.11 & $0.27^{\star *}$ & 0.16 & $0.54^{\star *}$ & & & & & \\
\hline GBC & 0.16 & -0.05 & -0.01 & 0.05 & 0.02 & 0.16 & 0.18 & & & & \\
\hline NAS & -0.13 & $-0.20 *$ & 0.07 & $0.19 *$ & -0.02 & 0.03 & 0.03 & -0.02 & & & \\
\hline $4 \mathrm{ME}$ & 0.15 & $0.23^{*}$ & 0.04 & -0.02 & 0.07 & 0.10 & $0.18^{*}$ & $0.31^{\star *}$ & $-0.62^{\star *}$ & & \\
\hline NEO & 0.02 & 0.01 & -0.05 & 0.20 & -0.09 & $0.26^{\star *}$ & 0.04 & 0.15 & 0.14 & 0.005 & \\
\hline SUM & $0.24^{\star *}$ & $0.31^{* *}$ & 0.14 & 0.02 & $0.56^{\star *}$ & $0.19 *$ & $0.22^{*}$ & $0.48^{* *}$ & 0.03 & $0.22^{*}$ & $0.31^{* *}$ \\
\hline
\end{tabular}




\subsubsection{QTL analysis and localization under control and salt stress conditions}

Thirty-two QTL were mapped. Under control conditions, 21 QTL were identified and 11 QTL under salt. A full description of the QTL, flanking marker, additive effects, and the percentage of variance explained by each QTL and their localization on LGs is giving in Tables 10 and 11 and in Figure 11). If the QTL show negative additive affects, the alleles for increasing the corresponding trait were inherited from TO100DH3. QTL with positive additive effects indicate that the alleles for increasing the trait were passed on by Early Big.

\section{QTL associated with the aliphatic GSL under control and salt stress conditions}

With regard to IBE under control conditions, two QTL, IBE-1C and IBE-2C, were mapped on LGs $\mathrm{C} 1$ and $\mathrm{C} 5$, respectively. IBE-1C and IBE-2 account for $23 \%$ of the phenotypic variation, while IBE-1C was detected at the significance level $P=0.05$. The additive effects of both QTL are negative. Under salt stress one QTL, IBE-1S, was identified on LG C2 with a positive additive effect. The percentage of variation explained by this QTL is 5\%. One QTL, PRO-1C, was found positioned on LG C3 under control conditions. PRO-1C was mapped at a significance level of $P=0.05$, with a positive additive effect and the percentage of phenotypic variation explained by this QTL is 16\%. Under salt stress, two QTL were localized: PRO-1S on LG C3 and PRO-2S on C8, both QTL show negative additive effects. These two QTL explain $26 \%$ of the phenotypic variation. No QTL were mapped under control conditions for RAA. Under salt stress, the QTL RAA-1S was localized on LG C9. This QTL was mapped at $P=0.05$, shows a positive additive effect, and explains $7 \%$ of the phenotypic variation. One QTL for GNL, GNL-1C, was identified on LG C5. This QTL shows a negative additive effect and explains $6 \%$ of the phenotypic variation. No QTL were mapped for GNL under salt stress. Under the control conditions, three QTL, GNA-1C, GNA-2C and GNA-3C were localized on LGs C3, C7 and C9, respectively. They explain 54\% of the observed phenotypic variation, where GNA-3C alone accounts for 33\%. GNA-2C and GNA-3C were detected at the significance level $P=0.05$. The additive effects for all of them were negative. Under salt stress, one QTL, GNA-1S, was identified on LG C7, which accounts for $15 \%$ of the phenotypic variation, and shows a negative additive effect. For total aliphatic GSL content two QTL, Alipahatic-1C and Aliphatic-2C, were identified on LGs C7 and C9, respectively. Aliphatic-1C and Aliphatic-2C were identified at $P=0.05$. Both QTL show negative additive effects and they account for $50 \%$ of the observed phenotypic variation. Under salt stress, one QTL, Aliphatic-1S, was detected on LG C7 with a positive additive effect. This QTL was identified at $P=0.05$. The fraction of variation explained by this QTL is $15 \%$.

\section{QTL associated with the indolic GSL under control and salt stress conditions}

In the case of GBC, three QTL, GBC-1C, GBC-2C and GBC-3C were detected on LGs C2, C3 and C9, respectively. All of them exhibit positive additive effects. GBC-1C and GBC-3C were mapped at $P=0.05$. All of them together explain $28 \%$ of the phenotypic variation. One QTL, GBC-1S, was identified under salt stress on LG C9. This QTL accounts for a $17 \%$ of the phenotypic variation. This QTL was mapped at $P=0.05$. Under control conditions, one QTL, NAS-1C, was detected on LG C4. This QTL explains 8\% of the phenotypic variation and shows a negative additive effect. Similarly, one QTL, NAS-1S, was found under salt stress on LG C4 and indicates a positive additive effect. The percentage of variation explained by this QTL is 6\%. No QTL were identified for $4 \mathrm{ME}$ under control, but one QTL, 4ME-1S, was 
localized under salt stress on LG C5. This QTL explains 5\% of the observed variation and shows a positive additive effect. For total indolic GSL under control conditions, three QTL, Indolic-1C, Indolic-2C and Indolic-3C, were mapped on LGs C2, C3 and C9, respectively. The additive effects are positive for all QTL. Collectively, they explain $26 \%$ of the observed phenotypic variation. Indolic-2C was mapped at $P=0.05$. Under salt stress, one QTL, Indolic1S, was found at $P=0.05$ on LG C9. This QTL explains $17 \%$ of the phenotypic variation of the indolic GSL content with a positive additive effect.

\section{QTL associated with the aromatic GSL under control and salt stress conditions}

In the case of the aromatic GSL NEO, two QTL were localized: NEO-1C on LG C3 and NEO2C on C4. Both QTL have negative additive effects. These QTL account for $26 \%$ of the observed phenotypic variation. NEO-1C was mapped at $P=0.05$. No QTL were mapped for indolic GSL under salt stress

\section{QTL associated with the total GSL content under control and salt stress conditions}

For total GSL content, three QTL, SUM-1C, SUM-2C and SUM-3C, were mapped on LGs: C7, C8 and C9, respectively. SUM-1C and SUM-2C show negative additive effects. SUM-2C has a positive additive effect. All of them together explain the percentage variation of $27 \%$. Under salt stress, one QTL, SUM-1S, was localized on LG C7, which explains 10\% of the phenotypic variation with a negative additive effect. 
Table V-10: QTL detected at LOD > 2 under control treatment (C) for glucosinolate content $\mu$ Mol/gDM in Brassica oleracea mapping population Bo1TBDH. (QTL significant with $P=0.05$ are marked bold).

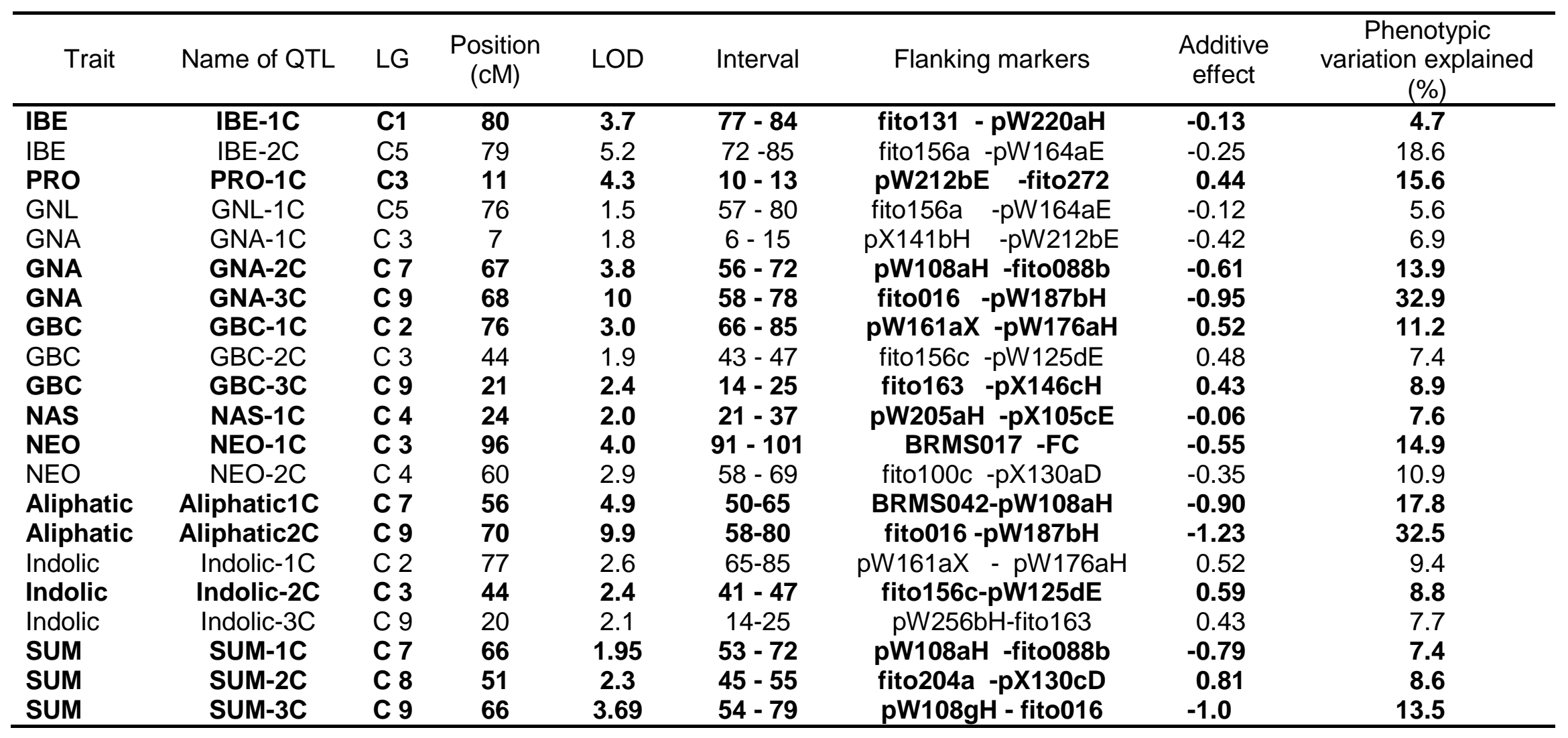

- Additive effect was calculated by subtracting TO1000DH3 alleles by Early Big alleles 
Table V-11: QTL detected at LOD > 2 under salt treatment (S) for glucosinolate content $\mu \mathrm{Mol} / \mathrm{g}$ DM in Brassica oleracea Bo1TBDH mapping population. (QTL significant with $P=0.05$ are marked bold).

\begin{tabular}{|c|c|c|c|c|c|c|c|c|}
\hline Trait & Name of QTL & LG & LOD & $\begin{array}{l}\text { Position } \\
\text { (cM) }\end{array}$ & Interval & Flanking markers & $\begin{array}{c}\text { Additive } \\
\text { effect }\end{array}$ & $\begin{array}{c}\text { Phenotypic } \\
\text { Variation explained } \\
(\%) \\
\end{array}$ \\
\hline IBE & IBE-1S & $\mathrm{C} 2$ & 1.2 & 90 & $85-97$ & fito019 -fito375 & 0.06 & 4.9 \\
\hline PRO & PRO-1S & C3 & 4.6 & 23 & $15-31$ & fito272 -fito066 & -0.26 & 15.8 \\
\hline PRO & PRO-2S & C8 & 2.5 & 9 & $0-18$ & pX103cD - fit040d & -0.17 & 9.8 \\
\hline RAA & RAA-1S & C9 & 1.7 & 67 & $53-84$ & fito016 - pW187bH & 0.01 & 6.8 \\
\hline GNA & GNA-1S & C7 & 4.0 & 72 & $65-78$ & fito088b - pX110aE & -0.52 & 15.3 \\
\hline GBC & GBC-1S & C9 & 4.6 & 21 & $15-25$ & fito163 -pX146cH & 0.31 & 17.4 \\
\hline NAS & NAS-1S & C4 & 1.5 & 68 & $63-77$ & pX130aD - pW178bH & 0.03 & 6.0 \\
\hline 4ME & 4ME-1S & C5 & 1.3 & 0 & $0-10$ & fito389 - pW125aE & 0.01 & 5.2 \\
\hline Aliphatic & Aliphatic-1C & C7 & 3.9 & 77 & 74-78 & fito088b - pX110aE & 0.60 & 14.5 \\
\hline Indolic & Indolic-1S & C9 & 4.6 & 20 & $15-25$ & pW256bH -fito163 & 0.32 & 16.8 \\
\hline SUM & SUM-1S & $\mathrm{C7}$ & 2.7 & 58 & $51-72$ & BRMS042 - pW108aH & -0.61 & 10.4 \\
\hline
\end{tabular}

- Additive effect was calculated by subtracting TO1000DH3 alleles by Early Big alleles. 
C1

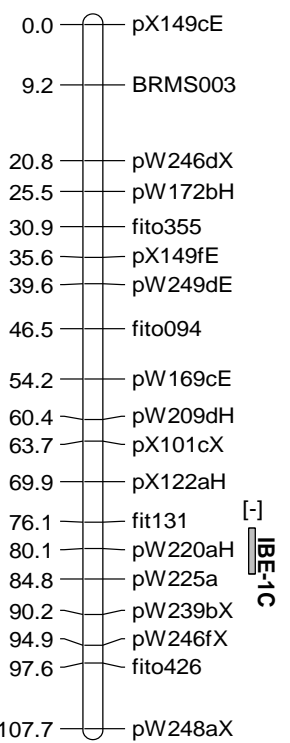

C2

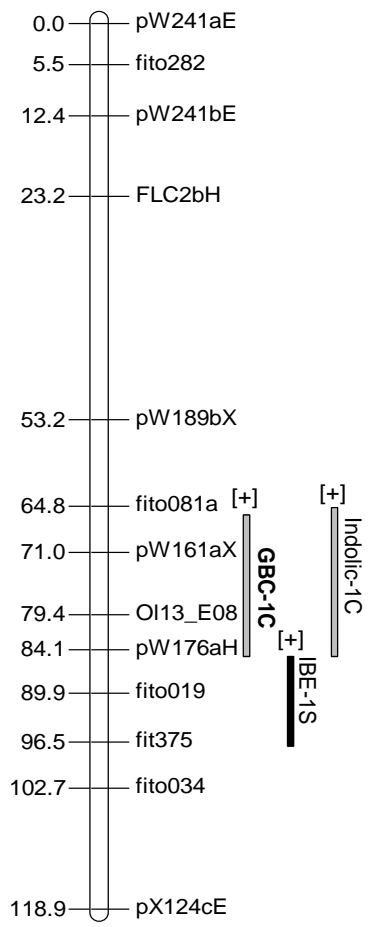

C3

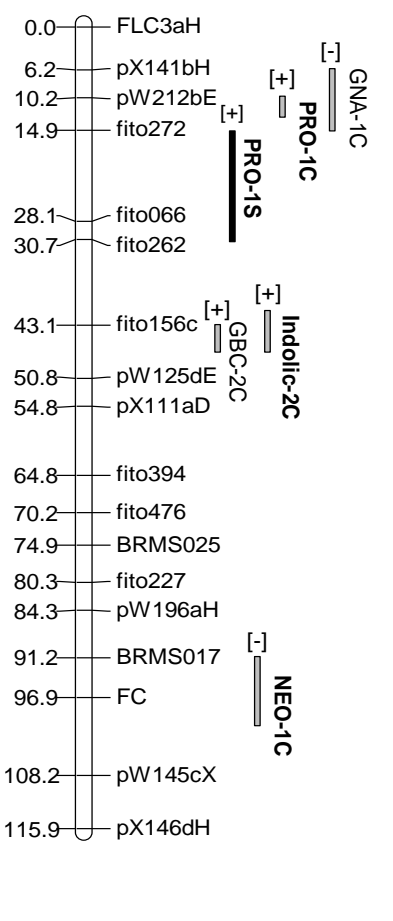

C4

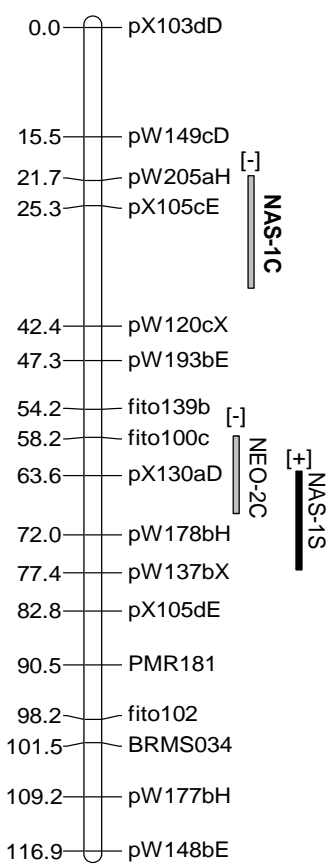

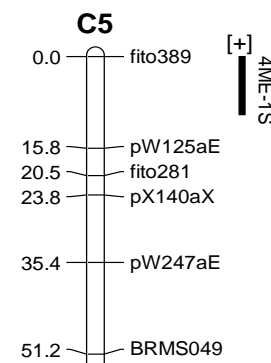
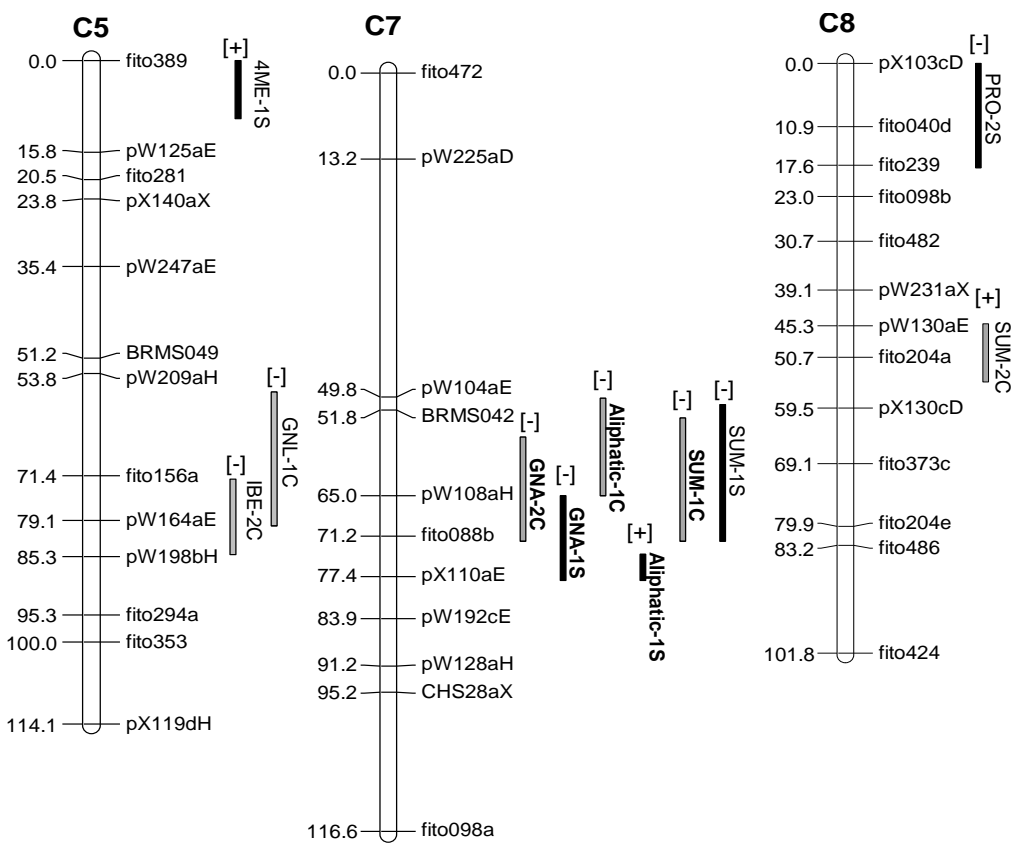

Figure V-11: Localization of QTL for glucosinolate in Brassica oleracea mapping population Bo1TBDH. (QTL significant with $P=0.05$ are marked bold) 


\subsection{Discussion II}

\subsubsection{Variation of GSL under control and salt stress conditions}

The parental lines exhibit a large contrast in GSL content. TO1000DH3 shows high GSL compared to Early Big under control and salt stress conditions. TO1000DH3 includes three aliphatic GSL components, IBE, PRO and GNA, as well as two indolic GSL constituents, GBC and NAS, and also one aromatic ingredient, NEO. Early Big includes one aliphatic component, GNL, two indolyl types, GBC and $4 \mathrm{OH}$, and one aromatic one, NEO. These findings are consistent with those of Sotelo et al. (2014). In the same population they found only four types: RRA, GBC, NAS and NEO in the parent Early Big. A transgressive distribution was observed for the individual components and the total GSL content as well (Figure 10 and Appendix 13). This transgressive segregation states that the positive and negative alleles are dispersed in the two parents. In agreement with our findings, similar distribution patterns have been described in B. juncea (Ramchiary et al. 2007) and B. oleracea (Sotelo et al. 2014).

Under control conditions in the DH population, the indolic GSL dominated the other classes with $40 \%$ of the total GSL. This agrees with previous studies. Our results are also consistent with results reported in the same population (Sotelo et al. 2014), where indolic GSL were dominant in leaves. It should be noted that in our study, the leaves were harvested at 35 days after sowing. Similar results were found in kale leaves, where the concentration of indolic GSL was higher at the early vegetative growth stage 30 days after sowing (Velasco et al. 2007). Under salt stress, all GSL components and total GSL decreased. GBC represents the dominant component in all categories. These findings agree with those of Velasco et al. (2007), who found that GBC is the predominant constituent in $B$. oleracea leaves. Recently, a study by Issa et al. (2010) in another B. oleracea (AGDH), GBC was the prominent indolic GSL.

The correlations between the single components of the same category are mostly positive. The negative correlation between individual components belonging to different classes can be explained by the cross-talk between the biosynthesis routes of the different classes. This cross-talk between the different GSL classes was evidenced in different species of Arabidopsis thaliana (Gogishvili et al. 2007b, Berger et al. 2007) and B. oleracea (Issa et al. 2010).

RAA and 4ME data are lacking for both parents; however, they were detectable in the mapping population. In contrast to our results, Sotelo et al. (2014) found that ALY was undetectable in parents, but was measurable in the mapping population. This discrepancy might be due to the different growth conditions and the time of harvesting the plant material. This assumption was supported by the findings of Brown et al. (2003) in Arabidopsis, who found that the total GSL and composition in leaves varied with time.

Under salt stress, the aliphatic GSL are abundant relative to the other classes. This change can be attributed to the strong reduction in indolyl GSL and aromatic GSL relative to the weak reduction in aliphatic GSL. The cross-talk between the 
Chapter V

biosynthesis of aliphatic and indolic GSL is evidenced in Arabidopsis (Gigolashvili et al. 2009), and in Brassica rapa ssp. Pekinensis (Kim et al. 2013). These authors reported that several transcription factors belonging to the cytochrome 450 family are involved in the biosynthesis of both the indolic and the aliphatic GSL. The reduction or blocking of the biosynthesis in the aliphatic GSL is accompanied by an increase in the indolic GSL and vice versa (Grubb and Abel 2006).

GBN, an aliphatic GSL, was detected only under salt stress, which might be due to the hydroxylation of GBN to GNL being suppressed by salinity, resulting in GBN accumulation. This speculation is advocated by the findings of (Yan and Chen, 2007), who found that under optimal growth conditions the hydroxylation step is accelerated due to the availability of nitrogen. Thus, this decline in the aliphatic hydroxylated forms may be ascribed to nitrogen-deficiency as a consequence of salt stress. The most well-known antioxidant RAA slightly decreased under salt stress. Conversely, Guo et al. (2013) observed a 2.1-fold increase in sulforaphane, one of the products of RAA hydrolysis under stress of $100 \mathrm{mM} \mathrm{NaCl}$ in Brassica oleracea var. italica cv. Youxiu. Similarly, we found a significant increase in RAA in a mapping population of $B$. napus Mansholts and Samourai under stress of $200 \mathrm{mM} \mathrm{NaCl}$.

The common diminution pattern of GSL individuals under salt stress suggests coordinate biosynthesis regulation. In Arabidopsis, Hirai et al. (2005) found that the genes that underlie the biosynthesis of GSL are co-regulated. This author suggests that one master mechanism controls the expression of these genes. This significant reduction in concentration of most GSL components and total GSL might be due to leakage of GSL from vacuoles into cytoplasm, where they are hydrolyzed by myrosinase (Pang et al. 2012). Another explanation is that the hydrolysis of GSL releases the inorganic elements, such as Sulfur and Nitrogen that are included in the GSL structure. The released elements are harnessed at earlier stages in the metabolic process, such as protein biosynthesis (Falk et al. 2007).

\subsubsection{QTL analysis and localization}

A total of 32 QTL were mapped, 21 under control conditions and 11 under salt stress. Based on the genetic comparative studies conducted to identify the homeologous regions between $B$. oleracea, B. rapa and Arabidopsis (Lukens et al. 2003, Iñiguez Luy et al. 2009), our aim has been to identify the genes that might be included in the synthesis of GSL.

Mapping QTL, a number of hotspots were identified, two on LG C9 and one on LG C7. At the top of LG C9, four QTL show co-localization: two QTL for GBC and two QTL for the sum of indolic GSL. In the case of GBC, one QTL is control-specific and the other salt-specific, as is the sum of total GSL. Furthermore, the additive effects of these QTL are positive, indicating that the alleles were transmitted from Early Big, the parent with high indolic content. These alleles are in a couple phase, as expected, as they are positively correlated, particularly under salt stress. This positive correlation is foreseeable because $\mathrm{GBC}$ is the major component of the indolic GSL class. At the lower part of LG C9, another cluster comprising four QTL was mapped. All of the QTL 
Chapter V

are aliphatic-GSL-specific. Three of them are control-specific and one is salt-specific.

The three control-specific QTL show negative additive effects, while the salt-specific one exhibits a positive additive effect. The antithetical additive effects indicate that the alleles that control the biosynthesis routes are in a repulsion phase. The colocalization of these four QTL is plausible because all of them are associated with methionine-derived GSL. Moreover, RAA is the precursor of GNA. These results point to the presence of a BoGSL-ALK gene modulating the biosynthesis of GNA from RAA through desaturation and the loss of methylsulphinyl core (Li and Quiros 2003). Supporting this notion, this region revealed homology with At4, where the GSL-ALK was mapped in Arabidopsis (Mithen et al. 1995). The identification of these genes, especially GS-ALK, is of great importance. The deactivation of GS-ALK might be helpful in producing Brassica cultivars with high RAA content (Li and Quiros 2003, Wentzell et al. 2007).

On LG C7, six QTL related only to aliphatic GSL were detected. The QTL GNA-1S and Aliphatic-1S revealed tight overlapping. This is expected because GNA represents the major component of the aliphatic GSL class. Based on the synteny data proposed by (Iñiguez-Luy et al. 2009), this genomic region shows collinearity with the $B$. rapa LG A7, where the QTL for GNA was mapped (Lou et al. 2007) and with the $B$. oleracea mapping population (AGDH) where one QTL for GNA was mapped on LG C7 (Issa et al. 2010). The total GSL content of QTL SUM-1C and SUM-1S revealed a complete overlap, meaning that one master mechanism is controlling the GSL biosynthesis under control and salt stress.

Two QTL were mapped at the top of LG C3, one for GNA and one for PRO. Our results are in agreement with those of Sotelo et al. (2014) for the same population, where these QTL were mapped at the same position. Consistent with our findings, in another $B$. oleracea mapping population (AGDH) on C3, one QTL for GNA and one for PRO were also mapped (Issa et al. 2010). This region shows homology with the top of Arabidopsis chromosome 5 (At5) and bottom of chromosome 2 (At2). The genes MAM 1 and MAM2 were identified at the top of At5 and the GSL-OH gene was mapped at the bottom of At2 (Kliebenstein 2009). Moreover, an orthologous to MAM 1 was identified in $B$. oleracea (Bol-ELONG). This gene also accounts for the formation of 4carbon GSL in Arabidopsis and B. oleracea (Li and Quiros 2003). All genes in this family have the same structure, direction and function as those in Arabidopsis and $B$. oleracea (Gao et al. 2006). Based on these results, we can conclude that this region harbors MAM 1 and MAM2, which are involved in the biosynthesis of GNA. GNA undergoes further modification with GSL-OH to produce the hydroxylated alkenyl PRO. In another study, GSL-OH was mapped on LG C9 close to the GSL-ALK gene (Gao et al. 2007). Most likely, there are many homologous genes scattered on different LGs. It is well known that triplicates from each Arabidopsis gene are expected to occur in the $B$. oleracea genome.

On LG C2, two QTL for GBC and total indolic GSL content were mapped. The QTL for GBC content in seeds was identified at the same position (Sotelo et al. 2014). By an in silico analysis of Arabidopsis, Sotelo et al. found that the gene CYP79B2 was in the 
Chapter V

interval of the QTL specific for total indolic GSL in seeds. These findings indicate that these genes are not tissue-specific. Similarly, in our study on B. napus mapping population of Mansholts and Samourai, QTL for leaf GSL co-localized with the QTL for seed, which had been mapped earlier in other studies. This is indicative for a master mechanism of GSL biosynthesis; GSL might be synthesized in vegetative organs and translocated later into seeds.

\section{Conclusion}

In may be concluded that salt stress decreases the GSL content and profile in parental lines and in the $\mathrm{DH}$ mapping population as well. Based on synteny studies, we propose the presence of a number of causal genes that were identified earlier as being involved in the different types of GSL biosynthesis.

Several reasons are thought to lie behind the reduction in total GSL under salt stress. Under salt stress, plants tend to reduce the biosynthesis of some metabolites, among them GSL (Pang et al. 2012, López-Berenguer et al. 2009). This supposition is supported by the findings of Steinbrenner et al. (2012) in B. rapa, who found that temporal stresses like salinity, drought and nutrient deficiency delayed the accumulation of some metabolites like GSL. The reduction in GSL under salt stress might result from leakage of GSL from the vacuole to the cytosol, where they are hydrolyzed by myrosinase (Pang et al. 2012). Additionally, it has been reported that GSL are reservoirs for nutrients, like Nitrogen and Sulfur. One of the effects of salinity is nutrient deficiency; therefore, plants hydrolyze GSL and benefit from the released elements as an alternative, so as to ensure the primary stages of metabolism such as protein biosynthesis (reviewed by Martinez-Ballesta et al. 2013).

More work would be helpful to reach a broader view and clearer insights into the effect of salinity on leaf GSL composition and content of $B$. oleracea. The availability of the complete genome sequence of $B$. oleracea will pave the way for the identification of the causal genes that control GSL variation. Importantly, the parental line, TO1000DH3 is the reference for the full genome sequence project, and the second parent, Early Big has been included in several studies to identify the causal genes involved in the biosynthesis of GSL. 


\section{Chapter VI}

\section{General discussion}

The present study investigates the effect of salinity on seed germination and on the young plant stage in doubled-haploid (DH) mapping populations of $B$. napus and $B$. oleracea. Furthermore, the effect of salinity on glucosinolate (GSL) in these populations was addressed.

\subsection{Effect of salinity on seed germination}

The effect of salinity on seed germination is investigated in two $\mathrm{DH}$ populations of $B$. napus, Alesi $\times \mathrm{H} 30$ and Mansholts $\times$ Samourai, and in one DH population of $B$. oleracea, Bo1TBDH. The saline conditions involved treatments with $200 \mathrm{mM} \mathrm{NaCl}$ in $B$. napus and $100 \mathrm{mM} \mathrm{NaCl}$ in $B$. oleracea. The germination parameters, germination percentage (G\%), germination pace (GP) and salt tolerance index (STI) were analyzed. A wide variation was observed in all populations, especially under salt stress. Salt stress reduced seed germination significantly, and slowed down the germination rate in all populations. Mostly, the distribution of traits was normal, with positive and negative transgressive segregation, but several $\mathrm{DH}$ lines showed performances better than the parent with high traits values and other $\mathrm{DH}$ lines revealed trait values lower than the low parent. The quantitative trait loci (QTL) analysis resulted in the identification of several QTL for all studied traits in all populations. A number of these QTL were adaptive, and were mapped under either stress or control conditions. Additionally, constitutive QTL were detected that control variations in the respective traits under both growth conditions. The constitutive QTL indicate that some genomic regions harbor genes that control seed germination under both control conditions and salt stress. The adaptive QTL show that some genomic regions hold genes that underlie the variation of traits under either salt or control conditions. Both QTL groups are important for the selection of salt-tolerant DH lines in a marker-assisted selection. The significant reduction in G\%, GP and STI is induced by osmotic stress and ion toxicity due to excess ions in the germination medium surrounding the seeds or to the accumulation of ions inside the seed tissues.

\subsection{Effect of salinity on plant growth}

The genotypic variation under salt stress of plant growth at the young plant stage was measured in the $B$. napus $\mathrm{DH}$ population of Mansholts and Samourai and the $B$. oleracea Bo1TBDH population. Salt treatments comprised $200 \mathrm{mM} \mathrm{NaCl}$ for the $B$. napus population and $100 \mathrm{mM} \mathrm{NaCl}$ for the B. oleracea population.

A significant variation was observed in all traits in both populations. In both populations, salinity reduced plant growth. The reduction in FW and DW was lose, while RWC showed a smaller reduction. This reduction resulted from the negative effect of osmotic stress induced by the high concentration of $\mathrm{Na}^{+}$and $\mathrm{Cl}^{-}$ions surrounding the plant root, which impairs water uptake. Another contributing factor may be the ion toxicity from accumulation of ions in the plant tissues. The imbalance between $\mathrm{Na}^{+}$and $\mathrm{Cl}^{-}$ions on the one hand and other ions causes nutritional deficiency 
Chapter VI

by hindering the uptake of essential nutrients such as $\mathrm{Ca}^{2+}, \mathrm{Mg}^{2+}$ and $\mathrm{K}^{+}$. This notion is supported by the negative and significant correlation between $\mathrm{Na}^{+}, \mathrm{FW}$ and DW. In both populations, the remaining parameters exhibit an increase under salt stress; the exception is $\mathrm{K}^{+}$in the $B$. olercea population. SPAD values show an increase under salt stress; this increase in SPAD values might be ascribed to the reduction in leaf area, which increases the number of chloroplasts per square centimeter. A dramatic increase was observed in the sodium-related traits, $\mathrm{Na}^{+} \mathrm{mg} / \mathrm{g} \mathrm{DM}$ and $\mathrm{Na}^{+} / \mathrm{K}^{+}$. Unexpectedly, $\mathrm{K}^{+}$increased in the $B$. napus $\mathrm{DH}$ population, which might be due to the ability of plants to maintain high $\mathrm{K}^{+}$content so as to employ it as osmoticum or a coenzyme. Conversely, $\mathrm{K}^{+}$content showed a reduction in $B$. oleracea population, though the $\mathrm{NaCl}$ concentration was lower than that applied for $B$. napus. This is expected under salt stress where $\mathrm{Na}^{+}$competes with $\mathrm{K}^{+}$to enter the cell through $\mathrm{K}^{+}$transporting channels. The maintenance of high $\mathrm{K}^{+}$concentration under salt stress is one of the salt tolerance parameters; therefore, with the findings of other groups these findings confirm the superiority of the amphidiploids species over their diploid ancestors.

In both populations, several QTL were mapped under control versus salt stress conditions. In the case of the $B$. napus $\mathrm{DH}$ population, groups of QTL hotspots were mapped to different linkage groups (LGs). The largest hotspot was localized on LG C3, where many traits clustered together. In other words, one genomic region harbors the gene(s) that regulate(s) the variation of more than one trait under both control and salt stress conditions. The variation of in these traits might be controlled by the pleiotropic effect of one gene, or by different, closely linked genes controlling variations independently. On LG A1, two QTL, i.e. SPAD-1S and SPAD-2S, were mapped under salt stress and found clustered together. These are adaptive QTL, since they were mapped only under salt stress. The QTL that were identified under both growth conditions, like SPAD-2C and SPAD-3S, are constitutive QTL. Likewise, in the case of the $B$. oleracea population, QTL hotspots were observed on LG C3, where there is an overlap between the intervals of QTL FW-3C, FW-2S, DW-1C, K-2C and K-1S. This overlapping between the QTL suggests that a common mechanism controls the variation in these traits under different growth conditions. These QTL hotspots add weight to these genomic regions, because more than one desirable trait can be improved jointly. Interestingly, QTL for $\mathrm{Na}^{+} / \mathrm{K}^{+}$were mapped in both populations on LG C9. This indicates the presence of gene(s) that control(s) $\mathrm{Na}^{+} / \mathrm{K}^{+}$uptake.

\section{Conclusion}

We can conclude that salt stress causes a reduction in plant growth either at the seed germination or at the young plant stage. In both populations, a reduction in the FW, DW and RWC was observed. Reduction in these parameters is associated with an increase in other constituents, like $\mathrm{Na}^{+}$content and SPAD values. The most plausible explanation for this decline in FW, DW and RWC is the osmotic stress imposed by the $\mathrm{NaCl}$ solutions or by the ion toxicity due to the build-up of $\mathrm{Na}^{+}$and $\mathrm{Cl}^{-}$ions. In both populations, two types of QTL constitutive and adaptive QTL were mapped. Constitutive QTL are not environment-specific; they govern the trait(s) variation(s) under both control and salt conditions, while the adaptive QTL govern the variation of 
traits under one environment, either control or salt conditions. Interestingly, QTL for $\mathrm{Na}^{+} / \mathrm{K}^{+}$were mapped in both populations on LG C9. This indicates the presence of gene(s) that control(s) $\mathrm{Na}^{+} / \mathrm{K}^{+}$uptake. Identification of the QTL hotspots adds significance to the genomic regions where they were mapped because more than one desirable trait can be improved jointly.

\subsection{Glucosinolates' variation under control and salt stress conditions}

Variation in leaf GSL was studied under the same growth conditions in both the $B$. napus and $B$. oleracea $\mathrm{DH}$ populations. In the case of the $B$. napus $\mathrm{DH}$ population of Mansholts and Samourai, Mansholts exhibits high GSL content under control conditions and salt stress compared with Samourai. Under salt stress, the two parents perform differently. Mansholts reveal an increase, while Samourai exhibits a drop in total GSL content. The DH population exhibits a reduction in total GSL content. This reduction is driven by a reduction in the aliphatic GSL. In the $\mathrm{DH}$ population and the parental lines, the aliphatic GSL type was predominant compared with the indolic and aromatic GSL types under control or salt stress. Under salt treatment in the $\mathrm{DH}$ population, there was an increase in the indolic and aromatic GSL and a fall in the aliphatic GSL, which may be attributed to cross-talk between the different biosynthesis pathways of the groups. All single components reveal a decline under salt stress, except RAA and GBC. Because of their antioxidant properties the increase in both RAA and GBC components might occur in order to detoxify the reactive oxygen species (ROS) induced by salt stress. Mostly, the GSL components belonging to the same class correlate positively and significantly under control and salt stress.

In the context of QTL mapping, several QTL were mapped under control and salt stress conditions in the $B$. napus population. Noteworthy is that a QTL hotspot was localized where QTL for seed GSL had been mapped earlier. This was clear, especially on LG A9, where there are five QTL for the aliphatic types PRO, RAA and GNA, in addition to one QTL for total aliphatic GSL and one for total GSL. This finding suggests that in this genomic region many genes are included in the biosynthesis of aliphatic GSL in seeds and leaves. Another large hotspot was detected on LG C2, where the second major QTL for seed GSL was identified. This hotspot includes QTL for aliphatic, indolic and aromatic GSL. There are probably genomic regions that harbor genes to control variations in the three major classes. Most likely, these genes are involved in the core structure of the biosynthesis stage. There are QTL that control GSL variation under either control or salt stress conditions, while other QTL control variation under both control and salt conditions. The correlations between the aliphatic GSL components are positive and significant, as also between the indolic GSL individuals. This is fully expected, because the components of each class have a common precursor.

In the case of the $B$. oleracea Bo1TBDH population, the two parents show a large variation in GSL components and concentrations. The parent TO shows a high GSL content relative to the parent EB. All of the single components reveal a reduction under salt stress, except GBC. Furthermore, GBN was detected under salt stress only. Under control and salt stress conditions in $\mathrm{TO}$ and in the $\mathrm{DH}$ population, PRO and 
Chapter VI

GBC represented the predominant aliphatic and indolic GSL, respectively. Unfortunately, due to the poor germination of EB we could not analyze its GSL under salt stress. Three QTL hotspots were identified; two on LG C9 and one on LG C7. At the top of C9, four QTL show co-localization: two QTL for GBC and two QTL for the sum of indolic GSL. The clustering of these QTL is expected, because GBC is the major component of the indolic class. Similarly, four QTL were mapped on the lower part. All of them were specific for aliphatic GSL components.

\subsection{QTL for seed germination versus QTL for plant growth at the young stage}

No coincidence was found between the positions of the QTL for seed germination and those QTL for plant growth. This result indicates that different genomic regions control salt tolerance at different growth stages. These findings are in accord with results reported earlier in other crops, like tomato (Foolad and Chen 1999) and barley (Mano and Takeda 1997). In the case of the B. napus DH population, all QTL for germination were localized on separate LGs where no QTL for growth stage was mapped. The only exception was one QTL for growth was mapped with QTL for seed germination on LG A9. Nevertheless, there was no overlap between the growth-related QTL with the germination-related QTL. As for the $B$. oleracea DH population Bo1TBDH, almost no overlap was found, though germination-related QTL shared the same LGs with QTL for growth traits (Figures 1, and 2). 

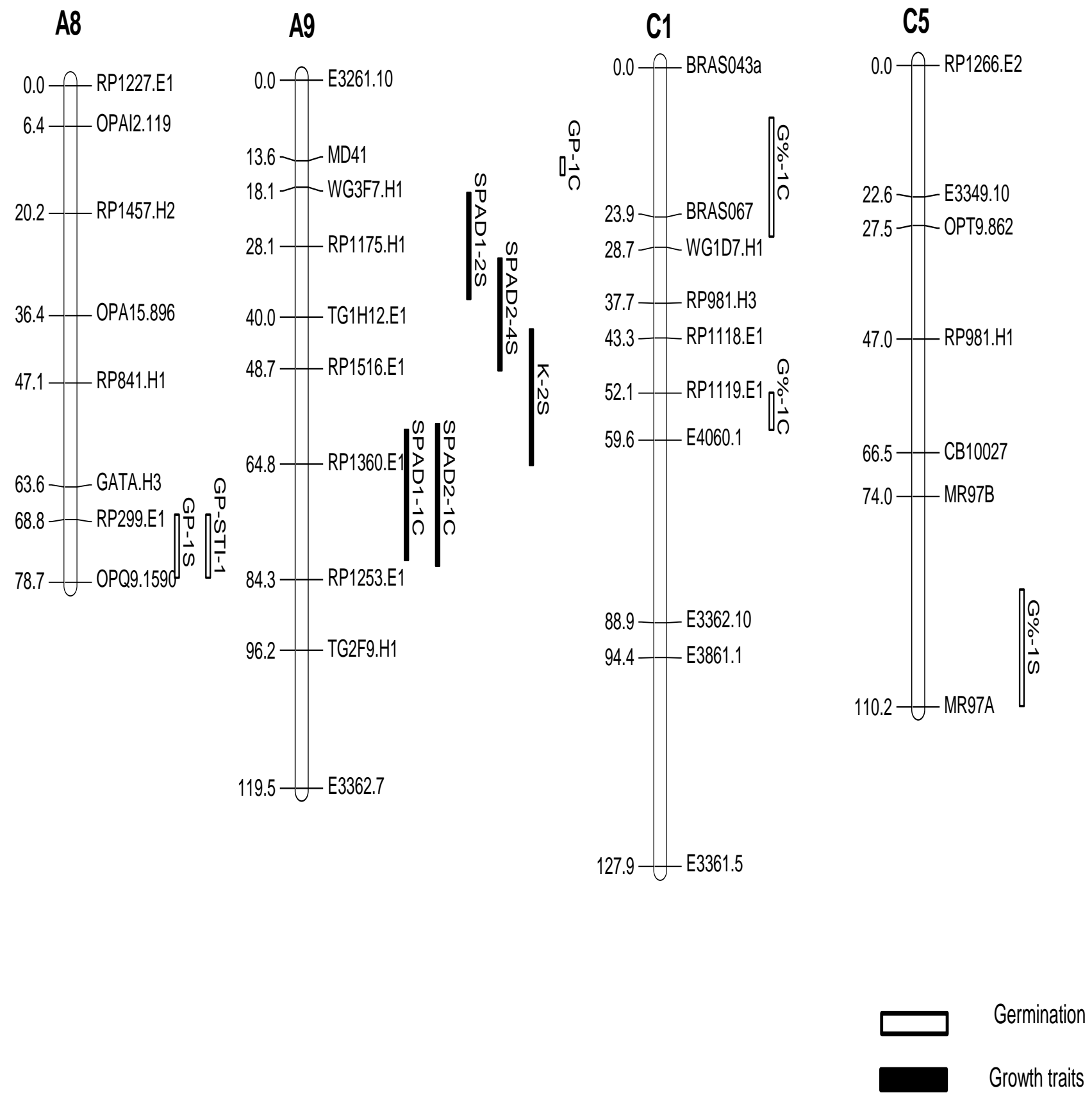

Figure 1: The relation between QTL for germination and QTL for growth traits in $B$. napus $\mathrm{DH}$ population Mansholts $\times$ Samourai. 

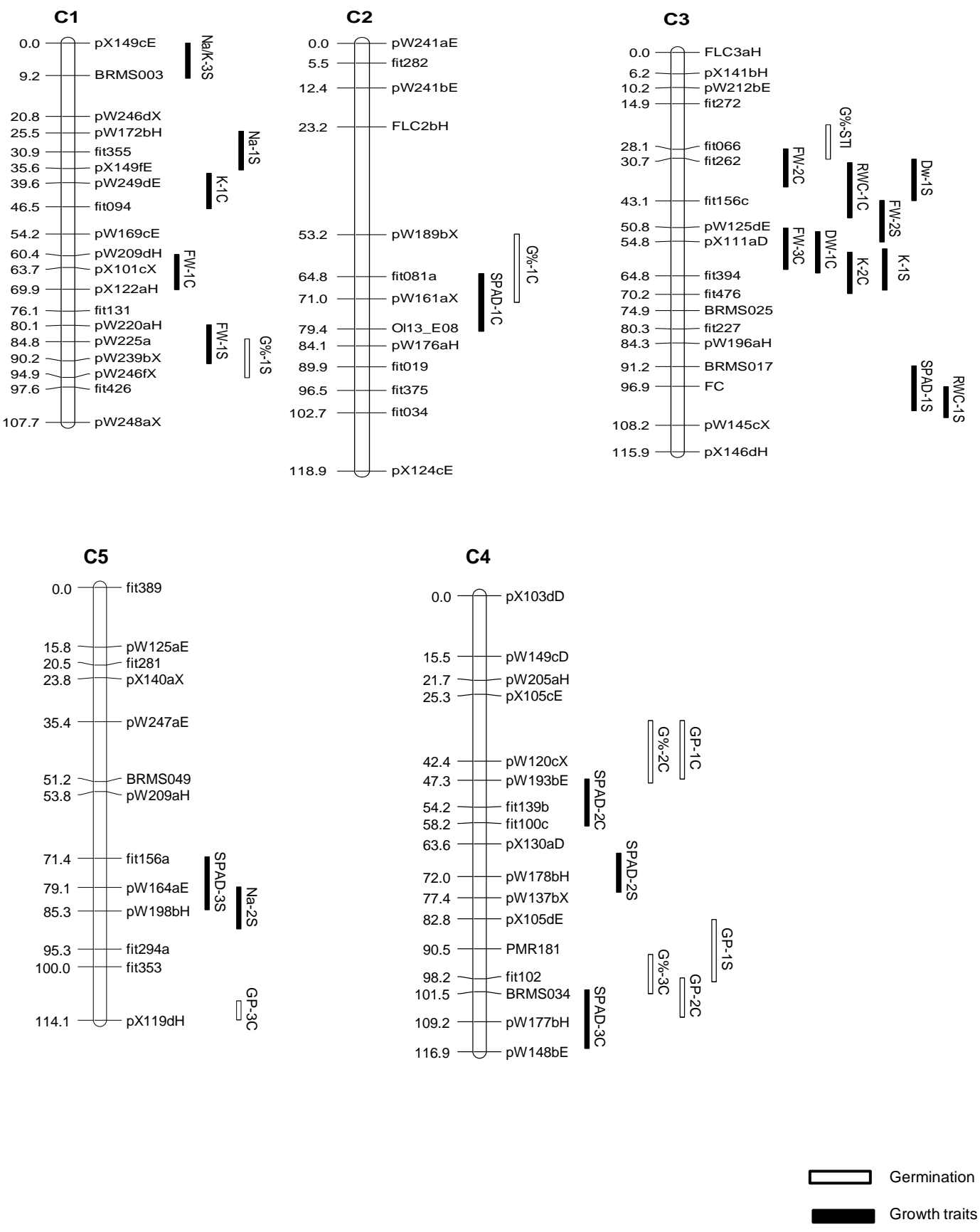

Figure VI-2: The relation between QTL for germination and QTL for growth traits in the Brassica oleracea DH population Bo1TBDH 


\section{Summary}

Brassica species are of great importance for human food and animal feed supply. Brassica napus occupies the second position among the oilseed crops behind soybean. Brassica oleracea includes numerous species of vegetables. Salinity is one of the abiotic stresses that adversely affect the productivity of these crops globally. Salinity tolerance varies along the plant ontogeny, meaning that it is stage-related, species-specific and organ-specific. In comparison to our knowledge about the genetic properties of seed glucosinolates (GSL), our knowledge about the genetic control of leaf GSL is rather limited.

The objectives of this project are: (1) to study the effect of salinity on two stages of plant growth, namely seed germination and the young plant stage, and to map QTL (Quantitative Trait Loci) that control salt tolerance in both growth stages in doubledhaploid (DH) mapping populations of $B$. napus and $B$. oleracea, (2) to examine the variation in leaf GSL content and the impact of salinity on GSL, and to map the QTL that control GSL variation under control and salt stress.

The effect of salinity on seed germination was investigated in three double haploid (DH) populations, two $B$. napus populations and one $B$. oleracea population. The first two were derived from Alesi $\times \mathrm{H} 30$ and from Mansholts $\times$ Samourai, respectively. The $B$. oleracea population was derived by crossing a DH rapid cycling TO1000DH3 (TO) line and a DH broccoli line Early Big (EB). $138 \mathrm{DH}$ lines for each population were tested either for germination experiments or for the greenhouse experiments. The frame work maps that were used for QTL mapping compromised 188, 208 and 128 markers Alesi $\times \mathrm{H} 30$, Mansholts $\times$ Samourai and $\mathrm{TO} \times \mathrm{EB}$, respectively.

The salt treatments were $200 \mathrm{mM} \mathrm{NaCl}$ for the $B$. napus populations and $100 \mathrm{mM}$ $\mathrm{NaCl}$ for the $B$. oleracea population. Ten seeds from each $\mathrm{DH}$ line were sown in nine $\mathrm{cm}$ Petri dishes on filter paper moistened with five $\mathrm{ml}$ tap water for control and five $\mathrm{ml}$ solution of the corresponding salt concentrations. The Petri dishes were incubated at $20^{\circ} \mathrm{C}$ in the dark. The number of germinated seeds was counted daily. The results revealed that salt stress significantly reduced seed germination and slowed down the germination rate. Nevertheless, several $\mathrm{DH}$ lines showed a better performance than the parent, with a high germination percentage and high germination pace (germination rate) in all populations. Several QTL were mapped for all the studied traits in all populations. A number of these QTL control the variation in these traits under both control and salt stress conditions, while others control the trait variations under either the control or salt stress.

The influence of salinity on plant growth at the young plant stage was evaluated in the $B$. napus $\mathrm{DH}$ population Mansholts $\times$ Samourai and the $B$. oleracea population TO $\times$ EB. The $\mathrm{DH}$ lines of each population and their parents were tested in pot experiments in the greenhouse under semi-controlled conditions in two replicates. The salt treatments were $200 \mathrm{mM} \mathrm{NaCl}$ for the $B$. napus populations and $100 \mathrm{mM} \mathrm{NaCl}$ for the B. oleracea population. A number of traits, i.e. fresh weight (FW), dry weight (DW), chlorophyll content (SAPD), relative water content (RWC), sodium content $\left(\mathrm{Na}^{+} \mathrm{mg} / \mathrm{g}\right.$ 
Summary

$\mathrm{DM}$, potassium content $\left(\mathrm{K}^{+} \mathrm{mg} / \mathrm{g} \mathrm{DM}\right)$, and sodium potassium ratio $\left(\mathrm{Na}^{+} / \mathrm{K}^{+}\right)$, were scored. The salt stress started on 21 days after sowing (das) for two weeks, the experiments were terminated on 35 das.

A significant variation was observed in all traits in both populations. In both populations salinity reduced plant growth, where a reduction in FW and DW was very large, while RWC showed a weak reduction. In both populations, the remaining parameters exhibited an increase under salt stress; the exception was $\mathrm{K}^{+}$in the $B$. oleracea population. SPAD values showed an increase. Similarly, $\mathrm{Na}^{+} \mathrm{mg} / \mathrm{g} \mathrm{DM}$ and $\mathrm{Na}^{+} / \mathrm{K}^{+}$exhibited a very large increase. Unexpectedly, $\mathrm{K}^{+}$increased in the $B$. napus $\mathrm{DH}$ population. Oppositely, the $\mathrm{K}^{+}$content decreased in $B$. oleracea population. Maintenance of high $\mathrm{K}^{+}$concentration under salt stress is one of the salt tolerance characteristics. These findings supporting the preceding results that revealed $B$. napus was more salt tolerant than $B$. oleracea.

In both populations, several QTL were mapped under control and salt stress. In the $B$. napus DH population, a number of QTL hotspots were mapped on different linkage groups (LGs). The largest hotspot was localized on LG C3. Likewise, in the $B$. oleracea population, QTL hotspots were detected on LG C3, where many traits cluster together. In other words, one genomic region harbors gene(s), which regulate(s) the variation of more than one trait under both control and salt stress conditions. The variation in these traits might be controlled by the pleiotropic effect of one gene or by different genes controlling their variation independently. The genomic regions, where QTL for more than one trait were mapped, are of great importance because more than one trait can be improved jointly.

Leaf GSL variation was investigated under the same growth conditions in both $B$. napus and $B$. oleracea $\mathrm{DH}$ populations. In both populations, the parental lines varied largely in their GSL profiles and contents. In the B. napus population, Mansholts exhibited high GSL content under control and salt stress conditions compared with Samourai. The two parents performed differently under salt stress, Mansholts revealed an increase, while Samourai exhibited a reduction in the total GSL content. In the $B$. oleracea population, the parental line TO showed higher GSL content than the parent EB. In both $\mathrm{DH}$ populations, all components revealed a decline under salt stress, except RAA and $\mathrm{GBC}$ in the $B$. napus population and $\mathrm{GBC}$ in the $B$. oleracea population. Because of their antioxidant properties, the increase in RAA and GBC might serve to detoxify the effects of ROS, which are produced as a consequence of salt stress. Several QTL were mapped under control and salt stress. Noteworthy, in the B. napus mapping population, QTL hotspots were mapped where QTL had been mapped earlier for seed GSL. This was clear, especially on LG A9 and LG C2. In the B. oleracea mapping population, QTL hotspots were localized on LG C9 and LG C7. The clustering of these QTL in both populations was logical because occasionally they were QTL for GSL components of the same class.

No consistency was found between the QTL controlling seed germination under salt stress and the QTL that control the trait variations at the young plant stage. These 
Summary

results suggest that different mechanisms control salt tolerance throughout the plant

life cycle. By combining QTL for salt tolerance of different developmental stages a good adaptation to salt stress can be achieved. 


\section{Zusammenfassung}

Brassica-Arten sind von großer Bedeutung für die menschliche Ernährung und für die Tierernährung. Brassica napus ist hinter der Sojabohne die zweit wichtigste Ölsaat. Brassica oleracea umfasst mehrere wichtige Gemüseformen. Die Produktivität dieser Arten wird weltweit durch Versalzung als ein biotischer Stressfaktor beeinträchtigt. Die Salztoleranz ist abhängig von der Pflanzenentwicklung, also stadienspezifisch, artspezifisch und organspezifisch. Im Vergleich zu unseren Kenntnissen über Samenglucosinolate ist wenig über die genetische Kontrolle von Blattglucosinolaten bekannt.

Die Arbeit hat folgende Zielsetzungen: (1) den Einfluss von Salzstress auf zwei Entwicklungsstadien zu untersuchen, und zwar auf die Keimung und die Jungpflanzenentwicklung, und in doppel-haploiden (DH) Populationen von $B$. napus und B. oleracea QTL (Quantitative Trait Loci) für Salztoleranz in beiden Entwicklungsstadien zu kartieren, und (2) die Variation im Blatt-GSL Gehalt zu untersuchen und QTL zu kartieren für den GSL Gehalt in einer Kontrolle und unter Salzstress.

Der Einfluss von Salzstress auf die Keimfähigkeit wurde an drei $\mathrm{DH}$ Populationen untersucht, zwei $B$. napus und eine $B$. oleracea Population. Die beiden erstgenannten Populationen wurde aus Alesi $\times \mathrm{H} 30$ bzw. Mansholts $\times$ Samourai entwickelt. Die $B$. oleracea Population entstand aus der Kreuzung zwischen der "rapid cycling“ Linie TO1000DH3 (TO) und einer DH Linie aus dem Broccoli Early Big (EB). Die Anzahl DH Linien 138 Für die QTL Analysen wurde eine framework map verwendet mit 188, 208 bzw. 128 Markern für die Populationen Alesi $\times$ H30, Mansholts $\times$ Samourai bzw. TO $\times$ EB.

Die Versuche wurden mit den Salzkonzentrationen $200 \mathrm{mM} \mathrm{NaCl}$ für $B$. napus und $100 \mathrm{mM} \mathrm{NaCl}$ für $B$. oleracea durchgeführt. Von jeder $\mathrm{DH}$ Linie wurden 10 Samen in 9 $\mathrm{cm}$ Petrischalen auf Filterpapier ausgelegt, das mit $5 \mathrm{ml}$ Leitungswasser als Kontrolle bzw. $5 \mathrm{ml}$ Salzlösung befeuchtet war. Die Petrischalen wurden bei $20{ }^{\circ} \mathrm{C}$ im Dunkeln inkubiert. Die Anzahl gekeimter Samen wurde täglich gezählt. Unter Salzstress war die Keimfähigkeit signifikant reduziert und die Keimgeschwindigkeit verlangsamt. Einige DH Linien übertrafen dabei ihre Eltern mit einer höheren Keimfähigkeit und Keimgeschwindigkeit. Es konnten für alle untersuchten Merkmale mehrere QTL identifiziert werden. Einige dieser QTL beeinflussen die Merkmalsausprägung sowohl in der Kontrolle als auch unter Salzstress, während andere QTL nur entweder in der Kontrolle oder in der Stressvariante auftreten.

Der Einfluss von Salz auf die Jungpflanzenentwicklung wurde in der $B$. napus DH Population Mansholts $\times$ Samourai und in der $B$. oleracea Population TO $\times$ EB untersucht. Von jeder Population wurden die $\mathrm{DH}$ Linien und die Eltern in Topfversuchen im Gewächshaus bei halbkotrollierten Bedingungen angezogen. Die Salzkonzentrationen waren $200 \mathrm{mM} \mathrm{NaCl}$ für $B$. napus und $100 \mathrm{mM} \mathrm{NaCl}$ für $B$. oleracea. Die erfassten Merkmale waren Frischgewicht (FW), Trockengewicht (DW), Chlorophyllgehalt (SPAD), relativer Wassergehalt (RWC), Natriumgehalt $\left(\mathrm{Na}^{+} \mathrm{mg} / \mathrm{g}\right.$ $\mathrm{DM})$, Kaliumgehalt $\left(\mathrm{K}^{+} \mathrm{mg} / \mathrm{g} \quad \mathrm{DM}\right)$ sowie das Natrium/Kalium-Verhältns $\left(\mathrm{Na}^{+} / \mathrm{K}^{+}\right)$. Der 

Aussaat beendet.

In beiden Populationen trat für alle Merkmale eine signifikante Variation auf. In beiden Populationen war das Wachstum unter Salzstress gehemmt, wobei FW und DW sehr stark reduziert waren während der RWC nur eine leichte Reduktion zeigte. Die anderen Merkmale zeigten unter Salzstress einen Anstieg mit Ausnahme von $\mathrm{K}^{+}$in der B. oleracea Population. Die SPAD Werte zeigten einen Anstieg. Auch $\mathrm{Na}^{+} \mathrm{mg} / \mathrm{g} \mathrm{DM}$ und $\mathrm{Na}^{+} / \mathrm{K}^{+}$zeigten einen starken Anstieg. Der $\mathrm{K}^{+}$Gehalt stieg in der $B$. napus Population unerwartet an, während er in der $B$. oleracea Population abnahm. Das Aufrechterhalten von hohen $\mathrm{K}^{+}$Konzentrationen unter Salzstress ist ein Merkmal für Salztoleranz. Diese Ergebnisse unterstützen frühere Ergebnisse dass $B$. napus eine höhere Salztoleranz hat als $B$. oleracea.

In beiden Populationen wurde sowohl in der Kontrolle als auch unter Salzstress eine Reihe von QTL identifiziert. In der B. napus Population wurden auf verschiedenen Kopplungsgruppen (LG) QTL „hotspots“ entdeckt. Der größte „hotspot“ lag auf LG C3. Auch in der B. oleracea Population wurde auf LG C3 ein „hotspot“ entdeckt mit QTL für mehrere Merkmale. Hier liegen also in derselben Region des Genoms Gene für mehr als nur ein Merkmal sowohl in der Kontrolle als auch unter Salzstress. Die Variation dieser Merkmale wird entweder von einem Gen mit pleiotropem Effekt gesteuert oder von mehreren unabhängigen Genen. Regionen mit QTL für mehrere Merkmale sind von großem Interesse weil dadurch mehr als nur ein Merkmal gleichzeitig verbessert werden kann.

Unter den gleichen Bedingungen wurde in den beiden $B$. napus bzw. $B$. oleracea Populationen auch die Variation in den Blatt-GSL untersucht. Die Elternlinien beider Populationen unterschieden sich stark in GLS Gehalt und Zusammensetzung. In der B. napus Population hatte Mansholts einen im Vergleich zu Samourai hohen GSL Gehalt sowohl in der Kontrolle als auch unter Salzstress. Unter Salzstress verhielten sich die beiden Eltern unterschiedlich, Mansholts zeigte einen Anstieg und Samourai eine Abnahme des GSL Gesamtgehalts. In der B. oleracea Population zeigte die Elternlinie TO eine höheren GSL-Gehalt als der Elter EB. Die einzelnen GSL Komponenten zeigten in beiden $\mathrm{DH}$ Populationen eine Abnahme bei Salzstress mit Ausnahme von RAA und GBC bei $B$. napus und $G B C$ bei $B$. oleracea. Aufgrund ihrer antioxidativen Eigenschaften könnte der Anstieg von RAA und GBC dazu dienen die ROS zu detoxifizieren, die als Reaktion auf Salzstress produziert wurden. Mehrere QTL wurden sowohl in der Kontrolle als auch unter Salzstress kartiert. In der B. napus Population wurden QTL „hotspots“ in Regionen identifiziert in denen bereits früher QTL für Samen-GSL lokalisiert wurden. Dies war vor allem auf LG A9 und LG C2 der Fall. In der B. oleracea Population wurden QTL "hotspots“ auf LG C9 und LG C7 lokalisiert. Das gleichzeitige Auftreten von QTL an derselben Position lässt sich teilweise dadurch erklären dass es sich um Komponenten derselben GSL Gruppen handelt. 
Zusammenfassung

Es gab keine Übereinstimmung zwischen den QTL für die Keimfähigkeit unter Salzstress und den QTL für Variation bei Jungpflanzen. Dies weist darauf hin dass für die Salztoleranz während der Pflanzenentwicklung unterschiedliche Mechanismen verantwortlich sind. Durch die Kombination von QTL für Salztoleranz in den unterschiedlichen Entwicklungsstadien lässt sich eine verbesserte Anpassung an Salzstress erreichen. 


\section{References}

Allender CbJ and King GJ (2010) Origins of the amphiploid species Brassica napus L. investigated by chloroplast and nuclear molecular markers. BMC Plant Biology 10:54.

Ashraf M (2001). Relationships between growth and gas exchange characteristics in some salt-tolerant amphidiploid Brassica species in relation to their diploid parents. Environ Exp Bot 45:155-163.

Ashraf $M$ and Foolad M (2013) Crop breeding for salt tolerance in the era of molecular markers and marker-assisted selection. Plant Breed. 132:10-20.

Ashraf M and Harris PJC (2004) Potential biochemical indicators of salinity tolerance in plants. Plant Sci 166:3-16.

Ashraf M, Athar HR, Harris PJC and Kwon TR (2008) some prospective strategies for improving crop salt tolerance. Adv Agron 97:45-110.

Ashraf M, McNeilly $T$ and Nazir M (2001) Comparative salt tolerance of amphidiploid and diploid Brassica species. Plant Sci. 160:683-689.

Basunanda P, Radoev M, Ecke W, Friedt W, Becker HC, Snowdon RJ (2010) Comparative mapping of quantitative trait loci involved in heterosis for seedling and yield traits in oilseed rape (Brassica napus L.). Theor Appl Genet 120:271281.

Becker HC, Engqvist GM, Karlsson B (1995) Comparison of rapeseed cultivars and resynthesized lines based on allozyme and RFLP markers. Theor Appl Genet 91:62-67.

Bennett RN, Wallsgrove RM (1994) Secondary metabolites in plant defensemechanisms. New Phytol 127: 617-633.

Berger B, Hülskamp M, Flügge UI (2007) The role of HIG1/MYB51 in the regulation of indolic glucosinolate biosynthesis. In Botaniches Institute der Mathematisch-Naturwissenschaftlichen Fakultät (Köln: Universität zu Köln), pp. 119.

Bettey M, Finch-Savage WE, King GJ, Lynn JR (2000) Quantitative genetic analysis of seed vigor and pre-emergence seedling growth traits in Brassica oleracea. New Phytol 148:227-286.

Bewley JD, (1997a) Seed germination and dormancy. Plant Cell 9:1055-1066.

Bhattacharya RC, Maheswari M, Dineshkumar V, Kirti PB, Bhat SR, Chopra VL (2004) Transformation of Brassica oleracea var. capitata with bacterial betA gene enhances tolerance to salt stress. Sci Hortic 100:215-227.

Bodnaryk RP (1994) Potent effect of jasmonates on indole glucosinolates in oilseed rape and mustard. Phytochemistry 35:301-305. 
Boyer JS (1982) Plant productivity and environment potential for increasing crop plant productivity, genotypic selection. Science 218:443-448.

Branca F, Cartea E (2011) Brassica. In: Kole C (ed) Wild crop relatives: genomic and breeding resources. Oilseeds. Springer, Heidelberg, pp 17-36.

Brown PD, Tokuhisa, JG, Reichelt M, Gershenzon J (2003) Variation of glucosinolate accumulation among different organs and developmental stages of Arabidopsis thaliana. Phytochemistry 62:471-481.

Cano EA, Perez-Alfocea F, Moreno V, Caro M, and Bolarin MC (1998) Evaluation of salt tolerance in cultivated and wild tomato species through In vitro shoot apex culture. Plant Cell, Tissue Organ Cult 53:19-26.

Chaves M M, Maroco J P, Pereira J S (2003) Understanding plant responses to drought -from genes to the whole plant. Funct Plant Biol 30:239-264.

Cleemput S and Becker HC (2011) Genetic variation in leaf and stem glucosinolates in resynthesized lines of winter rapeseed (Brassica napus L.). Genet. Resour. Crop Evol DOI: 10.1007/s10722-011-9701-x.

Clerkx EJ, El-Lithy ME, Vierling E, Ruys GJ, Blankestijn-De Vries H, et al. (2004) Analysis of natural allelic variation of Arabidopsis seed germination and seed longevity traits between the accessions Landsberg erecta and Shakdara, using a new recombinant inbred line population. Plant Physiol 135:432-443.

Collins NC, Tardieu F, and Tuberosa R (2008) Quantitative trait loci and crop performance under abiotic stress: where do we stand? Plant Physiol 147:469486.

Doerge RW, Churchill GA (1996) Permutations tests for multiple loci affecting quantitative character. Genetics 142:285-294.

Dubcovsky J, Santa Maria G, Epstein E, Luo MC, Dvoak J (1996) Mapping of the $\mathrm{K}^{+} / \mathrm{Na}^{+}$discrimination locus Kna1 in wheat. Theor Appl Genet 92:448-54.

Elavumoottil OC, Martin JP, Moreno, ML (2003) Changes in sugars, sucrose synthase activity and proteins in salinity tolerant callus and cell suspension cultures of Brassica oleracea L. Biol Plant 46:7-12.

EL-Hendawy SE, Hu Y, Sakagami JI, Schmidhalter U (2011) Screening Egyptian wheat genotypes for salt tolerance at early growth stages. Int $\mathrm{J}$ Plant Prod 5:283-298.

Ellis RH and Roberts EH (1980) Towards a rational basis for testing seed quality. In Seed Production, (ed. P.D. Hebblethwaite), pp. 605-635, Butter worths, London.

Epstein E, Norlyn JD, Rush DW, Kingsbury R W, Kelley DB, Cunningham GA, and Wrona AF (1980) Saline culture of crops: a genetic approach. Science 210:399-404. 
Fahey JW, Haristoy X, Dolan PM, Kensler TW, Scholtus I, et al. (2002) Sulforaphane inhibits extracellular, intracellular, and antibiotic-resistant strains of Helicobacter pylori and prevents benzopyrene-induced stomach tumors. Proc Natl Acad Sci USA 99:7610-15.

Falk KL, Tokuhisa JG, Gershenzon J (2007) The effect of sulfur nutrition on plant glucosinolate content: Physiology and molecular mechanisms. Plant Biology 9:573-581.

Feng J, Long Y, Shi L, Shi J, Barker G, et al. (2012) Characterization of metabolite quantitative trait loci and metabolic networks that control glucosinolate concentration in the seeds and leaves of Brassica napus. New Phytol 193: 96-108.

Flowers JL (1991) Interaction of salinity and temperature on the germination of Crambe- Agron J 83:169-172.

Flowers TJ (2004) Improving crop salt tolerance. J. Exp. Bot 55:307-319.

Flowers TJ, Troke PF, Yeo AR (1977) The mechanism of salt tolerance in halophytes. Annu Rev Plant Physiol. 28:89-121.

Foolad MR (1999) Comparison of salt tolerance during seed germination and vegetative growth in tomato by QTL mapping. Genome 42:727-734.

Foolad MR and Chen FQ (1999) RFLP mapping of QTLs conferring salt tolerance during the vegetative stage in tomato. Theor Appl Genet 99:235-243.

Foolad MR and Jones RA (1991) Genetic analysis of salt tolerance during germination in Lycopersicon. Theor Appl Genet 81:321-326.

Foolad MR and Jones RA (1993) Mapping salt-tolerance genes in tomato (Lycopersicon esculentum) using trait-based marker analysis. Theor Appl Genet 87:184-192.

Foolad MR, Subbiah P, Kramer C, Hargrave G, and Lin GY (2003) Genetic relationships among cold, salt and drought tolerance during seed germination in an interspecific cross of tomato. Euphytica 130:199-206.

Frandsen KJ (1943) The experimental formation of Brassica juncea Czern. et. Coss (Preliminary report). Dan Bot Ark 11: 1-17.

Frandsen KJ (1947) The experimental formation of Brassica napus L. var. oleifera D.C. and Brassica carinata Braun. Dan. Bot. Ark. 12:1-16.

Fricke W, Akhiyarova G, Veselov D, Kudoyarova G (2004) Rapid and tissuespecific changes in $A B A$ and in growth rate response to salinity in barley leaves. $\mathrm{J}$ Exp Bot 55:1115-1123.

Galpaz N and Reymond M (2010) Natural variation in Arabidopsis thaliana revealed a genetic network controlling germination under salt stress. PLoS ONE 5 (15198):1-10. 
Gao M, Li G, Potter D, McCombie W, Quiros C (2006) Comparative analysis of methylthioalkylmalate synthase (MAM) gene family and flanking DNA sequences in Brassica oleracea and Arabidopsis thaliana. Plant Cell Rep 25:592-598.

Gao M, Li G, Yang B, Qiu D, Farnham M, et al. (2007) High-density Brassica oleracea linkage map: identification of useful new linkages. Theor Appl Genet 115: 277-287.

Giamoustaris A and Mithen RF (1995). The effect of modifying the glucosinolate content of leaves of oilseed rape (Brassica napus spp oleifera) on its interaction with specialist and generalist pests. Ann Appl Biol 126: 347-363.

Gigolashvili T, Berger B, Flügge UI. (2009) Specific and coordinated control of indolic and aliphatic glucosinolate biosynthesis by R2R3-MYB transcription factors in Arabidopsis thaliana. Phytochem Rev 8:3-13.

Gigolashvili T, Berger B, Mock HP, Müller C, Weisshaar B, Flügge UI (2007b) The transcription factor HIG1/MYB51 regulates indolic glucosinolate biosynthesis in Arabidopsis thaliana. Plant J 50:886 - 901.

Gigolashvili T, Engqvist $M$, Yatusevich R, Müller C, FlüggeUI (2008) HAG2/MYB76 and HAG3/MYB29 exert a specific and coordinated control on the regulation of aliphatic glucosinolate biosynthesis in Arabidopsis thaliana. New Phytol 177:627-642.

Gómez-Campo C and Prakash S (1999) Origin and domestication In GómezCampo C (eds) Biology of Brassica Coenospecies Elsevier, Amsterdam, pp 3358.

Grattan SR and Grieve CM (1999) Salinity-mineral nutrient relations in horticultural crops. Sci Hort 78:127-157.

Grubb CD and Abel S (2006) Glucosinolate metabolism and its control. Trends Plant Sci 11: 89-100

Guo RF, Yuan GF, Wang QM (2013) Effect of $\mathrm{NaCl}$ treatments on glucosinolate metabolism in broccoli sprouts. J Zhejiang Univ Sci B 14: 124-131.

Haldane JBS (1919) The combination of linkage values, and the calculation of distances between the loci of linked factors. J Genet 8:299-309.

Halkier BA, Gershenzon J (2006) Biology and biochemistry of glucosinolates. Annu Rev Plant Biol 57:303-338.

Harper AL, Trick M, Higgins J, Fraser F, Clissold L, Wells R, Hattori C, Werner P and Bancroft I (2012) Associative transcriptomics of traits in the polyploid crop species Brassica napus. Nat Biotechnol 30:798-802.

Hasan M, Friedt W, Freitag NM, Link K, Pons-Kühnemann J, Snowdon RJ (2008) Association of gene-linked SSR markers to seed glucosinolate content in oilseed rape (Brassica napus ssp. napus). Theor Appl Genet 116:1035-1049. 
He $\mathrm{T}$ and Cramer GR (1992) Growth and mineral nutrition of six rapid-cycling Brassica species in response to sea water salinity. Plant Soil 139:285-294.

Hirai MY, Klein M, Fujikawa Y, Yano M, Goodenowe DB, Yamazaki Y, Kanaya S, Nakamura Y, Kitayama M, Suzuki H, et al. (2005) Elucidation of gene-to-gene networks in Arabidopsis by integration of metabolomics and transcriptomics. $\mathrm{J}$ Biol Chem 280: 25590-25595.

Howell PM, Sharpe AG, Lydiate DJ (2003) Homoeologous loci control the accumulation of seed glucosinolates in oilseed rape (Brassica napus). Genome 46:454-460.

Huang J, Hirji R, Adam L, Rozwadowski KL, Hammerlindl JK, Keller WA, Selvaraj G. (2000) Genetic engineering of glycinebetaine production towards enhancing stress tolerance in plants: metabolic limitations. Plant Physiol 122:747-756.

Huang S, Spielmeyer W, Lagudah ES, James RA, Platten JD, et al (2006) A sodium transporter (HKT7) is a candidate for Nax1, a gene for salt tolerance in durum wheat. Plant Physiol 142:1718-27.

Hunt L, Holdsworth MJ, and Gray JE (2007) Nicotinamidase activity is important for germination. Plant J 51: 341-351.

Husebye H, Chadchawan S,Winge P, Thangstad OP, Bones AM (2002) Guard cell- and phloem idioblast-specific expression of thioglucoside glucohydrolase 1 (myrosinase) in Arabidopsis. Plant Physiol 128:1180-88.

Iñiguez-Luy $F$, Lukens L, Farnham M, Amasino R, Osborn $T$ (2009) Development of public immortal mapping populations, molecular markers and linkage maps for rapid cycling Brassica rapa and Brassica oleracea. Theor Appl Genet 120:31-43.

Iñiguez-Luy FL and Federico ML (2011). The genetics of Brassica napus L. In: Bancroft I and Schmidt R (eds) Genetics and genomics of the Brassicaceae. Springer, New York Dordrecht Heidelberg London, pp 291-322.

Issa RA (2010) Identification of glucosinolate profile in Brassica oleracea for quantitative trait locus mapping. Ph.D. Thesis, University of Warwick, England.

Jain RK, Jain S, Nainawatee HS, Chowdhury JB (1990) Salt tolerance in Brassica juncea L.1. In vitro selection, agronomic evaluation and genetic stability. Euphytica 48:141-152.

Joosen RVL, Arends D, Willems LA, Ligterink W, and Jansen RC (2012) Visualizing the genetic landscape of Arabidopsis seed performance. Plant Physio 158:570-589.

Justen V (2010) The Effect of Light and Temperature on Glucosinolate Concentration in Turnip (Brassica rapa). Ph. D. Diss. Univ. of Minn., Twin-Cities. 
Khokon MA, Jahan MS, Rahman T, Hossain MA, Muroyama D, Minami I, Munemasa S, Mori IC, Nakamura Y, Murata Y (2011) Allyl isothiocyanate (AITC) induces stomatal closure in Arabidopsis. Plant Cell Environ 34:19001906.

Kirti PB, Hadi S, Kumar PA, Chopra VL (1991a) Production of sodium-chloridetolerant Brassica juncea plants by in vitro selection at the somatic embryo level. Theor Appl Genet 83:233-237.

Kliebenstein DJ (2009) A quantitative genetics and ecological model system: understanding the aliphatic glucosinolate biosynthetic network via QTLs. Phytochem Rev 8:243-254.

Kliebenstein DJ, Gershenzon J, Mitchell-Olds T (2001a) Comparative quantitative trait loci mapping of aliphatic, indolic and benzylic glucosinolate production in Arabidopsis thaliana leaves and seeds. Genetics 159:359-370.

Kliebenstein DJ, Kroymann J, Brown P, Figuth A, Pedersen D, et al. (2001b) Genetic control of natural variation in Arabidopsis glucosinolate accumulation. Plant Physiol. 126:811-825.

Koroleva OA, Davies A, Deeken R, Thorpe MR, Tomos D and Hedrich R (2000) Identification of a new glucosinolate-rich cell type in Arabidopsis flower stalk. Plant Physiol. 124:599-608.

Koyama ML, Levesley A, Koebner RMD, Flowers TJ, Yeo AR (2001) Quantitative trait loci for component physiological traits determining salt tolerance in rice. Plant Physio 125:406-422.

Kräling K, Röbbelen G, Thies W, Herrmann M, Ahmadi R (1990) Variation of seed glucosinolates in lines of Brassica napus. Plant Breeding 105:33-39.

Lexer C, Welch ME, Durph JLy, and Rieseberg LH (2003) Natural selection for salt tolerance quantitative trait loci (QTLs) in wild sunflower hybrids: implications for the origin of Helianthus paradoxus, a diploid hybrid species. Mol Ecol 12: 1225-1235.

Li G and Quiros CF (2003) In planta side-chain glucosinolate modification in Arabidopsis by introduction of dioxygenase Brassica homolog BoGSL-ALK. Theor Appl Genet 106:1116-1121.

Li G, Quiros CF (2002) Genetic analysis, expression and molecular characterization of BoGSL-ELONG, a major gene involved in the aliphatic glucosinolate pathway of Brassica species. Genetics 162:1937-1943.

Li YC, Kiddle G, Bennett R, Doughty K, and Wallsgrove R (1999) Variation in the glucosinolate content of vegetative tissues of Chinese lines of Brassica napus L. Ann Appl Biol 134:131-136. 
Lincoln SE, Daly MJ, Lander ES (1993) Constructing genetic linkage maps with MAPMAKER/EXP 3.0. A tutorial and reference manual. Whitehead Institute for Biomedical Research, Cambridge, MA.

López-Berenguer C, Martínez-Ballesta MC, García-Viguera C, Carvajal M. (2008) Leaf water balance mediated by aquaporins under salt stress and associated glucosinolate synthesis in broccoli. Plant Sci 174: 321-328.

López-Berenguer C, Martinez-Ballesta MC, Moreno DA, Carvajal M, Garcia Viguera C (2009) Growing hardier crops for better health: salinity tolerance and the nutritional value of broccoli. J. Agric. Food Chem. 57:572-578.

Lou P, Zhao J, He H, Hanhart C, Del Carpio DP, Verkerk R, Custers J Koornneef M, Bonnema G (2008) Quantitative trait loci for glucosinolate accumulation in Brassica rapa leaves. New Phytol 179:1017-1032.

Lukens L, Zou F, Lydiate D, Parkin I and Osborn T (2003) Comparison of a Brassica oleracea genetic map with the genome of Arabidopsis thaliana. Genetics 164:359-372.

Lysak and Koch (2011). Phylogeny, Genome, and Karyotype Evolution of Crucifers (Brassicaceae). The genetics of Brassica napus L. In: Bancroft I and Schmidt R (eds) Genetics and genomics of the Brassicaceae. Springer, New York Dordrecht Heidelberg London, pp 1-32.

Ma LQ, Zhou EF, Huo NX, Zhou RH, Wang GY and Jia JZ (2007) Genetic analysis of salt tolerance in a recombinant inbred population of wheat (Triticum aestivum L.). Euphytica 153:109-117.

Maathuis FJM and Amtmann A (1999) $\mathrm{K}^{+}$nutrition and $\mathrm{Na}^{+}$toxicity: the basis of cellular $\mathrm{K}^{+} / \mathrm{Na}^{+}$ratios. Ann of Bot 84:123-133.

Magrath R, Herron C, Giamoustaris A, Mithen R (1993) The inheritance of aliphatic glucosinolates in Brassica napus. Plant Breeding 111: 55-72.

Mano $\mathrm{Y}$ and $\mathrm{K}$ Takeda (1997) Mapping quantitative trait loci for salt tolerance at germination and the seedling stage in barley Hordeum vulgare L. Euphytica 94:263-272.

Martínez-Ballesta MC, Moreno DA, Carvajal M (2013) The physiological importance of glucosinolates on plant response to abiotic stress in Brassica. Int J Mol Sci 14:11607-11625.

Mass EV and Hoffman GJ (1977) Crop salt tolerance: Current assessment. J. Irrig. Drainage Div. Am.Soc Civ Eng 103:115-134.

McDanell R, McLean AEM, Hanley AB, Heaney RK, Fenwick GR (1988) Chemical and biological properties of indole glucosinolates (glucobrassicins): a review. Food Chem Toxicol 26: 59-70. 
Mewis I, Khan MAM, Glawischnig E, Schreiner M, Ulrichs C (2012) Water Stress and Aphid Feeding Differentially Influence Metabolite Composition in Arabidopsis thaliana (L.). PLoS ONE 7(11):e48661.

Mikkelsen MD, Petersen BL, Glawischnig E, Jensen AB, Andreasson E, Halkier BA (2003) Modulation of CYP79 genes and glucosinolate profiles in Arabidopsis by defense signaling pathways. Plant Physiol 131:298-308.

Ming ZY, Jian FW, Hong YC, Hu QZ, Hong SZ (2005) Inheritance and QTL mapping of salt tolerance in rice. Rice Sci 12:25-32.

Mithen R (1992) Leaf glucosinolate profiles and their relationship to pest and disease resistance in oilseed rape. Euphytica, 63:71-83.

Mithen RF, Raybould A and Giamoustaris A (1995) Divergent selection for secondary metabolites between wild populations of Brassica oleracea and its implication for plant-herbivore interactions. Heredity 75:472-484

Mithen (2001) Glucosinolates biochemistry, genetics and biological activity. Plant Growth Regul 34: 91-103.

Monforte AJM, Asins J, Carbonell EA (1997) Salt tolerance in Lycopersicon species. 5. Does genetic variability at quantitative trait loci affect their analysis? Theor Appl Genet 95:284-293.

Morinaga T (1934) The chromosome number of Brassica juncea and Brassica napus, on the hybrid between the two and on offspring line of the hybrid Jap $\mathrm{J}$ Genet [Japanese]. 9:161-163.

Munns R (1993) Physiological processes limiting plant growth in saline soils: Some dogmas and hypotheses. Plant Cell Enviro 16:15-24.

Munns R (2002) Comparative physiology of salt and water stress. Plant Cell Enviro 25:239-250.

Munns R (2005) Genes and salt tolerance: bringing them together. New Phytol 167:645-663.

Munns R and Tester M (2008) Mechanisms of salinity tolerance. Annu Rev Plant Biol 59:651-681.

Munns R, Guo J, Passioura JB, Cramer GR (2000) Leaf water status controls day-time but not daily rates of leaf expansion in salt-treated barley. Aust $\mathrm{J}$ Plant Physiol 27:949-57.

Nayidu N, Bollina V, Kagale S. (2013) Oilseed Crop Productivity under Salt Stress. P. Ahmad et al. (eds.), Ecophysiology and Responses of Plants under Salt Stress. Springer, Heidelberg, pp 249:265.

Nobel CL, Rogers ME (1992) Arguments for the use of physiological criteria for improving the salt tolerance in crops. Plant Soil 146:99-107. 
Nonogaki H (2006) Seed germination-The biochemical and molecular mechanisms. Breeding Sci 56:93-105.

Pang Q, Guo J, Chen S, Chen Y, Zhang L, Fei M, Jin S, Li M, Wang Y, Yan X. (2012) Effect of salt treatment on the glucosinolate-myrosinase system in Thellungiella salsuginea. Plant Soil 355:363-374.

Park BJ, Akira LZK, Kameya T (2005) Genetic improvement of Chinese cabbage for salt and drought tolerance by constitutive expression of a $B$. napus LEA gene. Plant Sci 169:553-558.

Paul MJ, Foyer CH (2001) Sink regulation of photosynthesis. J Exp Bot 52:1383-400.

Prasad, SR, Bagali, PG, Hittalmani S, Shashidhar HE (2000) Molecular mapping of quantitative trait loci associated with seedling tolerance to salt stress in rice Oryza sativa L. Curr Sci 78:162-164.

Purty RS, Kumar G, Singla-Pareek SL, Pareek A (2008) Towards salinity tolerance in Brassica an overview. Physiol Mol Biol Plants 14:39-49.

Qasim M, Ashraf M, Ashraf, MY, Rehman SU, Rha ES (2003) Salt induced changes in two canola cultivars differing in salt tolerance. Biol Plantarum 46: $629-632$.

Qiu QS, Barkla BJ, Vera-Estrella R, Zhu JK, and Schumaker KS (2003) $\mathrm{Na}^{+} / \mathrm{H}^{+}$ exchange activity in the plasma membrane of Arabidopsis. Plant Physiol 132: 1041-1052.

Quesada V, Garcia MS, Piqueras P, Ponce MR, and Micol JL (2002) Genetic architecture of $\mathrm{NaCl}$ tolerance in Arabidopsis. Plant Physiol 130:951-963.

Quesada V, Ponce MR, Micol JL (2000) Genetic analysis of salt-tolerant mutants in Arabidopsis thaliana. Genetics 154:421-436.

Quijada PA, Udall JA, Lambert B, Osborn TC (2006) Quantitative trait analysis of seed yield and other complex traits in hybrid spring rapeseed (Brassica napus L.): 1 . Identification of genomic regions from winter germplasm. Theor Appl Genet 113: 549-561.

Rajagopal D, Agarwal, Tyagi W, Singla-Pareek SL, Reddy MK, Sopory SK (2007) Pennisetum glaucum $\mathrm{Na}^{+} / \mathrm{H}^{+}$antiporter confers high level of salinity tolerance in transgenic Brassica juncea. Mol Breeding 19:137-151.

Rakow, G. 2004. Species origin and economic importance of Brassica. p. 3-11. In E.C. Pua and C.J. Douglas (ed.). Biotechnology in Agriculture and Forestry, Vol. 54 Brassica. Springer-Verlag Berlin Heidelberg, New York.

Ramchiary N, Bisht NC, Gupta V, Mukhopadhyay A, Arumugam N, et al. (2007) QTL analysis reveals context-dependent loci for seed glucosinolate trait in the oilseed Brassica juncea: importance of recurrent selection backcross scheme for the identification of 'true' QTL. Theor Appl Genet 116: 77-85. 
Ren Z, Zheng Z, Chinnusamy V (2010) RAS1, a quantitative trait locus for salt tolerance and ABA sensitivity in Arabidopsis. PNAS 107:5669-5674.

Rosa AS, Rodrigues PMF (1998) The effect of light and temperature on glucosinolate concentration in the leaves and roots of cabbage seedlings. J Sci Food Agric. 78: 208-212.

Shabala S and Cuin TA (2007) Potassium transport and plant salt tolerance. Physiol Plantarum133:651-69.

Shannon MC and Grieve C (1999) Tolerance of vegetable crops to salinity. Scient Hort 78:5-38.

Siahsar BA and Narouei M (2010) Mapping QTLs of physiological traits associated with salt tolerance in "Steptoe $x$ Morex" doubled haploid lines of barley at seedling stage. J Food Agric Environ 8:751-759.

Sønderby IE, Geu-Flores F, Halkier BA (2010) Biosynthesis of glucosinolate gene discovery and beyond. Trends Plant Sci 15:283-296.

Song K, Osborn TC, Williams PH (1990) Brassica taxonomy based on nuclear restriction fragment length polymorphisms (RFLPS). 3. Genome relationships in Brassica and related genera and the origin of $B$. oleracea and $B$. rapa. Theor Appl Genet 79:497-506.

Sotelo T, Soengas P, Velasco P, Rodriguez VM , Cartea ME (2014) Identification of Metabolic QTLs and Candidate Genes for Glucosinolate Synthesis in Brassica oleracea Leaves, Seeds and Flower Buds. PLoS ONE 9: e91428.

Srivastava S, Fristensky B, Kav NNV (2004) Constitutive expression of a PR 10 protein enhances the germination of Brassica napus under saline conditions Plant. Cell Physiol 45:1320-1324.

Stebbins GL (1966) Chromosomal variations and evolution. Science 152:14631469.

Steinbrenner AD, Agerbirk, N, Orians CM, Chew FS (2012) Transient abiotic stresses lead to latent defense and reproductive responses over the Brassica rapa life cycle. Chemoecology 22:239-250.

Talalay P, Fahey JW, Holtzclaw WD, Prestera T, Zhang Y (1995) Chemoprotection against cancer by phase 2 enzyme induction. Toxicol Lett 82: 173-179.

Textor S, Gershenzon J (2009) Herbivore induction of the glucosinolatemyrosinase defense system: major trends, biochemical bases and ecological significance. Phytochem Rev 8:149-170.

Thornalley PJ (2002) Isothiocyanates: mechanism of cancer chemopreventive action. Anti-Cancer Drugs 13:331-38. 
Traka MH, Saha S, Huseby S, Kopriva S, Walley PG, Barker GC, Moore J, Mero G, van den Bosch F, Constant H, et al. (2013) Genetic regulation of glucoraphanin accumulation in Beneforté ${ }^{\circledR}$ broccoli. New Phytol. 198:1085-95.

Troufflard S, Mullen W, Larson T, Graham I, Crozier A and Amtmann A (2010) Potassium deficiency induces the biosynthesis of oxylipins and glucosinolates in Arabidopsis thaliana. BMC Plant Biol 10:172.

Tunçtürk M, Tunçtürk R, Yildirim B, Çiftçi V. 2011. Changes of micronutrients, dry weight and plant development in canola (Brassica napus L.) cultivars under salt stress. Afr J Biotechnol 10: 3726-3730.

U N (1935) Genomic analysis in Brassica with special reference to the experimental formation of Brassica napus and peculiar mode of fertilization. Jpn J Bot 7:389-452

USDA-ARS (2008) Research Databases Bibliography on Salt Tolerance George E Brown, Jr Salinity Lab US Dep Agric, Agric Res Serv Riverside, CA.

Utz HF (2003) PLABSTAT: A computer program for statistical analysis of plant breeding experiments. Institute of Plant Breeding, Seed Science and Population Genetics, University of Hohenheim, Stuttgart, Germany.

Uzunova M, Ecke W, Weissleder K, Röbbelen G (1995) Mapping the genome of rapeseed (Brassica napus L.). I. Construction of an RFLP linkage map and localization of QTLs for seed glucosinolate content. Theor Appl Genet 90:194204.

Vallejo AJ, Yanovsky MJ, Botto JF (2010) Germination variation in Arabidopsis thaliana accessions under moderate osmotic and salt stresses. Ann Bot (Lond) 106:833-842.

Velasco P, Cartea ME, Gonza'lez C, Vilar M, Orda's A (2007) Factors affecting the glucosinolate content of kale (Brassica oleracea acephala). J Agric Food Chem 55:955-962.

Velasco P, Soengas P, Vilar M, Cartea ME, del Rio M (2008) Comparison of glucosinolate profiles in leaf and seed tissues of different Brassica napus crops. J Am Soc Hort Sci 133:551-558.

Villalta IG, Bernet P, Carbonell EA, Asins MJ (2007) Comparative QTL analysis of salinity tolerance in terms of fruit yield using two solanum populations of F-7 lines. Theor Appl Genet 114:1001-1017.

Wang Z, Wang J, Bao Y, Wu Y, Zhang H (2011) Quantitative trait loci controlling rice seed germination under salt stress. Euphytica 178:297-307.

Warwick SI (2011) Brassicaceae in agriculture. In: Schmidt R, Bancroft I (eds) Genetics and genomics of the Brassicaceae. Springer, Berlin, pp 33-65. 
Wentzell AM, Rowe HC, Hansen BG,Ticconi C, Halkier BA, Kliebenstein DJ (2007) Linking metabolic QTLs with network and cis-eQTLs controlling biosynthetic pathways. PLoS Genet 3:1687-701.

Wittkop B, Snowdon J, Friedt W (2009) Status and perspectives of breeding for enhanced yield and quality of oilseed crops for Europe. Euphytica 170:131-140.

Xin Y, Shaojun D, Sixue C, Xiufeng $Y$ (2008) Effect of $\mathrm{NaCl}$ Stress on Glucosinolate Content in Rosette Leaves of Arabidopsis thaliana. Journal of Northeast Forestry University 36:51-56.

Yan X, and Chen S (2007) Regulation of plant glucosinolate metabolism. Planta 226:1343-1352.

Yang J, Hu C, Hu H, Yu R, Xia Z, Zhu J (2008) QTLNetwork: mapping and visualizing genetic architecture of complex traits in experimental populations. Bioinforma. 24:721-723.

Zamani-Nour S, Clemens R, Möllers C (2013) Cytoplasmic diversity of Brassica napus L., Brassica oleracea L. and Brassica rapa L. as determined by chloroplast microsatellite markers. Genet Resour Crop Evol 60:953-965.

Zhang HX, Hodson JN, Williams JP, Blumwald E (2001). Engineering salttolerant Brassica plants: Characterization of yield and seed oil quality in transgenic plants with increased vacuolar sodium accumulation. PNAS 98:12832-12836.

Zhao Z, Zhang W, Stanley BA, Assmann, SM (2008) Functional proteomics of Arabidopsis thaliana guard cells uncovers new stomatal signaling pathways WOA. Plant Cell 20:3210-3226.

Zheng GH, Gao Y, Wilen PRW and Gusta LV (1998) Canola seed germination and seedling emergence from prehydrated and redried seeds subjected to salt and water stresses at low temperature. Ann Appl Biol 132:339-348. 


\section{Appendices}

Appendix 1

Mean, minimum, and maximum of germination percentage, germination pace, and respective salt tolerance indices determined in $\mathrm{DH}$ populations of a) $B$. napus Alesi $\times \mathrm{H} 30$, b) $B$. napus Mansholts $\times$ Samourai and c) $B$. oleracea Bo1TBDH populations under control and salt treatment.

\begin{tabular}{|c|c|c|c|c|c|c|c|}
\hline Population & Ranges & \multicolumn{2}{|c|}{ Germination \% } & \multicolumn{2}{|c|}{ Germination pace } & G\% STI & GP STI \\
\hline & & Control & Salt & Control & Salt & & \\
\hline \multicolumn{8}{|l|}{ a) Alesi $\times \mathrm{H} 30$} \\
\hline & Minimum & 90.0 & 10.0 & 0.2 & 0.1 & 7.1 & 34.4 \\
\hline & Maximum & 100.0 & 100.0 & 0.6 & 0.3 & 100.0 & 81.0 \\
\hline & Mean & 99.6 & 74.9 & 0.3 & 0.1 & 74.5 & 56.2 \\
\hline \multicolumn{8}{|l|}{ b) Mansholts $\times$ Samourai } \\
\hline & Minimum & 90.0 & 0.0 & 0.2 & 0.0 & 0.0 & 0.0 \\
\hline & Maximum & 100.0 & 100.0 & 0.6 & 0.3 & 100.0 & 100.0 \\
\hline & Mean & 89.03 & 74.8 & 0.4 & 0.2 & 75.2 & 47.8 \\
\hline \multicolumn{8}{|l|}{ C) Bo1TBDH } \\
\hline & Minimum & 60.0 & 0.0 & 0.1 & 0.0 & 0.0 & 0.0 \\
\hline & Maximum & 100.0 & 100.0 & 0.4 & 0.3 & 100.0 & 100.0 \\
\hline & Mean & 98.7 & 78.4 & 0.2 & 0.2 & 76.5 & 72.1 \\
\hline
\end{tabular}


Appendix 2
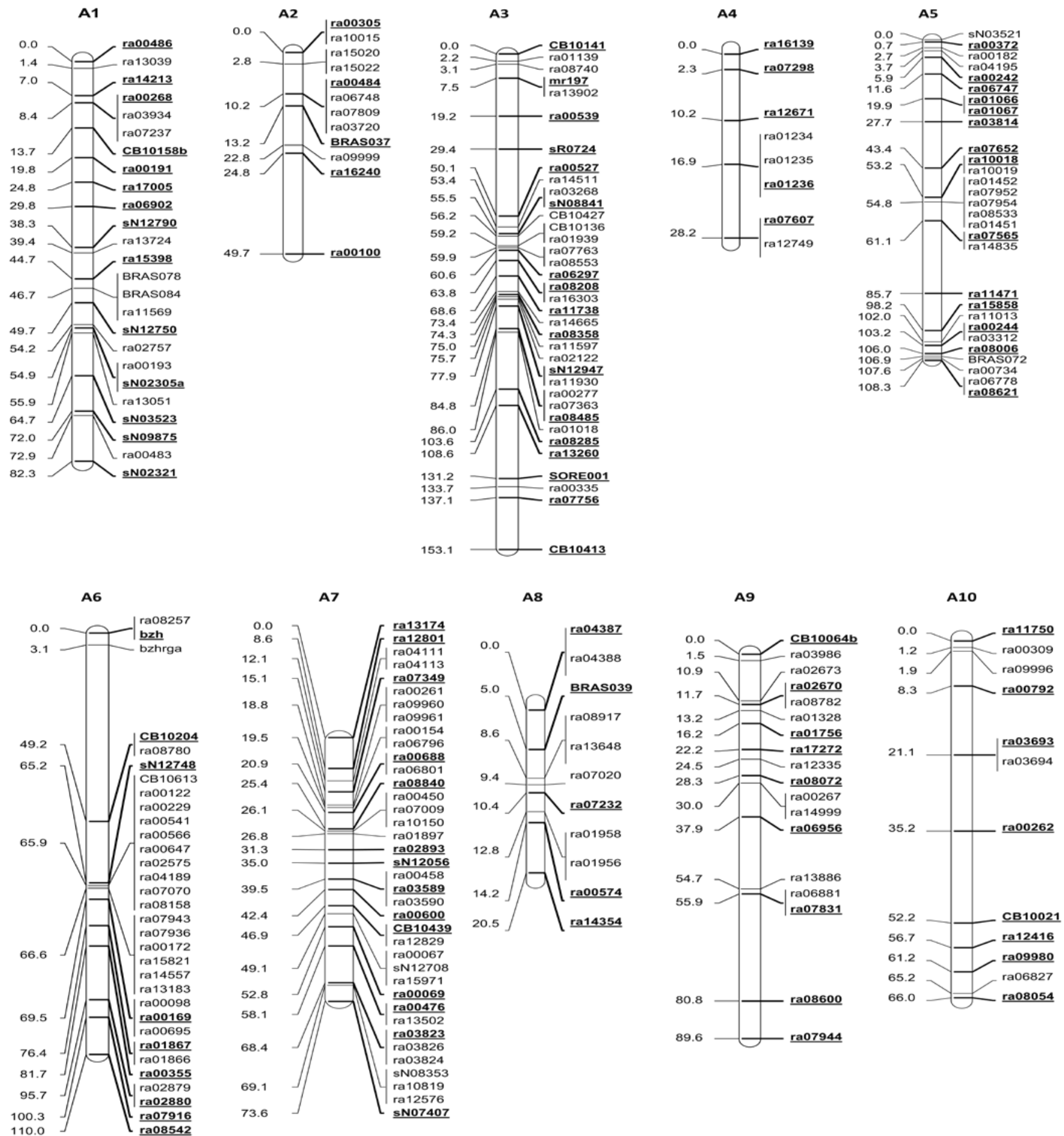

Figure 5: Linkage map of Brassica napus cross Alesi $\times \mathrm{H} 30$. The vertical bars represent linkage groups $\mathrm{N} 1-\mathrm{N} 10=\mathrm{A} 1-\mathrm{A} 10$ and N11-N19 = C1-C9 (international nomenclature). Marker locus names and positions (cM) are located to the left and right of the vertical bars, respectively. 


\section{Linkage map of Alesi $\times$ H30 Continued from page 168}

C1

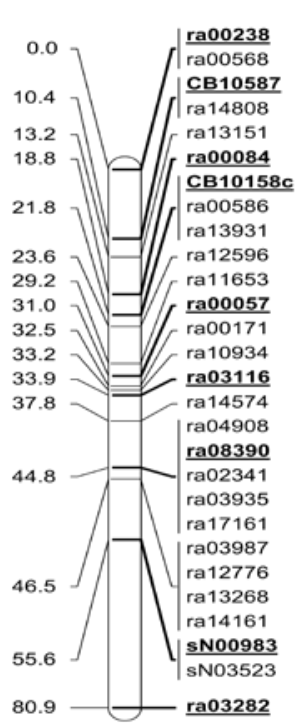

C3

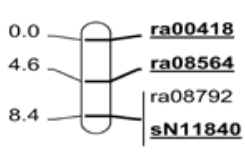

C6

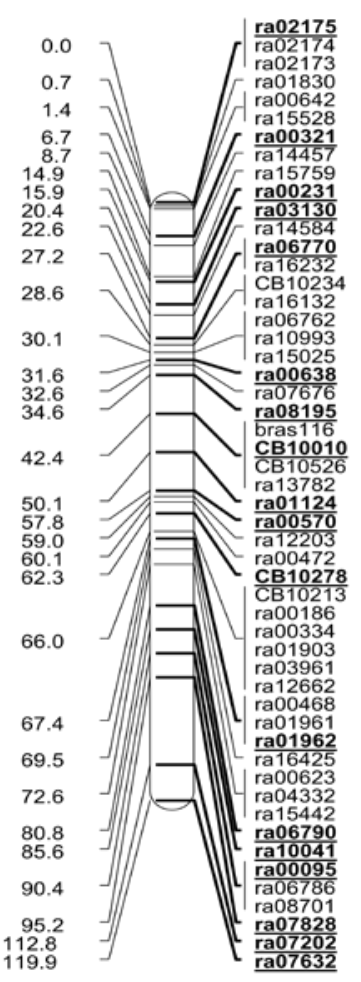

C7

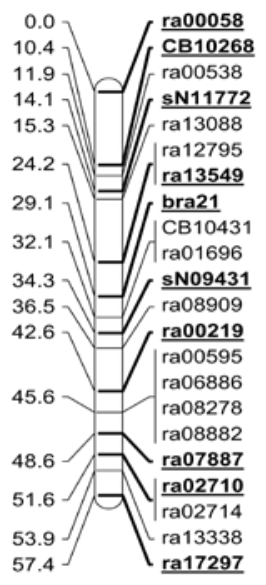

C8

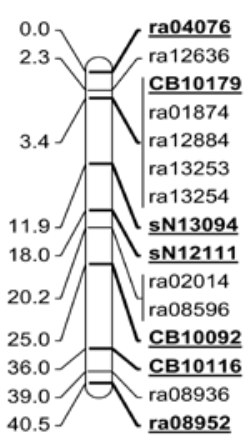

C4a

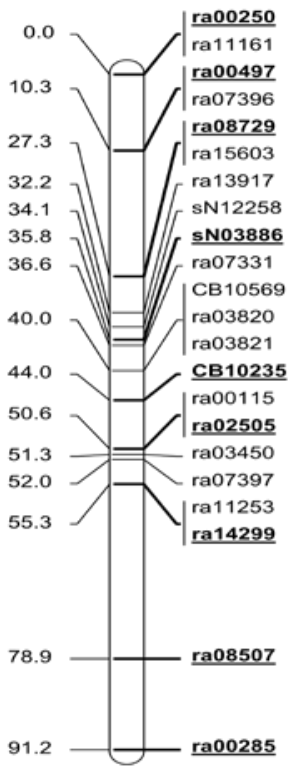

C4b
C5a

$\left.\begin{array}{l}0.0 \\ 3.8\end{array}\right) \quad r^{\mathrm{ra006} 32}$

$\left.\begin{array}{l}3.8 \\ 6.3\end{array}\right]$ ra01657

$6.0-1$ CB10020c

$\begin{aligned} & 17.3 \\ & 23.9\end{aligned} / \frac{\frac{\mathrm{sNO0990}}{\mathrm{ra01363}}}{\mathrm{ra12667}}$

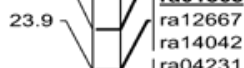

$24.9-=\left\{\begin{array}{l}\mathrm{ra04231} \\ \mathrm{ra04232} \\ \mathrm{CB} 10636\end{array}\right.$

$26.3 \quad \underline{\underline{\text { ra07101 }}}$

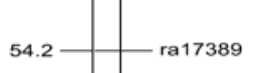

${ }_{74.5}>0$ sN01035

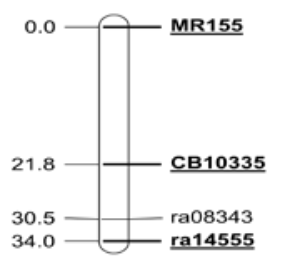

0.0
1.1

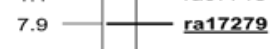

53.7

C5b

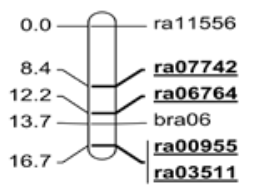

C9

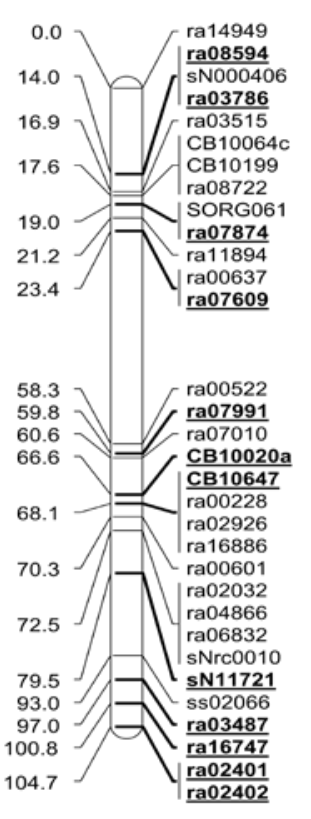

22

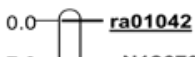


Appendix 3
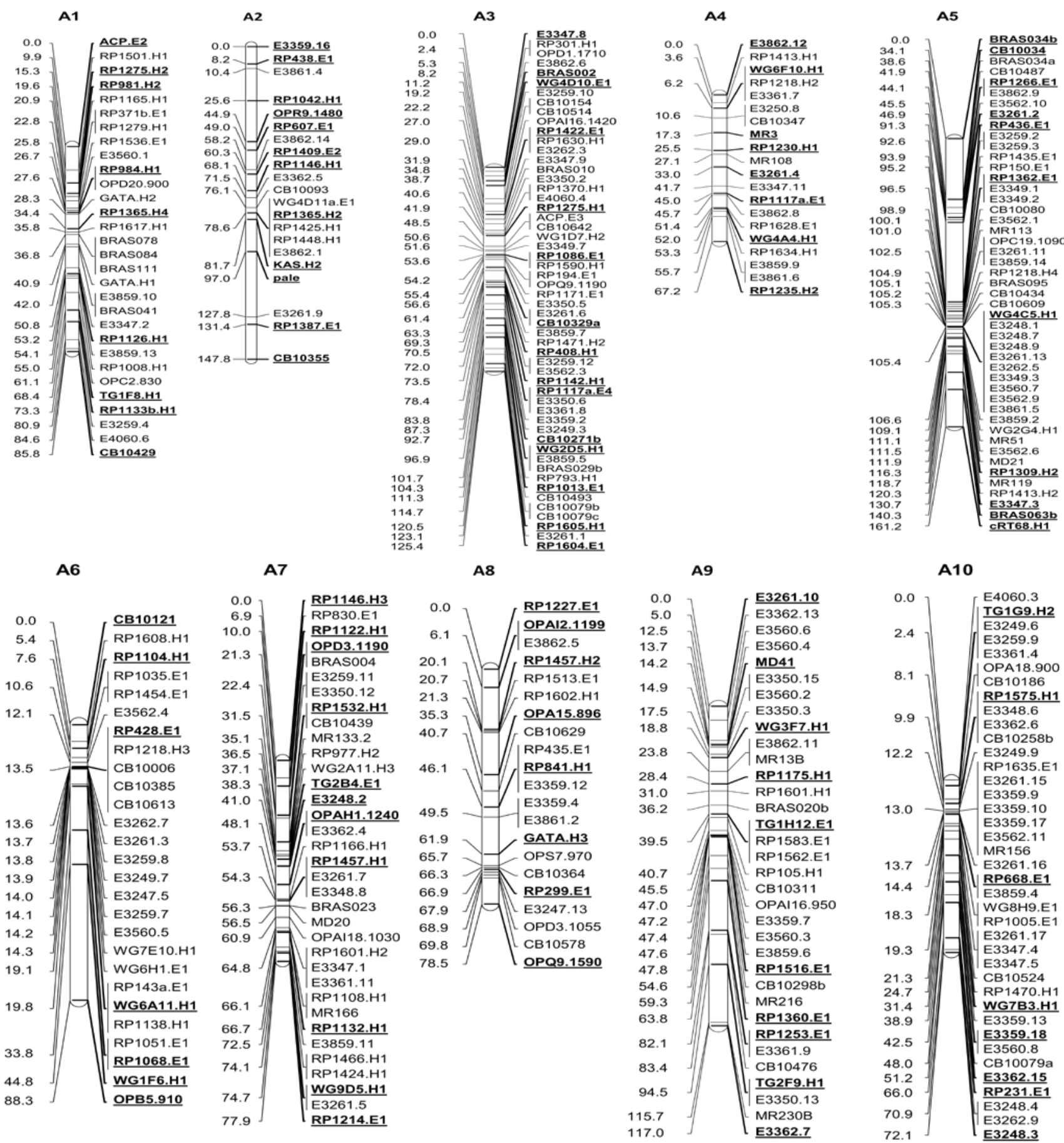

Figure 5: Linkage map of Brassica napus cross of Mansholtsx Samourai based on a population of double haploid lines. Vertical bars represent linkage groups N1-N10 = A1A10 and N11-N19 = C1-C9 (international nomenclature). Marker locus names and positions (cM) are located to the left and right of the vertical bars, respectively. 
Linkage map of Mansholts $\times$ Samourai continued from page 170

C1

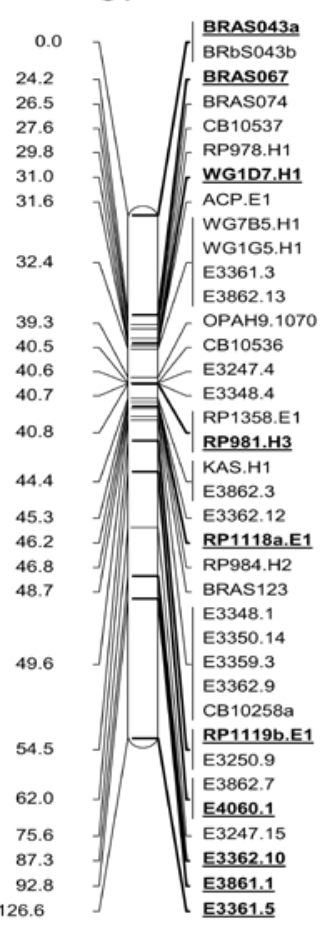

C6

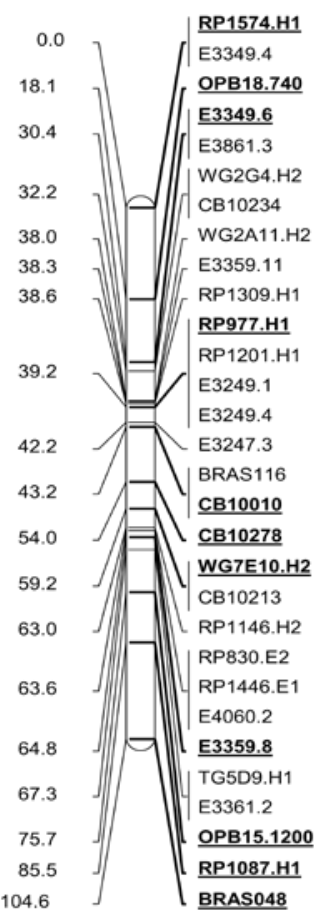

c2

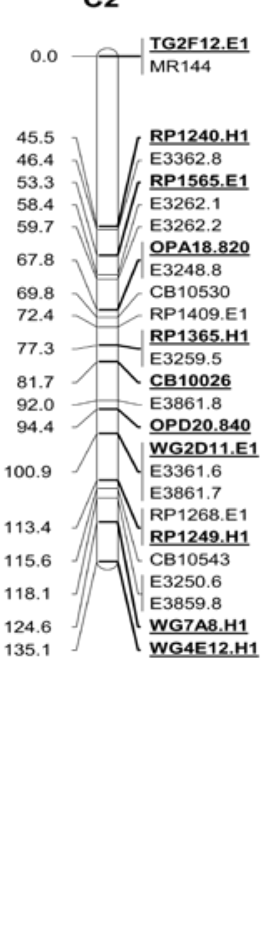

C3

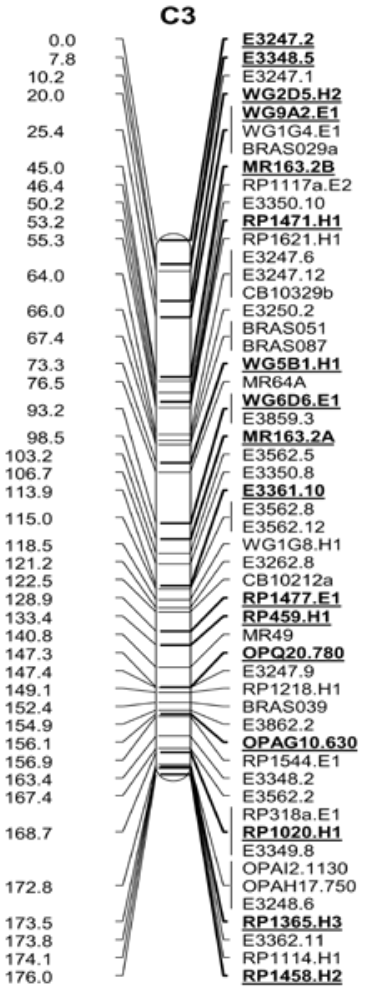

C4

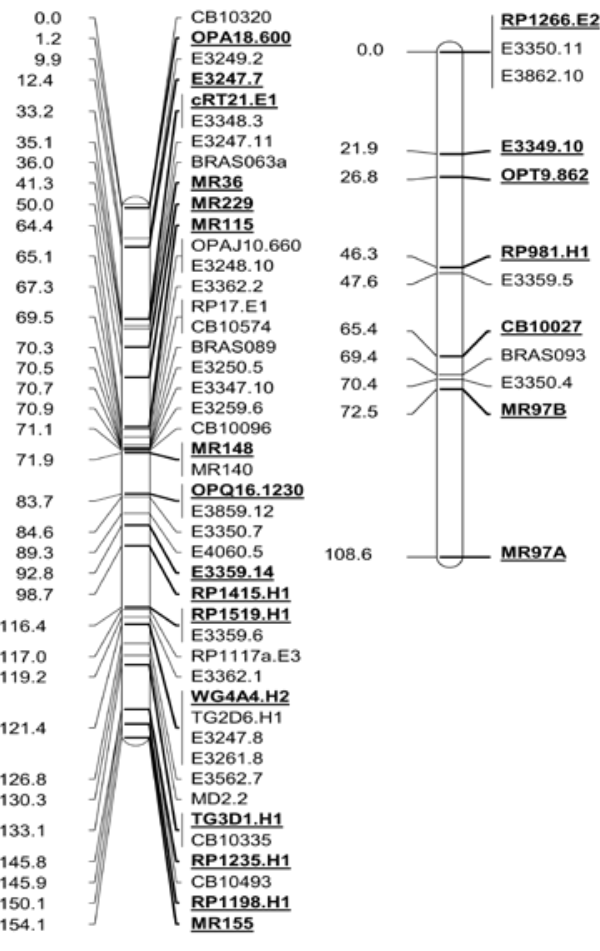

C5 (n)

(

.




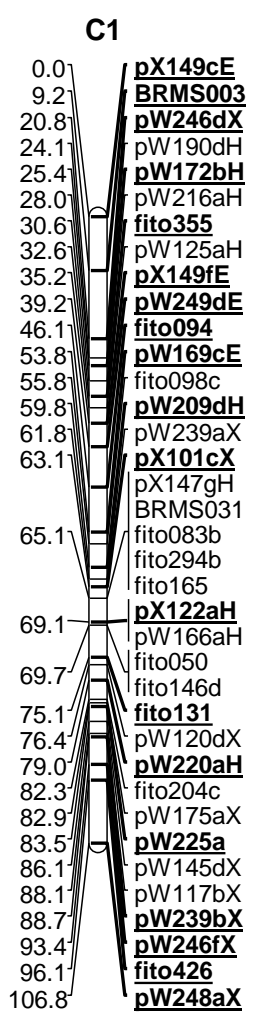

c6

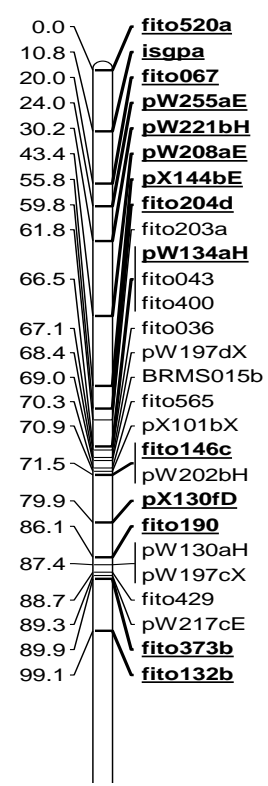

C2

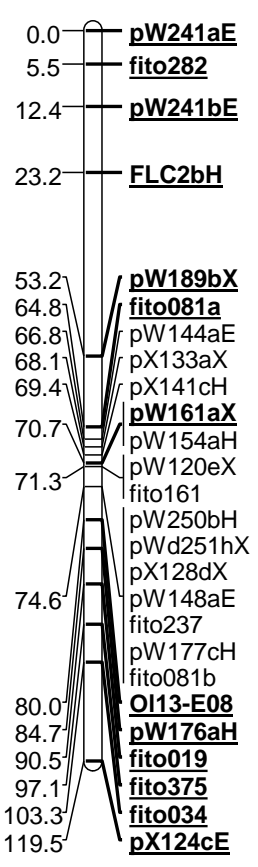

C7

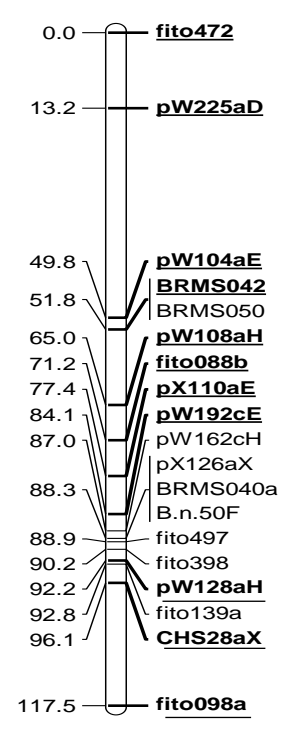

C3

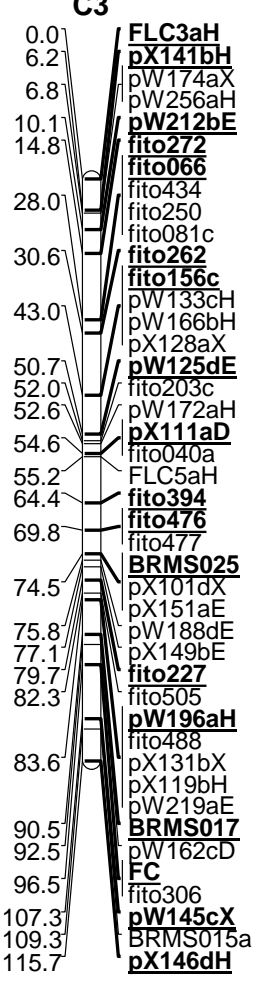

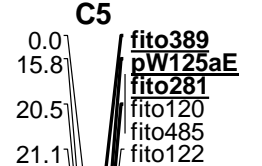

21.1

22.

35.

35.

$51.0 \quad-\frac{\text { BRMS049 }}{\text { BRMS045 }}$

51.6 $=1$ fito045

53.6 $\mid\left(\begin{array}{l}\text { pW126aE } \\ \text { pW209aH }\end{array}\right.$

- fito156a

71.2 $\left\{\begin{array}{l}\text { pX139dH } \\ \text { pX101aX }\end{array}\right.$

$71.5)=\left(\begin{array}{l}\text { p } \\ \mathrm{pW} 190 \mathrm{cX} \\ \mathrm{p} X 151 \mathrm{bE}\end{array}\right.$

1.8

1.8

fito316
$p \times 147 \mathrm{fH}$
pX126bX
fito259

pW127cE

73.7 = Na10-F06b

75. fito132a

(

8.3

0.9

4.2

\begin{tabular}{l|l}
84.2 & WW198bH \\
94.0 & fito100b \\
fito294a
\end{tabular}

95. fito279b

98.6 pW213bX

113.7 $\frac{\text { fito353 }}{\text { pX119d }}$

C8

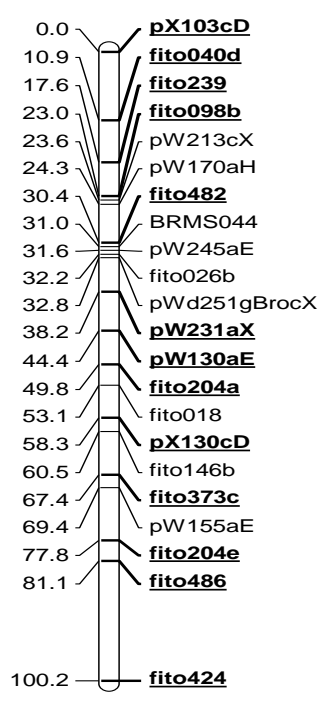

C9

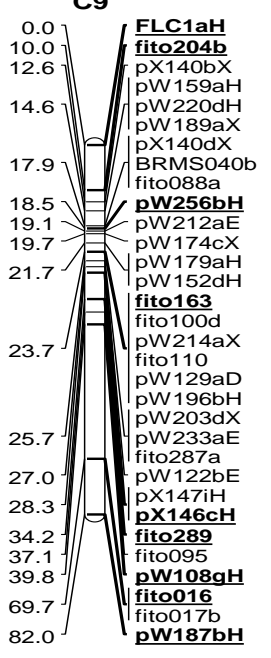

Linkage map of Brassica oleracea Bo1TBDH population. The vertical bars represent linkage groups N11-N19 = C1-C9 (international nomenclature). Marker locus names and positions (cM) are located to the left and right of the vertical bars, respectively. The markers that have been used for framework map construction are marked bold and underlined 
Appendices

Appendix 5

Salinity tolerant cultivars and lines of Brassica species developed through breeding

\begin{tabular}{|c|c|c|c|}
\hline $\begin{array}{l}\text { Brassica } \\
\text { species }\end{array}$ & Cultivars/lines & Parameter for testing tolerance & References \\
\hline \multirow[t]{3}{*}{ B. napus } & $\begin{array}{l}\text { Dunkeld } \\
\text { (canola) }\end{array}$ & Biomass and seed yield & Qasim (2000) \\
\hline & ST9194 & Germination & $\begin{array}{l}\text { Puppala et al. } \\
\text { (1999) }\end{array}$ \\
\hline & $\begin{array}{l}\text { Rapora, } \\
\text { Mytnitskii, } \\
\text { Chisayanatane }\end{array}$ & Seed yield & Pokrovskii (1990) \\
\hline \multirow[t]{12}{*}{ B. juncea } & Common Green & Vegetative stage & Kwon et al. (1997) \\
\hline & Varuna & Germination & Rai (1977) \\
\hline & & Seed yield & $\begin{array}{l}\text { Kumar and Malik } \\
\text { (1983), Kumar } \\
\text { (1984) }\end{array}$ \\
\hline & TH 68 & Germination & Singh et al. (1984) \\
\hline & $\mathrm{RH} 30$ & Seed yield & $\begin{array}{l}\text { Dhawan et al. } \\
\text { (1987), Kumar } \\
(1984)\end{array}$ \\
\hline & $\begin{array}{l}\text { Pusa Bold, } \\
\text { Kranti }\end{array}$ & Seed yield & Kumar (1995) \\
\hline & CS4, CS15 & Seed yield & Uma et al. (1992) \\
\hline & Pant Rai 2030 & Seed yield & Sinha (1991) \\
\hline & RH 7818 & Seed yield & $\begin{array}{l}\text { Dhawan et al. } \\
\text { (1987) }\end{array}$ \\
\hline & DIRA 337 & Seed yield & Sinha (1991) \\
\hline & BM-1, LL-84 & Biomass and seed yield & Ashraf (1992) \\
\hline & P-15, KS-51 & Biomass and seed yield & $\begin{array}{l}\text { Ashraf et al. } \\
\text { (1994) }\end{array}$ \\
\hline \multirow[t]{2}{*}{ B. carinata } & $\begin{array}{l}\text { C90-1191, } \\
\text { P5/80, Yellow } \\
\text { Dodella }\end{array}$ & Germination and seedling growth & $\begin{array}{l}\text { Ashraf and Sharif } \\
\text { (1997) }\end{array}$ \\
\hline & $\begin{array}{l}\text { C90-1115, 77- } \\
321\end{array}$ & Seed yield & $\begin{array}{l}\text { Ashraf and Sharif } \\
\text { (1998) }\end{array}$ \\
\hline \multirow[t]{2}{*}{ B. rapa } & BSH1 & Germination & Paliwal (1972) \\
\hline & & Seed yield & Kumar (1984) \\
\hline
\end{tabular}

- For references listed in this table see (Nayidu et al. 2013) 


\section{Appendix 6}

Minimum, maximum and of fresh weight (FW), dry weight (DW), relative water content (RWC), chlorophyll content measured by SPAD (SPAD1, SPAD2), Sodium content ( $\mathrm{Na}^{+} \mathrm{mg} / \mathrm{g}$ D.M.), Potassium content ( $\mathrm{K}^{+} \mathrm{mg} / \mathrm{g}$ D.M.) of Brassica napus DH population (Mansholts $\times$ Samourai) $(\mathrm{n}=138)$, and parental lines under control and salt stress $(200 \mathrm{mM} \mathrm{NaCl})$.

\begin{tabular}{|c|c|c|c|c|c|c|c|c|c|c|}
\hline \multirow[t]{3}{*}{ Traits } & \multicolumn{6}{|c|}{ DH population } & \multirow{2}{*}{\multicolumn{2}{|c|}{$\frac{\text { Mansholts }}{\text { Mean }}$}} & \multirow{2}{*}{\multicolumn{2}{|c|}{$\frac{\text { Samourai }}{\text { Mean }}$}} \\
\hline & \multicolumn{2}{|c|}{ Min } & \multicolumn{2}{|c|}{ Max } & \multicolumn{2}{|c|}{ Mean } & & & & \\
\hline & Control & Salt & Control & Salt & Control & Salt & Control & Salt & Control & Salt \\
\hline$F W(g)$ & 2.09 & 1.58 & 7.32 & 4.15 & 4.58 & 2.67 & 5.2 & 2.91 & 5.1 & 2.79 \\
\hline $\mathrm{DW}(\mathrm{g})$ & 0.34 & 0.22 & 0.93 & 0.65 & 0.59 & 0.42 & 0.68 & 0.48 & 0.63 & 0.48 \\
\hline RWC & 82.83 & 82.45 & 91.57 & 87.64 & 87.19 & 84.62 & 87.70 & 83.58 & 87.06 & 82.80 \\
\hline SPAD1 & 19.88 & 35.78 & 43.93 & 48.57 & 38.06 & 42.31 & 42.99 & 46.25 & 39.91 & 44.83 \\
\hline SPAD2 & 19.93 & 36.01 & 44.79 & 52.81 & 38.87 & 44.89 & 42.47 & 46.82 & 39.60 & 46.16 \\
\hline $\mathrm{Na}^{+} \mathrm{mg} / \mathrm{g} \mathrm{DM}$ & 0.76 & 14.57 & 2.40 & 35.92 & 1.14 & 24.16 & 1.05 & 21.65 & 1.10 & 24.43 \\
\hline $\mathrm{K}^{+} \mathrm{mg} / \mathrm{g} \mathrm{DM}$ & 34.02 & 30.06 & 81.03 & 63.27 & 47.95 & 50.29 & 49.64 & 46.57 & 49.82 & 46.20 \\
\hline $\mathrm{Na}^{+} / \mathrm{K}^{+}$ & 0.02 & 0.27 & 0.25 & 0.76 & 0.03 & 0.48 & 0.020 & 0.46 & 0.021 & 0.53 \\
\hline
\end{tabular}

Min $=$ Minimum, Max $=$ maximum 


\section{Appendix 7}

Minimum, maximum and of fresh weight (FW), dry weight (DW), relative water content (RWC), chlorophyll content measured by SPAD (SPAD1, SPAD2), Sodium content ( $\mathrm{Na}^{+} \mathrm{mg} / \mathrm{g}$ D.M.), Potassium content (K+ $\left.\mathrm{mg} / \mathrm{g} \mathrm{D} \mathrm{M}\right)$ of Brassica oleracea DH population $\operatorname{Bo1TBDH}(n=138)$, and parental lines under control and salt stress $(100 \mathrm{mM} \mathrm{NaCl})$.

\begin{tabular}{|c|c|c|c|c|c|c|c|c|c|c|}
\hline \multirow{3}{*}{ Traits } & \multicolumn{6}{|c|}{ DH population } & \multirow{2}{*}{\multicolumn{2}{|c|}{$\frac{\text { TO1000DH3 }}{\text { Mean }}$}} & \multirow{2}{*}{\multicolumn{2}{|c|}{$\frac{\text { Early Big }}{\text { Mean }}$}} \\
\hline & \multicolumn{2}{|c|}{ Min } & \multicolumn{2}{|c|}{ Max } & \multicolumn{2}{|c|}{ Mean } & & & & \\
\hline & Control & Salt & Control & Salt & Control & Salt & Control & Salt & Control & Salt \\
\hline $\mathrm{FW}(\mathrm{g})$ & 2.27 & 0.96 & 6.18 & 3.97 & 4.14 & 2.84 & 3.42 & 2.05 & 3.89 & 2.4 \\
\hline $\mathrm{DW}(\mathrm{g})$ & 0.11 & 0.14 & 0.58 & 0.57 & 0.42 & 0.35 & 0.33 & 0.20 & 0.39 & 0.28 \\
\hline RWC & 86.72 & 42.93 & 95.30 & 93.77 & 89.75 & 87.18 & 88.89 & 86.77 & 89.72 & 87.24 \\
\hline SPAD & 34.43 & 42.10 & 62.20 & 66.84 & 52.25 & 55.12 & 48.82 & 49.54 & 53.8 & 54.32 \\
\hline $\mathrm{Na}^{+} \mathrm{mg} / \mathrm{g} \mathrm{DM}$ & 1.43 & 17.51 & 4.44 & 54.39 & 2.73 & 28.17 & 2.68 & 26.90 & 2.60 & 21.76 \\
\hline $\mathrm{K}^{+} \mathrm{mg} / \mathrm{g} \mathrm{DM}$ & 57.67 & 22.30 & 81.61 & 59.61 & 67.94 & 44.59 & 67.13 & 51.77 & 58.97 & 50.37 \\
\hline $\mathrm{Na}^{+} / \mathrm{K}^{+}$ & 0.02 & 0.27 & 0.07 & 0.76 & 0.04 & 0.65 & 0.04 & 0.36 & 0.04 & 0.32 \\
\hline
\end{tabular}

Min = Minimum, Max $=$ maximum 
Appendix 8
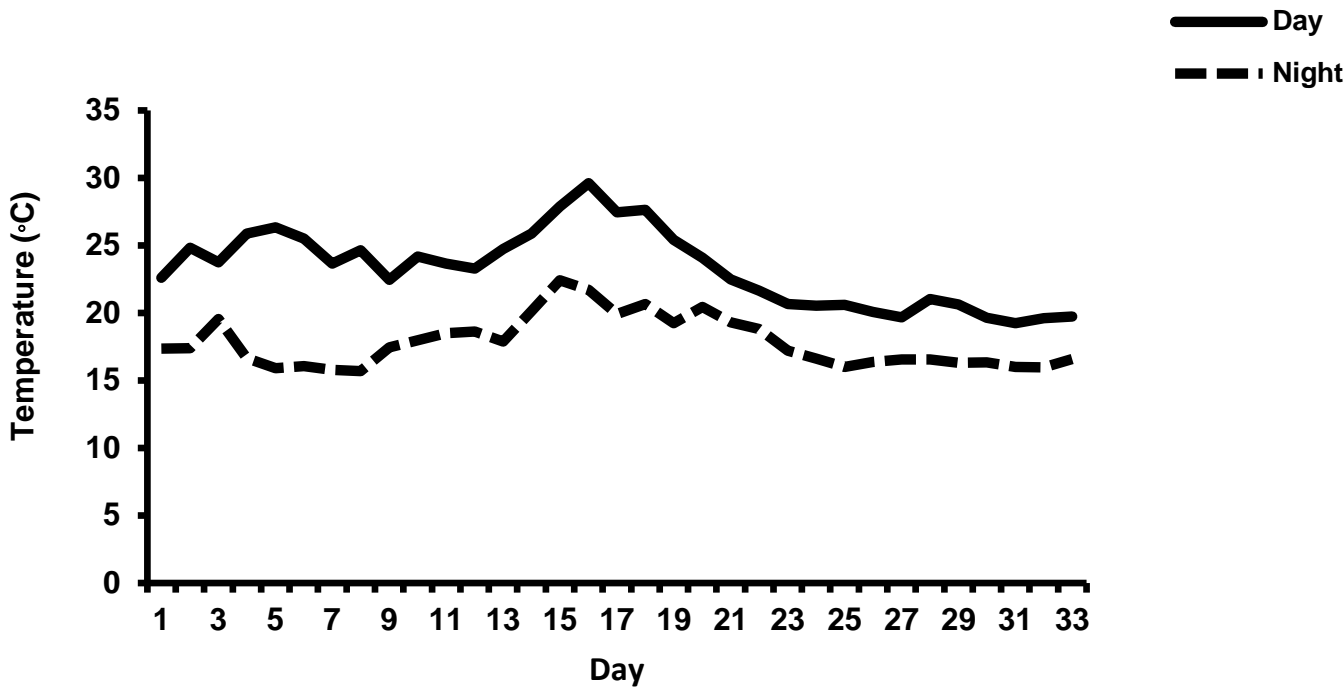

Temperature of replicate one day and night

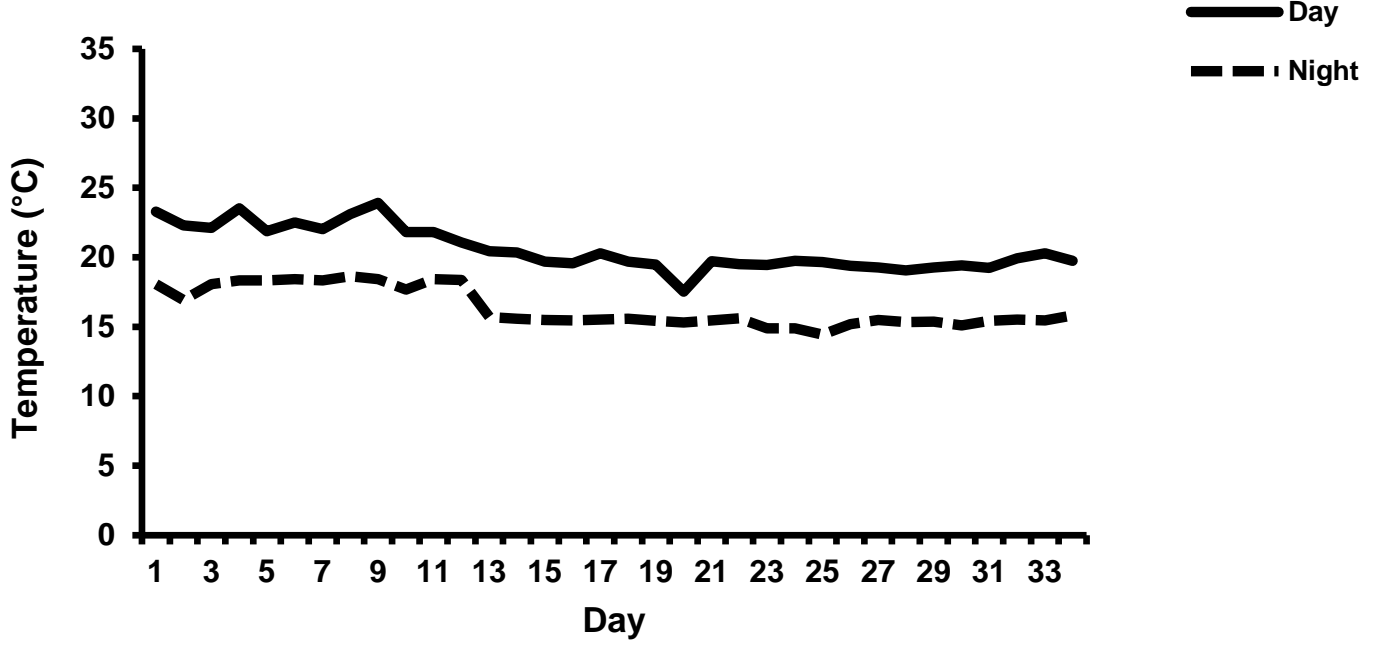

Temperature of replicate two day and night

The fluctuation of temperature fluctuation day and night across the duration of the experiment for $B$. napus $\mathrm{DH}$ population Mansholts $\times$ Samourai for replicate one and replicate is presented for both replicates 
Appendix 8 continued from page 176

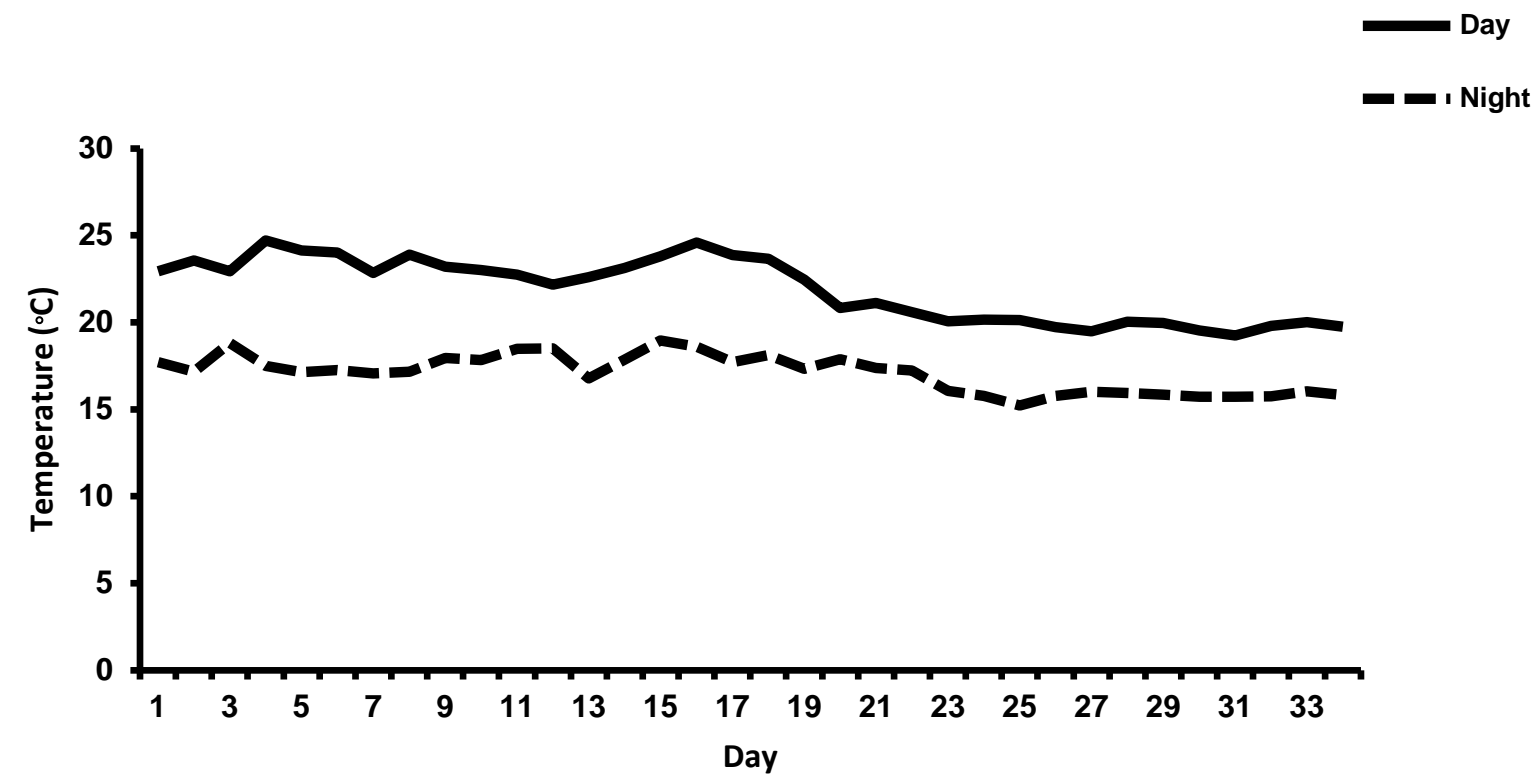

Average of temperature overall the two replicates

Appendix 9

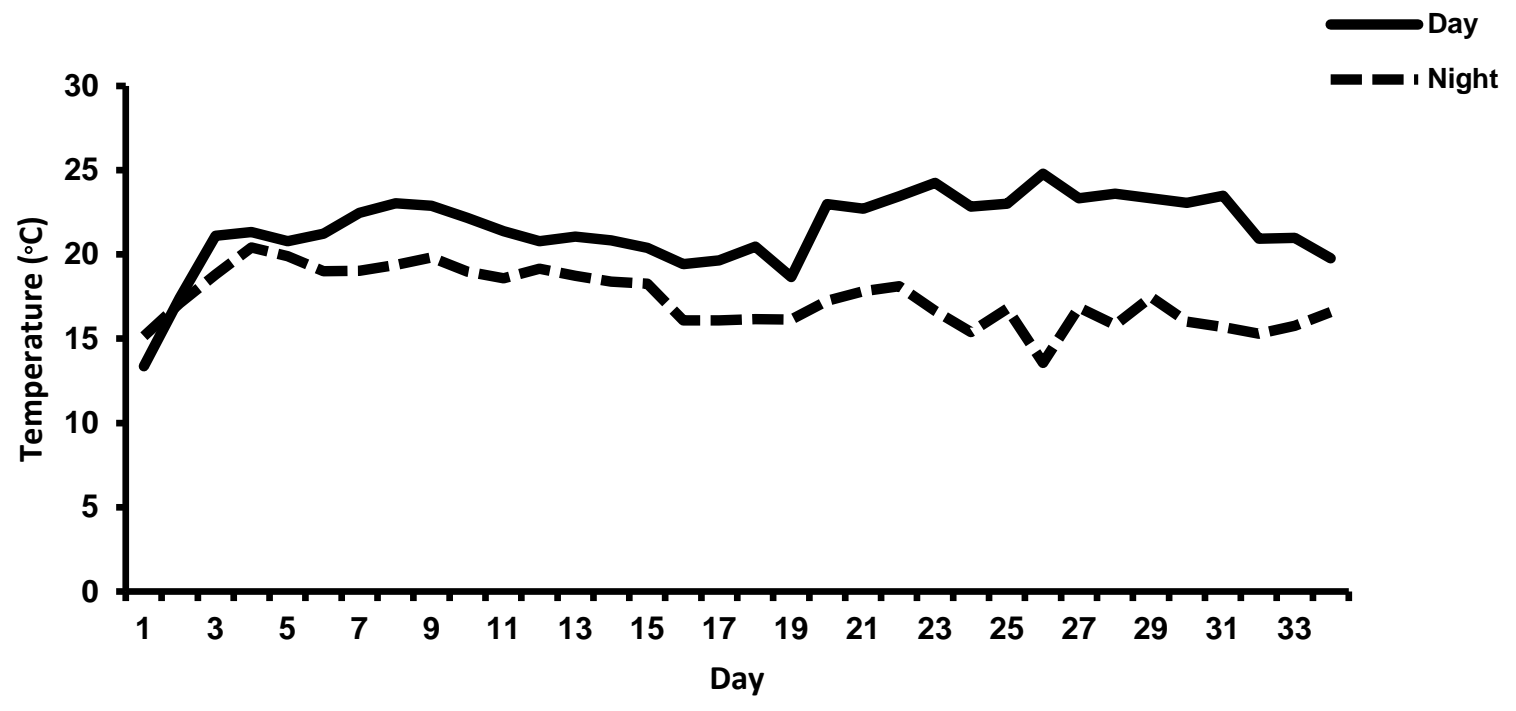

Temperature of replicate one

The fluctuation of temperature fluctuation day and night across the duration of the experiment for $B$. oleracea Bo1TBDH DH population for replicate one and replicate is presented for both replicates. 
Appendix 9 continued from page 177

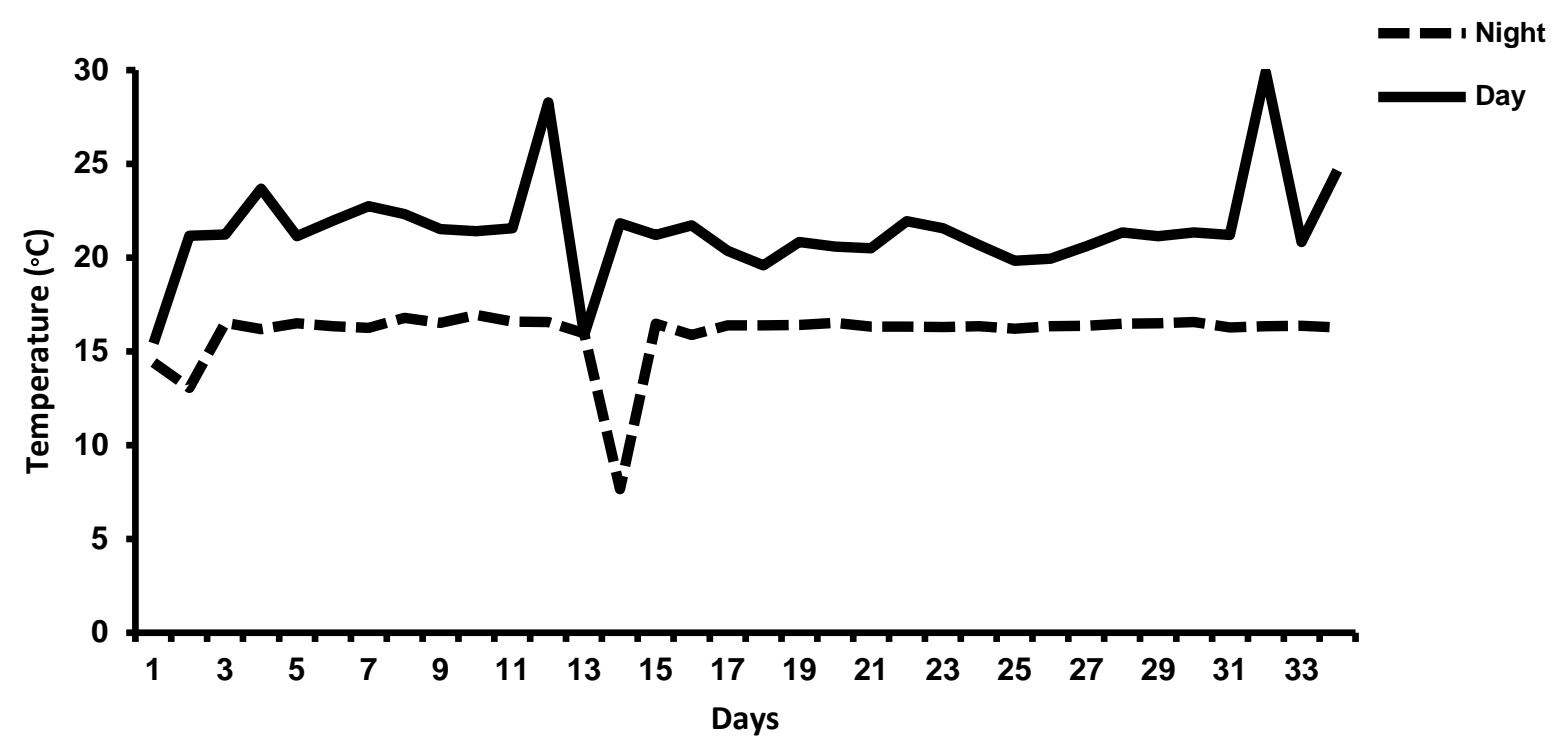

Temperature of replicate two

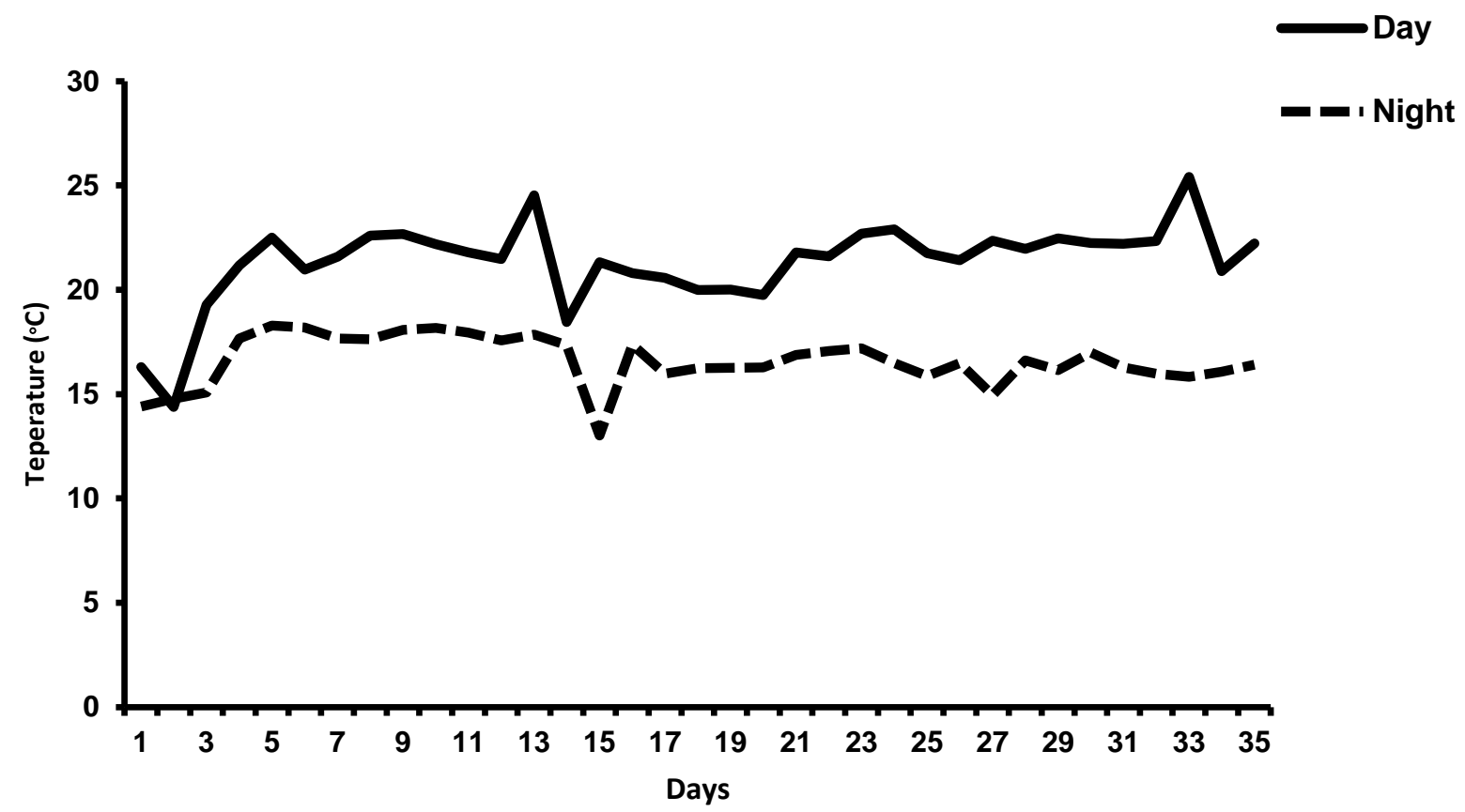

Temperature mean overall the two replicates 
Appendices-

Appendix 10

Mean squares and $F$ test of significance from the ANOVA and heritabilities of glucosinolates for B.napus DH population Mansholts $\times$ Samourai, $\mathrm{n}=138 \mathrm{DH}$ lines under control condition and salt stress $(200 \mathrm{mM} \mathrm{NaCl})$.

\begin{tabular}{|c|c|c|c|c|c|c|c|c|}
\hline \multirow[b]{2}{*}{ Sources of Variance } & \multicolumn{4}{|c|}{ Control } & \multicolumn{4}{|c|}{ Salt } \\
\hline & Genotypes (G) & Replicates (R) & $G \times R$ & $h^{2}$ & Genotypes (G) & Replicates (R) & $G \times R$ & $h^{2}$ \\
\hline DF & 137 & 1 & 137 & & 137 & 1 & 137 & \\
\hline PRO & 3.30 ** & 8.84 & 1.1 & 66.68 & $1.82^{\star \star}$ & $0.39 * \star$ & 0.45 & 75.49 \\
\hline GNL & 0.005 & 0.0005 & 0.005 & 7.77 & $0.03^{* *}$ & $0.02^{* *}$ & 0.004 & 87.41 \\
\hline RAA & $0.03^{\star *}$ & $0.204^{\star \star}$ & 0.019 & 31.37 & $0.13^{\star *}$ & $0.39 *$ & 0.08 & 40.11 \\
\hline RAE & $0.10+$ & $2.45^{\star \star}$ & 0.09 & 20.37 & $0.15^{\star \star}$ & $1.57^{\star \star}$ & 0.01 & 35.88 \\
\hline GNA & $0.9, * *$ & $13.41^{\star *}$ & 0.28 & 70.00 & $0.13^{\star \star}$ & $0.50 * \star$ & 0.06 & 54.26 \\
\hline $4 \mathrm{OH}$ & $0.2^{\star \star}$ & $0.39 \star \star$ & 0.1 & 44.89 & $0.006^{\star \star}$ & 0.003 & 0.003 & 44.95 \\
\hline GBN & $1.1^{\star \star}$ & 0.48 & 0.58 & 47.51 & $1.13^{\star \star}$ & $6.09 * \star$ & 0.43 & 61.73 \\
\hline GBC & 0.74 & $59.30^{* *}$ & 0.55 & 14.94 & $2.08^{\star \star}$ & 0.89 & 0.58 & 71.87 \\
\hline NAS & $0.17+$ & $6.74^{\star \star}$ & 0.13 & 22.43 & $0.04^{* *}$ & $0.86^{\star *}$ & 0.02 & 59.11 \\
\hline $4 \mathrm{ME}$ & $0.0063+$ & $0.14^{\star \star}$ & 0.005 & 22.86 & $0.011^{\star *}$ & $0.04^{\star \star}$ & 0.002 & 79.01 \\
\hline NEO & 0.02 & 0.02 & 0.02 & 4.73 & $0.64^{\star \star}$ & 0.18 & 0.15 & 75.97 \\
\hline SUM & $18.52^{\star \star}$ & 3.59 & 5.96 & 67.96 & $9.86^{\star *}$ & $7.78^{\star}$ & 2.12 & 78.51 \\
\hline
\end{tabular}

** Significant at $P=0.01 ;$ * significant at $P=0.05$ and + significant at $P=0.1$ 
Appendix 11

$\square$ Control $\square$ Salt
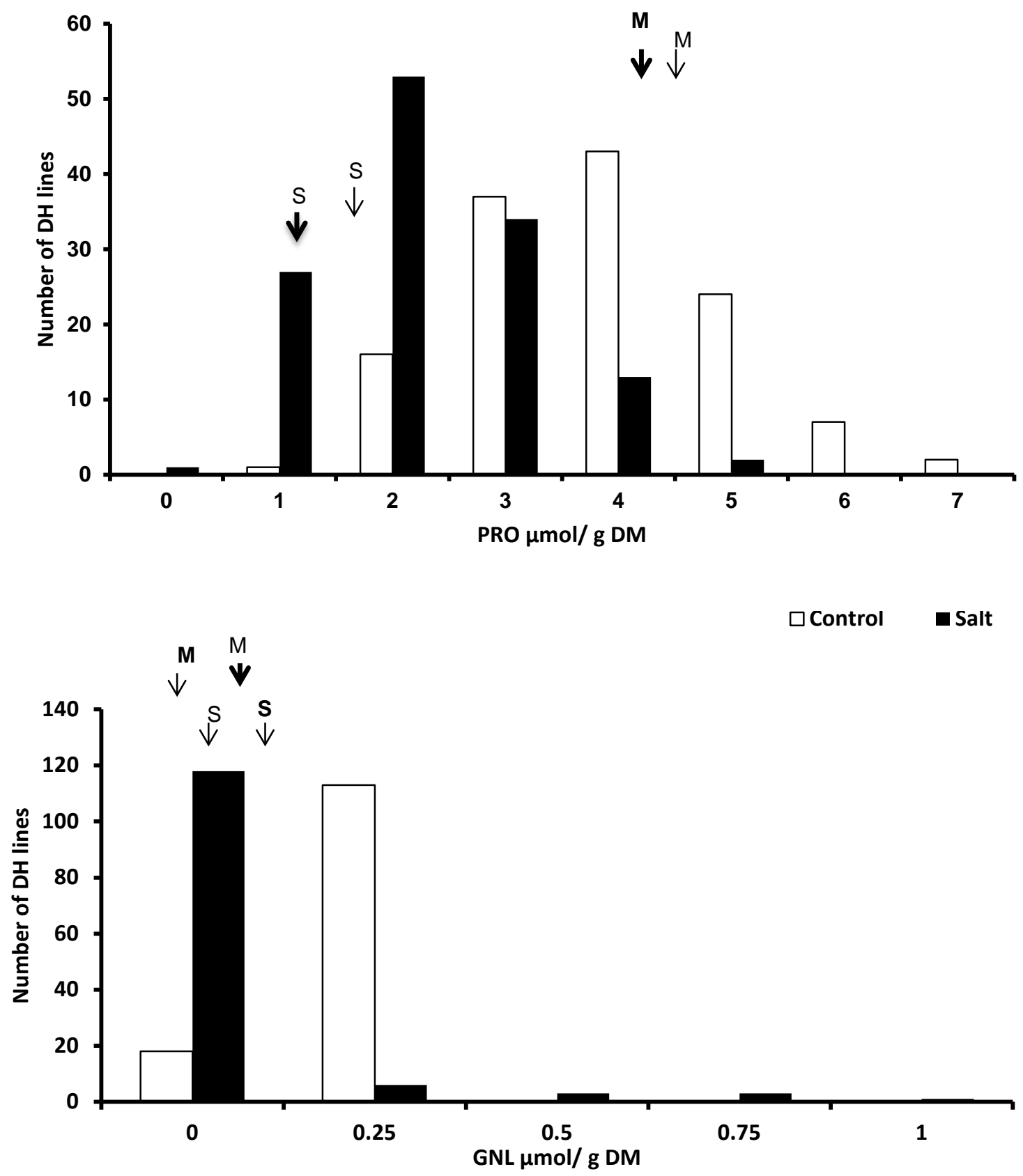

Distribution of single components and total glucosinolates under control and salt stress in B. napus $\mathrm{DH}$ population Mansholts $\times$ Samourai, $\mathrm{n}=138 \mathrm{DH}$ lines under control condition and salt stress $(200 \mathrm{mM} \mathrm{NaCl})$.

$\mathrm{M}=$ Mansholts, $\mathrm{S}=$ Samourai, regular format arrows = parents performance under control and Bold format arrows $=$ parents performance under salt stress. 
Appendix 11 continued from page 180
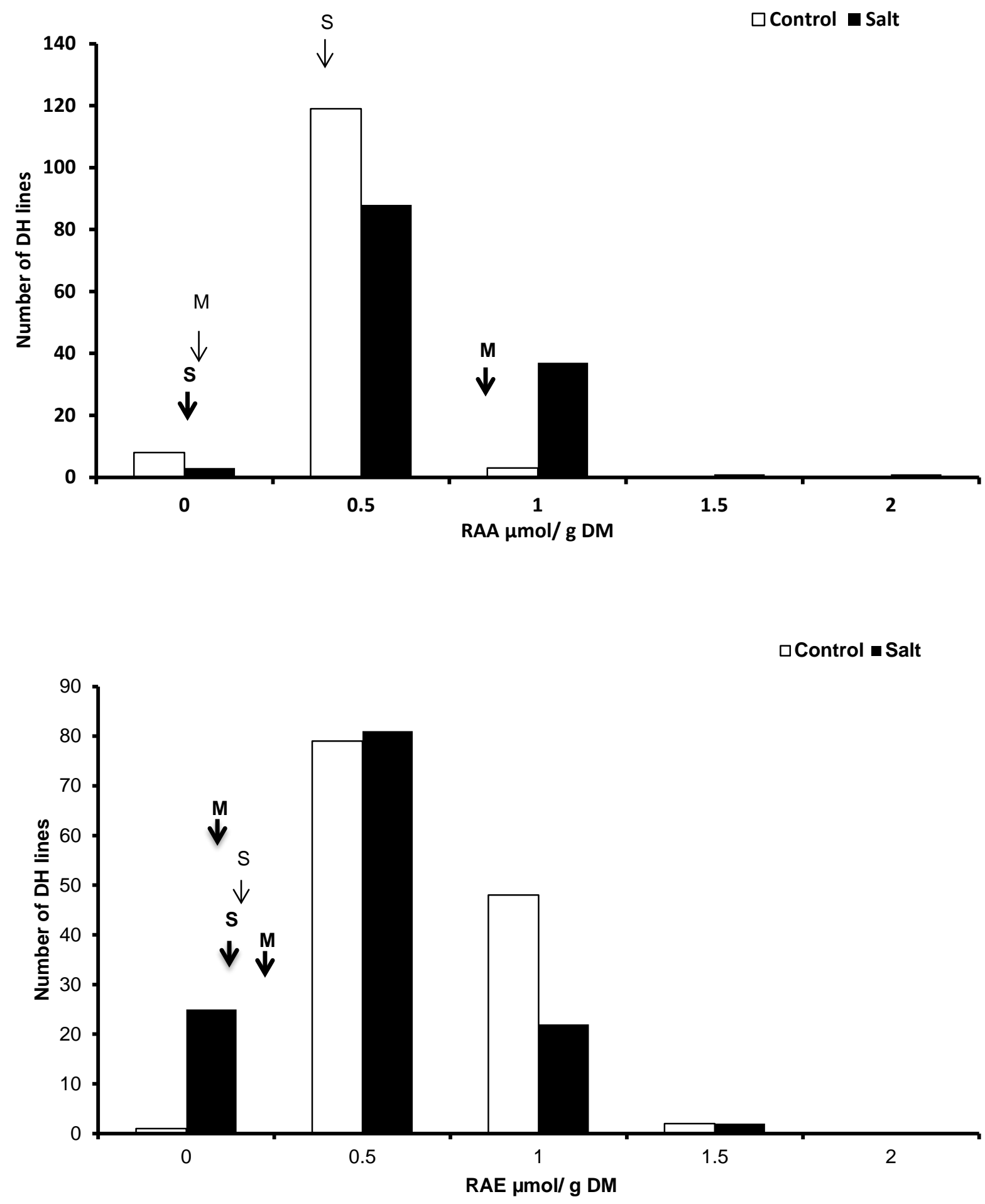
Appendix 11 continued from page 181
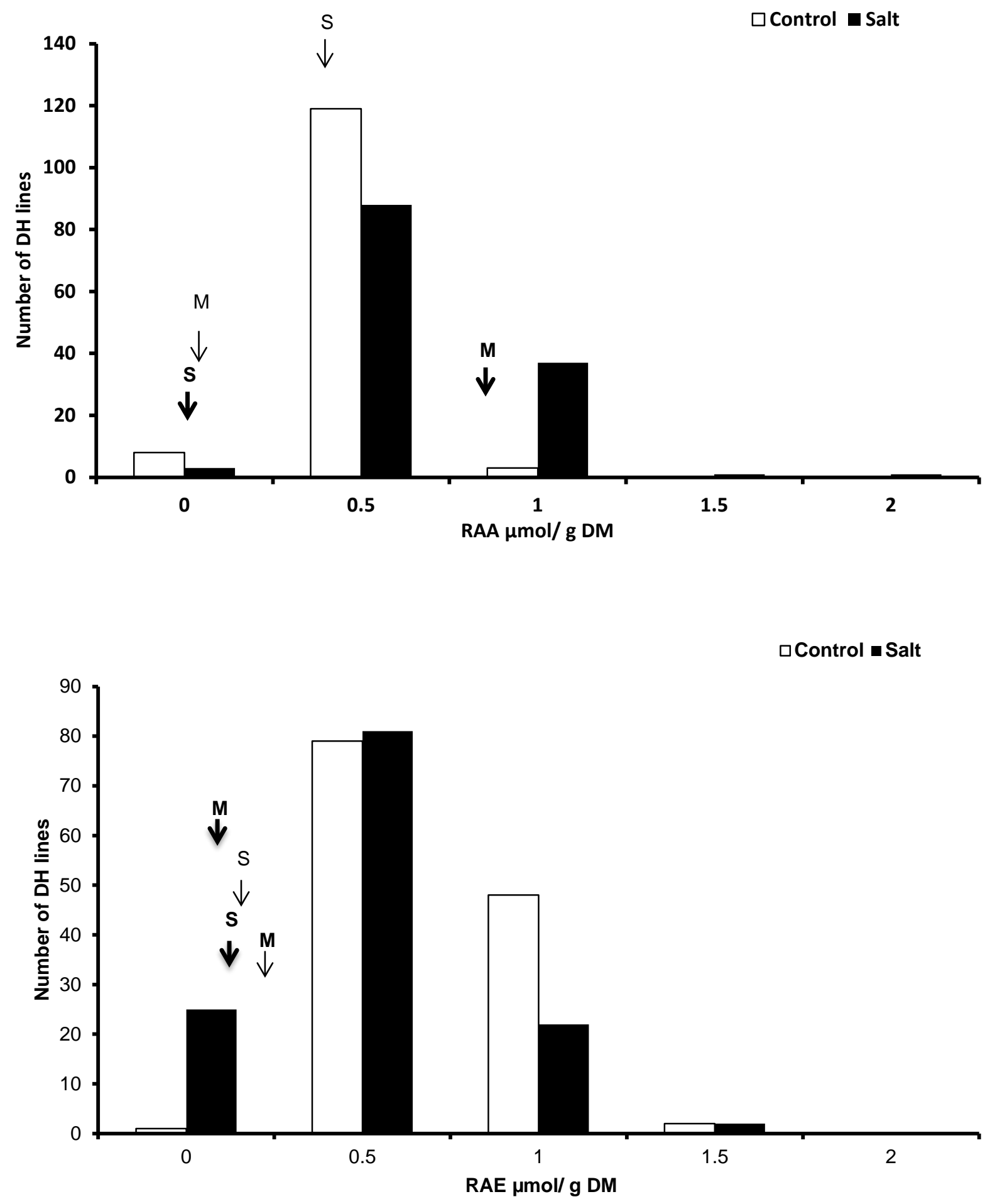
Appendices-

Appendix 11 continued from page 182

$\square$ Control $\square$ Salt
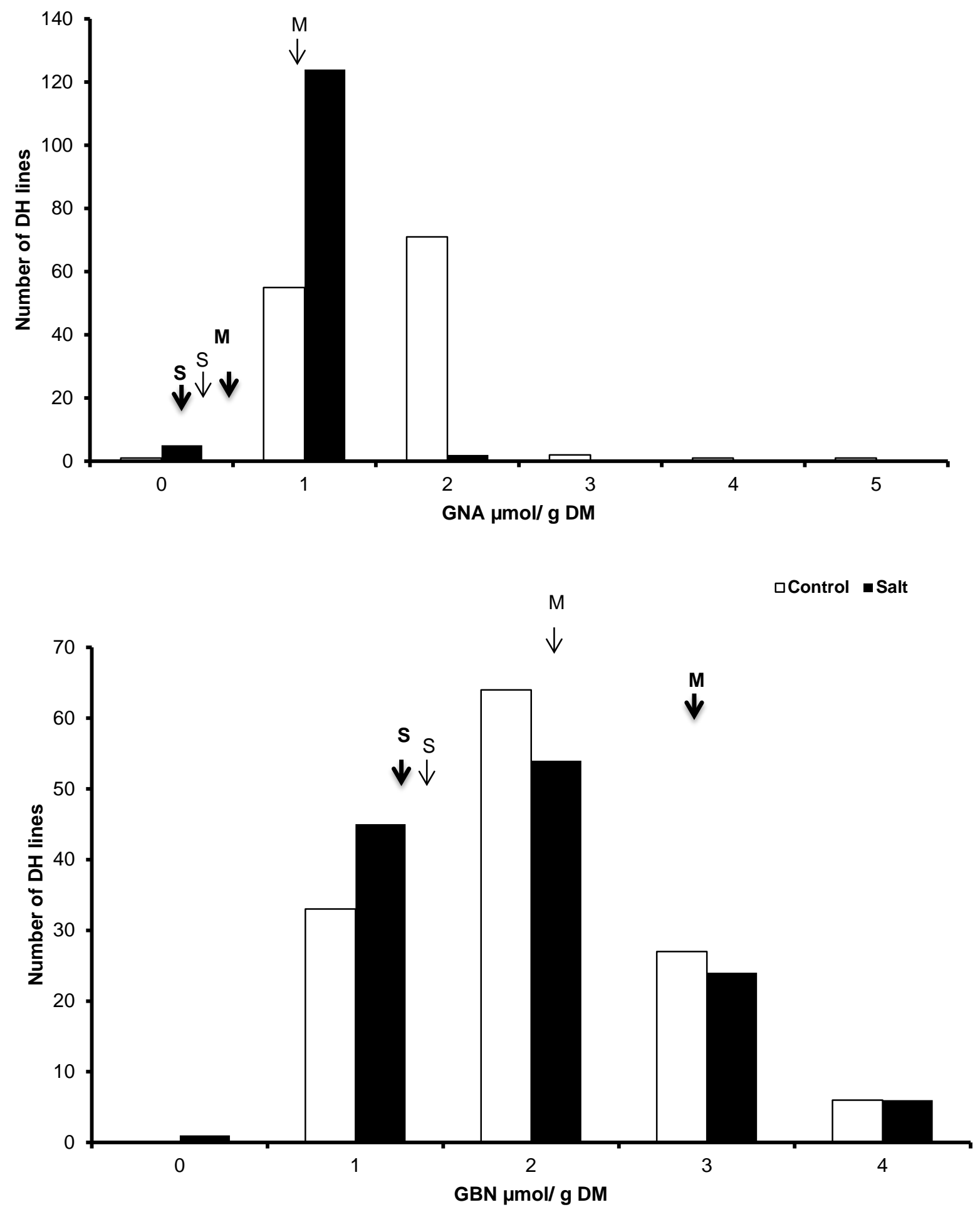
Appendix 11 continued from page 183

口Control $\square$ Salt
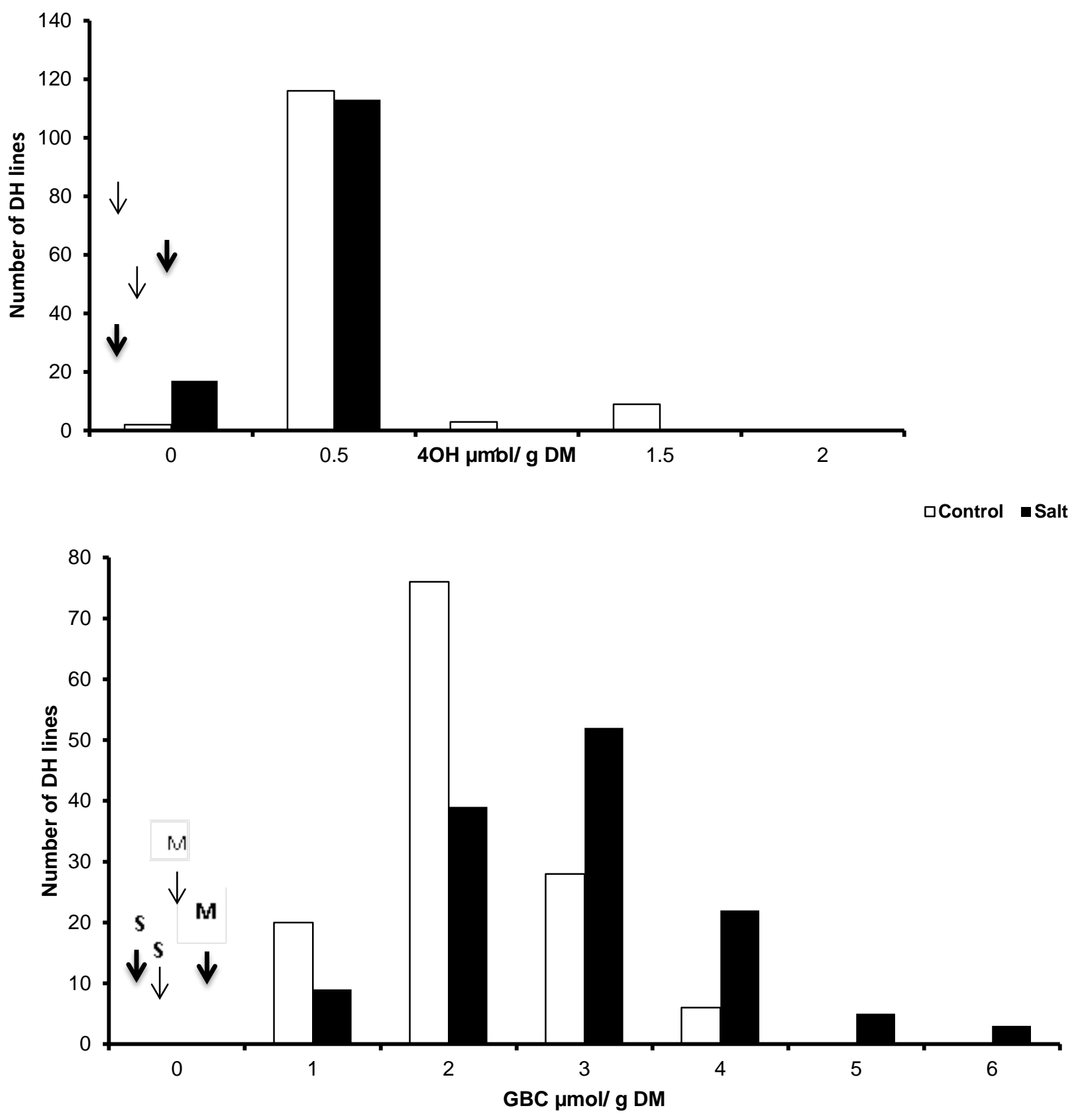

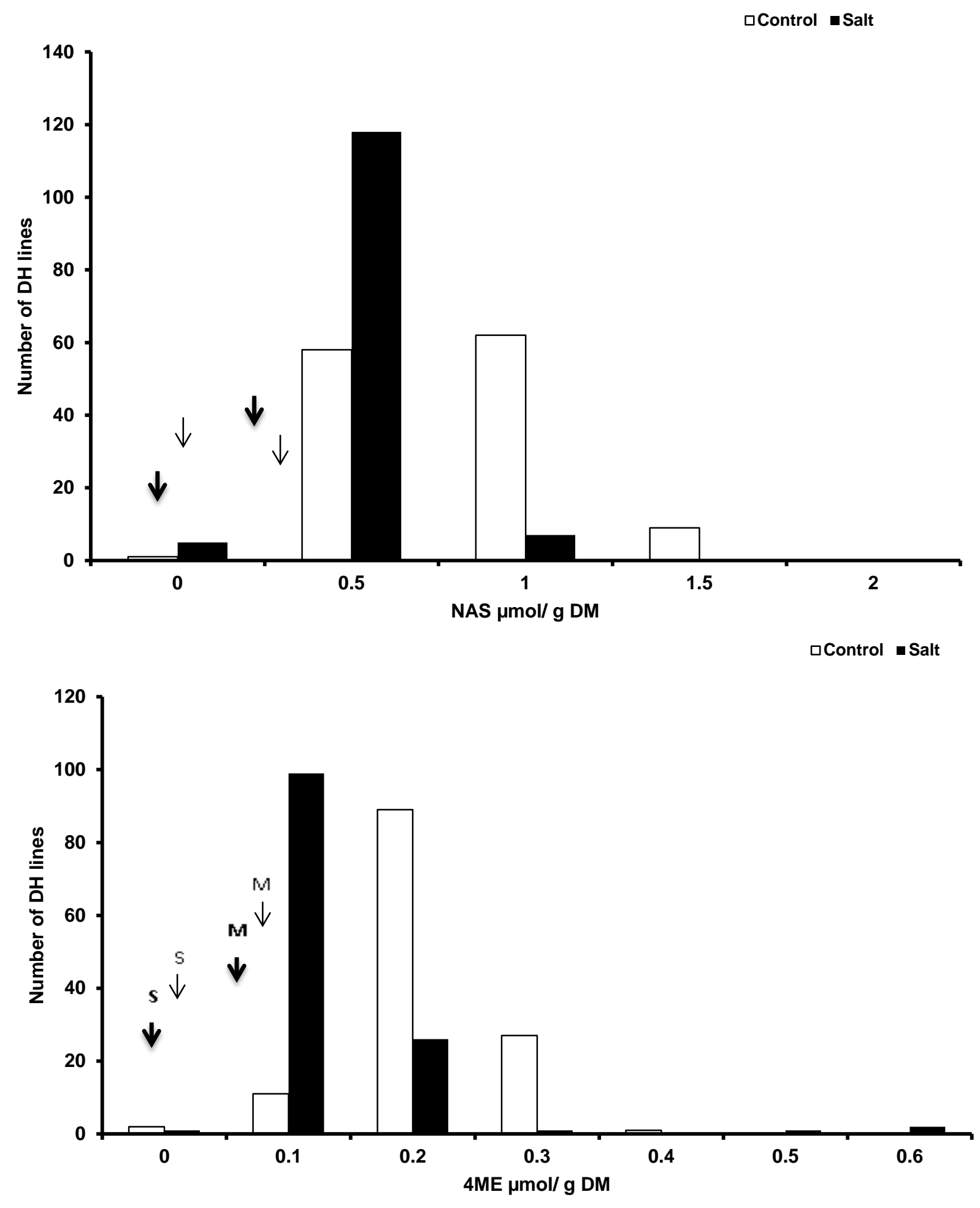


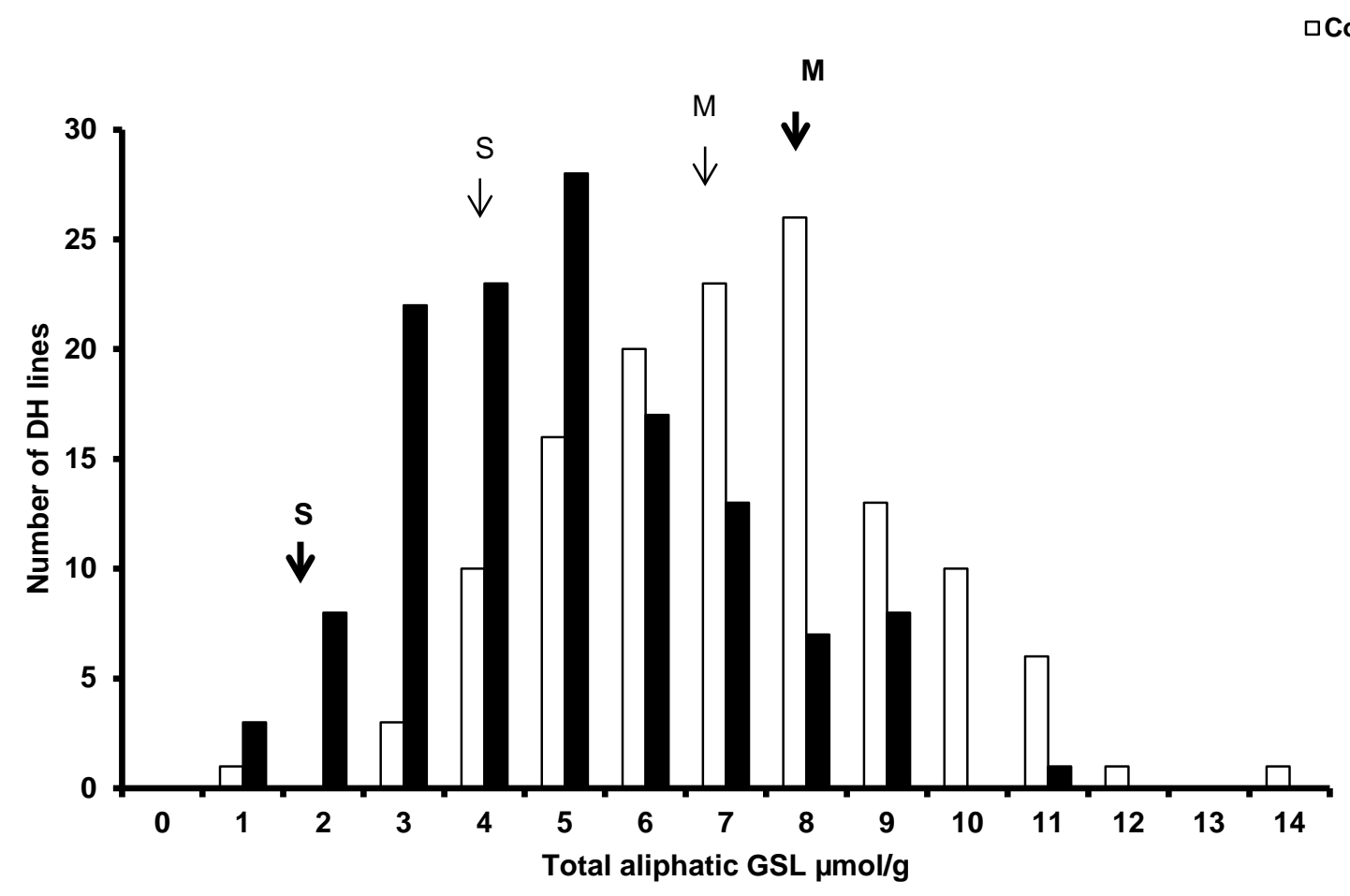

口Control $\square$ Salt

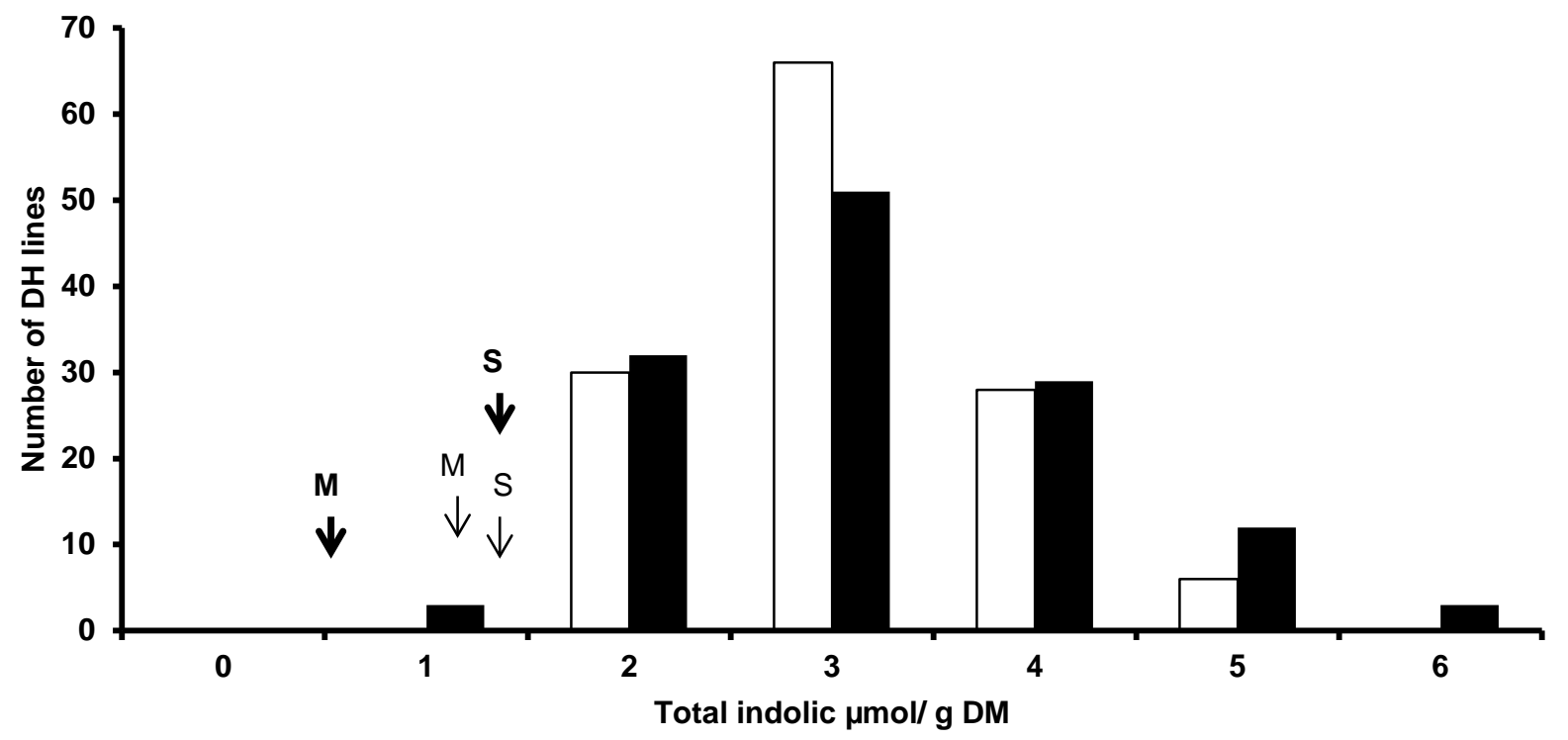




\section{Appendix 12}

Mean squares and $F$ test of significance from the ANOVA and heritabilities of glucosinolates for $B$. oleracea DH population $\mathrm{Bo1TBDH}, \mathrm{n}=138 \mathrm{DH}$ lines under control condition and salt stress $(100 \mathrm{mM} \mathrm{NaCl})$.

\begin{tabular}{|c|c|c|c|c|c|c|c|c|}
\hline \multirow[b]{2}{*}{ Sources of Variance } & \multicolumn{4}{|c|}{ Control } & \multicolumn{4}{|c|}{ Salt } \\
\hline & Genotypes (G) & Replicates (R) & $\mathrm{G} \times \mathrm{R}$ & $h^{2}$ & Genotypes (G) & Replicates (R) & $G \times R$ & $h^{2}$ \\
\hline DF & 137 & 1 & 137 & & 137 & 1 & 137 & \\
\hline IBE & $0.62^{\star \star}$ & $1.84^{*}$ & 0.32 & 47.98 & 0.17 & 0.08 & 0.18 & - \\
\hline PRO & $1.63^{\star \star}$ & 0.250 & 0.21 & 87.02 & 0.45 & 0.05 & 0.52 & - \\
\hline GNL & $0.40 * \star$ & $4.67^{\star \star}$ & 0.25 & 36.75 & 0.44 & 0.24 & 0.45 & - \\
\hline RAA & $0.002^{*}$ & $0.004+$ & 0.001 & 27.76 & 0.001 & 0.001 & 0.001 & - \\
\hline GNA & $5.83^{\star \star}$ & $5.73^{*}$ & 0.88 & 84.81 & 2.78 & 0.15 & 3.31 & - \\
\hline $4 \mathrm{OH}$ & $0.002^{*}$ & $0.07^{\star \star}$ & 0.001 & 31.04 & 0.0009 & 0.002 & 0.001 & - \\
\hline GBN & - & - & - & - & 0.0004 & 0.000 & 0.001 & - \\
\hline GBC & $4.88^{\star \star}$ & 2.56 & 1.83 & 62.41 & 1.077 & $2 . .33$ & 1.09 & - \\
\hline NAS & 0.10 & $1.25^{\star \star}$ & 0.08 & & 0.035 & 0.01 & 0.04 & - \\
\hline $4 \mathrm{ME}$ & $0.02^{\star \star}$ & $0.25^{\star \star}$ & 0.01 & 39.97 & 0.007 & 0.02 & 0.006 & 14.95 \\
\hline NEO & 2.45 & 0.300 & 1.97 & 19.43 & 0.75 & 2.49 & 0.86 & - \\
\hline SUM & $18.55^{\star \star}$ & 5.46 & 8.47 & 54.30 & 5.99 & 22.40 & 6.98 & - \\
\hline
\end{tabular}

** Significant at $P=0.01$; * significant at $P=0.05$ and + significant at $P=0.1$ 
Appendices-

Appendix 13
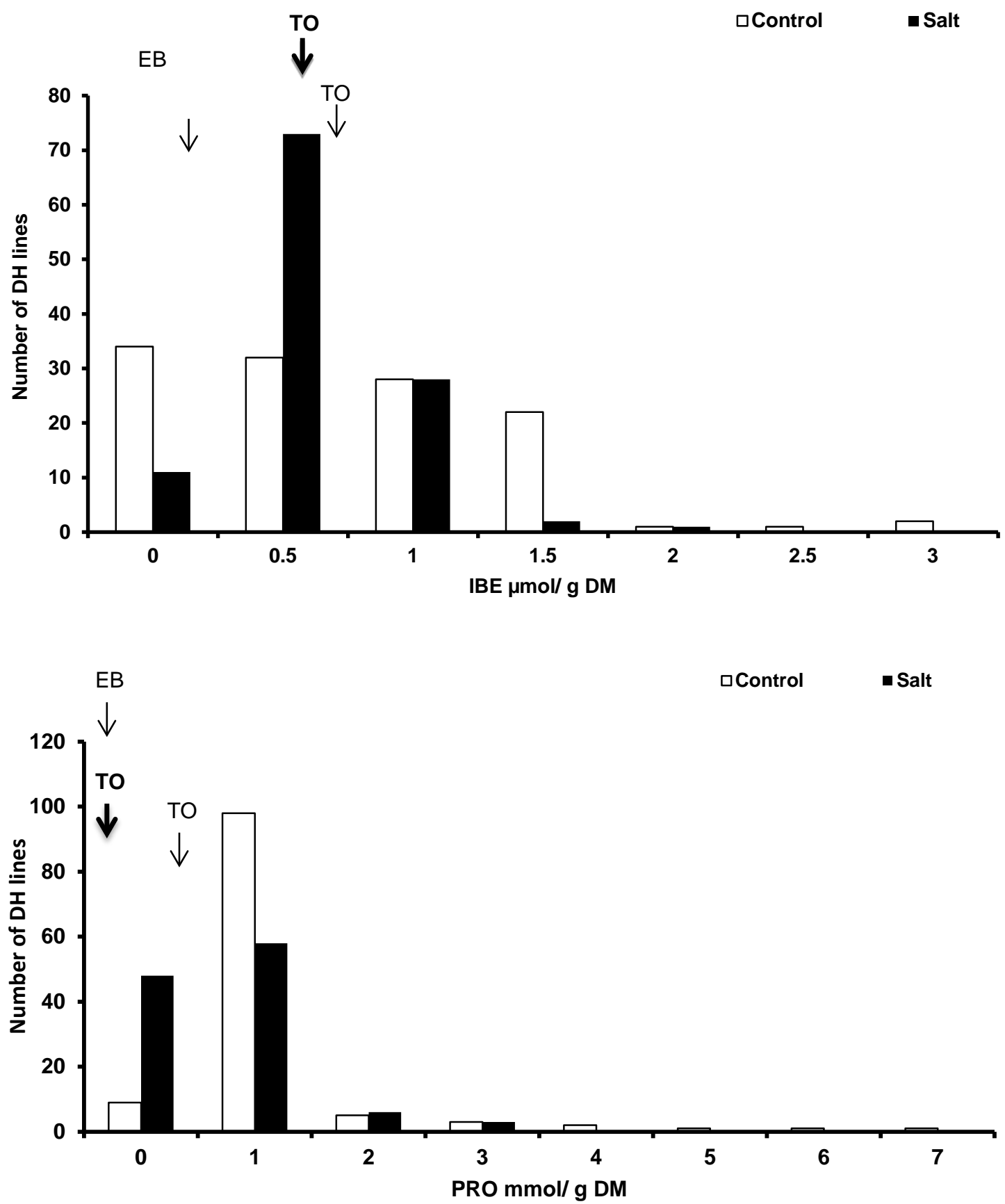

Distribution of glucosinolates for $B$. oleracea $\mathrm{DH}$ population $\mathrm{Bo1TBDH}, \mathrm{n}=138 \mathrm{DH}$ lines under control condition and salt stress (100 $\mathrm{mM} \mathrm{NaCl})$.

$\mathrm{TO}=\mathrm{TO} 1000 \mathrm{DH} 3, \mathrm{~EB}=$ Early Big, regular format arrows = parents performance under control and Bold format arrows = parents performance under salt stress 


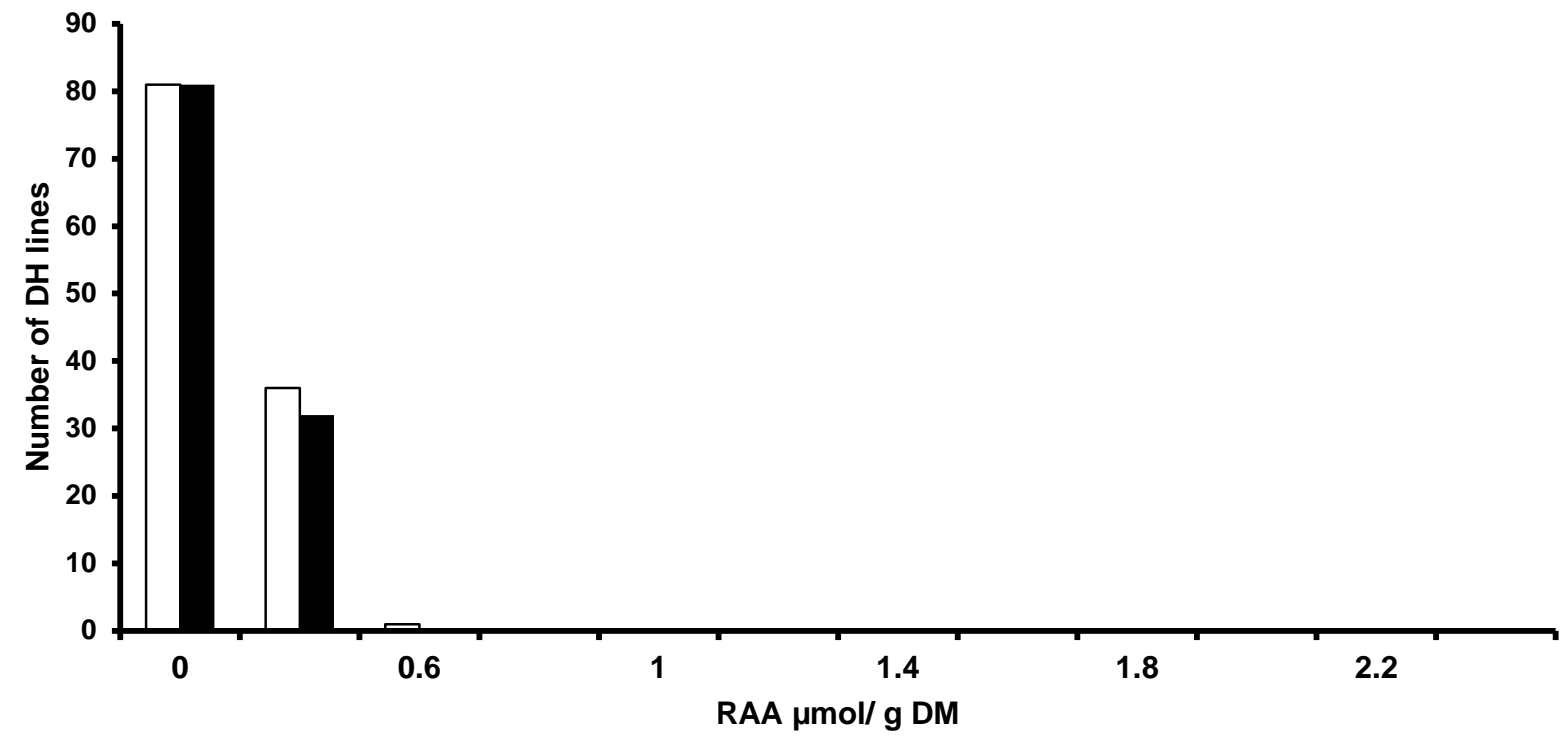

RAA was not detected in both parents

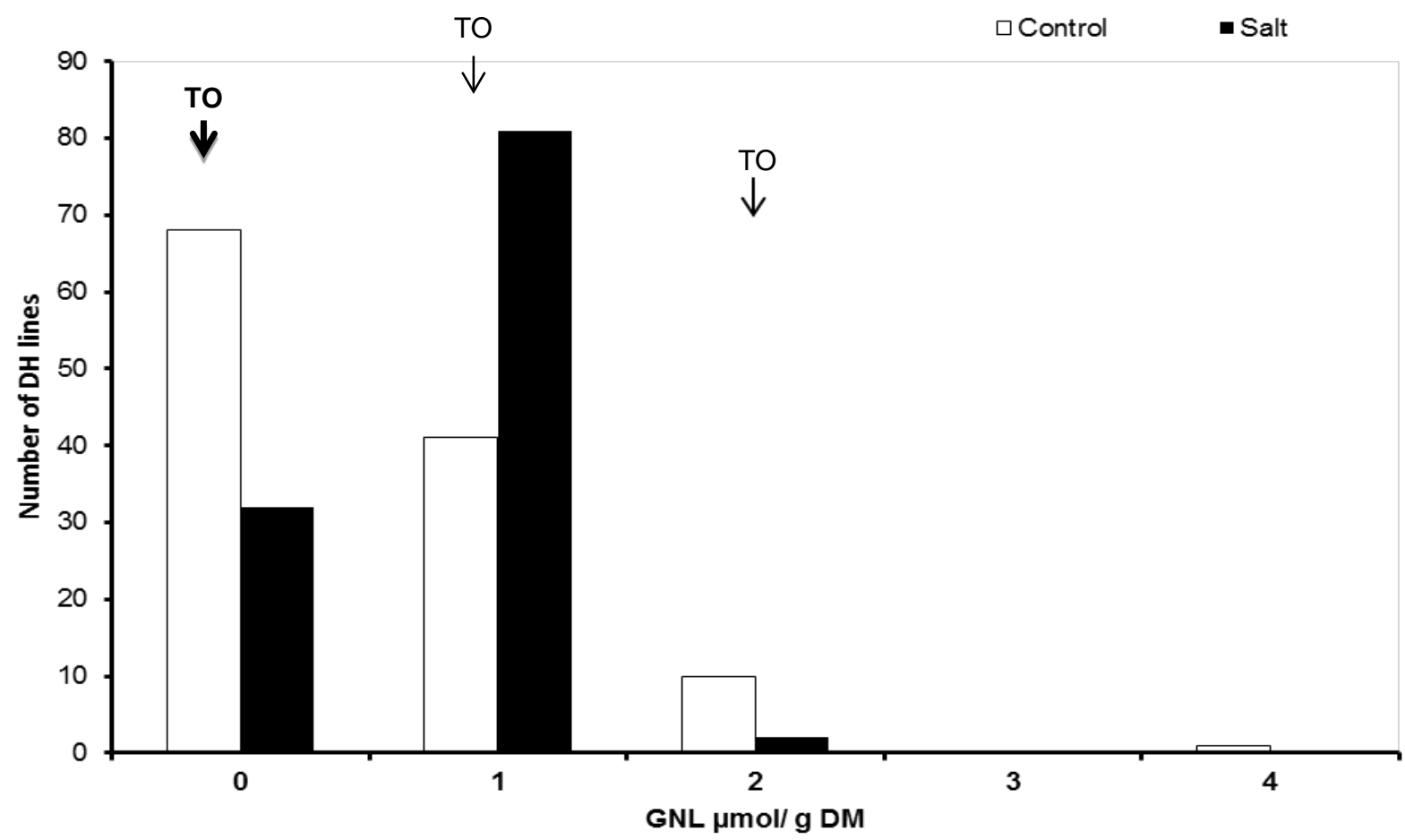


Appendices-

Appendix 13 continued from page 189
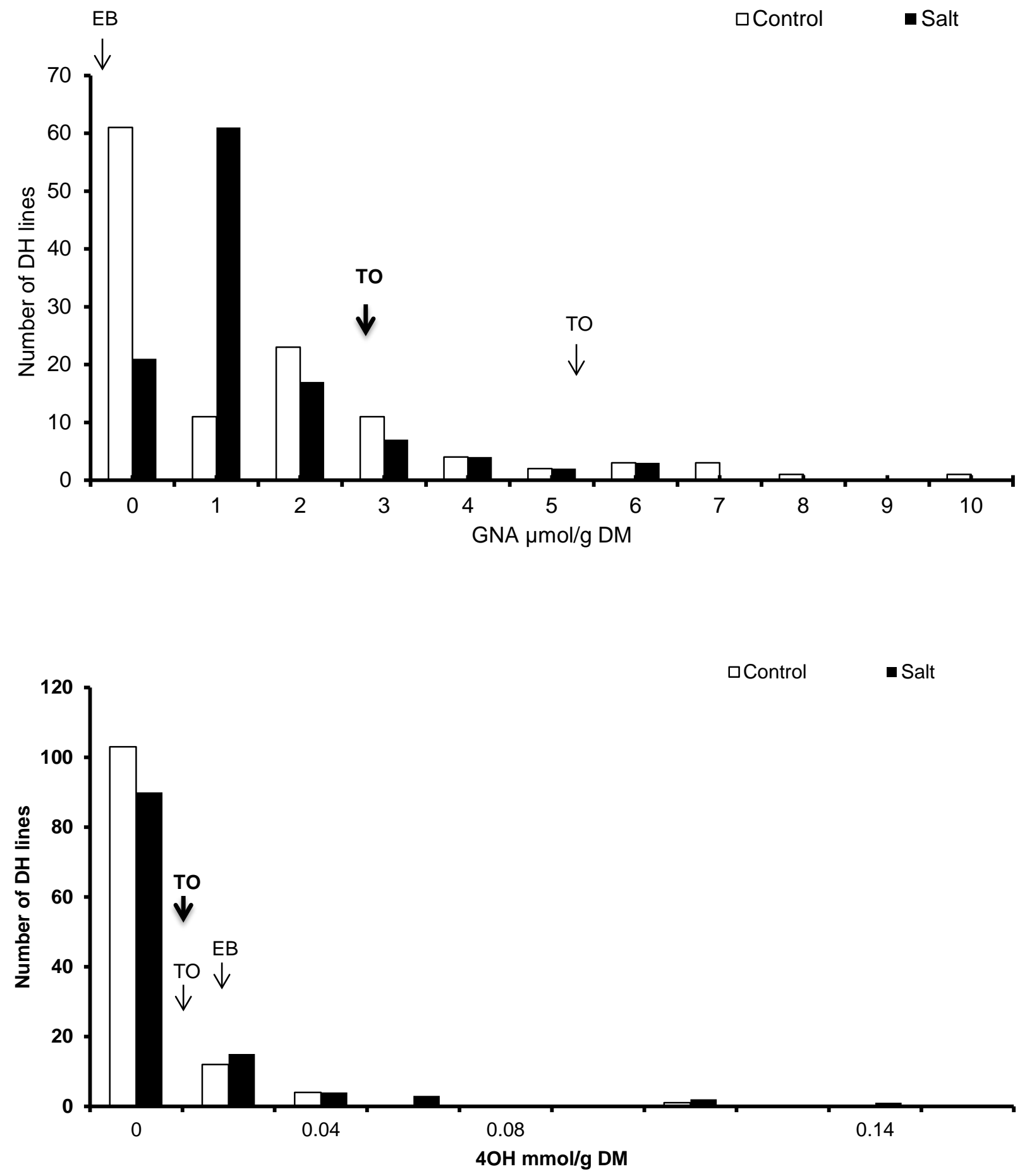
Appendix 13 continued from page 190
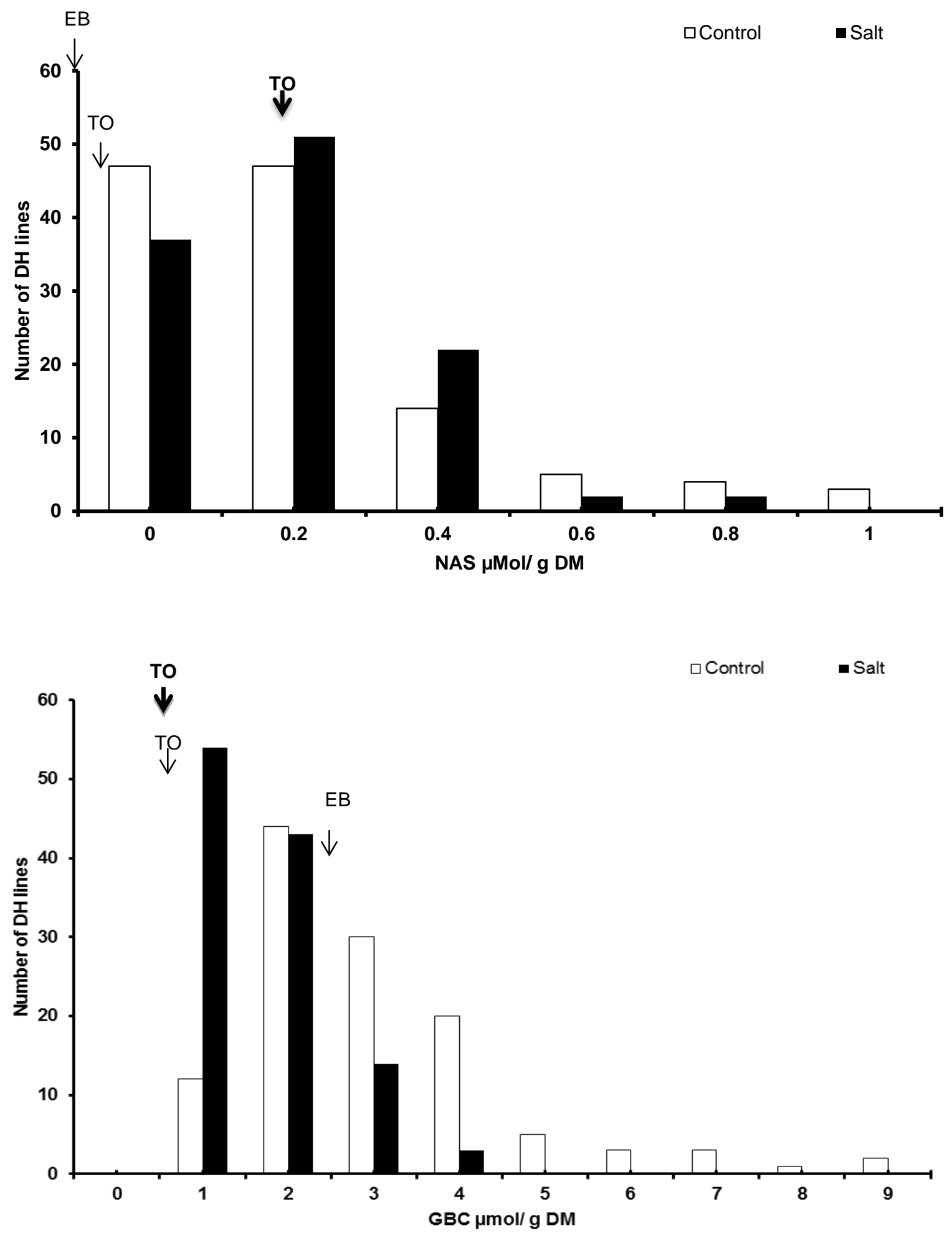
$\square$ Control $\quad$ Salt

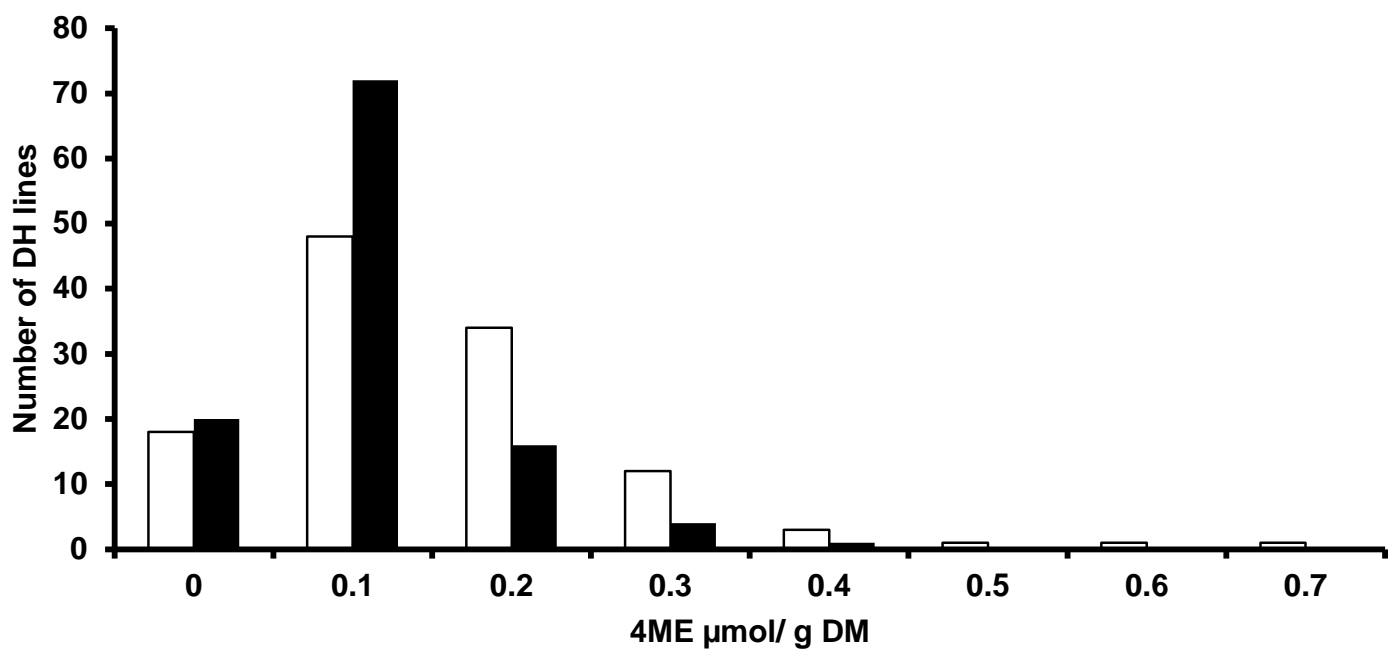

4ME was not detected in both parents

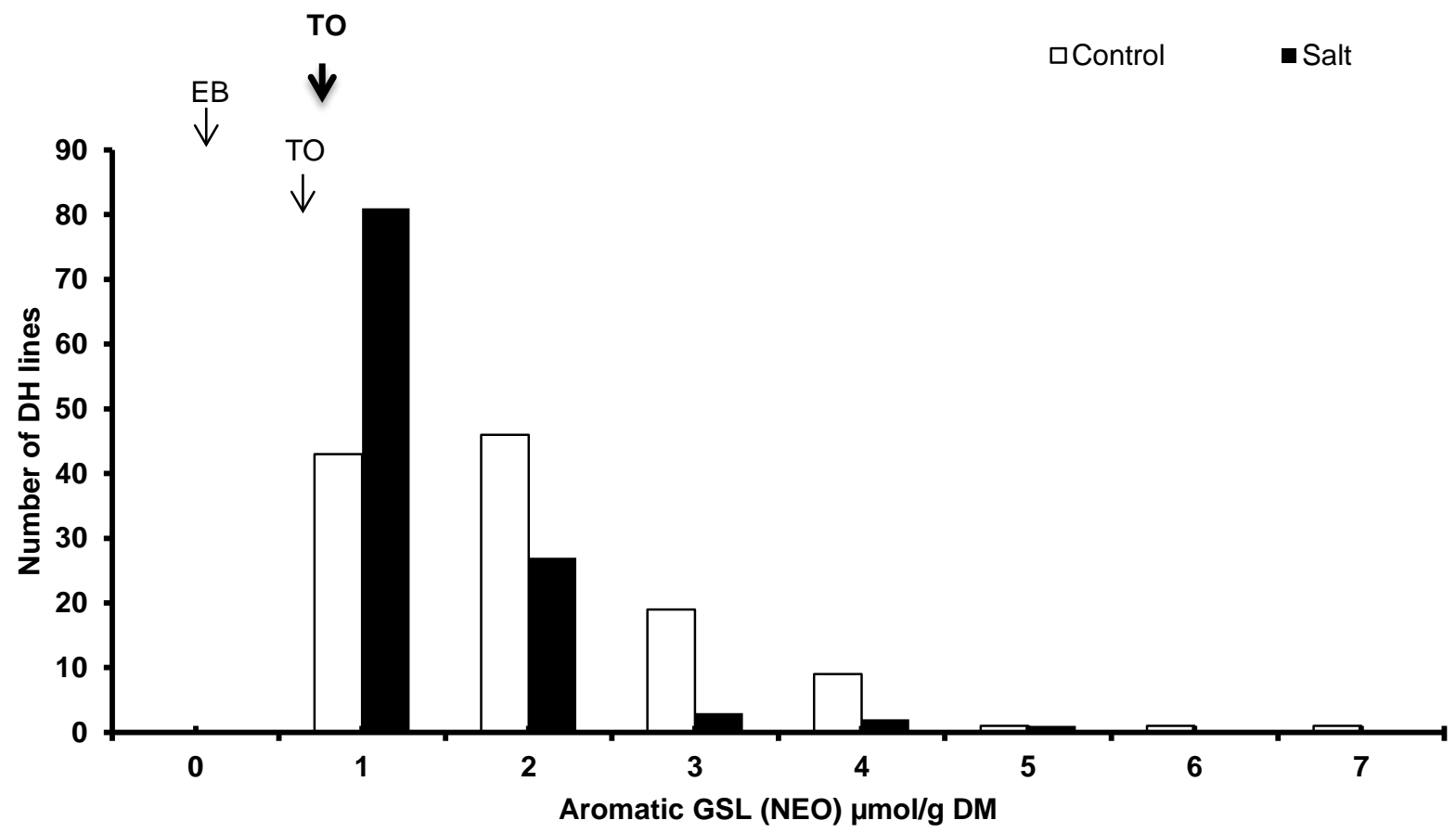




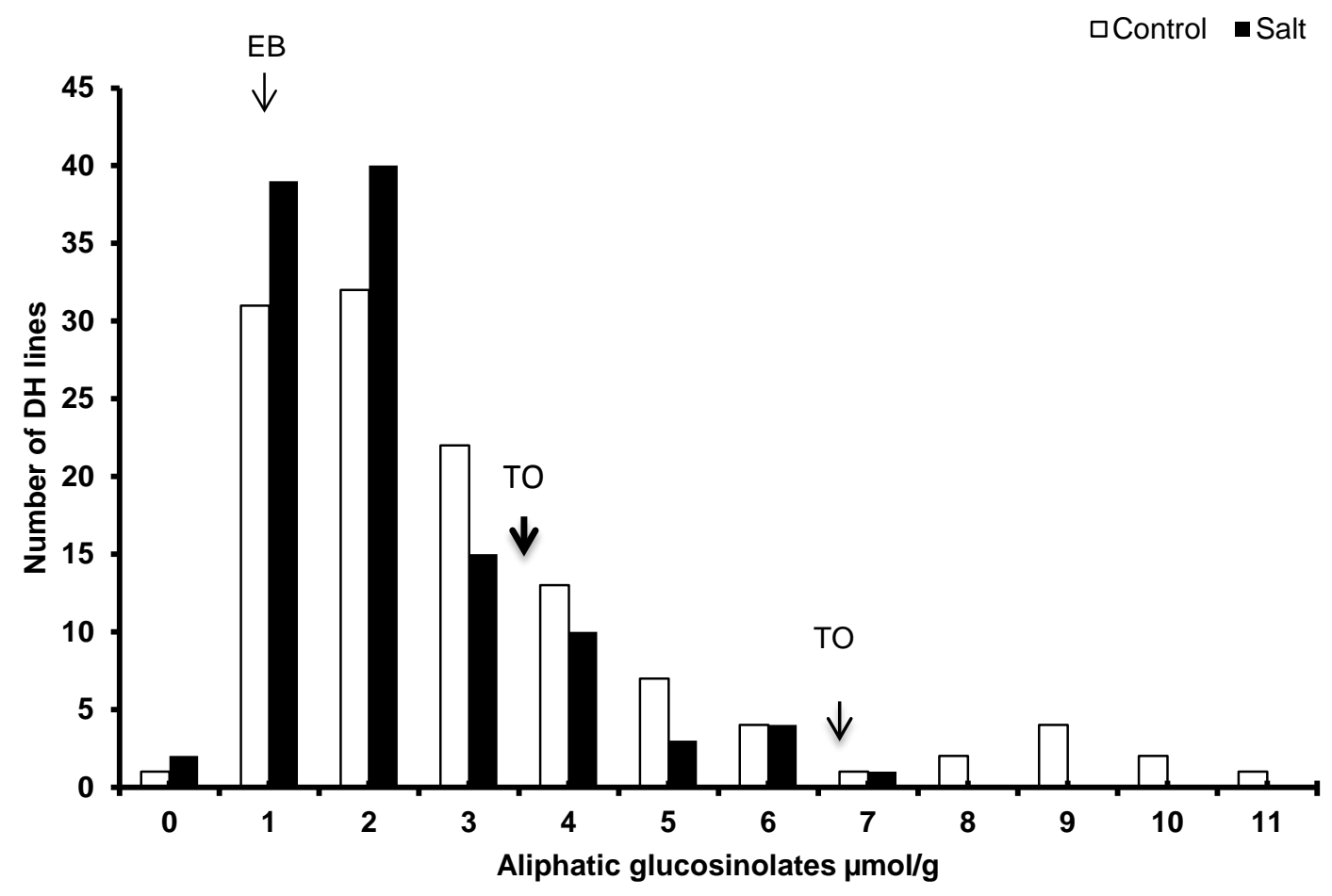

$\square$ Control $\square$ Salt

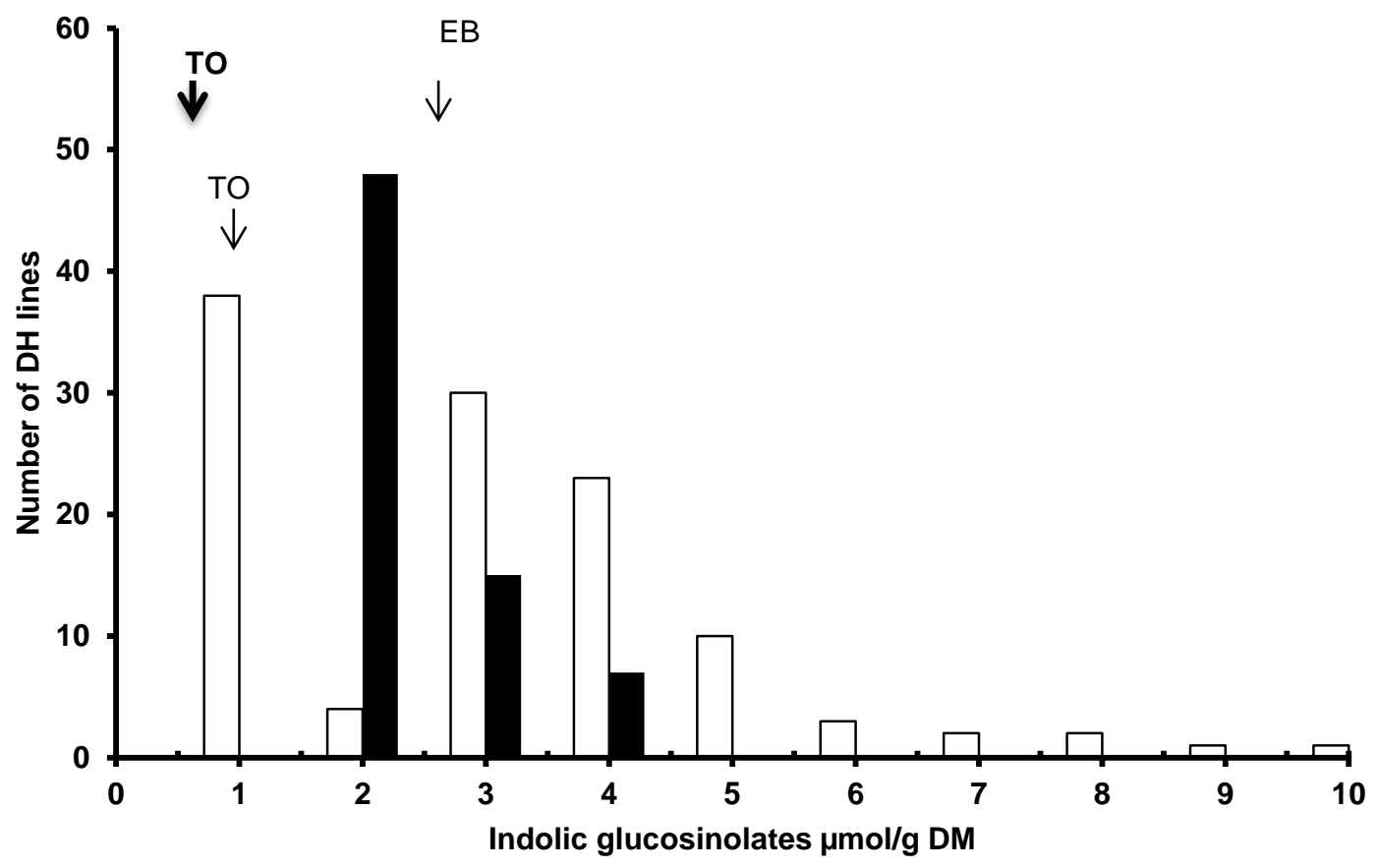




\section{Acknowledgments}

$$
\text { الحمد لله رب العالمين }
$$

All the praises are to Allah for helping me to finish this work. I would like to acknowledge the following people for their advice, contributions and efforts with respect to my work. First and foremost, I would like to thank my Ph.D. advisor Prof. Dr. Heiko Becker for giving me the opportunity to learn and to be a member of his research group. I sincerely appreciate his willingness, patience and encouragement to try new topic and to work independently. I would also like to thank my co-supervisor Prof. Dr. Klaus Dittert for the time he spent reviewing this dissertation, and to Prof. Dr. Elke Pawelzik for kindly to be a member of my examination committee. I would like to extend thanks to Dr. Antje Schierholt for her help to establish the irrigation system and for her guidance, patience and supporting.

I would like to extend thanks to my colleagues of the Ph.D students Ahmed Sallam, Edy Suprianto, Haiko Brandes, Sebastian Miersh, Makis Kampouridis, Nina Behnke Siyang Liu, Mohamed Ghanbari, Mareile Stever, Li shia Teh, Ariana Velázquez, Winda Puspitasari and Julia Rudloff for the fantastic time that we have spent together and for their support.

I am grateful for Dr. Wolfgang Ecke who has kindly provided me with linkage map, and guided me through the QTL analysis. I thank all the staff members of the division of Plant Breeding, Georg-August-Universtät Göttingen; Dr. Christin Möllers, Dr. Sabine von Witzke-Ehbrecht, Dr. Bernd Horneburg and Prof. Dr. Wolfgang Link who have assisted me in completing this research.

I would like to thank Gunda Asselmeyer, Birgit Olberg and Uwe Ammermann who have helped me through the glucosinolates analysis. Thanks to Dr. Bernd Steingrobe, Susanne Koch and Marlies Niebuhr for help with the technical support for using the Microwave system and flame photometer to estimate the Sodium and Potassium content. Thanks to the field workers who have helped me in the pots filling and the seeds, sowing especially, Andreas Henn.

No words can express my deep thinking to my wife Rasha Osman for her support, patience and encouragement particularly, at the hard times. I am especially thankful for the support and encouragement of my family members in Egypt especially, my mother and my father.

I have to thank the people of the Egyptian community members in Göttingen who have given me their full support and guidance. They made me feel that I am in Egypt.

I would like to appreciate the financial support of the Ministry of the Higher education in Egypt and the German Academic Exchange Service (DAAD).

Thanks to KWS for providing the $\mathrm{DH}$ population and the marker data of Alesi $\times \mathrm{H} 30$, and to Sebastian Miersh for developing the full linkage map

By the way, I would like to extent my thanks to my beloved boys, Ammar and Hazem for being crazy, which pushed me to stay for a long time in the institute to finish my work. 


\section{Curriculum vitae of Yasser Shaaban Sayed Moursi}

\section{Biographical}

\begin{tabular}{|c|c|}
\hline Name & Yasser Shaaban Sayed Moursi \\
\hline Position & $\begin{array}{l}\text { Assistant Lecturer, Botany department, Faculty of Sciences, } \\
\text { University of Fayoum, Egypt }\end{array}$ \\
\hline Date of Birth & 14/01/1981, Fayoum, Egypt \\
\hline Marital Status & Married \\
\hline Nationality & Egyptian \\
\hline Official Address & $\begin{array}{l}\text { Botany department, Faculty of Sciences, } \\
\text { University of Fayoum, Fayoum, Egypt. } \\
\text { Fax } 0020846370025\end{array}$ \\
\hline E-mail & ymoursi@gwdg.de ; ysm01@fayoum.edu.eg \\
\hline
\end{tabular}

\section{Education}

1998-2002

2006-2008

: B.Sc. in Botany, Botany department, Faculty of Sciences, University of Fayoum Grade: Very Good

: M.Sc. in Botany (Genetics and cytology) Botany department, Faculty of Sciences, University of Fayoum

Grade: Excellent

\section{Thesis title}

Genetic diversity of Brassica rapa the progenitor of oilseed rape Brassica napus

2011-2014 : Preparing for Ph.D. studies in Division of Plant Breeding, GeorgAugust- Universität Göttingen, Germany.

Thesis title

Genetic mapping of QTL controlling salt tolerance and glucosinolates in Brassica napus and Brassica oleracea

\section{Academic records}

2003-2008

: Demonstrator (Teaching and Research Assistant), Botany department, Faculty of Sciences, University of Fayoum

2008-2014

: Assistant Lecturer (Teaching and Research Assistant), Botany department, Faculty of Sciences, University of Fayoum

\section{Awards}

$2010-2014$

: DAAD PhD Scholarships, Division of Plant Breeding, Faculty of Agricultural Sciences, Georg-August- Universität Göttingen, Germany 


\section{Attended workshops and training courses:}

12-16.11.2012 : Molecular biology techniques

13-17.02.2012 : Training course in Statistics and STATISTICA, University of Göttingen, Germany

02-06.09.2013 : Workshop on Molecular Techniques in Phytopathology, University of Göttingen, Germany

\section{Attending conferences:}

05-09.06.2012

28.02-01.03.12

18-20.09.2012 :

19-21.09.2012

24-26.09.2013

$11-13.02 .2014$
The IRC $13^{\text {th }}$ International Rapeseed Congress 201, Praque, Czech Republic

: Breeding crops for sustainable agricultural production international conference. Justus -Liebig-Universität Gießen, Germany

: Genome Research Working Group Conference of the GPZ. Martin Luther University Halle-Wittenberg, Germany

: Resilience of agricultural systems against crises Conference. GeorgAugust- Universität Göttingen, Germany

: Georg-August- Universität Göttingen, Germany

: Conference of the Genome Research Working Group, Max Plant Institute for Plant Breeding Research. Köln, Germany.

\section{Experiences:}

- Methodology : Plant breeding methods, DNA isolation, gel documentation, genetic engineering, cytogenetic techniques, PCR, electrophoresis, molecular marker (RAPD, AFLP, SNPs), association analysis, QTL mapping.

- Software $\quad$ : Plabstat, Plabplan, STATISTICA, TASSEL 3.0, QTL network, Mapmaker 3.0, Mapchart 2.0, STRTUCTURE 2.3.4 for population genetic structure

\section{Field of study:}

- Quantitative genetics, Population genetics, Molecular plant breeding and genetics, and Cytogenetics.

\section{Languages:}

- Arabic (mother language)

- English

- German 